\title{
Pliocene-Pleistocene orbital cyclostratigraphy and glacial evolution of the East Antarctic Ice Sheet from continental rise IODP site U1361, Wilkes Land margin, East Antarctica
}

\author{
By
}

Georgia Rose Grant

A thesis presented to

Victoria University of Wellington, in fulfilment of the requirements for the degree of

Master of Science

In

Geology

Victoria University of Wellington, Wellington, New Zealand 2012 


\section{Abstract}

Stability of the East Antarctic Ice Sheet (EAIS), in response to the orbitally-paced cooling climate of the Late Neogene, is largely unknown. The Wilkes Land margin of East Antarctica, largely grounded below sea level, has previously been proposed to respond dynamically during the warmer climate of the Pliocene, similarly to other marine based sectors of Antarctica (i.e. West Antarctica). Sediment deposition on the Wilkes Land continental rise, recovered in Integrated Ocean Drilling Program U1361A drillcore provides a distal but continuous record of EAIS fluctuations. Changes in sedimentary depositional environments at U1361A core site, were determined through analysis of lithofacies and physical property logs: natural gamma-ray (NGR), gamma-ray attenuation bulk density (GRA), magnetic susceptibility (MS) and $L^{*}$ colour reflectance. NGR primarily reflected biogenic content and a synchronous relationship between NGR, GRA and MS was used to identify interglacial and glacial phases, whereby decreased NGR, GRA and MS values indicated an increase in biogenic material. $\mathrm{L}^{*}$ colour reflectance was more variable through time, displayed higher frequency fluctuations and a changing relationship with the other physical property logs down core. Two depositional models, based on facies interpretations and the defined physical property relationships, were produced for the Middle Late Pleistocene (last 550 kyr; model A) and mid-Pliocene ( 4.2-3.6 Ma; model B), which represent end members. Depositional processes common to both models occurred in the intervening core, spanning the Late Pliocene-Early Pleistocene (3-1 Ma). Model A, applied to the Middle Late Pleistocene, shows that alternating diatom-rich clays to silty clays in the upper $9 \mathrm{~m}$ of core U1361A, reflect the large amplitude $\sim 100 \mathrm{kyr}$ paced glacial-interglacial cycles, which is confirmed by spectral analysis of the physical properties for this interval. Model B, applied to the Early Pliocene, suggest that the depositional processes recorded by facies may have been less sensitive to EAIS fluctuations, probably due to the fact that the ice margin was generally more distal to the core site during glacial-interglacial cycles of advance and retreat. Nevertheless, these more subtle changes in lithology 
were characterised by variations in the physical property logs, and spectral analysis of these time series implied orbital pacing was still influential on depositional processes at this time (displaying power in precession and obliquity frequencies).

Spectral analysis of the physical property logs and visual correlations to the benthic $\delta^{18} \mathrm{O}$ stack, confirmed the $4.2-1 \mathrm{Ma}$ interval was paced by $\sim 40 \mathrm{kyr}$ and implies obliquity-paced oscillations of the margin of the EAIS. Precession periodicities, significant in spectra throughout the $4.2 \mathrm{Myr}$ record, are proposed to be the response of phytoplankton productivity in response to seasonal insolation controlling sea-ice extent. 


\section{Acknowledgements}

Foremostly, I would like to express my thanks and gratitude to the many people that provided support and encouragement throughout my undergraduate and postgraduate study. It was a process, not without contributions from external influences. Secondly, this project could not have been undertaken without the IODP Expedition 318 Scientists. Thank you for collecting my lovely core.

To my supervisors (in alphabetical order) Rob McKay and Tim Naish, I am indebted to you both for your commitment to my project. I cannot express enough thanks for your academic support but possibly more importantly, your belief in my ability to achieve this feat. Rob, your door was always open, and you approached everything with the same sense of importance. This respectful stance gave me faith in my project and I will be forever grateful for all your time and effort.

Tim, your endless enthusiasm, while sometimes misplaced, was very much appreciated and a great source of encouragement. Your patience and general considerate demeanour gave me confidence in my own ideas and ability to explain them. I really couldn't have asked for a better pair of supervisors, you both contributed significant amounts and were incredibly supportive through the whole process.

To my family, I literally could not have done it without you. Mum and Dad, my siblings and grandparents, thank you so much for your endless patience with my whinging, constant encouragement and pick-me-up packages. I hope I have made you proud! To Tamsin, Ame, MoPatt, Tamara and new mother Phoebe, you are all the most incredible people and a constant source of inspiration to me. You bring out the absolute best in me, always lend an ear or shoulder and provide, what I know will be lifelong friendships. 
My fellow students, specifically Kolja, Gemma, Bella, Vaughan, Kylie and Timmy. Thanks for the hours of entertainment and more recently, group therapy sessions with 'dou bro' always on hand. Such an awesome gifted group of people.

Murray Williams, family friend, advisor and my emergency contact. Thank you for taking an interest, taking me out to dinner for my birthday when dad couldn't make it down.

To the ARC VUW staff, you are just awesome. Warren, Nick and Alex, it is always nice to see you. I will miss the round table, home brews and whiskey sessions. 


\section{Table of Contents}

Abstract__ i

Acknowledgements _

Table of Contents___ v

List of Figures __vi

List of Tables__ ix

List of Charts__ ix

CHAPTER 1: Introduction ___ 1

CHAPTER 2: Literature Review

2.1 Antarctic glacial history ___ 9

2.2 Climate cyclicity _ 19

2.3 Southern Ocean circulation___ 33

2.4 Sedimentation on glaciated continental margins___ 43

CHAPTER 3: Materials and Methods___ 54

3.1 Core recovery __ 54

3.2 Core logging $\quad 55$

3.3 U1361A age model__ 59

3.4 Data processing _ 63

3.5 Data Analysis__ 67

CHAPTER 4: Results___ 72

4.1 Facies analysis and physical properties___ 72

4.2 Spectral Analysis__ 80

CHAPTER 5: Discussion___ 99

5.1 Sediment depositional history of U1361A___ 99

5.2 Sediment cyclicity of U1361A__ 114

5.3 Comparison of U1361A to AND-1B__ 120

Conclusions__ 124

References__ 129 


\section{List of Figures}

Figure 1.1. Antarctic bed elevation, with the Wilkes subglacial basin highlighted (modified from Lythe et al., 2001). 5

Figure 1.2. Core sites drilled during IODP EXP 318, with U1361 highlighted in white and seismic transects in bold for Figures 1.3 and 1.4 (Expedition 318 Scientists, 2010). 6

Figure 1.3. Multichannel seismic reflection showing core site U1359 which is in a similar location to U1361 (Expedition 318 Scientists, 2010). 7

Figure 1.4; Multichannel seismic reflection transect along the levee of Jussieau channel (Expedition 318 Scientists, 2010). 7

Figure 2.1. The Cenozoic history of Antarctic ice sheet development and atmospheric $\mathrm{pCO}_{2}$ from a range of datasets, compiled by Richard Levy (Duce et al., 2011). 10

Figure 2.2. The benthic $\delta^{18} \mathrm{O}$ stack for 5.3 Ma to present (Liseicki and Raymo, 2005). 13

Figure 1.3. A comparison of ice sheet models for the warm Pliocene from Hill et al., (2007; in Dolan et al., 2011), Pollard and DeConto (2009) and the hypothesised deglaciation proposed by Webb et al., (1984). 16

Figure 2.4. Schematic diagram of Milankovitch cycles, showing the two extremes of obliquity and precession, and the present precession configuration, superimposed on the eccentricity cycle.

20

Figure 2.5. $\delta^{18} \mathrm{O}$ isotope record (Lisiecki and Raymo, 2005) and orbital solutions (Laskar et al., 2004) for the last 3 Myrs.

21

Figure 2.6. Power spectra for a) Insolation (Laskar, 2004) and benthic $\delta 180$ (Liseicki and Raymo, 2005) for the last 800kyr; b) Insolation and benthic 8180 for 5.3 Ma to present. $\_25$

Figure 2.7. Glacial depositional environments for facies in AND-1B drillcore (Naish et al., 2009a) and glacial proximity cyclicity in comparison to the benthic $\delta^{18} \mathrm{O}$ stack (Liseicki and Raymo, 2005). 32

Figure 2.8. Schematic diagram of water and ocean fronts located about the Antarctic margin (Cater et al., 2009). 
Figure 2.9. Location of Southern Ocean fronts, from Carter et al., (2009), modified from original data in Orsi and Whitworth (2005).

Figure 2.10. The ocean conveyor belt, first conceptualised by Stommel in 1958 (from Lozier, 2010).

Figure 2.11. A schematic diagram of present day ocean circulation of the Antarctic- Australian Basin (McCartney and Donohue (2007). 39

Figure 2.12. A schematic diagram of water mass circulation in the Adelie Depression on the Wilkes Land margin (Williams et al., 2008). 39

Figure 2.13. Sediment input and transport on the continental shelf and rise of a glaciated margin (modified from Boggs, 2001 after Stow et al., 1996). 46

Figure 2.14. The effect of channel curvature on momentum, lost through overbank spill (Piper and Normark, 1983). 48

Figure 2.15. Facies model for silt turbidites by Bouma (1962; simplified by Hsu 1989) and mud turbidites by Stow and Piper (1984). 48

Figure 2.16. A seismic profile off the Wilkes Land margin (Donda et al., 2007). 50

Figure 2.17; Facies model for mud and silty-sandy contourites (Stow and Piper, 1984)._51

Figure 2.18. Images of turbdites, plumites and contourites (Lucchi and Rebesco, 2007)._51

Figure 3.1. Raw physical property logs for U1361A (Expedition 318 Scientists, 2010)__ 58

Figure 3.2. Shipboard age model for site U1361A (Tauxe et al., in press). 62

Figure 3.3. Examples of drilling disturbance in core photos from U1361A. 66

Figure 4.1. U1361A core summary (modified from Expedition 318 Scientists, 2010). 74

Figure 4.2. Core images illustrating facies A and B (0.25-1.3 mbsf), D (91.4-92.5) and E (96.497.5) in core U1361A. 75

Figure 4.3. An example of facies and physical property response for the upper $\sim 2.5 \mathrm{~m}$ of U1361A. 77

Figure 4.4. Coherency spectra for 3- $0 \mathrm{Ma}$ of the physical property logs. 79 
Figure 4.5. Core correlation and summary of Interval 1 (9-0 mbsf). 82

Figure 4.6. Spectral estimates for Interval 1 (9-0 mbsf). 83

Figure 4.7. Core summary and correlations for Interval 2 (36.5-18.5 mbsf). 85

Figure 4.8. Univariate spectral analysis for Interval 2 (36.5-18.5 mbsf). 86

Figure 4.9. Core summary and correlation for Interval 3 (55-38.6 mbsf). 88

Figure 4.10. Univariate spectral analysis for Interval 3 (55.3-38.6 mbsf). 89

Figure 4.11. Core summary and correlations for Interval 4 (72-56.5 mbsf). 91

Figure 4.12. Univariate spectral analysis for Interval 3 and 4 (72-38.6 mbsf). 92

Figure 4.13. Core summary and correlations for Interval 5 (101-77 mbsf). 94

Figure 4.14. Univariate spectral analysis for Interval 5 (101-77 mbsf). 95

Figure 4.15. Core summary and correlations for the mid Pliocene (80-70 mbsf). 97

Figure 5.1. Benthic $\delta^{18} \mathrm{O}$ stack (Liseicki and Raymo, 2005). 102

Figure 5.2. Sedimentation model A, for the interval 9-0 mbsf ( $550 \mathrm{ka})$. 106

Figure 5.3. Sedimentation model B for the interval 101-77 mbsf ( 4.2-3.6 Ma). 112

Figure 5.4. Correlation of facies log and natural gamma-ray to orbital parameters for the interval 101-77 mbsf. 117

Figure 5.5. A comparison between U1361A and AND-1B core records and the benthic $\delta^{18 O}$ stack (Liseicki and Raymo, 2005) for 4.2-0 Ma. 123 


\section{List of Tables}

Table 1.1. Wilkes Land seismic stratigraphy, unconformities (Donda et al., 2007). 8

Table 4.1. Generalised descriptions for facies observed in U1361A. 73

Table 4.2. Relative values for physical property logs (GRA, NGR, MS and L*) associated with facies scheme for U1361. 78

Table 4.3. Orbital frequencies at which physical properties are significantly coherent. 79

Table 4.4; Significant orbital frequencies identified in spectral analysis for Interval 1 (9-0 mbsf of U1361A). 83

Table 4.5. Significant orbital frequencies identified in spectral analysis for Interval $2(36.5-18.5$ mbsf of U1361A). 86

Table 4.6. Significant orbital frequencies identified in spectral analysis for Interval 3 (55.3-38.6 mbsf of U1361A).

Table 4.7. Significant orbital frequencies identified in spectral analysis for Interval 4 and for combined Intervals 3 and 4 (72-56.5 mbsf; 72-38.6 mbsf of U1361A). 92

Table 4.8. Significant orbital frequencies identified in spectral analysis for Interval 5 (101-77 mbsf of U1361A). 95

Table 5.1. A summary of ice sheet and oceanic processes that influence sedimentation during for each phase as identified in Figure 5.2. 107

Table 5.2. A summary of ice sheet and oceanic processes influencing sedimentation for each phase identified in Figure 5.3.

\section{List of Charts}

Chart 3.1. Flow chart of data processing steps. 65 


\section{Chapter 1 Introduction}

Integrated Ocean Drilling Program (IODP) Expedition 318 recovered seven drill core records from the Wilkes Land margin of East Antarctica (including core U1361A used in this study, Figures 1.1 and 1.2), in order to gain insight and understanding of how the East Antarctic Ice Sheet (EAIS) grows and decays during different climate states throughout the Late Cenozoic. While the oxygen isotope curve provides evidence for climate evolution and cyclicity throughout the Neogene (Shackleton and Kennett, 1975; Lisiecki and Raymo, 2005), it represents a globally integrated record of ice volume and deep ocean temperature change. Ice-proximal geological records are therefore needed to determine the exact response of Antarctic ice sheets and any associated change in the Southern Ocean.

Previous drilling expeditions to the Ross Sea region have recovered evidence for orbitally-paced oscillations of the marine based West Antarctic Ice Sheet (WAIS) during the Plio-Pleistocene (e.g. Naish et al., 2009). Recent ice sheet modelling (Pollard and DeConto, 2009), in combination with results by Naish et al., (2009), has provided an estimate of Antarctic ice volume change. However, geological evidence for the timing and nature of glacial variability of the EAIS is inconclusive.

Lithofacies interpretations in combination with physical property logs from U1361A were used to explore the sensitivity of the EAIS and associated variability in ocean circulation at the Wilkes Land margin at glacial-interglacial timescales in the Late Neogene. This contributes to a principal goal of IODP Expedition 318: "To obtain a high resolution record of Antarctic variability during the Neogene and Quaternary" (Expedition 318 Scientists, 2010). A more specific goal of this thesis is to understand the response of the EAIS to orbital influences during the period past climatic warmth of the Pliocene between 5-3 Ma and global cooling from $~ 3$ Ma which has led to the development of the bipolar glacial Quaternary (2.5-0 Ma) world and the present cold polar Antarctic ice Sheet.

The thesis aims to achieve this goal by: 
1) Defining relationships between the sediment core lithofacies and physical property logs as two key proxies of environment change.

2) Identifying the nature of cyclicity in the facies and physical property logs for the upper $\sim 100 \mathrm{~m}$ of core U1361A, and developing a glaciomarine depositional history for the last $\sim 4$ Myrs for the Wilkes Land margin of EAIS.

3) Identifying evidence for orbital variability and longer-term climatic influences affecting sediment deposition at the core site U1361A.

4) Addressing the oceanographic and glacial processes controlled by both orbital and longer term climatic variability.

Due to the novel nature of this study, and general paucity of geological drill core data for the Antarctic margin, the thesis begins with a comprehensive literature review (Chapter 2) of Antarctic glacial history, orbital-scale climate variability, Southern Ocean circulation and sedimentation on glaciated continental margins. This provides a summary of the current state of knowledge regarding the Late Neogene EAIS and oceanographic variability at the Wilkes Land margin. Emphasis is placed on the varying views concerning EAIS volume variability during the warm Pliocene period (5-3 Ma), and the orbital pacing of Antarctic ice sheet variability during the Late Neogene.

Chapter 3 Materials and Methods, outlines the application of the age model provided by Tauxe et al., (2012), the recovery of U1361A, logging of the physical property logs (gamma-ray attenuation bulk density, natural gamma-ray, magnetic susceptibility and colour reflectance), and how the data were processed in Matlab ${ }^{\circledR}$ and analysed using spectral analysis techniques.

The relationship between physical property logs and the core stratigraphy is assessed in the first section of Chapter 4 Results. The selected intervals are displayed showing correlation of the facies and physical properties cycles to the benthic $\delta^{18} \mathrm{O}$ stack (Lisiecki and Raymo, 2005), with core summaries and spectral analysis for each physical property time series outlined in the second part of the Chapter 4. 
The discussion (Chapter 5) provides a sedimentation model linking the facies and physical property responses to sedimentation processes. This was done in order to understand how depositional cycles at the U1361A core site were controlled by oceanographic and ice sheet processes during the Late Neogene, and, specifically how these processes were being influenced by orbital pacing of glacial to interglacial variations. Lastly, correlation to the Antarctic Drilling Program core 1B (AND-1B) in the Ross Sea region illustrates that ice sheet and oceanographic variability of the EAIS at the Wilkes Land margin is comparable with the WAIS in the Ross Sea sector.

\section{Regional Setting}

The Wilkes Land margin of the EAIS is grounded below sea-level, with a significant subglacial basin located inland (Figure 1.1). It is therefore suggested to respond dynamically in warmer-than-present conditions, much like WAIS collapses recorded in the AND-1B core (e.g. Pollard and Deconto, 2009; Naish et al., 2009). The U1361A core site is located on the lower continental rise, situated on the eastern levee of the Jussieau submarine channel, one of a series of continental slope canyons that transition down-slope into coalescing deep-sea fans (Figure 1.2). While less proximal to the EAIS than continental shelf sites, as a subsiding passive margin with progressive steepening of the rise, relatively continuous sediment accumulation is recorded at core site U1361A. The drill site is located offshore of the Mertz Glacier polynya, formed by katabatic winds which helps to keep the area relatively free of sea-ice, and is also situated within the Wilkes gyre, one of the three major source regions of Antarctic Bottom Water (McCartney and Donohue, 2007).

The lower continental rise is characterised by low relief channels, acting as conduits for sediment transport via turbidity currents and intersected with asymmetric sediment ridges (Escutia et al., 2000). Channel morphology on the Wilkes Land lower rise, is characterised by a thicker western levee, consistent with forcing by a 
westward Coriolis Effect for the Southern Hemisphere (De Santis et al., 2003, Escutia et al., 2005).

Comprehensive seismic surveying of the Wilkes Land margin identifies nine seismic sequences representing four seismic units of discrete phases of sediment deposition since the initial Australian- East Antarctic rift (Donda et al., 2007; summarised in Table 1.1; Figures 1.3 and 1.4). Drilling during IODP Expedition 318 has confirmed that Unit 4 provides a continuous sediment record for the Plio-Pleistocene. The mid Pliocene to present interval studied here, is contained within the upper $\sim 100 \mathrm{~m}$ of U1361A, which is located above the WL-U8 unconformity (Figure 1.4). Seismic sequences WL-S8 and WL-S9 are much thinner on the continental rise than in underlying units, indicating decreased sediment supply, consistent with sediment been trapped on the outer-shelf forming a prograding wedge (Escutia et al., 2005; Donda et al., 2003).

From the deposition of sequence WL-S7 to present, erosion is apparent in the Jussieau and Buffon Channels with partial infilling interpreted from sediment drapes onlapping the flanks of the Jussieau Channel (Donda et al., 2003, De Santis et al., 2003). A lower energy environment and infilling to the east of sediment ridges on the rise, is hypothesised to be the result of sheltering from the ridge itself (De Santis et al., 2003). This is supported by modern bottom current configuration, as currents converge within the Jussieau Channel (Bindoff et al., 2000).

Sediment waves identified on the lower rise in sequence WL-S8 indicate strong bottom currents were active in depositing contourites (De Santis et al., 2003). However an upslope migration and decreasing amplitude downslope of sediment waves within a sediment ridge on the rise is consistent with down-slope current processes (De Santis et al., 2003; Donda et al., 2003). In a model by Rebesco et al., (1997), increased sediment supply to the shelf edge during maximum ice advance, triggers turbidity currents, from which suspended fines are entrained by contour currents (in this case the AABW, flowing westward) and deposited to form sediment ridges located between turbidite channels. 
Sedimentary processes in this environment is therefore likely to consist of 1) overbank deposition by down-slope density and turbidity currents; 2) pelagic rain of biogenic opal; 3) ice rafted debris; and 4) reworking of sediments by contour currents associated with the Antarctic Slope Current. Changes in the behaviour of the Mertz Glacier polynya and the Wilkes Gyre are likely to significantly impact sedimentary processes at the U1361A drill site as they will alter contour current activity, density-driven down-slope currents, and biological productivity. However, polynya extent, sea-ice extent, Wilkes Gyre activity and ocean circulation are also likely to be intimately linked to ice volume variations and therefore should respond at similar timescales.

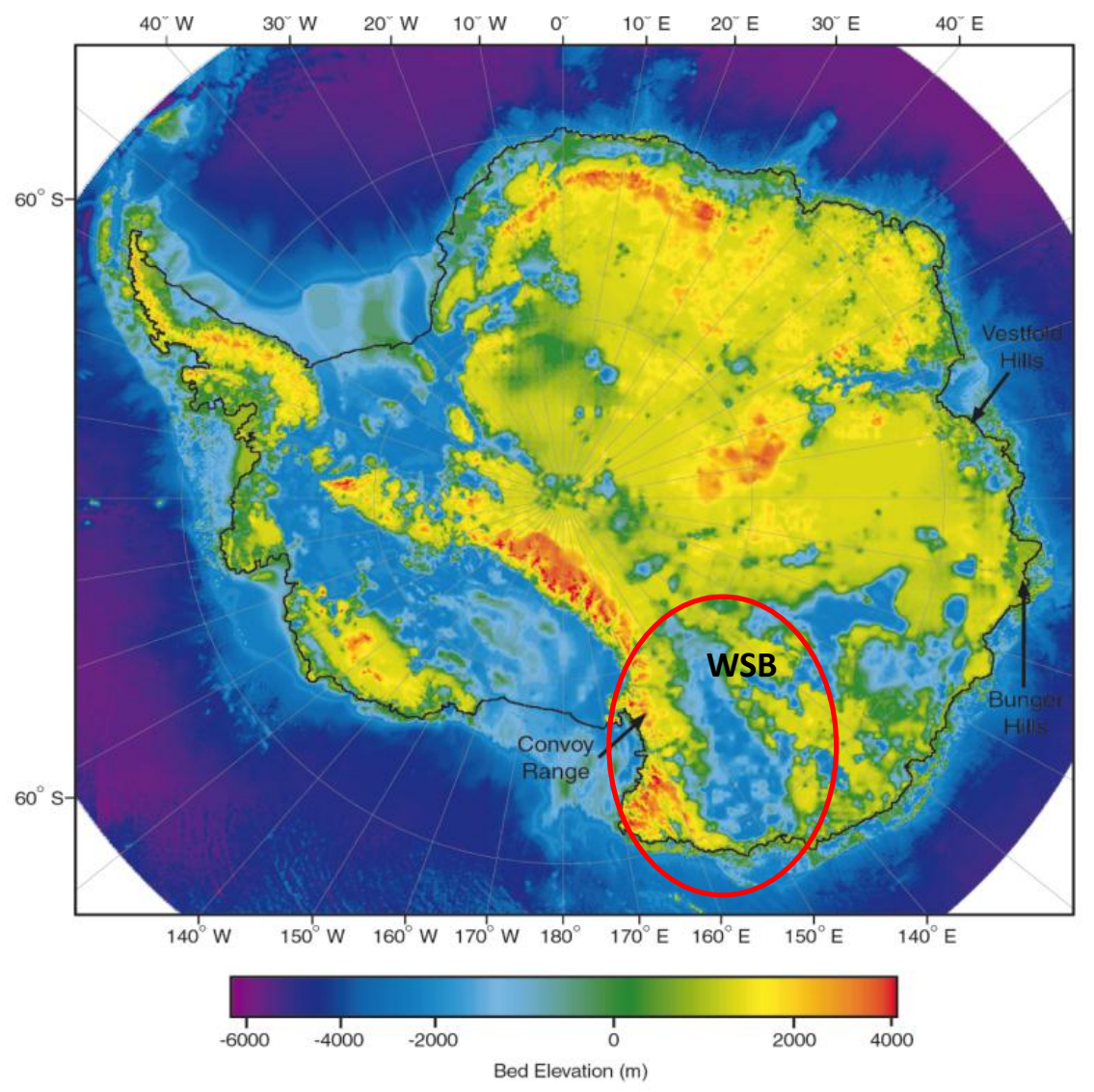

Figure 1.1. Antarctic bed elevation, with the Wilkes Sub-glacial basin (WSB) highlighted. (modified from Lythe et al., 2001) 


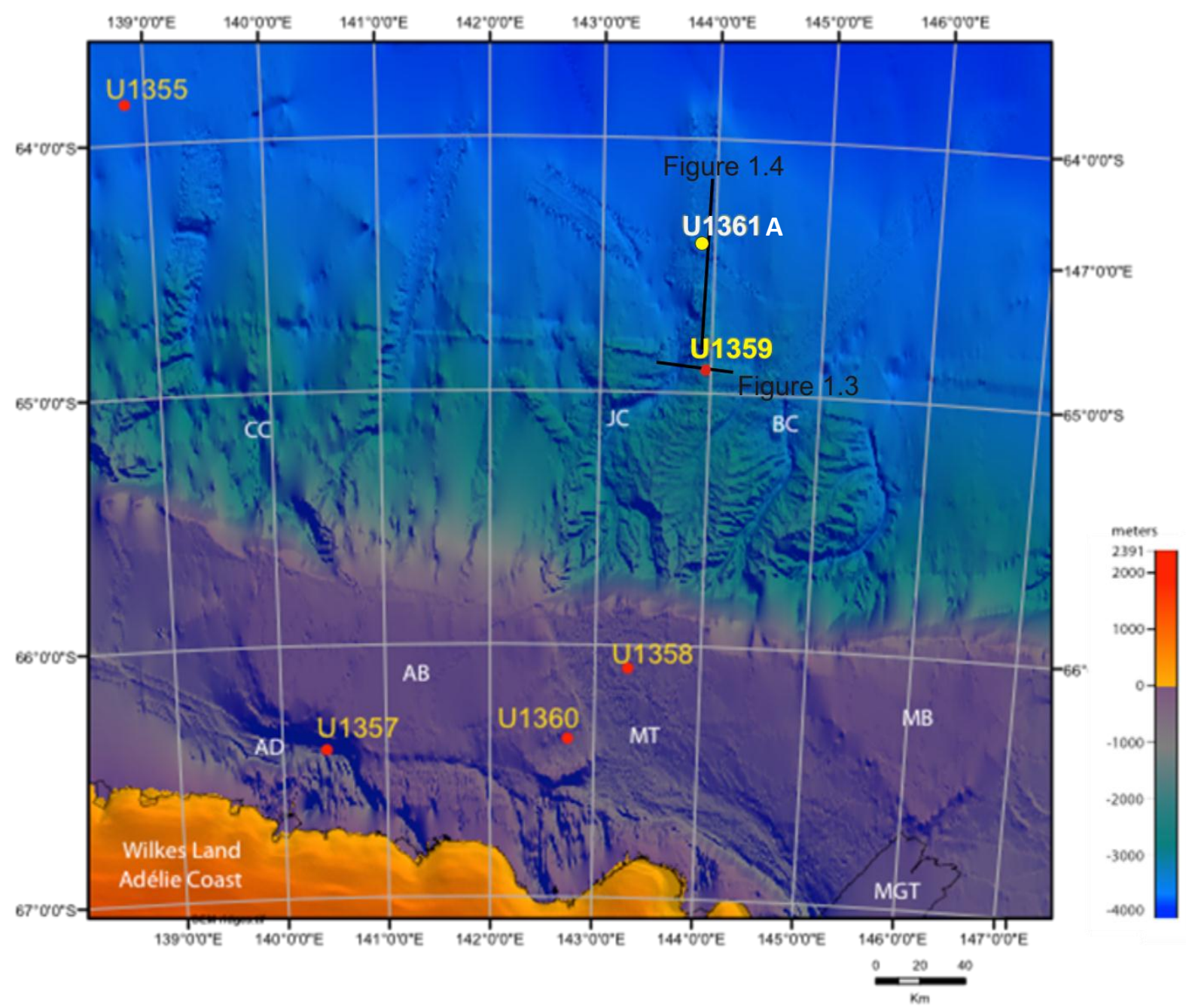

Figure 1.2. Core sites drilled during IODP Expedition 318, with U1361A highlighted in white and seismic transects in black for Figures 1.3 and 1.4 (Expedition 318 Scientists, 2010). 


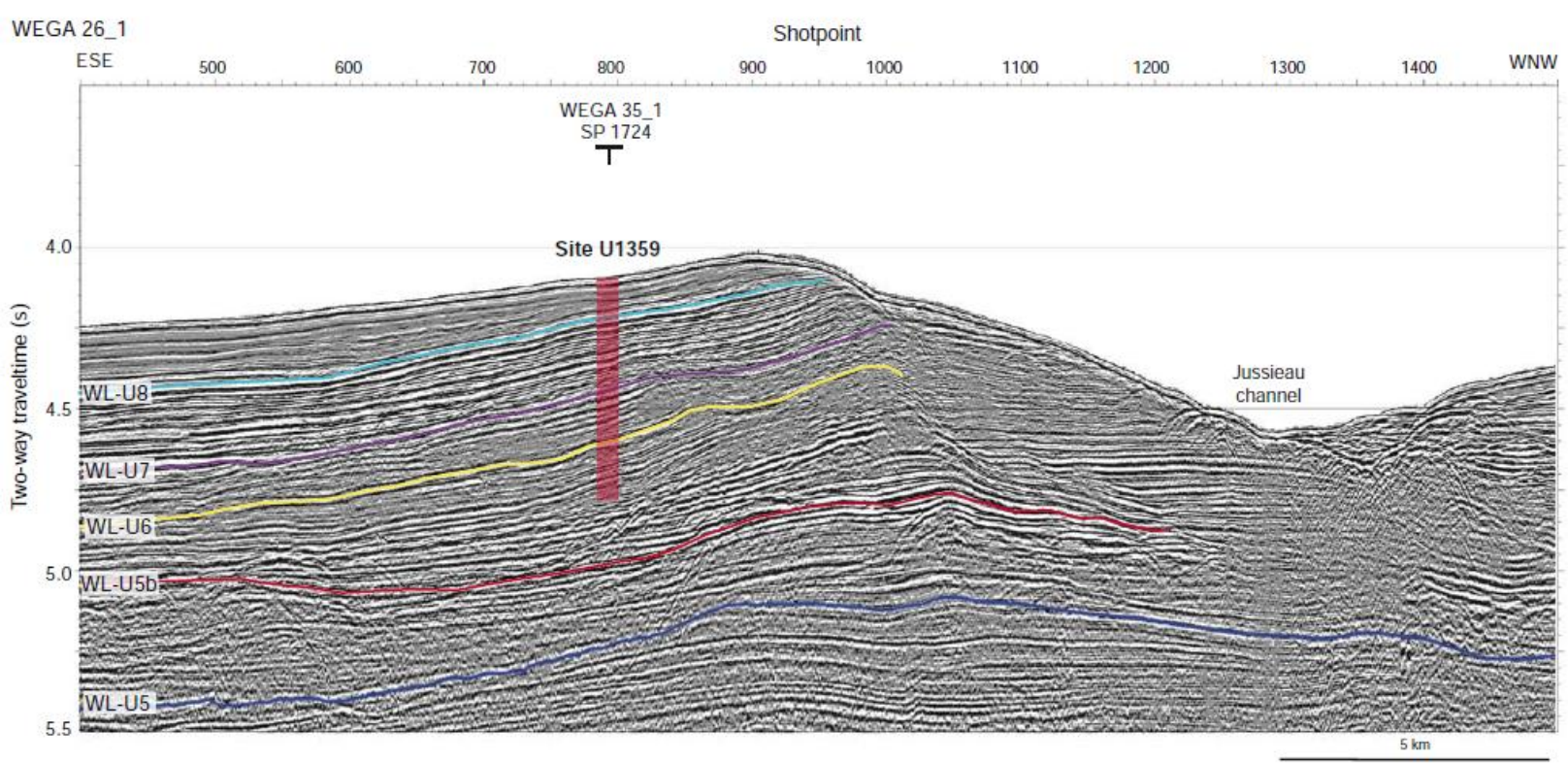

Figure 1.3. Multichannel seismic reflection showing core site U1359 which is in a similar location to U1361, relative to the Jussieau channel, with previously identified unconformities (see Table 1.1; Expedition 318 Scientists, 2010).

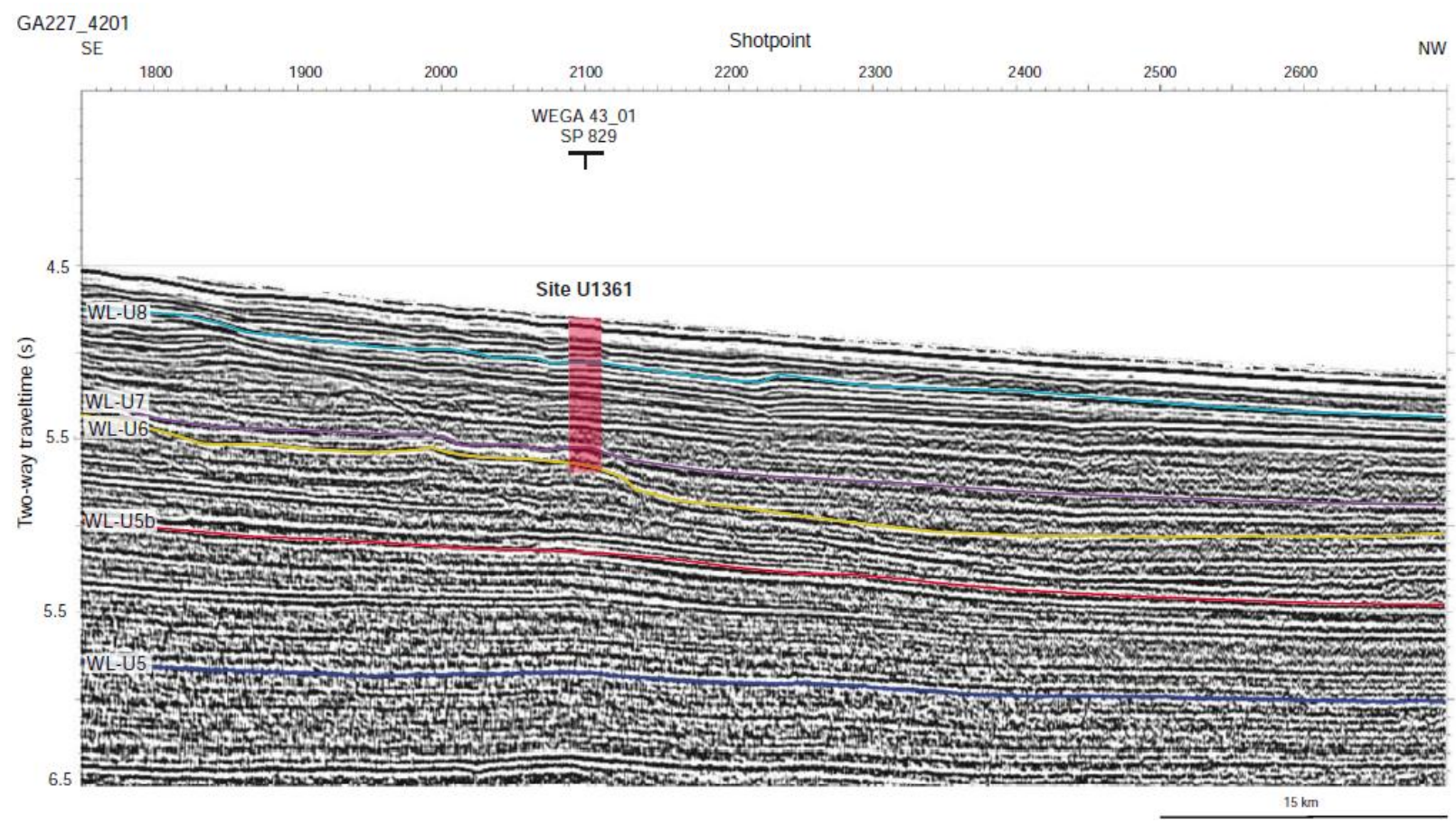

Figure 1.4; Multichannel seismic reflection transect along the levee of Jussieau channel, showing core site U1361 relative to previously identified seismic unconformities (see Table 1.1; Expedition 318 Scientists, 2010). 
Table 1.1. Wilkes Land seismic stratigraphy. Outlining unconformities (WL-U\#), sequences (WL-S\#) and associated deposition of environment for each Unit 1 through 4 after Donda et al., 2007.

\begin{tabular}{|c|c|c|c|}
\hline WL-U8 & WL-S9 & Unit 4 & $\begin{array}{l}\text { Decreased sediment supply to the continental rise, sediment collected } \\
\text { on the shelf, associated with a more stable ice sheet at Wilkes Land. }\end{array}$ \\
\hline $\begin{array}{l}\text { WL-U6 } \\
\text { WL-U5 }\end{array}$ & $\begin{array}{l}\text { WL-S7 } \\
\text { WL-S6 } \\
\text { WL-S5 }\end{array}$ & Unit 3 & $\begin{array}{l}\text { Maximum sediment supply to the continental slope and rise, } \\
\text { development of channel-levee complexes and formation of sediment } \\
\text { ridges and drifts. Dynamic and temperate ice sheet present at Wilkes } \\
\text { Land. }\end{array}$ \\
\hline WL-U3 & WL-S4 & Unit 2 & $\begin{array}{l}\text { Early emplacement of the EAIS with increased sediment supply to the } \\
\text { continental rise and episodic erosion or non-depositional events. }\end{array}$ \\
\hline $\begin{array}{l}\text { WL-U2 } \\
\text { WL-U1- }\end{array}$ & $\begin{array}{l}\text { WL-S3 } \\
\text { WL-S2 }\end{array}$ & Unit 1 & $\begin{array}{l}\text { Early post-rift period when the continental margin was undergoing } \\
\text { thermal subsidence and no grounded ice sheets present on the Wilkes } \\
\text { Land margin. }\end{array}$ \\
\hline
\end{tabular}




\section{Chapter 2 Literature Review}

\subsection{Antarctic Glacial History}

Much of the Cenozoic glacial history of Antarctica has been inferred from the marine oxygen isotope record (Figure 2.1; e.g. Zachos et al., 2001a). However, direct evidence for the onset and evolution of glaciation derived from ice-proximal geological records from the Antarctic margin, is required to understand the timing and contribution of Antarctic ice to global ice volume changes inferred from the oxygen isotope record. The onset of continental-scale Antarctic glaciations was originally inferred from a $1 \%$ enrichment in benthic $\delta^{18} \mathrm{O}$ foraminifera at $\sim 34 \mathrm{Ma}$ (e.g. Kennett and Shackleton, 1975). Subsequent drilling in Prydz Bay (ODP Leg 119) and the Ross Sea (CIROS-1) recovered Early Oligocene glaciomarine sediment providing unequivocal direct evidence for icebergs calving at sea-level (Hambrey et al., 1991; Barrett, 1989). The onset of ice-rafted debris during the Earliest Oligocene at the Kerguelen Plateau (ODP Leg 120) constrained the timing of the first large icebergs calving at the Antarctic margin to coincide with the 1\%o enrichment in benthic $\delta^{18} \mathrm{O}$ foraminifera (Wise et al., 1991; Zachos et al., 1992). High-resolution oxygen isotope records have enabled the identification of a stepwise glaciation (Oi-1 and $\mathrm{Oi}-1 \mathrm{a}$; events of $\sim 40 \mathrm{kyr}$ duration, separated by $400 \mathrm{kyr}$ ), suggesting an eccentricity and obliquity paced climate at this time (Coxall et al., 2005).

Though the Antarctic continent reached a polar position during the Early Cretaceous ( 120 Ma), thermal isolation due to the opening of oceanic gateways (Tasmania-Antarctic at $\sim 34 \mathrm{Ma}$ and Drake Passage at $\sim 30 \mathrm{Ma}$ ) is thought to have contributed to the onset of Antarctic glaciation (Zachos et al., 2001a). However, a numerical ice sheet model implies that a threshold in declining global $\mathrm{CO}_{2}$ levels was the primary triggering mechanism (DeConto and Pollard, 2003), with prolonged nodes in orbital eccentricity likely to have had some influence on the exact timing 
and stepwise nature of ice sheet development (Zachos et al., 2001a; DeConto and Pollard, 2003).

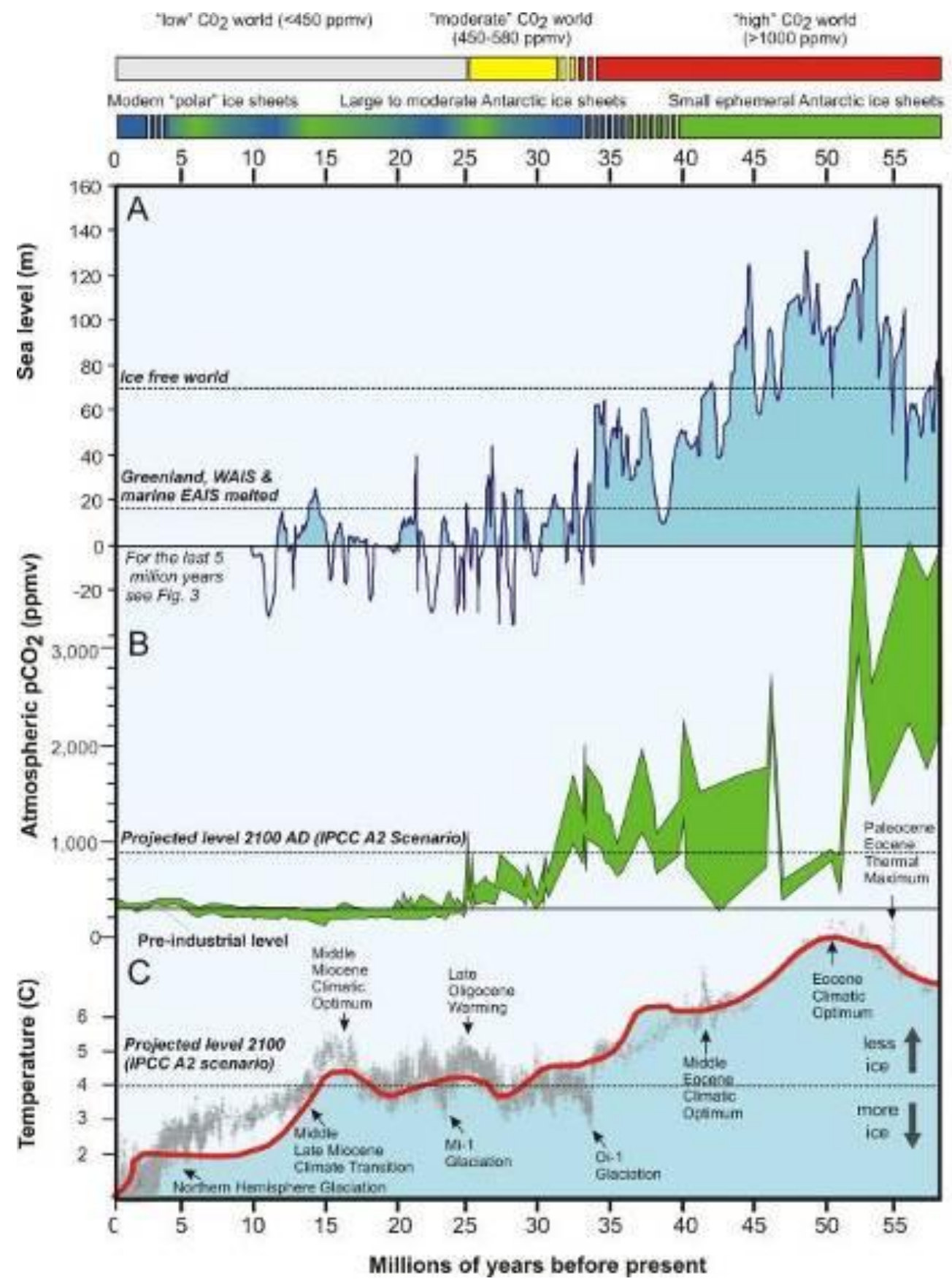

Figure 2.1. The Cenozoic history of Antarctic ice sheet development and atmospheric $\mathrm{pCO}_{2}$ from a range of datasets. (A) Global sea-level variations in response to polar ice volume fluctuation as recorded by sequence stratigraphy on the New Jersey Margin (e.g., Miller et al., 2005; Kominz et al., 2008). (B) Atmospheric $\mathrm{CO}_{2}$ concentrations reconstructed from organic biomarkers and foraminifera preserved in ocean sediments (Pearson and Palmer, 2000; Pagani et al., 2005). (C) Global atmospheric temperature curve (bold red line) adapted from Crowley and Kim (1995) overlaid on compiled benthic $\delta^{18} \mathrm{O}$ data representing global ice volume and deep ocean temperature (Zachos et al., 2001a). Interpretations of major climatic transitions associated with evolution of the Antarctic ice sheets are shown at the top of the figure. Compiled by Richard Levy in Duce et al., (2011). 


\subsubsection{A dynamic Oligocene-Miocene ice sheet}

Sea-level and $\mathrm{CO}_{2}$ reconstructions for the Early Oligocene (following the Oi-1 and Oi-1a events) show a pronounced decreasing trend followed by a late Oligocene warming (Figure 2.1). High resolution and continuous $\delta^{18} \mathrm{O}$ and $\delta^{13} \mathrm{C}$ records spanning the Oligocene (33.9-23 Ma) were obtained from marine sediment cores in the Southern Ocean (ODP Site 1218) and illustrate eccentricity ( 400 kyr, $\sim 125 \mathrm{kyr}$ and $\sim 95 \mathrm{kyr})$ and obliquity ( 40 kyr) orbital modulation of Antarctic glaciations and the global carbon cycle (Palike et al., 2006). Sediment cores recovered in the western Ross Sea as part of the Cape Roberts Drilling Project, provided direct evidence from shallow glaciomarine sequences deposited by three East Antarctic Ice Sheet (EAIS) advance and retreat events, each one occurring across either a obliquity or eccentricity cycle just prior to the Oligocene/Miocene boundary (Naish et al., 2001).

The Mi-1 event is a $400 \mathrm{kyr}$-duration of a $0.8 \%$ temporary enrichment in $\delta^{18} \mathrm{O}$ records equivalent to a sea-level fall of $\sim 60 \mathrm{~m}$ just after the Oligocene-Miocene boundary, suggestive of a large transient Antarctic glaciation at this time ( $\sim 23 \mathrm{Ma}$; Zachos et al., 2001a). An erosional hiatus in CRP-2 sediment core coincides with the Mi-1 event, supporting the interpretation that this isotope excursion was the consequence of a large Antarctic ice sheet advance event (Naish et al., 2001). Orbital configuration during the Mi-1 event corresponds to a node in obliquity and a minimum in eccentricity, favourable to ice sheet expansion on Antarctica (Zachos et al., 2001b).

The Early Miocene Antarctic ice sheets oscillated in response to orbital forcing with several other large transient Mi-events noted in $\delta^{18} \mathrm{O}$ records and culminated in a minimum during the Middle Miocene Climatic Optimum 15 Ma (Miller et al., 1987, 1991; Shevenell et al., 2004; Figure 2.1). While proximal geological constraints regarding variations in the size of the ice sheet at this time are poor, glacial and vegetation reconstructions from deposits in the Transantarctic Mountains imply temperate to subpolar glaciers and a climate capable of supporting shrub-herb tundra (Lewis et al., 2007). 
The Middle Late Miocene Climate Transition is characterised by a $1 \%$ enrichment in benthic $\delta^{18} \mathrm{O}$ records is interpreted to represent a shift to quasi-permanent EAIS at $\sim 14 \mathrm{Ma}$ (Figure 2.1; Kennett, 1977; Shevenell et al., 2004). Well preserved volcanic ashes in tills deposited by dry-based glaciers in the Transantarctic Mountains have been dated at $13.8 \mathrm{Ma}$, and there is no evidence of a return to wetbased glaciation that was in place prior to $14 \mathrm{Ma}$ (Marchant et al., 1993; Lewis et al., 2007).

\subsubsection{Late Neogene ice sheet variability}

A general positive trend in $\delta^{18} \mathrm{O}$ and a decrease in $p \mathrm{CO}_{2}$ levels suggest an overall cooling since the Middle Late Miocene Climate Transition at 14 Ma. The benthic $\delta^{18} \mathrm{O}$ stack (Lisiecki and Raymo, 2005) shows marked increase in amplitude of glacial-interglacial cycles between 3.0 and $2.5 \mathrm{Ma}$, superimposed on a longer term cooling trend and culminating in the glacial maxima of marine isotope stages 100, 98, 96 at $\sim 2.5 \mathrm{Ma}$. This represented the onset of the first major glaciations of the northern hemisphere continents (Raymo et al., 1987), supported by deep sea evidence for increased ice rafting in the North Atlantic and North Pacific at this time (Jansen et al., 1996; Haug et al., 1999), and producing $100 \mathrm{~m}$-scale global sealevel fluctuations (Naish, 1997).

Prior to $\sim 3 \mathrm{Ma}$, glacial-interglacial oscillations in the $\delta^{18} \mathrm{O}$ record are smaller and imply global sea-level cycles of up $30 \mathrm{~m}$ that are thought to be primarily driven by Antarctic ice sheet fluctuations (Kennett and Hodell, 1990; Naish and Wilson, 2009).

The warm Pliocene Epoch (5-3 Ma) experienced global average surface temperatures $2-3^{\circ} \mathrm{C}$ above present and $\mathrm{CO}_{2}$ levels of $\sim 400 \mathrm{ppm}$ (Pagani et al., 2010; Seki et al., 2010), although the extent of variability at the marine margin of the EAIS during this warm period remains uncertain. 


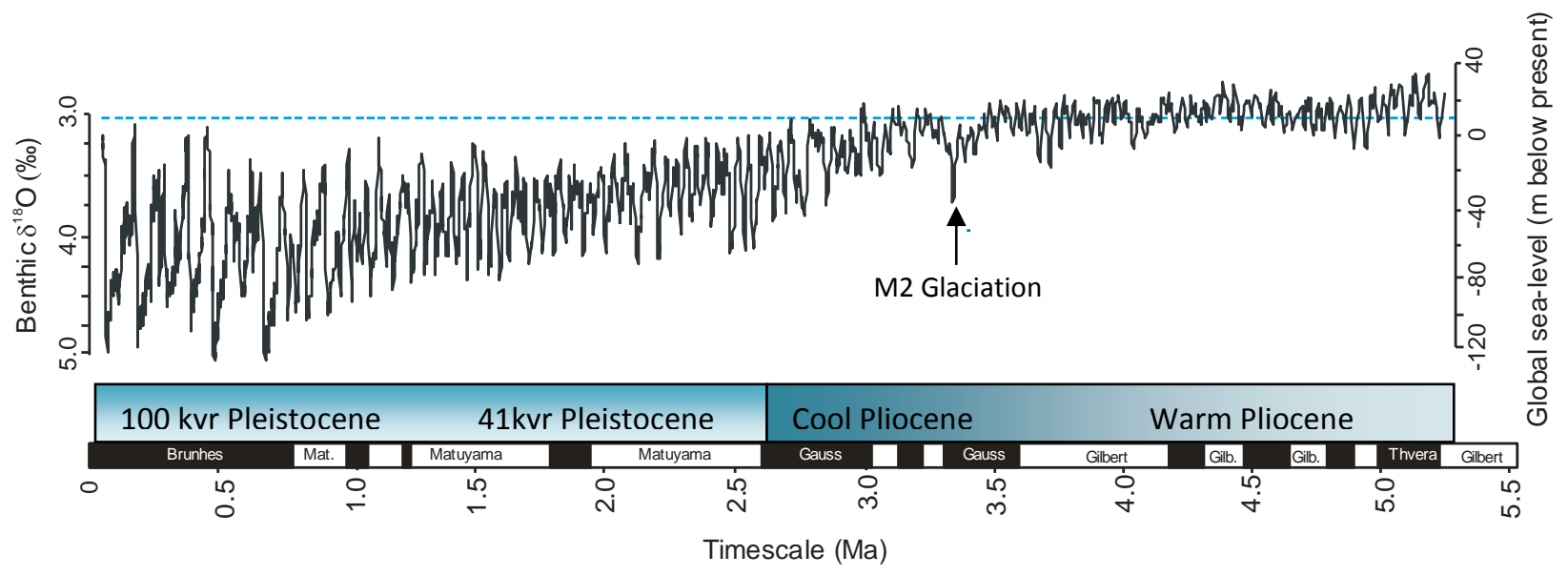

Figure 2.2. The benthic oxygen isotope stack for 5.3 Ma to present (Lisiecki and Raymo, 2005), converted to sealevel by placing constraints on tectonic subsidence and sediment accumulation at the Wanganui Basin, New Zealand (Naish and Wilson, 2009). The blue dashed line represents sea-level and $\delta^{18} \mathrm{O}$ for a deglaciated West Antarctic Ice Sheet and Greenland Ice Sheet. The M2 glaciation is associated with the re-appearance of grounded ice in the Ross Sea following a $1 \mathrm{Myr}$ period of reduced WAIS extent (McKay et al., 2012a).

The discovery of glacial till with Pliocene-age marine microfossils (diatoms) in the Sirius Formation, located high in the Transantarctic Mountains started a debate on major deglaciation of the EAIS during the Pliocene of up to two-thirds of its present day volume (40m sea-level equivalent; Webb et al., 1984). It was hypothesised that open marine sediments were deposited in Wilkes and Pensacola subglacial basins during a period of Pliocene deglaciation. These are hypothesized to have been subsequently eroded and transported by an advancing EAIS and redeposited within the glacial till of the Sirius Group when the EAIS over-rode and/or cut through the Transantarctic Mountains (Webb et al., 1984). It has been argued by numerous studies that the Pliocene diatoms were not contemporaneous within their deposits, or were subsequently incorporated into the Sirius Groups millions of years later through wind-introduced processes (Barrett et al., 1997; Mckay et al., 2008a).

Diamictites, sandstones and mudstones in the Sirius Formation at Oliver Bluffs, contains Nothofagus beardmorensis fossil leaves, stems and pollen (Francis and Hill, 1996). These fossil remains were compared to modern Nothofagus antarctic, found in South America at elevations up to $700 \mathrm{~m}$ and summer temperatures not above $\sim 5^{\circ} \mathrm{C}$ (Mercer, 1986). This comparison suggests mean annual temperatures of 
$-12^{\circ} \mathrm{C}$ in the Transantarctic Mountains (Francis and Hill, 1996). However, the age of the Nothofagus fossils remain contentious in the Beardmore deposits. Lewis et al., (2008) however, finds well-dated fossil evidence representing the last vestiges of a tundra community inhabiting the McMurdo Dry Valleys at $14 \mathrm{Ma}$, the age at which the EAIS is suggested to have shifted to a permanent cold, polar regime (Lewis et al., 2007).

The Lambert Glacier/Prydz Bay region, which is currently the largest drainage system of the EAIS, contains a series of Miocene (or older) to Early Pleistocene in age glaciogenic deposits, termed the Pagodroma Group. These deposits contain facies that resemble modern polythermal tidewater fjordal deposits, with numerous sequences containing evidence of deposition by calving icebergs in the absence of an ice shelf (Hambrey and McKelvey, 2000). These deposits are several hundred kilometres inland from the present calving line of the Amery Ice Shelf (Hambrey and McKelvey, 2000), indicating that a large ice shelf was not present in the Lambert Graben during Miocene and Pliocene interglacials. The stratigraphic signature of Late Miocene deposits recovered in AND-1B core depicts a 'subpolar'style glaciation producing a significant volume of meltwater (McKay et al., 2009). Evidence for warmer oceanic conditions during most of the Pliocene, at the Prydz Bay margin of the EAIS comes from diatoms in offshore cores (ODP site 1165 and 1166) which suggest minimal sea-ice concentration (Whitehead et al., 2005). However, offshore drilling in Prydz Bay provides evidence for migration of the Lambert Glacier terminus expanding $>500 \mathrm{~km}$ onto the outer continental shelf during the Miocene and Pliocene, indicating the marine margin of EAIS did fluctuate significantly volume during the Late Neogene (Hambrey and McKelvey, 2000).

AND -1B core, drilled beneath the McMurdo Ice Shelf, Antarctica, has been used to interpret the growth and decay of the West Antarctic Ice Sheet (WAIS) during the warm Pliocene (Naish et al., 2009a). The presence of a $90 \mathrm{~m}$ thick diatomite unit in the Pliocene intervals of the AND-1B drill core indicates that open marine 
conditions persisted in western Ross Sea for a period of $\sim 1$ Myr between 4.6-3.4 Ma (Naish et al., 2009a; McKay et al., 2012a), and implies a significantly reduced WAIS during this time (Pollard and DeConto, 2009). Moreover, McKay et al. (2012a) reconstruct sea surface temperatures of between $+2-6^{\circ} \mathrm{C}$ using the biomarker TEX $\mathrm{X}_{86}$ sea surface temperature proxy during these open water condition, while diatom census counts indicate reduced summer sea-ice extent and duration. Subsequent to this prolonged retreat event, the reappearance of grounded ice diamictite facies in AND-1B core between Marine Isotope Stage (MIS) Mg4 to MIS M2 (Mckay et al., 2009; Figure 2.2), indicates widespread expansion of the WAIS in the western Ross Sea at this time (Mckay et al., 2012a; Figure 2.2). Although, the WAIS periodically retreated and advanced at obliquity frequencies during the Late Pliocene, diatoms and $\mathrm{TEX}_{86}$ data from interglacial diatomites indicate a progressive expansion and increased duration of summer sea-ice and cooling of sea surface temperatures in the Ross Sea during between 3.2 and 2.5 Ma (McKay et al., 2012a).

While ice sheet models are still unable to account for all feedback mechanisms in the climate system and some of the key forcings used to drive models, such as basal geology and topography, and ocean melting rates are poorly constrained, they provide a mechanism to test the sensitivity of ice sheet response under set climate scenarios. For the Early Pliocene warm period, model results of EAIS deglaciation extent are variable, but are in agreement that the collapse of Wilkes and Pensacola subglacial basins is unreasonable for the range of known Pliocene climate boundary conditions as indicated by the geologic record (Hill et al., 2007, Pollard and DeConto, 2009). A coupled British Antarctic Survey Ice Sheet Model (BASISM) and the Had3AM atmospheric General Climate Model (GCM; Haywood et al., 2002) used by Hill et al., (2007) and Dolan et al., 2011, gave two ice sheet configurations. The smallest Antarctic ice sheet volume presented a retreat at the Wilkes Land margin, with a $20 \%$ loss in volume of the EAIS compared to the present day, although the southern portion of Wilkes and Aurora subglacial basins are still covered (Figure 2.3a). The ice sheet models of Hill et al., (2007) and Dolan et al., (2011) however, do not incorporate marine grounding-line processes and are not coupled to ocean 
dynamics. It is therefore, unlikely they accurately captured the effect of ocean melt, a significant mechanism of ice sheet retreat (Pollard and DeConto, 2009; Mackintosh et al., 2010). Pollard and DeConto (2009) find, apart from small variations at the Wilkes Land margin and Prydz Bay, the EAIS remains stable throughout the Plio-Pleistocene, with $\sim 3 \mathrm{~m}$ sea-level equivalent contributed from EAIS margins (Figure 2.3b).

A recent probabilistic analysis of peak Pliocene global sea-level estimates from geochemical proxies $\left(\delta^{18} \mathrm{O}, \mathrm{Mg} / \mathrm{Ca}\right)$, backstripping of shallow-marine continental margin sequences and uplifted paleoshorelines reports a mean estimate of $+19 \mathrm{~m}$ and a $68 \%$ probability that Pliocene sea-level was between $+22 \pm 5 \mathrm{~m}$ (Miller et al., 2012). This would require a complete deglaciation of Greenland (+7 $\mathrm{m}$ sea-level rise) and WAIS (+5 m sea-level rise), and between 5-15 m of contribution of the EAIS.
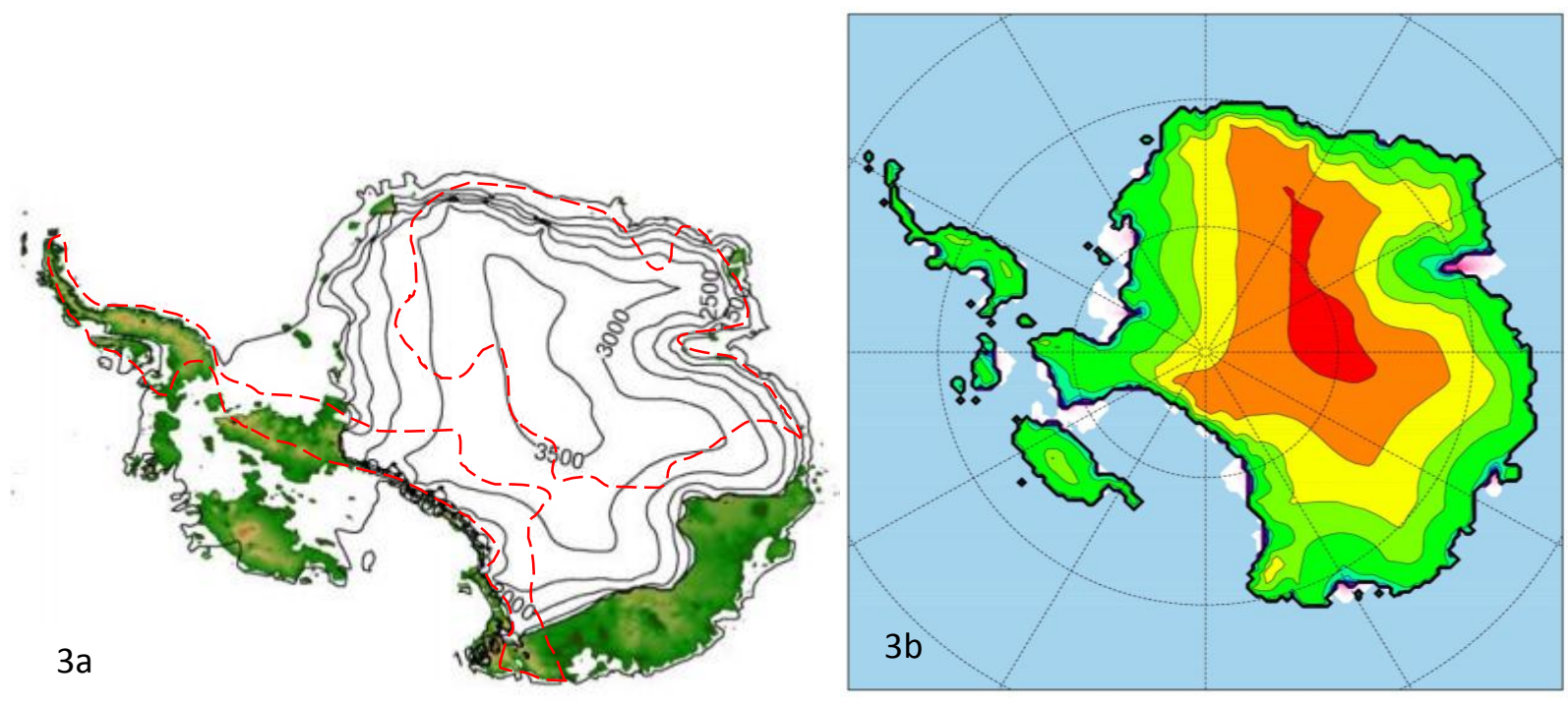

Figure 1.3. A comparison of ice sheet models for the warm Pliocene. An ice sheet model by Hill et al., (2007; in Dolan et al., 2011) experiences a more prominent retreat at the Wilkes Land margin (3a) compared to the model provided by Pollard and DeConto $(2009 ; 3 \mathrm{~b})$. The dashed red line in Figure 2.3a represents the hypothesised deglaciation of Webb et al., (1984). 


\subsubsection{The Mid-Pleistocene Climate Transition and development of the Modern Polar}

Ice Sheet

The shift from $\sim 40 \mathrm{kyr}$ obliquity climate pacing to $100 \mathrm{kyr}$ pacing of the glacialinterglacial cycles during the mid-Pleistocene transition ( $~ 800 \mathrm{ka})$ coincides with an intensification of Northern Hemisphere glaciations, as indicated by increased amplitude of fluctuations in the benthic $\delta^{18} \mathrm{O}$ curve for the Late Pleistocene (Lisiecki and Raymo, 2005). A notable characteristic of the Late Pleistocene $100 \mathrm{kyr}$ glacialinterglacial cycles is the asymmetric nature of the benthic $\delta^{18} \mathrm{O}$ curve, suggesting that ice sheets take $\sim 90$ kyrs to grow, and only $\sim 10$ kyrs to collapse (Raymo et al., 2006). The cause for rapid deglaciations since the mid-Pleistocene transition is inconclusive. The EAIS and WAIS ice sheets are thought to have been relatively stable since the mid-Pleistocene transition, with modern ice sheet configuration typical for most past interglacials (Pollard and DeConto, 2009; McKay et al., 2012a). Geological evidence from the Ross Sea and Prydz Bay supports a further cooling and stabilisation of Antarctic ice sheet margins in the Late Pleistocene with the development of ice shelves persisting through interglacial periods (O'Brien et al., 2001; Hillenbrand et al., 2009; McKay et al., 2012a).

The last evidence for a WAIS collapse event recorded in proximal geological records from the Ross Sea is during MIS 31 ( 1 Ma), where an anomalous foraminiferal ooze and coccolith bearing facies is present in CRP-1 core and open water diatomites occur in AND-1B (Scherer et al., 2008; McKay et al., 2012a). An extreme high in southern high latitude insolation controlled by orbital precession at this time has been proposed as a potential cause for this (Scherer et al., 2008). There is currently no direct geological evidence of WAIS collapse events during the last four interglacials (Marine Isotope Stages 11, 9, 7 and 5) which were between $2-4.5^{\circ} \mathrm{C}$ warmer then present interglacial (Jouzel et al., 2007). However, far-field sea-level estimates for the last interglacial, MIS 5 at $\sim 125 \mathrm{ka}$, indicate that there was a $95 \%$ probability that global sea-level peaked at $6.6 \mathrm{~m}$ higher then present, and a $67 \%$ probability it exceeded $9.0 \mathrm{~m}$ (Kopp et al., 2009). Such sea-levels require a reduced 
global ice volume compared to present day with contributions from Greenland and the WAIS.

High resolution ice cores for the late Pleistocene provide an opportunity to explore temperature and $\mathrm{CO}_{2}$ forcing of ice volume fluctuations (EPICA, 2006; Jouzel et al., 2007). Paleo reconstructions of atmospheric and oceanic circulation, through a combination of marine sediment and ice cores, and general climate models (Steffensen et al., 2008), provide insight into leads and lags of climate constituents and phase assessment of Northern and Southern Hemisphere climate fluctuations during the Holocene (Schaefer et al., 2009). The European Project for Ice Coring in Antarctica (EPICA) Dome C ice core record spans the past 800 kyrs, and records eight successive glacial cycles revealing the interplay between obliquity and precession cycles are responsible for the temperature variance in past interglacials, while greenhouse gases and more specifically $p \mathrm{CO}_{2}$ act as an amplifier (Jouzel et al., 2007). 


\subsection{Climate cyclicity}

Earth's orbital variability is thought to be the key control on regulating the pacing of past glacial to interglacial cycles. Traditional Milankovitch theory proposed that summer insolation intensity at high latitudes controls snow preservation throughout the year, and thus the presence or absence of continental ice sheets (Milankovitch, 1941). Over four decades have passed since orbital cyclicity in climate records was first identified (Emiliani, 1966; Hays et al, 1976), yet the response of the climate system, and in particular polar ice sheets, to orbital forcing is still much debated (e.g. Raymo et al., 2006; Huybers et al., 2006). The insolation or incoming solar radiation at one latitude on Earth's atmosphere is dependent on the combined values of three cycles - eccentricity, obliquity and precession (Milankovitch, 1941).

Obliquity is the tilt of the Earth's axis (Figure 2.4) and oscillates between $22.1^{\circ}$ and $24.5^{\circ}$ at a dominant frequency of $41 \mathrm{kyr}$, with secondary frequencies of $54 \mathrm{kyr}$ and 28 kyr (Figure 2.5). Mean annual insolation is largely controlled by obliquity, as it defines the latitudes of the polar circles, influencing the pole to equator latitudinal insolation gradient, and has equal influence on the Southern and Northern Hemispheres.

Precession of the equinoxes (precession) varies at a frequency of $19 \mathrm{kyr}$ and $23 \mathrm{kyr}$ cycles, and changes the direction of Earth's tilt toward the sun which in turn controls the timing of the seasons (equinoxes) relative to when Earth is perihelion or aphelion (Figure 2.4; Figure 2.5). As such, precession controls the intensity and duration of the seasons and the influence of precession is out of phase between hemispheres - i.e. when a northern hemisphere summer occurs during perihelion, Southern Hemisphere summers will occur during aphelion, and therefore, the Northern Hemisphere will have warmer summers than the Southern Hemisphere. The eccentricity cycle is a measure of the shape of the Earth's orbit and is a combination of $95 \mathrm{kyr}, 120 \mathrm{kyr}$ and $400 \mathrm{kyr}$ cycles, although is commonly recognised as a 100 kyr cycle (Figure 2.4; Figure 2.5). As eccentricity alters the shape of Earth's 
orbit, i.e. the relative distance between the Earth and the sun during aphelion and perihelion, eccentricity acts modulates the amplitude of precession.

While Milankovitch cycles are able to be mathematically calculated for the geological past, real evidence in geological records of the orbital cycles is needed to understand the overall effects of Milankovitch pacing of Earth climate.

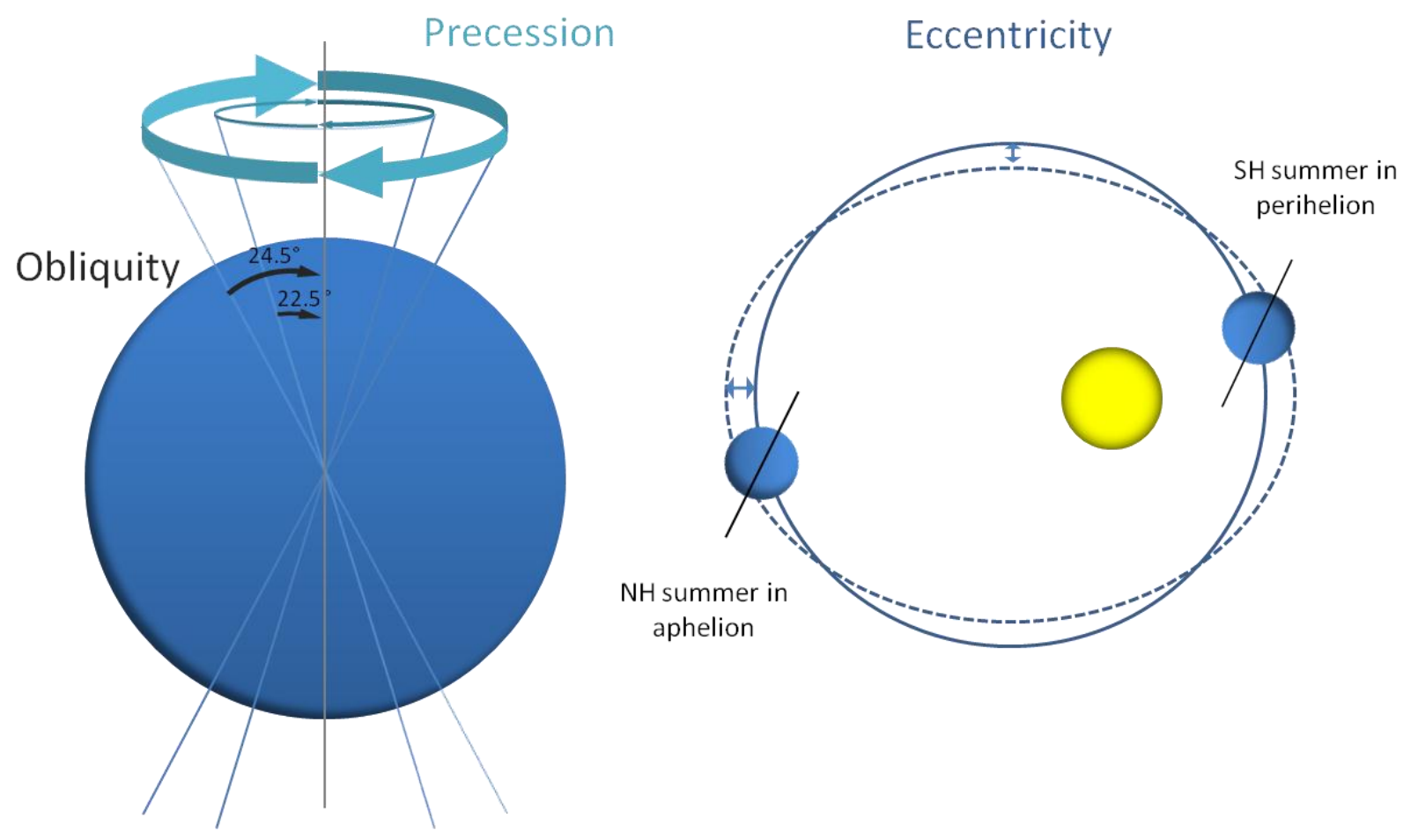

Figure 2.4. Schematic diagram of Milankovitch cycles, showing the two extremes of obliquity and precession, and the present precession configuration, superimposed on the eccentricity cycle. Eccentricity is the only orbital cycle to control total insolation values as it changes the Earth's distance from the sun; precession and obliquity control the distribution of insolation. 


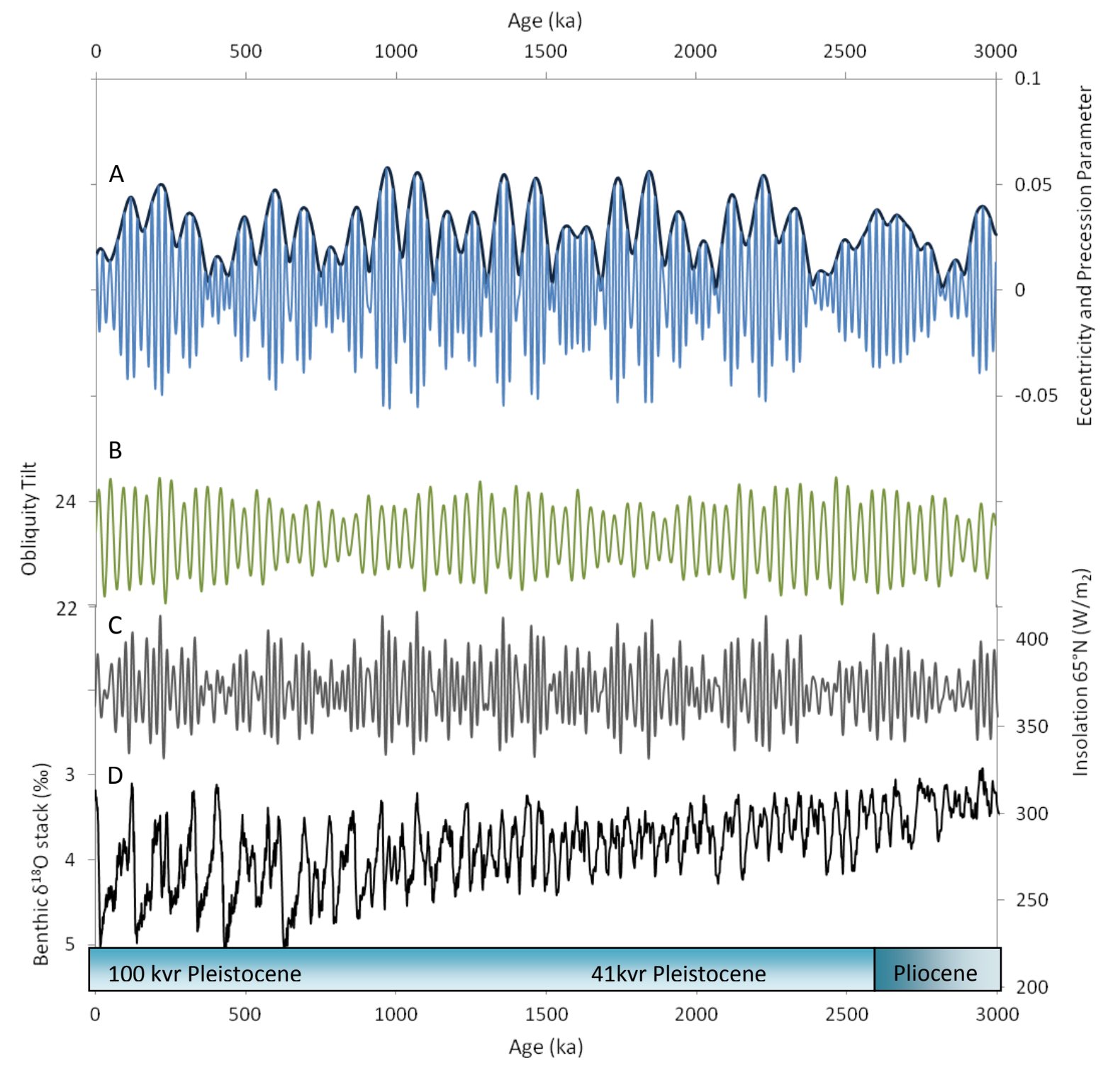

Figure 2.5. $\delta^{18} \mathrm{O}$ isotope record and orbital solutions (Laskar et al., 2004) for the last $3 \mathrm{Myrs.} \mathrm{A)} \mathrm{Precession} \mathrm{and}$ eccentricity insolation values $65^{\circ} \mathrm{N}$. B) Obliquity at $65^{\circ} \mathrm{N}$. C) Insolation at $65^{\circ} \mathrm{N}$. D) Benthic foraminifera $8^{18} \mathrm{O}$ stack (Lisiecki and Raymo, 2005). 


\subsubsection{Milankovitch in the benthic $\delta^{18} \mathrm{O}$ curve for the Plio-Pleistocene}

Milankovitch cycle frequencies have been identified in a variety of geological records. Perhaps the most notable are the benthic foraminiferal oxygen isotope $\left(\delta^{18} \mathrm{O}\right)$ records derived from the deep ocean, a proxy for global ice volume/sea-level and ocean temperature. However, the oxygen isotope record contains globally integrated ice volume and sea-level, as well as local temperature and salinity signals. A limited ability to identify each individual component of these local and global ocean environmental factors, as well as sea-level response to local and regional tectonics, has impaired the accuracy to which the response of Milankovitch cyclicity in each hemisphere can be recorded. The principle behind interpreting the oxygen isotope record as an ice volume record is that precipitation (in the form of snow), is isotopically lighter than seawater as ${ }^{16} \mathrm{O}$ is preferentially evaporated over ${ }^{18} \mathrm{O}$ - i.e. when ice sheets build up, the ${ }^{18} \mathrm{O} /{ }^{16} \mathrm{O}$ ratio in the ocean increases (Flower, 1999). The chemistry of calcareous marine microfossil shells (e.g. foraminifera) record the seawater composition at the time the organism was alive, providing that isotopic fractionation during calcification is in isotopic equilibrium with the ocean (Flower, 1999), or that the offset from equilibrium is known. The ${ }^{18} \mathrm{O} / 16 \mathrm{O}$ ratio is also controlled by ocean temperature, and in regions of significant freshwater input salinity can also influence this ratio. Therefore, the ${ }^{18} \mathrm{O} / 16 \mathrm{O}$ ratio in the world's oceans is an integrated measure of ice volume, temperature and salinity.

The ratio is expressed as $\delta^{18} \mathrm{O}$ based on the following equation (Flower, 1999).

$$
\delta^{18} \mathrm{O}=\left[\frac{\left({ }^{18} \mathrm{O} /{ }^{16} \mathrm{O}\right)_{\text {sample }}}{\left({ }^{18} \mathrm{O} /{ }^{16} \mathrm{O}\right)_{\text {standard }}}-1\right] \times 1000
$$

Relative contributions of ice volume, ocean temperature and salinity changes recorded in the $\delta^{18} \mathrm{O}$ signal from foraminifera have been estimated through a variety of methods. Shifts in the $\delta^{18} \mathrm{O}$ composition from deep ocean foraminifera have been 
assigned entirely to changes in ice volume on the assumption that temperature changes of the abyssal ocean are minimal on glacial-interglacial timescales (Shackleton, 1987; Prentice and Mathews, 1988).

However, since the Last Glacial Maximum (LGM), a greater temperature influence on the isotopic composition of sea water has been identified for high-latitude sites in comparison to equatorial benthic $\delta^{18} \mathrm{O}$ (e.g. Boyle and Keigwin, 1986; Shackleton and Opdyke, 1973; Thunell et al., 1994; Shackleton et al., 1995). The $\delta^{18} \mathrm{O}$ shift between the LGM and the present typically ranges from $1.1 \%$ to $1.4 \%$ for deep water equatorial Pacific sites (e.g. Shackleton and Opdyke, 1973; Thunell et al., 1994; Shackleton et al., 1995). These values are close to the coral reef calibrated $\delta^{18} \mathrm{O}$ changes of 1.2\%o (Fairbanks and Mathews, 1978; Chappell and Shackleton, 1986) and 1.3-1.4\% (Pillans et al, 1998) for the period from the LGM to the present, attributed solely to ice volume. From these studies a sea-level calibration for oceanic $\delta^{18} \mathrm{O}$ records of $0.011^{-0} 0.012 \% \mathrm{~m}^{-1}$ has been derived for the last $140 \mathrm{kyr}$ (Pillans et al., 1998). Some authors (Prentice and Mathews, 1988; Naish, 1997; Pillans et al., 1998; Naish and Wilson 2009) have argued that this sea-level calibration can be assumed to be the same over the last $5 \mathrm{Ma}$.

$\mathrm{Mg} / \mathrm{Ca}$ analyses of foraminiferal calcite provide an independent temperature estimate that, combined with $\delta^{18} \mathrm{O}$ records can isolate $\delta^{18} \mathrm{O}_{\text {water, }}$ though it is complicated by uncertainties in calibrations and carbonate ion effects (e.g., Lear et al., 2004).

In the past $3 \mathrm{Myr}$, the benthic $\delta^{18} \mathrm{O}$ record has oscillated at orbital (precession, obliquity and eccentricity) frequencies (Figure 2.5). It remains unclear as to why the climate system has responded differently to orbital influences at different periods of time during the last $5 \mathrm{Myr}$, given there has been relatively little change in orbital geometry of the solar system and solar output during this time (Laskar et al., 2004). The changes in climate pacing in terms of frequency (from $41 \mathrm{kyr}$ to $100 \mathrm{kyr}$ ) and amplitude ice volume (Figure 2.5) indicates that the climate system has changed in how it responds to orbital forcing due to internal feedbacks (e.g. ice sheets) and 
longer term changes in boundary conditions (e.g. paleogeography and the carbon cycle).

Spectral analysis of the benthic $\delta^{18} \mathrm{O}$ and insolation records allows the relative influence of the orbital frequency components of eccentricity, obliquity and precession on insolation received at the top of the atmosphere and its influence on elements of Earth's climate system (e.g. ice sheets) to be extracted (Figure 2.6). The lack of a precession signature for much of the past 5.3 Myr in the $\delta^{18} \mathrm{O}$ benthic stack, contrasts with the strong power precession holds in the insolation time series (Figure 2.6). The relatively low power of eccentricity frequencies in the insolation spectra illustrates the relatively weak influence of eccentricity on insolation, despite it being a strong modulator of the amplitude of precession. This contrasts with the strong spectral power at the $100 \mathrm{kyr}$ frequencies in the benthic $\delta^{18} \mathrm{O}$ record for the past 800 kyr (Figure 2.6). Numerous hypotheses have been suggested for the development of the $100 \mathrm{kyr}$ glacial-interglacial cyclicity during the Middle Late Pleistocene. These include: (1) a non-linear response to weak orbital forcing (Raymo et al., 2006) possibly involving the internal feedbacks and dynamics of a large Laurentide ice sheet (Clark and Pollard, 1998), or feedbacks in the carbon cycle (Shackleton, 2000; Broecker, 2000); or (2) a threshold response to orbital forcing whereby the Northern Hemisphere ice sheets deglaciate every $4^{\text {th }}$ or $5^{\text {th }}$ precession cycle (Raymo, 1997) or every $3^{\text {rd }}$ or $4^{\text {th }}$ obliquity cycle (Huybers and Wunsch, 2005). Obliquity has significant power in both the benthic $\delta^{18} \mathrm{O}$ record and insolation spectra, and prevails as the dominant frequency for glacial to interglacial cycles over the past 5.4 Myr, and alongside eccentricity and precession is a significant frequency for the last 800 kyrs (Figure 2.6).

These differences between insolation as the climate forcer and the $\delta^{18} \mathrm{O}$ benthic record as the climate response raises fundamental questions, such as, how do individual ice sheets respond to orbital forcing? Early views concerning the dominant role seasonal insolation controlled by precession on ice volume have come into question, given the dominance of obliquity observed in the $\delta^{18} \mathrm{O}$ record. 


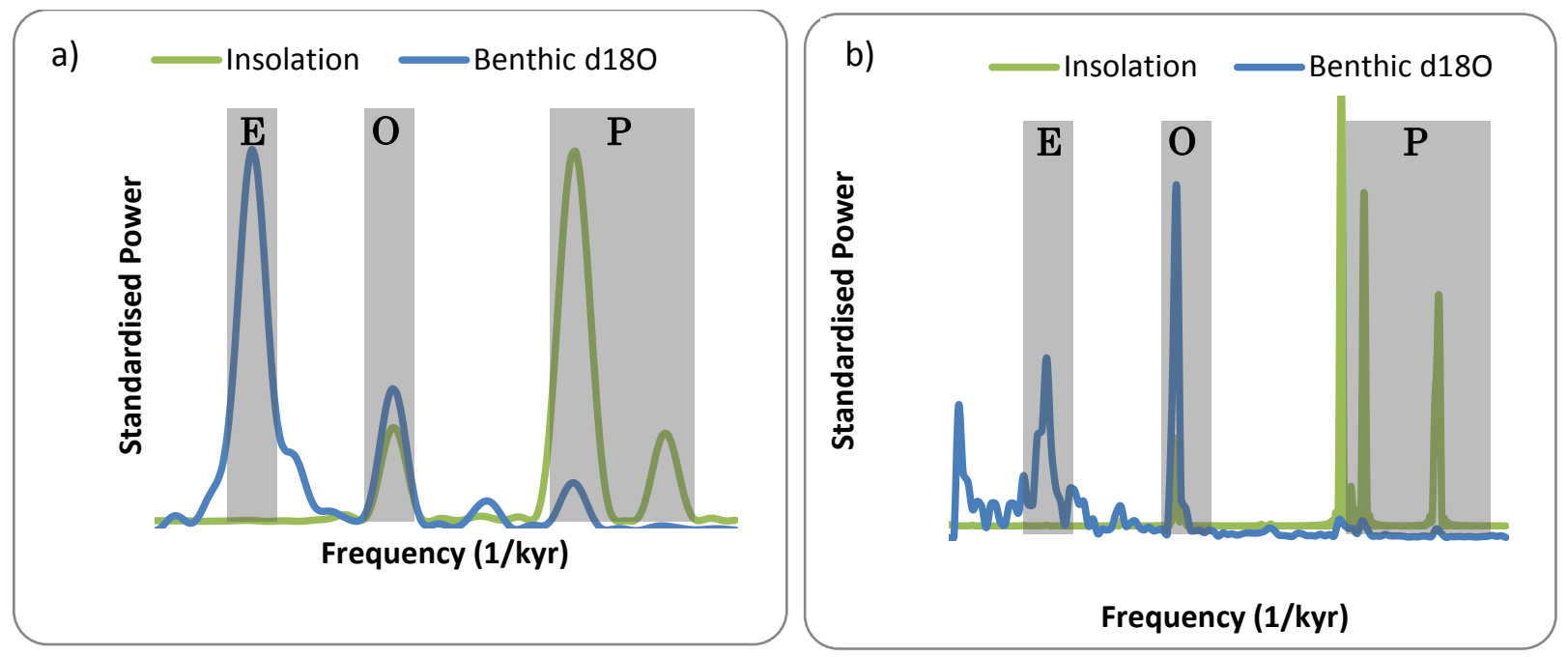

Figure 2.6. Power spectra for a) Insolation (Laskar et al., 2004) and benthic $\delta^{18} \mathrm{O}$ (Lisiecki and Raymo, 2005) for the last $800 \mathrm{kyr}$; b) Insolation and benthic $\delta^{18} \mathrm{O}$ for $5.3 \mathrm{Ma}$ to present. Grey bands highlight the dominant frequencies of $\mathrm{E}$ : eccentricity, $\mathrm{O}$ : obliquity and $\mathrm{P}$ : precession.

\subsubsection{Milankovitch forcing of the Earth's climate system}

Raymo et al., (2006) hypothesised that a dynamic EAIS with terrestrial margins during the Late Pliocene/Early Pleistocene responded directly to local summer insolation intensity, which is primarily controlled by orbital precession. The absence of the $\sim 21 \mathrm{kyr}$ precession cycle in the globally-integrated marine $\delta^{18} \mathrm{O}$ record prior to $800 \mathrm{ka}$ is explained by an anti-phase behaviour of the polar ice sheets in each hemisphere. On the basis of differing $\delta^{18} \mathrm{O}$ signatures for Antarctic and Northern Hemisphere ice sheets, Raymo et al., (2006) argued that only a modest increase in ice volume from Antarctica is needed to mask a much larger magnitude of ice volume decrease in the Northern Hemisphere - i.e. a small Antarctic ice sheet advance removes a relatively small amount of $16 \mathrm{O}$ from the ocean, while at the same time a large melting event in Northern Hemisphere would add a relatively small amount of ${ }^{16} \mathrm{O}$.

Raymo et al., (2006) then argue that the continued trend of a cooling climate in the Pleistocene resulted in expansion of the EAIS to the continental shelf $(\sim 1 \mathrm{Ma})$, coeval with expansion and thickening of the northern hemisphere ice sheets, as 
evinced by increased amplitudes in the benthic $\delta^{18} \mathrm{O}$ record and a transition to a 100 kyr glacial cycle (Lisiecki and Raymo, 2005). From $1 \mathrm{Ma}$, advance and retreat of the EAIS became linked to Northern ice sheet variation through its dominating influence on ocean temperature and sea-level, controlling ablation of the EAIS marine margin, resulting in an in-phase relationship between hemispheres during the 100kyr world (Raymo et al., 2006). A requirement of the Raymo et al., (2006) theory is that significant ice existed on the northern hemisphere prior to $2.7 \mathrm{Ma}$, but there is little geological evidence to support this. Ice rafted debris records in the North Atlantic and Pacific Oceans show the onset of large scale ice sheets at 2.7 Ma (Maslin et al., 1998).

\section{Obliquity pacing of glacial cycles}

Young and Bradley (1984) and Raymo and Nisancioglu (2003), suggest that the summer annual insolation gradient explains obliquity periodicity in the Late Pliocene/Early Pleistocene. Obliquity influences mean annual insolation, which primarily controls the annual distribution of solar radiation, in particular the latitudinal insolation gradient which in turn controls the latitudinal temperature gradient (Young and Bradley, 1984). The latitudinal temperature gradient influences the vigour of atmospheric and oceanic circulation and the transport of heat and moisture between the equator and polar regions. Broecker (2000) discusses a series of feedbacks that may amplify the initially weak influence of orbital forcing on insolation to cause glaciations. The sequence of events involves insolation driven cooling, steepening of the latitudinal temperature gradient and increasing atmospheric circulation (westerly wind field), which in turn promotes dust loading of the atmosphere as evinced in Antarctic ice cores (Lambert et al., 2008) and Southern Ocean sediment cores (Martinez-Garcia et al., 2011). The Fe-rich dust results in increased primary productivity, drawing down atmospheric $\mathrm{CO}_{2}$ which amplifies atmospheric cooling and promotes the growth of sea-ice. Further cooling from icealbedo and height mass balance feedbacks promotes ice sheet growth during full glacial conditions. 
Several recent studies have linked changes in Atlantic meridional overturning and Antarctic circumpolar ocean circulation to obliquity forcing (e.g. Lisiecki et al., 2008; Toggweiler et al., 2008). An interglacial mechanism has been proposed whereby the southward expansion of westerly winds and associated northward Ekman transport is compensated for by enhanced upwelling of warmer, $\mathrm{CO}_{2}$-rich Circumpolar Deep Water, which also promotes atmospheric warming (Toggweiler et al., 2008). Naish et al., (2009) propose that $40 \mathrm{kyr}$ orbital cycles may regulate the southward export and upwelling of Circumpolar Deep Water, influencing melt rates at the grounding lines of Antarctic ice sheets, given their sensitivity to sea-level and ocean temperatures (e.g. Pollard and DeConto, 2009; Mackintosh et al., 2010; Weber et al., 2012).

Through the shifting of atmospheric circulation by the latitudinal temperature gradient, the obliquity paced signal is transferred throughout the climate system imprinting $\sim 40 \mathrm{kyr}$ cycles on the marine $\delta^{18} \mathrm{O}$ record. Transference of heat from lower latitudes through atmospheric and surface oceanic circulation increases with steeper temperature gradients produced during minimum (obliquity) tilt (Young and Bradley, 1984). Correlation between the latitudinal insolation gradient and the marine $\delta^{18} \mathrm{O}$ record suggests increased latitudinal temperature gradients promote ice sheet growth (Raymo and Nisancioglu, 2003). Nisancioglu (2004) produces a model based on this type of forcing but it results in dominant precession periodicity. Davis and Brewer (2009) show this theory is still valid by using a pollen-based reconstruction of the latitudinal temperature gradient during the Holocene for comparison with palaeoclimate records (monsoon, arctic oscillation and ocean circulation), to show that propagation of obliquity to the climate system could be explained by latitudinal insolation gradient forcing of the latitudinal temperature gradient through atmospheric and oceanic circulation.

Huybers (2006) hypothesised that the mechanism for obliquity cycles recorded in the benthic $\delta^{18} \mathrm{O}$ stack is dependent on integrated summer insolation which varies primarily on $\sim 40 \mathrm{kyr}$ obliquity frequency. A summer day is defined when insolation 
exceeds a threshold that would likely result in a positive degree day and therefore the number of melt days an ice sheet may receive $\left(\sim 275 \mathrm{~W} / \mathrm{m}^{2}\right.$ for latitudes between $40-60^{\circ} \mathrm{N}$; Huybers, 2006). Precessional controls on seasonal duration and insolation intensity are negated by Kepler's second law on planetary orbit where insolation intensity is directly anticorrelated to duration - e.g. intense summers are shorter while long summers are cooler because the Earth orbit is faster during perihelion than aphelion (Huybers, 2006).

Huybers and Tziperman (2008) presented an ice sheet/energy-balanced model using the full seasonal insolation cycle as a forcing and could reproduce $40 \mathrm{kyr}$ cycles if two conditions are met: 1) the zone of ablation must be north of $\sim 60^{\circ} \mathrm{N}$ (where obliquity has more influence on insolation) and 2) the ice sheet is above its melt threshold for a significant period of the summer (Huybers and Tziperman, 2008). Through restricting basal melting (as in colder climates), the surface slope of the ice sheet increases, maintained by a reduced and intense ablation zone allowing equator-ward growth (where insolation is paced by precession). Huybers and Tziperman (2008) suggest a 'locked' ice sheet base is the reason for many models producing a precession periodicity (i.e. Nisancioglu, 2004). A long-term cooling climate may result in raising the insolation melt threshold for an ice sheet, and if this exceeds $340 \mathrm{~W} / \mathrm{m}^{2}$, precession pacing becomes equally important as obliquity and is proposed as a possible cause for a strengthened precession influence in the Middle-Late Pleistocene (Huybers, 2006). The threshold changes depending on background temperature. Precession becomes the more influential cycle through several processes in a cooler climate: 1) counterbalancing of seasonal insolation changes is lost and precession becomes more influential and 2) thicker ice sheet growth produces height mass-balance feedbacks and a colder surface temperature, ablation stops under these conditions and the ice-sheet can spread to lower latitudes where precession is the dominant cycle of variability (Huybers and Tziperman, 2008). 


\subsubsection{Direct records of ice sheet variability from sedimentary facies analysis of continental margin geological records}

Direct records of ice volume allow the benthic $\delta^{18} \mathrm{O}$ record to be evaluated and give insight into which components of the climate system respond to which Milankovitch cycles. These direct records are found in marine sediment cores from the Antarctic margin, such as the Wilkes Land margin sediment cores described in this thesis, distal sea-level records recorded on continental margins (e.g. Wanganui Basin; Naish and Wilson, 2009) and ice cores, used to determine the sea-level/ice volume component of the benthic $\delta^{18} \mathrm{O}$ record (e.g. Shackleton et al., 2000).

The magnitude of ice volume fluctuations reconstructed from changes in global sealevel rise and fall from geological records is relatively well-constrained for the last glacial-interglacial cycle from uplifted fossil coral shorelines (e.g. Chappell et al., 1996). However, sea-level reconstructions going further back in time have larger errors both in terms of the amplitude and timing of the sea-level change (e.g. Miller et al., 2005; Naish and Wilson, 2009; Miller et al., 2012). A further complicating factor is that global sea-level rise in response to changes in polar ice volume is highly variable across Earth's surface due to the time-dependent influences of gravitational and glacio-isostatic processes (e.g. Mitrovica and Wahr, 2011; Raymo et al., 2011). While computer Earth deformation models of these processes, constrained by a global array of sea-level reconstructions, have been used to fingerprint the source of polar melt water for times in the last 125 kyrs (e.g. Kopp et al., 2009), sea-level reconstructions cannot provide information on ice volume source further back in time. This is why geological records, such as described in this thesis, that directly record past advances and retreats of the polar ice sheet margins are critical to evaluating the response of specific ice sheets to orbital forcing, and therefore, their contribution to the $\delta^{18} \mathrm{O}$ oxygen isotope global ice volume record.

Evidence from marine and terrestrial stratigraphic sections provide qualitative and quantitative information on ice sheet and sea-level changes. The identification of changing ice proximal environments through time, using sedimentary facies 
analysis and concepts of sequence stratigraphy, has proved a powerful tools for reconstructing Antarctic ice sheet history (e.g. Barrett et al., 1989; Fielding et al., 2000; McKay et al., 2009).

The cyclical vertical changes in facies, which represent cyclical changes in depositional environments, are reconstructed from a range lithological and biological characteristics (e.g. Walker and James, 1992), and have been used to document past advances and retreats of the ice sheet margin across the continental shelf and coeval changes in water depth. Within a high resolution chronostratigraphic framework based on the integration of magnetic polarity stratigraphy, biostratigraphy and numeric ages of volcanic ashes, the sedimentary cycles can be evaluated in terms orbital controls (e.g. Naish et al., 2001; 2009a). AND-1B core, drilled in the Ross Sea, Antarctica, has been used to interpret the growth and decay of the WAIS within Ross Embayment during the Pliocene Epoch using facies analysis to recognise cycles of glacial advance and retreat (Naish et al., 2009a). Naish et al., (2009a) described 38 cycles of oscillation between ice-proximal to open ocean conditions, where the signature of a grounded ice sheet is recorded during glacial and open ocean ice free conditions during interglacials. Relatively continuous, welldated intervals of the core are used to illustrate $\sim 40 \mathrm{kyr}$ obliquity influence on glacial-interglacial oscillations of the ice sheet (Figure 2.7). They also identified an interval of diatomaceous sediment spanning 4.6-3.4 Ma (including an extensive hiatus) during which time the WAIS was significantly reduced and Ross Sea surface temperatures were above freezing during summer, with no perennial summer seaice (McKay et al., 2012a).

Geological drill core records from the continental slope and rise around Antarctica, such as the Wilkes Land Expedition 318 cores described in this thesis, provide a less proximal signature of changes in ice margin proximity and coastal sea-ice. An advantage of these records is that they are more continuous and do not suffer erosion caused by periodic ice sheet advances. A disadvantage is that they do not contain the direct physical imprint of the ice sheet. Nevertheless a range of proxies 
have been used successfully to reconstruct ice sheet variability from these more distal settings including: 1) sedimentary facies analysis combined with continuous measurements of the physical properties of the sediments (environmental change/ ice proximity; O'brien et al., 2001; Grutzner et al., 2005; Hepp et al., 2009); 2) sediment particle size and iceberg rafted debris intensity (ice dynamics and proximity; Naish et al., 2009a); 3) paleoecological analysis of microfossils (seaice/polynya variability, ocean temperature and salinity; Grutzner et al., 2005; Hillenbrand and Cortese, 2006; McKay et al., 2012a), and 4) geochemical proxies (ocean temperature; McKay et al., 2012a). A challenge with these sediment cores, that are typically recovered by ship-based ocean drilling is that core recovery is often poor $(<40 \%)$. This is not the case for the IODP U1361A core with an average recovery of $87 \%$ and $99.4 \%$ recovery within the Plio-Pleistocene interval of the core (Expedition 318 Scientists, 2010). 


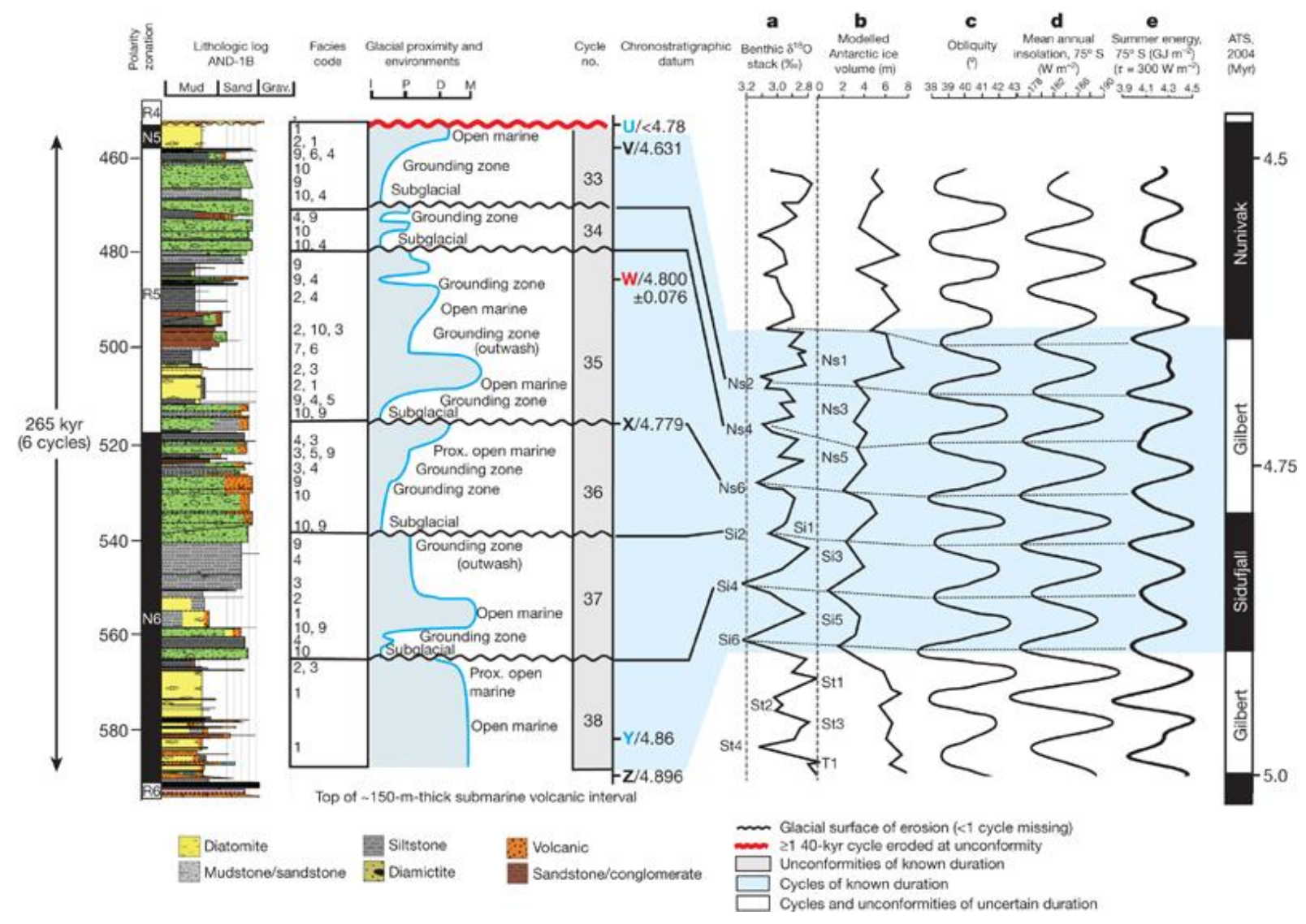

Figure 2.7. Naish et al., (2009a) interpret glacial depositional environments for facies in AND-1B drillcore (450$600 \mathrm{mbsf}$ ) and correlate glacial proximity cyclicity to the benthic $\delta^{18} \mathrm{O}$ stack (Lisiecki and Raymo, 2005). Obliquity pacing for the six glacial-interglacial cycles is clearly shown. 


\subsection{The Southern Ocean}

The Southern Ocean has a major influence on distributing heat, salt, gasses and nutrients around the globe (Carter et al., 2009). The present Southern Ocean circulation is dominated by the Antarctic Circumpolar Current (ACC), established $\sim 34 \mathrm{Ma}$ with the opening of the Tasman-Antarctic gateway and Drake Passage. Interaction with the waxing and waning of Antarctic ice sheets and orbitally forced climates largely controls water mass formation and dispersal. The difference in relative density of water masses, related to water temperature and salinity, leads to bottom water formation in the polar regions and global circulation, termed the

Thermohaline Circulation (Schmitz, 1995). The thermohaline circulation has traditionally been cited as a major climate driver in interpretations of paleooceanographic record (Broecker, 1991), however physical oceanographers place more emphasis on the role of wind driven circulation, and recognition of this is becoming increasingly important in the interpretation of palaeo-oceanographic records (Toggweiler et al., 2006).

Wilkes Land is one of three regions of Antarctic Bottom Water (AABW) production, alongside the Ross and Weddell Sea. While modern water masses and their distribution are well documented for the region, the palaeo-oceanography is largely unknown and is one of the primary objectives for IODP Expedition 318. The Leg 318 cores provide an opportunity for documenting variations in ice sheet extent, sea-ice variability and surface water conditions adjacent to Wilkes Land, and their relationship to changes in the ACC.

\subsubsection{Southern ocean water masses}

The ACC circumnavigates the Antarctic continent, connects the Pacific, Indian and Atlantic oceans, and is the world's largest current in terms of volume transport with an average of $136 \pm 7.8 \mathrm{~Sv}$, measured across Drake Passage (Cunningham et al., 
2003). It extends vertically from the sea surface to the sea floor, flows eastward, and is composed of several water masses (Figures 2.8 and 2.9). Circumpolar Deep Water (CDW) is the main component (volumetrically) of the ACC and is classified by densities between $28.27 \mathrm{~kg} \mathrm{~m}^{-3}$ and $28.03 \mathrm{~kg} \mathrm{~m}^{-3}$. Upper and Lower Circumpolar Deep Water (UCDW; LCDW) are distinguished by an oxygen minimum for UCDW and a salinity maximum for LCDW (Orsi et al., 1995). The salinity maximum reflects the relative input of North Atlantic Deep Water (NADW), which is entrained with other southbound waters to form the LCDW (Orsi et al., 1995; Whitworth et al., 1998). Upwelling of LCDW at several locations at the continental slope mixes with super-cold shelf waters (formed through saline rejection of freezing sea-ice) to form AABW (Orsi et al., 1999). The main regions of AABW formation are the Weddell Sea, Ross Sea and Wilkes Land margin, in order of relative production, has densities exceeding $28.27 \mathrm{~kg} \mathrm{~m}^{-3}$ and temperatures below $-1.7^{\circ} \mathrm{C}$ (Whitworth et al., 1998). This high density leads to dispersal down the continental slope before becoming confined within the abyssal basins around the Antarctic margin.

Antarctic Intermediate Water (AAIW) is a relatively low salinity water mass that downwells between the Polar and Subantarctic Fronts and overlies UCDW. Subantarctic Mode Water (SAMW) is well mixed and ventilated water, formed from winter cooling and mixing of surface waters on the north of the Subantarctic Front (Rintoul et al., 2001). 


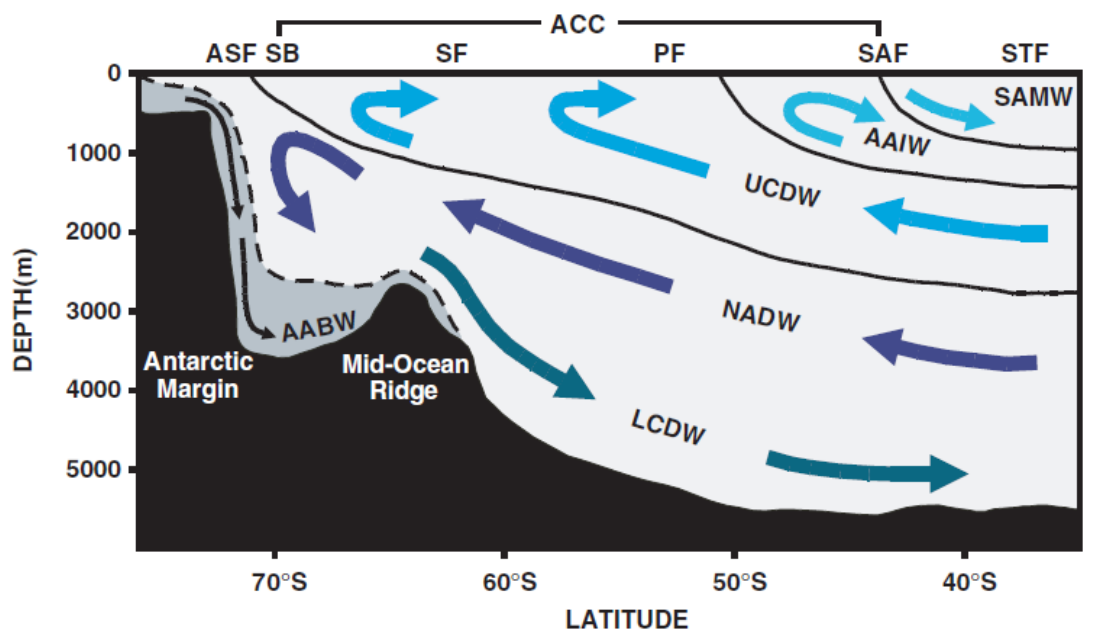

Figure 2.8. Schematic diagram of water and ocean fronts located about the Antarctic margin as seen in following figure. Antarctic Bottom Water (AABW); Lower Circumpolar Water (LCDW); North Atlantic Deep Water (NADW); Upper Circumpolar Deep Water (UCDW); Antarctic Intermediate Water (AAIW); Subantarctic Mode Water (SAMW); Antarctic Circumpolar Current (ACC); Antarctic Southern Front (ASF)/;Southern Boundary of the ACC (SB); Southern Front (SF); Polar Front (PF); Subantarctic Front (SAF); Subtropical Front (STF; in Cater et al., 2009).

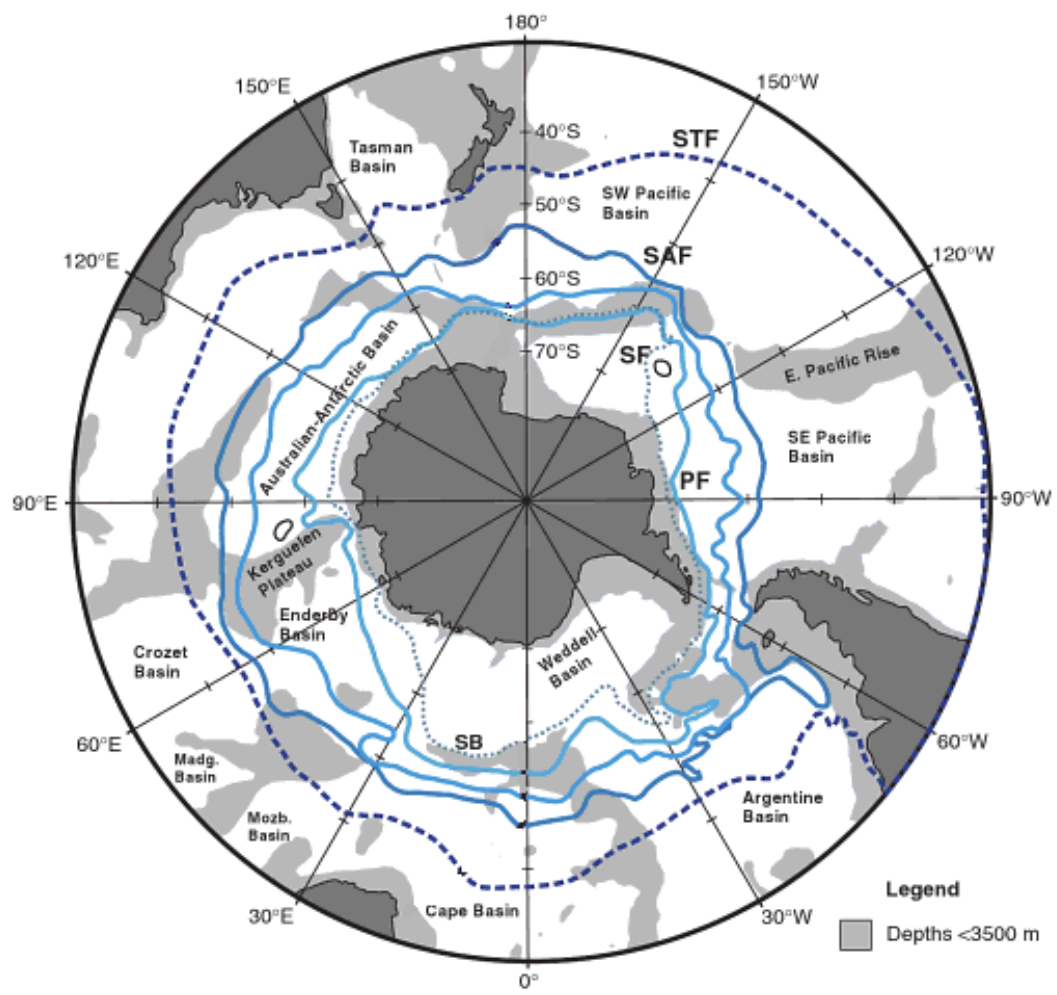

Figure 2.9. Location of Southern Ocean fronts as mentioned in previous figure: Southern Boundary of the ACC (SB; light blue dashed line); Southern Front (SF; light blue solid line); Polar Front (PF; medium blue solid line); Subantarctic Front (SAF; dark blue solid line) and Sub-tropical Front (STF; dark blue dashed line). Figure is from Carter et al., (2009), but is modified from original data in Orsi and Whitworth (2005). 


\subsubsection{Southern Ocean Circulation}

Antarctic Bottom Water sinking at the high latitude glaciated margins, flows equatorward through Deep Western Boundary Currents off the west coasts of New Zealand, Africa and South America (Figure 2.10). Through wind driven upwelling, AABW contributes to surface waters northward of the equator, before undergoing cooling and sinking at the North Atlantic margin, eventually becoming the Northern Hemisphere equivalent, North Atlantic Deep Water (NADW) which has a lower input into the global ocean relative to AABW (Carter et al., 2009).

ACC transport is mainly confined within the Subantarctic and Polar Fronts (Figure 2.8) and flow is primarily wind driven that acts to induce northward Ekman transport which is compensated at depth by southward flowing and upwelling CDW (Toggweiler and Samuels, 1995). To the south of the ACC, cyclonic gyres located in the Weddell and Ross Seas and the Wilkes Land coast also play a role in transferring heat and salt from the ACC to the continent (Orsi et al., 1993).

To the north of the ACC, subtropical gyres located in the South Pacific, Indian and Atlantic Ocean basins are forced by low-latitude easterly trade winds and highlatitude westerlies. They transport excess tropical heat polewards and AABW northwards along DWBC's (Roemmich, 2007). Ridgeway and Dunn (2007) provide observational evidence for a Southern Hemisphere oceanic subtropical supergyre, connecting the Pacific, Indian and Atlantic Basin at intermediate water depths. 


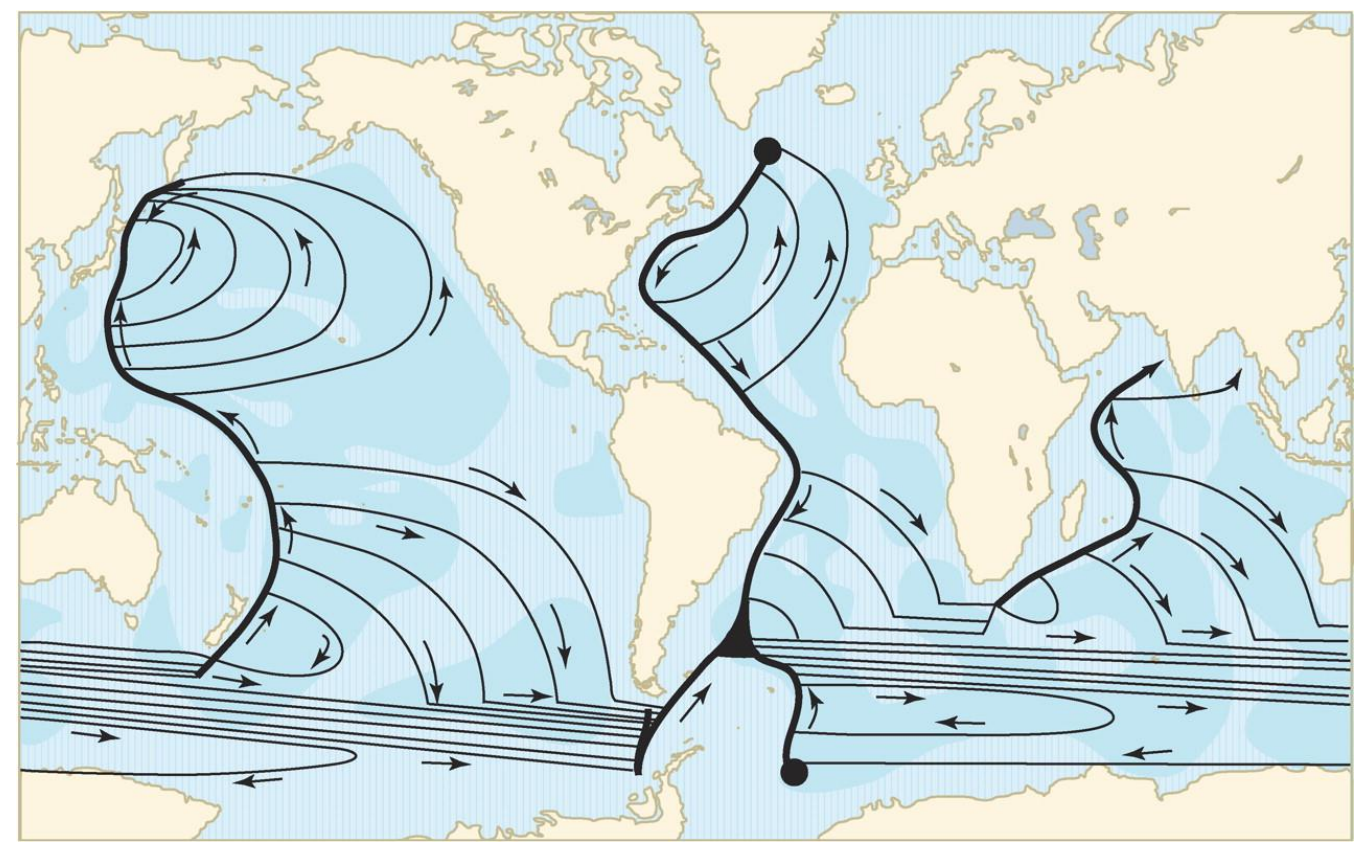

Figure 2.10. The ocean conveyor belt was first conceptualised by Stommel in 1958 (Lozier, 2010). This diagram describes the equatorward flow of dense waters through Deep Western Boundary Currents and the return of warmer less dense waters.

\subsubsection{Wilkes Land ocean circulation}

The Wilkes Land region has been intensively studied to further define modern water mass distribution (e.g. McCartney and Donohue, 2007; Rintoul, 2007; Figure 2.11), yet little is known regarding oceanographic variability on glacial to interglacial timescales. Wilkes Land margin produces a component of the AABW, Adelie Land Bottom Water (ALBW), and unlike other regions of bottom water production, it does not have a prominent ice shelf. AABW in the Australian-Antarctic Basin is supplied by Ross Sea Bottom Water (RSBW) and ALBW (Rintoul, 2007). ALBW is primarily produced within the katabatic wind driven Mertz Glacier Polynya (MGP; Figure 2.12 ), and local coastal polynya formed along the continent by atmospheric forcing (Massom et al., 2001). ALBW has a colder and fresher signature then RSBW, however due to increasing melt in recent years, both have freshened significantly (Rintoul, 2007). 
The continental shelf at the Wilkes Land margin holds components of locally produced dense cool Ice Shelf Water (ISW) formed from the ice sheet margin and Mertz Glacier, and upwelling warm, relatively fresh, modified Circumpolar Deep Water (MCDW; Figure 2.12; Williams et al., 2008). Williams et al., (2008) provide an overview of the annual cycle of water masses present in the Adelie Depression on the continental shelf (Figure 2.12), as follows: During winter sea-ice formation (April-September) enhanced brine rejection drives convection and produces a wellmixed water column in the Adelie Depression, while the sill on the outer continental shelf the upper water column remains stratified (Figure 2.12). The peak of the winter sea-ice cover occurs during October and November and is characterised by increased brine rejection that is compensated by an export of dense water or an influx of low salinity ISW or MCDW. During the sea-ice destruction (January) and conditioning (January-March) phases, sea-ice melt results in increased stratification of the water column and an increased inflow of MCDW (Williams et al., 2008).

These short term observations may be extrapolated to characterise oceanographic variability around Wilkes Land over longer time periods and during warmer and colder climates. Oceanographic modelling of offshelf flow of ALBW shows strong inter-annular variability (Marsland et al., 2004), and modelling of warming climate induced perturbations (increase in precipitation and warming surface temperatures) indicate ALBW production will weaken in the future (Marsland et al., 2007). The relative amounts of upwelling warm MCDW on glacial timescales is likely to affect the stability of the ice sheet margin in the Wilkes Land margin. 


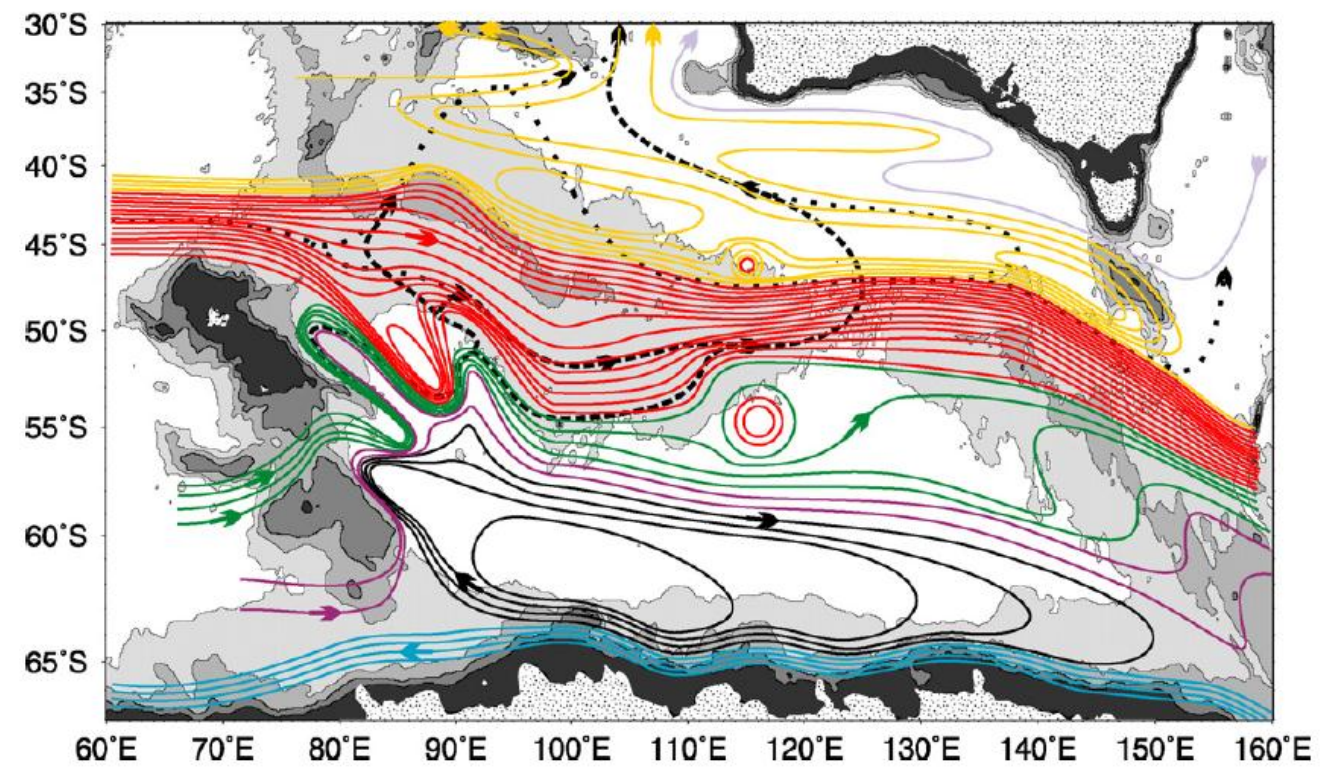

Figure 2.11. A schematic diagram of present day ocean circulation of the Antarctic- Australian Basin with $10 \mathrm{~Sv}$ contour intervals (McCartney and Donohue, 2007). The Wilkes-Adelie Land gyre is illustrated by the black contour line, with southern limb is driven by the westward flowing Antarctic slope current (blue contours) and northern limb by the eastern ACC (red contours). The black dashed lines indicate pathways (not volume) of bottom waters $\left(<1^{\circ} \mathrm{C}\right)$.

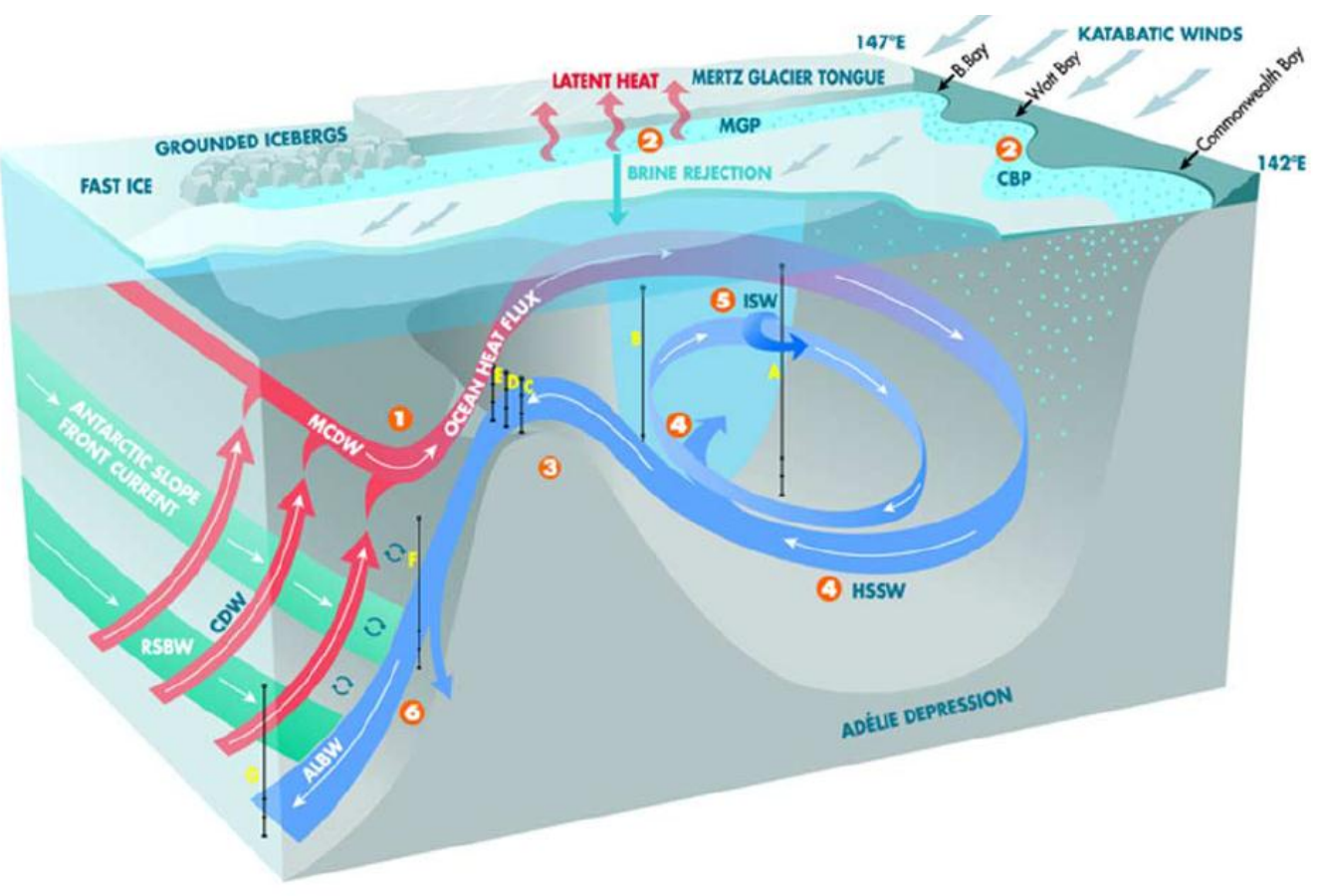

Figure 2.12. A schematic diagram of water mass circulation in the Adelie Depression on the Wilkes Land margin. MGP: Mertz Glacier Polynya; CBP: Commonwealth Bay Polynya; ISW: Ice shelf water; HSSW: High salinity shelf water; CDW: Circumpolar Deep Water; MCDW: Modified Circumpolar Deep Water; ALBW: Adelie Land Bottom Water; RSBW: Ross Sea Bottom Water (Williams et al., 2008). Transect G, approximates the position of drill site U1361 on the continental rise. 


\subsubsection{Ocean variability on orbital timescales and implications for ice sheet stability}

Changes in oceanic circulation for the Late Neogene are invariably linked with climate cycles. High resolution atmospheric, oceanic and cryospheric proxy records are needed to determine whether changes in oceanic circulation initiate a response in global ice volume or if it is a mechanism by which the climate signal is transferred. The response of the Southern Ocean to glacial-interglacial cycles has primarily been inferred through geochemical tracers found in high to mid-latitude marine sediment cores with glacial periods characterised by cooler sea surface temperatures, increased windiness, equatorward migration of ocean fronts, intensification of the westerly wind belt, and a larger sea-ice field (summarised in Naish et al., 2009b). The main pathway of the ACC is largely constrained by bathymetry, and therefore cannot experience a wholesale shift in location, but a projected strengthening of Southern Hemisphere westerly winds is expected to increase northward transport of southern waters due to a stimulated Ekman layer (Pahnke and Zahn, 2005). Sea surface temperature reconstructions can be used to infer front positions and are shown to shift latitudinally during past glacial to interglacial cycles (Howard and Prell, 1992; Gersonde et al., 2003; Crundwell et al., 2008).

The ${ }^{13} \mathrm{C}$ concentration in foraminifera recovered from marine sediment cores can be used as a proxy to infer relative flow of NADW during glacial and interglacial regimes (Charles and Fairbanks, 1992), because NADW is enriched in ${ }^{12} \mathrm{C}$ and is depleted in nutrients, relative to AABW. Modern atmospheric warming of the ocean is increasing stratification and reducing mixing of the upper ocean which has long term effects on the deep ocean to act as a carbon sink (Salle et al., 2010). Recent studies support a reduced NADW input into the Southern Ocean during recent glacials, with no major reorganisation of Southern Ocean water masses (McCave et al., 2008). However, other studies indicate an intensified AABW production compensating a reduced NADW inflow, reflected by an increased flux of the Pacific DWBC, inferred by an increase in the size of 'sortable silt', a proxy for current 
strength at ODP site 1123 offshore of New Zealand (Hall et al., 2001). In addition, an increased Antarctic sea-ice field (Gersonde et al., 2005) will increase albedo, acting as a positive feedback to drive further cooling and increasing saline rejection resulting in intensified $\mathrm{AABW}$ production.

Although winds are considered to decrease in warmer climates, as inferred by decreased dust in ice core records (e.g. Petit et al., 1999; EPICA, 2006; Jouzel et al., 2007; Steffensen et al., 2008), modern observations do not come to the same conclusions (Toggweiler et al., 2006). The location of wind belts and fronts in the Southern Hemisphere has implications for the westerly wind belt driven ACC and subtropical gyres. The westerly wind belt now resides over the ACC which was predicted to intensify ACC flow and amplify the tilt of the isopycnals causing an increase in ventilation of 'old' carbon rich waters e.g. NADW upwelling around the Antarctic continental margin (Boning et al., 2008). However, recent studies reveal the ACC is not speeding up as increased Ekman transport is balanced by increased eddy activity (Boning et al., 2008).

At present, a poleward shift of the westerly wind belt has intensified the wind stress curl, increasing South Pacific gyre circulation (Hill et al., 2008). This is a response of the positive phase of the Southern Annular Mode (SAM), associated with stronger westerly circumpolar flow. SAM is the product of variability in the meridional atmospheric pressure gradient between the southern mid and high latitudes (Gomez et al., 2012). The present ongoing positive SAM is a likely result of upper atmospheric warming creating an increased vertical temperature gradient (Toggweiler and Russell, 2008). Climate models predict this ongoing SAM is occurring in concert with a strengthening of the Southern Ocean supergyre, as a result of greenhouse warming in combination with, or solely from ozone depletion (Cai et al., 2005).

Satellite data indicate that a small increase in the Antarctic sea-ice field has occurred since 1978, which is interpreted to be associated with the positive Southern Annular Mode as well as ozone depletion and its effect on the Polar Vortex (Turner 
et al., 2009). However, modelled future projections predict a significant decrease in the Antarctic sea-ice concentrations by the end of the century (IPCC, 2007) which in turn may reduce the albedo effect. A freshening of both the AABW (Rintoul, 2007) and NADW (Dickson et al., 2002) has been seen in recent decades and this has implications for buoyancy driven circulation. NADW reduction and freshening has been hypothesised to slow down or a cause a shutdown of the meridional overturning circulation in the North Atlantic potentially resulting in abrupt climate change events (Broecker, 2003). This may result in a cooling in the Northern hemisphere and warming in the Southern hemisphere, known as the "bipolar climate see-saw".

Ice sheet models have identified ocean melt as the primary driver behind retreat of Antarctic ice sheets (Hill et al., 2007, Pollard and DeConto, 2009; Mackintosh et al., 2010). An increase in CDW upwelling of relatively warm waters onto the Antarctic continental shelves is theorised to be the mechanism by which ocean induced melting occurs (Pollard and DeConto, 2009). The Wilkes Land may be particularly vulnerable to this process because of: 1) a lack of a buttressing ice shelves and 2) the presence of the low lying Wilkes Sub-glacial Basin. Rise in sea-level is considered secondary, but important for the destabilisation East Antarctic Ice Sheet marine grounding lines (Mackintosh et al., 2011). 


\subsection{Sedimentation on glaciated continental margins}

Ocean water masses and their circulation at high-latitude margins are strongly influenced by ice sheet growth and retreat, affecting both sea-level, dense bottom water production, salinity and temperature profiles of the water column, and iceberg production - which in turn influence sediment transport processes, pathways and ultimately deposition in deeper marine environments. The influence of cryogenic processes on glaciomarine sediment deposition over long timescales (thousands to millions of years) is recorded in the sedimentary successions that build up on the continental shelf, slope and rise of high-latitude continental margins. These successions differ from lower-latitude, non-glaciated continental margin processes, where tectonics and sea-level change are the predominant controls on depositional architecture (e.g. Wilgus et al., 1988, and papers therein). Sedimentary facies analysis and facies models are used as tools to understand changes in processes and depositional environments through time.

Primary sources of sediment and processes of deposition (described below) represented in U1361A core studied here, reflect variations in distal ice berg rafting (IRD), the presence or absence of sea-ice (biosiliceous sediments), and the proximity of the grounding line to the upper slope (availability of terrigenous glaciogenic sediments). Downslope transport and oceanographic processes will ultimately control the nature of the facies represented (e.g. turbidites, contourites, pelagic and hemipelagic) in the cores, but the cyclical stacking patterns of the facies are controlled by long-term modulation of these primary glaciogenic influences.

\subsubsection{Sedimentary facies analysis and sequence stratigraphy}

The term facies describes a unit of rock deposited in a certain environment of deposition, determined by a range of physical (lithofacies) and biological characteristics (biofacies). Walther's Law, states that laterally adjacent depositional 
environments will be recorded as a vertical facies succession, with gradational contacts (Walthers, 1984). This usually occurs in response to changes in base-level and/or, in the case of glacial environments, changes in the proximity of the grounding line. Another criterion for the preservation of a vertical facies succession is the provision of adequate accommodation space (e.g. Jervey, 1988) by either eustatic, isostatic or tectonic processes. Facies separated by erosive contacts were not necessarily deposited in laterally adjacent environments as unconformities represent 'missing time' and potentially a large shift in depositional environments. Facies often occur in associations, characteristic of certain environments, and provide more confidence on the interpretation of that environment. A facies model is a predictable vertical and lateral representation of facies successions and associations depicting a range of sedimentary environments, and may be generated graphically, through mathematical and statistical analysis, or computer simulation (Walker and James, 1992).

Vertical successions of facies recording repetitive sequences of facies are called facies cycles. Facies cycles may be the response to an external forcing mechanism such as tides or orbital cycles, or may be the response of internal or local forcing mechanisms such as storms, earthquakes or delta lobe switching. The former type of facies cycle may be termed an allocycle and is usually periodic (e.g. such as a Milankovitch/orbital forcing). The latter type of facies cycle is termed an autocycle, is usually non-periodic and associated with random events. Facies cycles preserved on continental margins are often interpreted using cyclostratigraphy or sequence stratigraphy. Cyclostratigraphy is the study of sedimentary facies cycles usually in one-dimension such as a geological drill core or outcrop. Sequence stratigraphy is the study of sedimentary cycles in two or three dimensions and considers environmental changes in linked contemporaneous environments across the entire continental margin from the hinterland to the deep ocean.

In geological drillcore records, the vertical stacking of repetitive facies successions, which represent changing depositional environments, have been used to define 
glaciomarine sequences representing glacial-interglacial cycles of ice sheet advance and retreat on the continental shelf (Fielding et al., 2000; Powell and Cooper et al., 2002; Dunbar et al., 2008; McKay et al., 2009).

\subsubsection{Continental rise sedimentation}

A continental rise is usually only present in passive margins, and sediment deposition is primarily a function of hemipelagic/pelagic sedimentation and sediment transported from the continental shelf to the rise via sediment gravity flows in slope canyons (Kennett, 1982). Glaciated margins also have sediment deposition that is influenced by glacial meltwater, sea-ice production, and icebergs. Sediment transport and deposition at glacial margins can be classified into ice contact (glacial overriding), grounding line proximal, (grounding zone and immediately offshore marine on the continental shelf) and ice distal (usually open marine outer continental shelf, slope and rise) environments. On the shelf these environments change markedly during glacial-interglacial cycles, however slope and rise settings are typically ice distal. IODP Expedition 318 U1361A marine sediment core record comprises an ice distal record of lower slope and basin floor sedimentation, influenced both by glacial proximity and ocean circulation, which may also be influenced by glacial proximity. Sea-level, while indirectly important via its influence on ice margin stability, plays a subordinate role on the depositional architecture of drillcore records in these deep marine environments. Processes depositing sediment on the continental rise include turbidity currents, sediment plumes, assorted density flows, bottom (contour) currents, pelagic and hemipelagic settling, and ice berg rafting (Figure 2.13). 


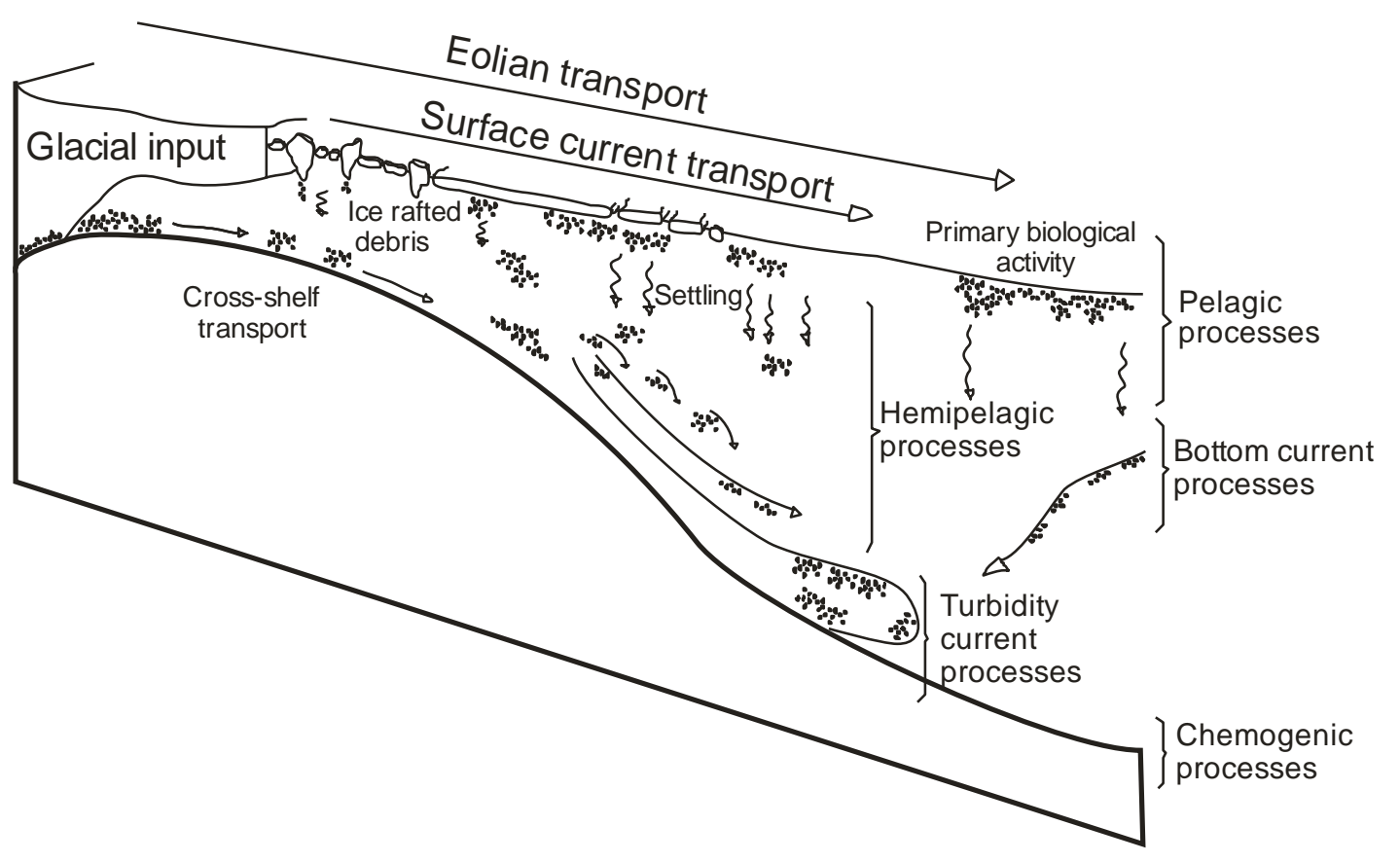

Figure 2.13. Sediment input and transport on the continental shelf and rise of a glaciated margin (modified from Boggs, 2001 after Stow et al., 1996). Bottom current processes are bottom water eddies and nepheloid layers; turbidity currents include canyon currents and bottom nepheloid suspension; chemogenic processes refer to dissolution and authigenesis.

\section{Turbidity Currents}

Turbidity currents are a type of density current which flow down slope due to density differences between sediment laden waters and the surrounding waters. Eroded and entrained sediment remains in suspension, supported in the water column by turbulence and this process is sustained as the dense, turbid cloud flows down slope increasing in speed. The turbidity current will continue until the density contrast is lost due to settling of suspended sediment and this commonly results in graded bedding (Kuenen, 1937; 1950; Bouma, 1962). Turbidity currents are generated on the outer shelf or upper slope and transport sediment to the continental rise through submarine canyon systems, with erosion occurring in the channel while relatively non-erosive overbank spill deposition occurs on the channel levees (Figure 2.14). Sediment failure on the upper continental slope can be triggered by episodic earthquakes, overloading causing slope instability, storm surges and bedload inflow from glacial ice and meltwater. Turbidity currents are 
most likely, the primary transport mechanism of sediment to the lower continental rise and abyssal ocean on a passive margin, such as Wilkes Land, East Antarctica.

Glaciated margins are supplied with terrigenous sediment from basal and supraglacial melt out, subglacial fluvial processes near the grounding zone, ice rafting and aeolian sources. Since the Last Glacial Maximum when the East Antarctic Ice Sheet (EAIS) was grounded on the outer continental shelf, it has retreated to the innermost continental shelf. Under present day conditions and past interglacial configurations the majority of glacially-transported sediment is retained on the continental shelf. During glacial maximums, when the EAIS grounding line has expanded to the outer continental shelf, sediment is more readily available for further transportation to the rise and abyssal plain via turbidity currents. Consequently, sedimentary facies dominated by turbidite deposition are often a feature of glacial phases in Antarctic continental margin geological drill core records (ODP Leg 113: Grobe et al., 1992; Leg 188: O’Brien et al., 2001; Leg 178: Hillenbrand and Ehrman, 2005).

Turbidites are the sediment deposits of turbidity currents and an idealised turbidite facies assemblage consists of a series of five units of sands and muds (Bouma, 1962; Figure 2.15a), although this which has been modified and simplified by Hsü (1989; Figure 2.15b). Stow and Piper (1984) have produced a separate facies model for mud-rich turbidites (Figure 2.15c). The ideal sequence of a turbidite facies is rarely found in the geological record, more often base-cut-out and top-cut-out sequences are recovered, where only part of the turbidite sequence is preserved (Stow and Piper, 1984). In an overbank spill environments, such as that at IODP site U1361A, only the upper non-erosive mud-rich section of the turbidite sequence is likely to be preserved, as the majority of the coarse bed load will be deposited within the channel system (Piper and Normark, 1983; Figure 2.14). 


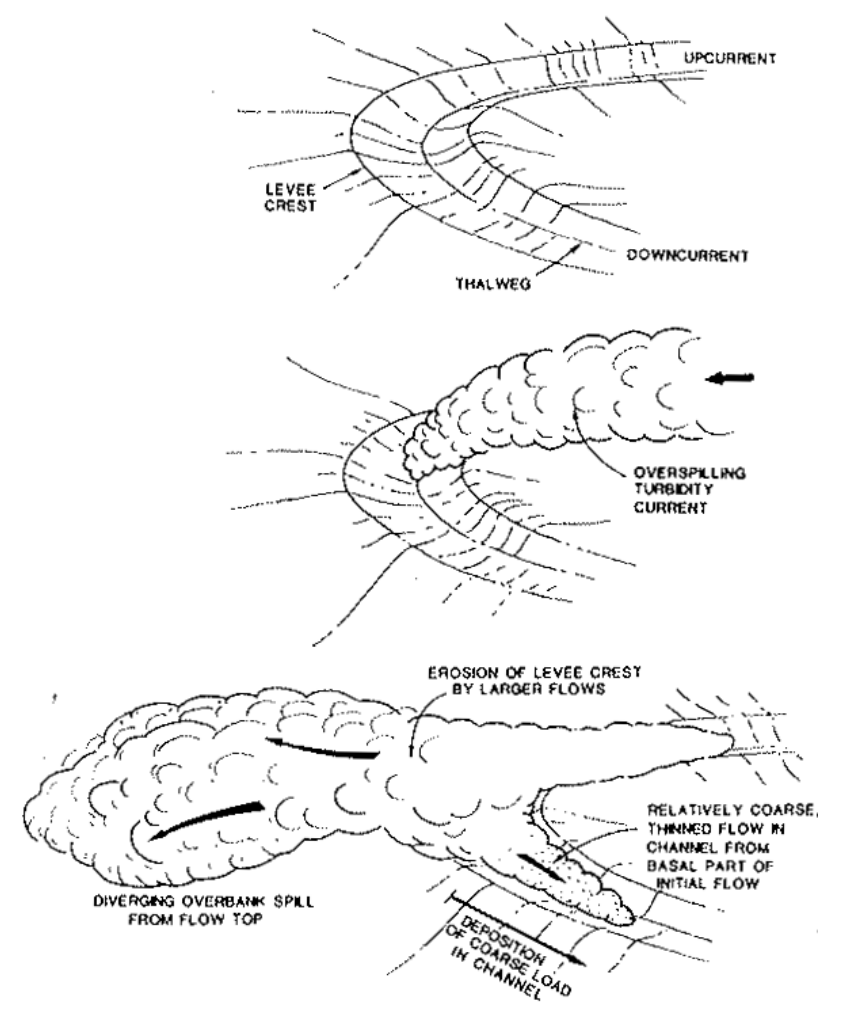

Figure 2.14. The effect of channel curvature on momentum, lost through overbank spill (Piper and Normark, 1983).

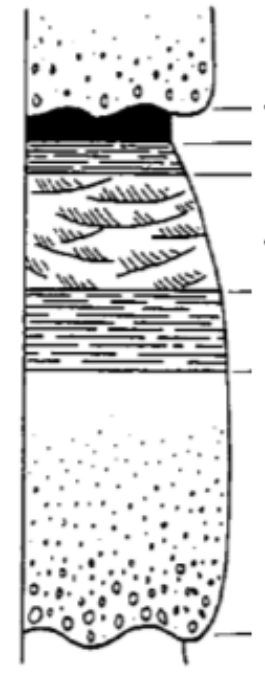

1
PELAGITE

TURBIDITE MUD \pm graded I laminoted - - - - - -

TURBIDITE SILT groded, fine, parallel-iaminated

groded, medium cross-laminated

\pm graded, medium parallel-laminated

massive, medium-coorst poor or no-grading sharp \pm scoured base

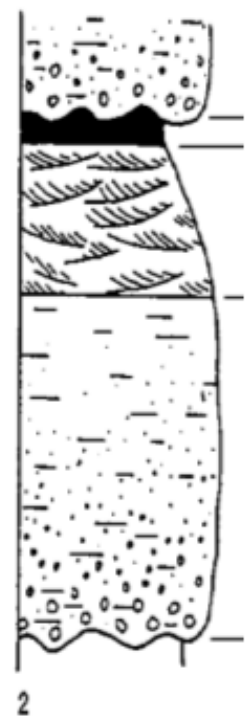

B

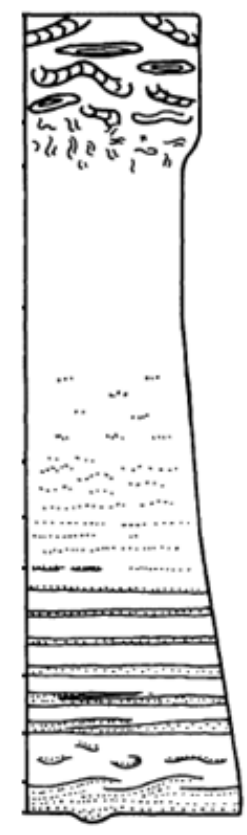

PELAGITE/HEMIPELLAGITE $-----------$ bioturbation, microbioturbotion UNGRADED TURBIDITE MUD $------\cdots---$ GRADEO TURBIDITE MUD \pm sitt lenses

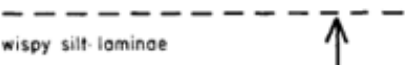
indistinct silt laminoe

regular parollel sitt laminoe

irregular, thin lenticular silt lominoe

convolute silt laminae thick bosol lenticular silt lamino

C

Figure 2.15. Turbidite sequences for silt turbidites (A) by Bouma (1962); simplified by Hsu (1989; B), and mud turbidites (C) Stow and Piper (1984). 


\section{Contour Currents}

Bottom currents that flow parallel to continental margins follow bathymetric contours, hence they are called contour currents. The westward flowing Antarctic Slope Current (ASC), forced by the circumpolar easterly winds, likely results in a significant contour current that may influence continental rise sediment deposition processes. The ASC flows in the opposite direction to the eastward flowing ACC, and as such it connects the southern limits of the Adelie-Wilkes Land, Weddell and Ross Sea gyres (Figure 2.11; McCartney and Donoghue, 2007). A likely increase in windiness during glacial maximums is suggested to increase the ASC transport (McCartney and Donoghue, 2007). Thus, like turbidites and the sedimentary deposits from contour currents, contourites may be more invigorated during glacial phases in Antarctic margin sediment cores.

The stratigraphic architecture of contour currents is identified in seismic profiles as sediment waves or drifts on the seafloor at the Wilkes Land margin (Figure 2.16; Donda et al., 2007). Contourites are sediments deposited or reworked by persistent bottom currents, but they have a low preservation rate making it difficult to identify in the geologic record (Stow and Piper, 1984). Criteria used to distinguish contourites from other deep sea facies are irregular vertical sequences with normal (grain size decreases downwards) and reverse grading (grain size increases upwards), evidence of relatively continuous bioturbation but with suggestion of current induced sediment deposition, and features indicating a combined insitu and exotic origin (Stow and Piper, 1984). Although there is no regular sequence of structures within contourite facies, the appearance of both reverse grading and normal grading (as in turbidites), is distinctive in contourites (Figure 2.17; Stow and Piper, 1984).

A study of shallow cores collected from the Pacific margin of the Antarctic Peninsula, describe sediment deposition by turbidity currents, contour currents and meltwater plumes (Lucchi and Rebesco, 2007; Figure 2.18). The varying influence of afore mentioned processes are interpreted as different stages of the last glacial cycle 
along a continental shelf and rise transect (Lucchi and Rebesco, 2007). The present and penultimate interglacials are characterised by bioturbated muds with abundant ice-rafted debris (IRD), the deglaciation phase is described as terrigenous structureless mud with IRD layers, centimeter-scale laminated muds with rare IRD deposited by turbidity currents is produced during glacial periods and the glaciation phase is characterised by terrigenous structureless mud with rare IRD, deposited by meltwater plumes, aeolian and ice-rafted detritus (Lucchi and Rebesco, 2007). The correlation of the cores along a seismic transect across a turbidity channel levee system, enabled the identification of turbidity versus contourite depositional processes.

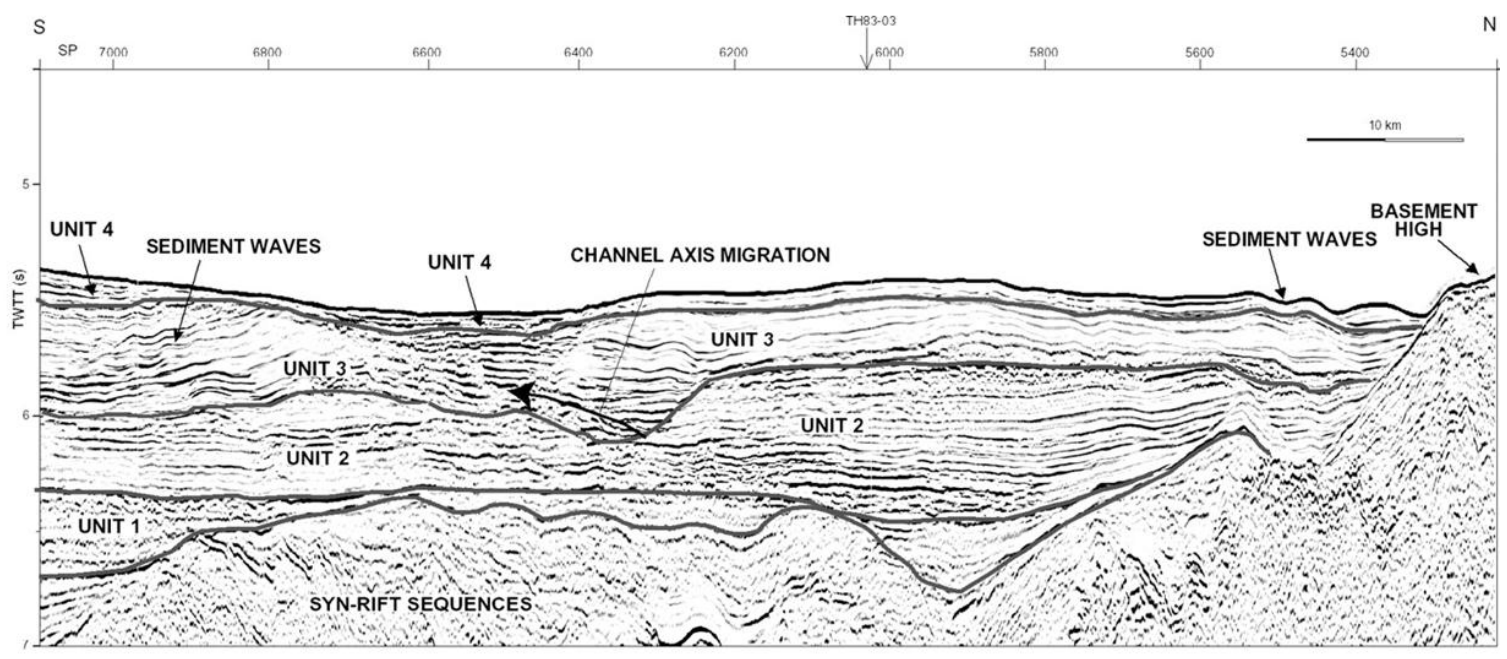

Figure 2.16. A seismic profile perpendicular to the Wilkes Land coast, identifies modern and paleo- sediment waves indicating the presence of bottom contour currents (Donda et al., 2007). 


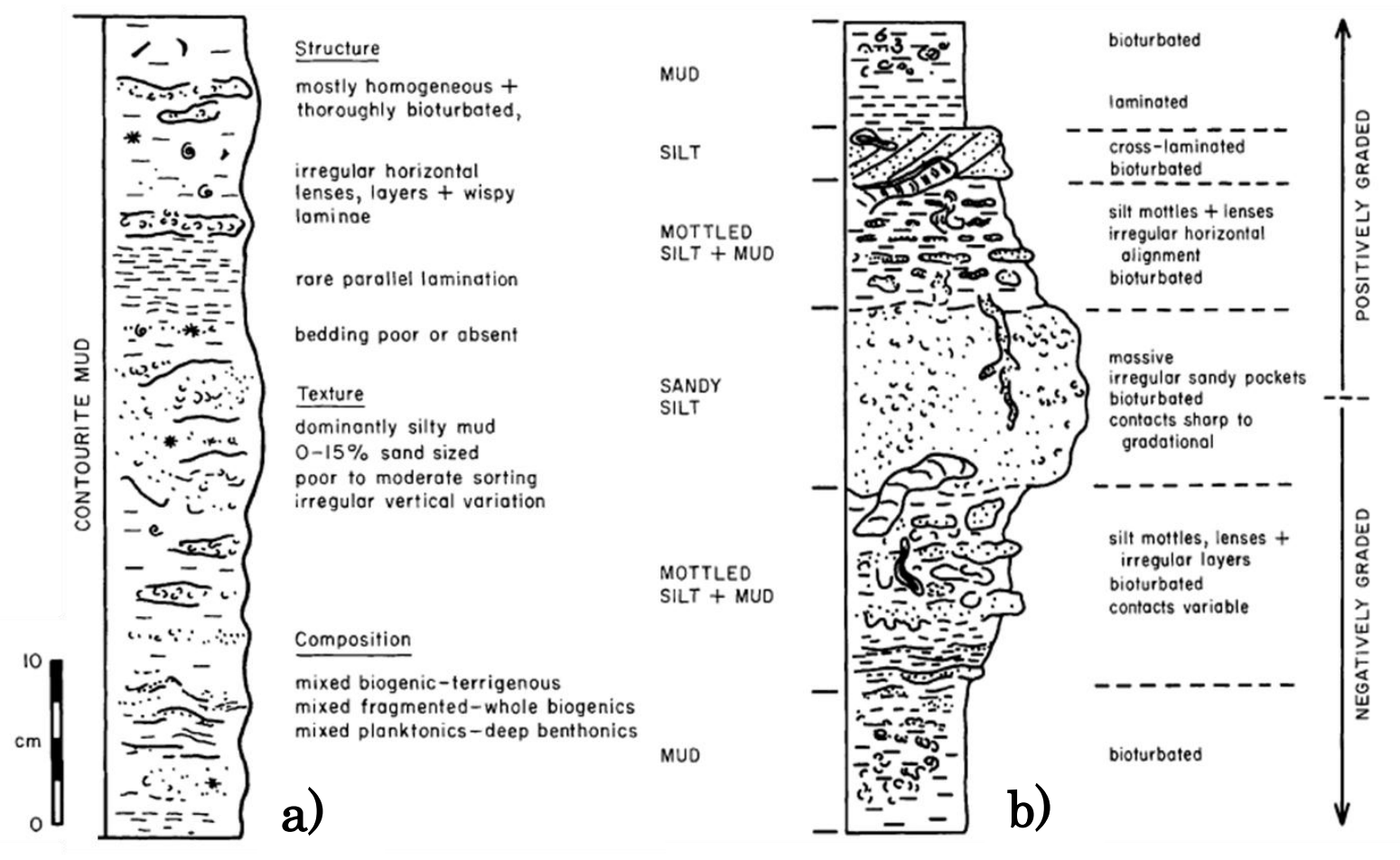

Figure 2.17; Facies model for a) mud and b) silty-sandy contourites, describing composition, texture and sedimentary structures (Stow and Piper, 1984).

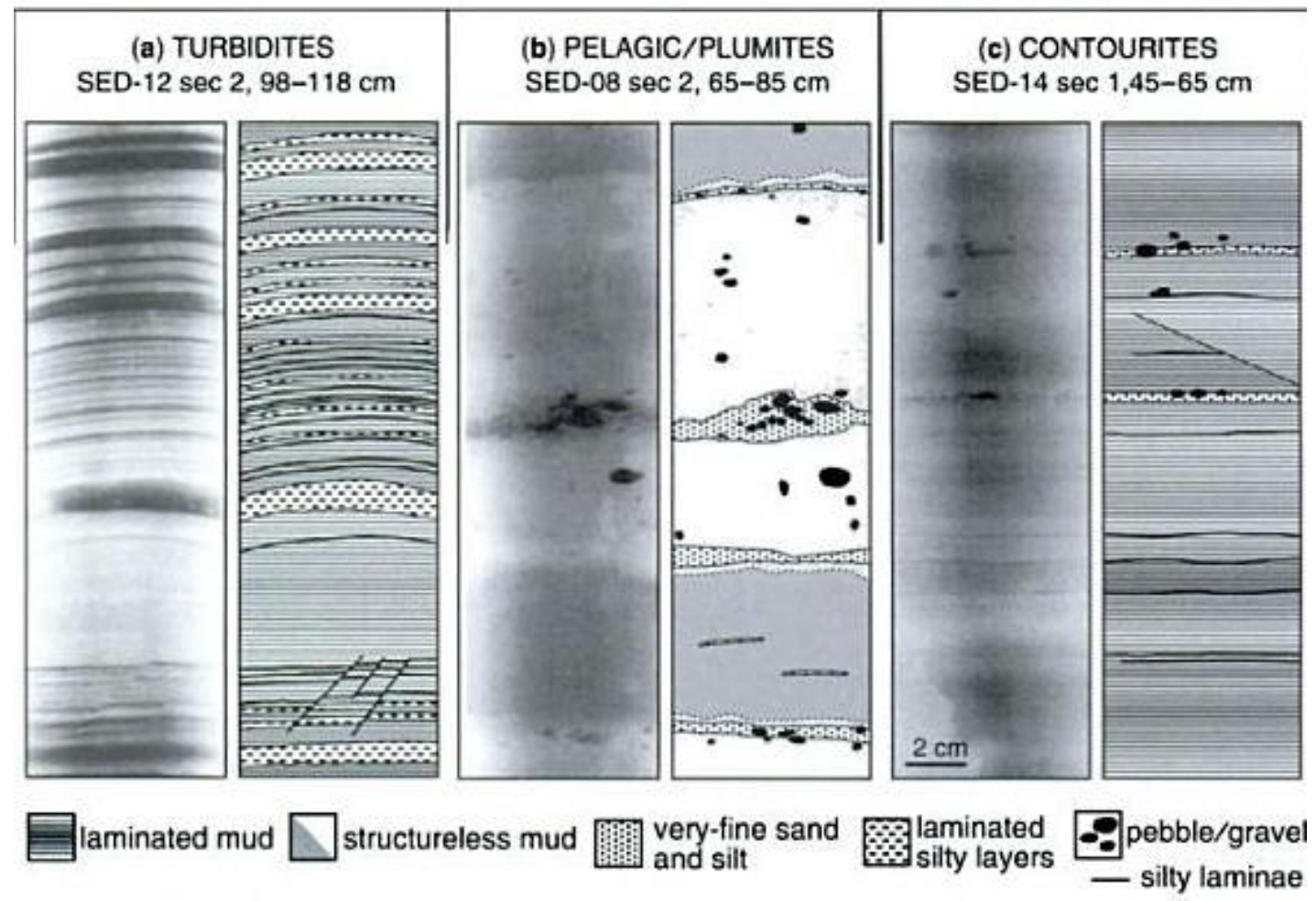

Figure 2.18. An example of interpreted end member facies, predominated by one process of deposition a) turbitidy currents depositing laminated muds with rare ice-rafted debris, b) meltwater plumes depositing structureless muds with IRD layers and rare silt lenses, c) bottom water currents producing finely laminated mud with IRD layers (Lucchi and Rebesco, 2007). 


\section{Hemipelagic Settling}

Pelagic clay and ooze is made up of biogenic remains, settled out of the water column on to the seafloor (Berger, 1974), although it may contain a minor volcanic ashes and windblown sediment component, and iceberg rafted debris in a glaciated margin. Hemipelagic muds are a combination of terrigenous and biogenic materials settled from suspension (Berger, 1974). This type of sediment deposition has relatively low sedimentation rates and is commonly bioturbated (Hesse, 1975). Terrigenous material is supplied through multiple avenues including: 1) sediment laden meltwater forming buoyant (hypopycnal) plumes, where fine sediments 'float' on the surface due to the density difference between freshwater and the surrounding saline water; 2) the near-bottom nepheloid layer containing suspended sediment settled from the above water column and re-suspended fines from the seafloor (it is more dense then the surrounding ambient water but has a low settling velocity and therefore is able to hold sediment in suspension for days to weeks); 3) aeolian derived sediment, which can travel up several hundreds of kilometres from shore; and 4) ice rafted debris, which include fine sediment and gravel sized clasts and are transported by sea-ice and icebergs (Boggs, 2001). Hemipelagic facies are commonly homogenous and structureless and under normal oxic conditions bioturbation is pervasive, removing primary sedimentary structures and resulting in a mottled appearance (Hesse, 1975; Stow and Piper, 1984). Texturally, hemipelagic sediments are silty clays and associated changes in clay percentage with relative biogenic content can form composition cyclicity (Stow and Piper, 1984).

In the Northern Hemisphere, iceberg rafted debris are deposited more frequently during interglacials, particularly at the transition from a glacial when armadas of icebergs may be discharged from a retreating calving line (Broecker, 2000), although such a relationship for the Antarctic margin is disputed (Kanfoush et al., 2000; Clark et al., 2000). The association of iceberg rafted debris with biogenic-rich sediments represents open, ice free highly productive oceanic conditions. Such an association would support deposition during interglacial conditions for these facies, 
whereas hemipelagic facies are often associated with glacial episodes of increased glacial sediment delivery, especially if there is meltwater associated with the subglacial system.

\section{Diagenesis and bioturbation}

Post burial processes occurring on the continental rise include bioturbation, reworking of sediments, authigenesis and dissolution. Bioturbation is the disturbance of sediments by benthic species, sedimentation rates need to be relatively slow for this process to occur (when terrigenous input is decreased), otherwise the animals are inundated with sediment and buried. This is likely associated with increased oxygenation of bottom water and/or a decrease in terrigenous input. Authigenesis is the formation of new minerals in situ, in association with dissolution of unstable minerals due to the [changing] chemical composition of seawater. These two processes (authigenesis and dissolution) change the porosity of rocks (secondary porosity). 


\section{Chapter 3 Materials and Methods}

\subsection{Core recovery}

Two holes were drilled at site U1361: Hole U1361A reached a depth of $388.0 \mathrm{mbsf}$, while Hole U1361B reached $12.1 \mathrm{mbsf}$. Hole U1361B is not examined in this thesis due to its shallow depth and poor recovery. The sediment cores were recovered using a variety of drilling methods, dependent on the lithology of the substrate. The Advanced Piston Corer system is used for soft sediments and incurs relatively low drilling disturbance relative to the other coring systems. The Extended Core Barrel system is deployed when the formation becomes too stiff for the Advanced Piston Corer system (i.e. semi-lithified), but these cores in U1361A are characterised by a high level of drilling disturbance, including pervasive brecciation and 'biscuited' core (Expedition 318 Scientists, 2010). As such, this study only investigates the intervals of core that were recovered by the Advanced Piston Corer system (151.5 - 0 mbsf), which spans the entire Plio-Pleistocene, due to the minimal degree of drilling deformation in these intervals.

\section{Drilling-induced core deformation}

Cores may be significantly disturbed as a result of the coring process. Unlithified sediment is commonly washed down the core hole and may be sampled in following cores. The top 10-50 cm of each core must be examined for potential 'fall-in' (Expedition 318 Scientists, 2010). Slight to moderate deformation is commonly identified by a concave-down deformation of bedding and laminations that were assumed to be originally deposited horizontally (Expedition 318 Scientists, 2010). Drilling disturbance was assigned a value on board through visual observations of the cut core face. 


\subsection{Core Logging}

U1361A was logged for gamma-ray attenuation bulk density, magnetic susceptibility, natural gamma radiation and colour reflectance, henceforth referred to as GRA, MS, NGR and colour reflectance respectively. GRA and MS were measured by the Whole Round Multi-Sensor Logger. NGR was measured separately using the NGR-logger and colour reflectance was measured on a Minolta Photospectrometer CM-2002. The quality of this data is highly dependent on the condition of the core (see section 3.1; Figure 3.1). The physical property logs are used as an indication of sedimentological changes that can be related to directly to the established lithofacies scheme (Expedition 318 Scientists, 2010), but may also represent more subtle compositional or textural variations at a higher resolution than the pre-established facies scheme and visual descriptions allow for.

Detailed reports on the configuration and specifications of GRA, MS, NGR and colour reflectance measurements for ODP and IODP expeditions can be found in the Physical Properties Handbook by Peter Blum, 1997, located at http://wwwODP.tamu.edu/publications/tnotes/tn26.

Raw physical properties data for U1361A can be obtained from the IODP data depository http://sedis.iodp.org/.

\section{Gamma-ray Attenuation Bulk Density}

The GRA densitometer has a spatial resolution of $0.5 \mathrm{~cm}$ and works on the principle that incident photons are scattered by the electrons of the sediment material (Expedition 318 Scientists, 2010). The attenuation of the incident intensity is related to the electron density of the sediment in the core multiplied by the diameter, which in turn can be converted to a bulk density value once suitably calibrated (Evans, 1965; Harms and Choquette, 1965). 
Bulk density primarily reflects grain density and porosity. Porosity is mainly controlled by lithological texture and composition, compaction and diagenetic processes. A linear increase of GRA density with depth is expected due to compaction of the sediments by overburden (Expedition 318 Scientist, 2010). Drilling induced disturbance such as 'fall-in', core breaks, fractures and drilling slurry create spurious values in GRA.

Gamma-ray attenuation (GRA) bulk density was measured at $2.5 \mathrm{~cm}$ intervals with a 10 second integration time and the values measured reached up to $2.58{\mathrm{~g} . \mathrm{cm}^{-3}}^{3}$ for U1361A (Expedition 318 Scientists, 2010).

\section{Magnetic Susceptibility}

Magnetic susceptibility provides information on the composition of the sediments, indicating relative presence of magnetic minerals. High magnetic susceptibility values are associated with iron sulphides and iron-titanium oxides, magnetite, haematite, ilmenite and pyrrhotite (Hunt et al., 1995). Sedimentary rocks have variable values depending on the inclusion of magnetic minerals. Sediments rich in biogenic content have low magnetic susceptibility values due to reduced terrigenous content. Diagenetic oxidation can alter the magnetic strength of minerals.

Whole-core magnetic susceptibility was measured at $2.5 \mathrm{~cm}$ intervals $(2$ second integration time). Spurious peaks caused by gravel clasts, were commonly present in the top of each core section as 'fall-in' material.

\section{Natural Gamma-ray}

NGR is a measure of gamma-rays emitted from whole-round core sections. The decay of uranium, thorium and potassium (primarily found in clay minerals), produces the majority of gamma radiation (Expedition 318 Scientists, 2010). NGR is sampled every $\sim 10 \mathrm{~cm}$, for a sampling time of at least five minutes. Spatial 
resolution of NGR is limited, as the geometry of the device and nature of radiation measurement, resolves a $\sim 40 \mathrm{~cm}$ length of core for each measurement. This produces a characteristically smoothed curve. The full-width-half-maximum is $\sim 12 \mathrm{~cm}$ and represents a reasonable spatial resolution, whereby layers thinner then this can only be recognised if gamma-ray emission is vastly different to the surrounding material.

\section{Reflectance Spectrophotometry and Colorimetry}

Colour reflectance is recorded by three parameters $\left(\mathrm{L}^{*}, \mathrm{a}^{*}\right.$ and $\left.\mathrm{b}^{*}\right)$ created by the International Commission on Illumination (CIE), it is commonly called CIELAB or "lab colour space". Lab colour space refers to a lightness variable $\left(\mathrm{L}^{*}\right)$ and two chromaticity variables ( $\mathrm{a}^{*}$ as the green to red axis and $\mathrm{b}^{*}$ as the blue to yellow axis). The three coordinates of CIELAB represent the lightness of the colour $\left(\mathrm{L}^{*}=0\right.$ yields black and $L^{*}=100$ indicates diffuse white; specular white may be higher), its position between $\mathrm{red} /$ magenta and green $\left(\mathrm{a}^{*}\right.$, negative values indicate green while positive values indicate magenta) and its position between yellow and blue ( $b^{*}$, negative values indicate blue and positive values indicate yellow). CIELAB values can be converted to CIE XYZ and RGB values.

Colour reflectance measurements were taken on the archive half. As measurements were made after splitting the core, post-drilling disturbance during the splitting procedure, e.g. cracking, smearing or scuffing of the core face, may also influence these measurements. A consistent time lag ( 1 hour) after core splitting was implemented to reduce error between cores due to oxidation and the core drying out that both act to 'lighten' the core face. 


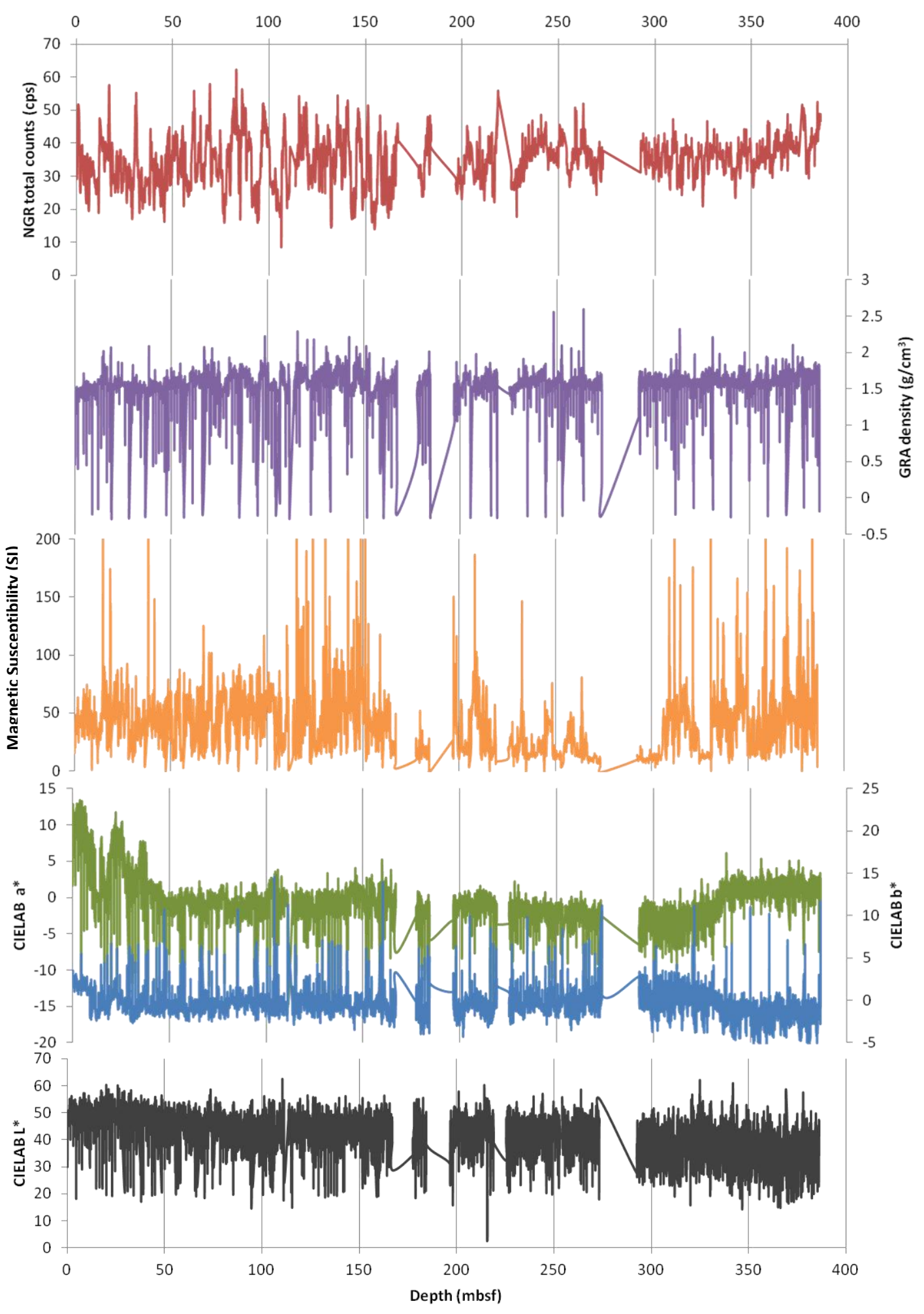

Figure 3.1. Raw physical property logs for whole core U1361A; NGR; GRA density; Magnetic susceptibility; Colour reflectance $L^{*} a^{*} b^{*}$. The near continuous upper $160 \mathrm{~m}$ is in direct contrast to below this depth, when the Extended Core Barrel was deployed and core recovery was low to absent for multiple core sections. 


\subsection{Age model}

The age model for U1361A is constrained by biostratigraphic and paleomagnetic techniques and did not identify any hiatuses for the 4.2-0 Ma interval but does recognise a highly condensed interval of the core between 78 and 75 meters below sea floor (mbsf; Tauxe et al., 2012; Figure 3.3). Some intervals of the core were impacted by limited recovery or extreme drilling disturbance that compromised the integrity of the lithostratigraphy and physical properties logs and these sections of the core were discarded for analysis (Figure 3.3). Several distinct climatic periods in the Plio-Pleistocene were targeted for detailed analysis in the thesis, and most of these intervals are preserved in the U1361A stratigraphic record. These include: 1) the warm Early Pliocene (4.2-2.58 Ma) preceding the development of the continental-scale Northern Hemisphere Ice Sheets; 2) the Early Pleistocene, when benthic foraminifera $\delta^{18} \mathrm{O}$ suggest a $\sim 40 \mathrm{kyr}$ obliquity pacing of global ice volume fluctuations; 3) the Middle Late Pleistocene ( 800 ka) following the mid-Pleistocene transition, i.e. the change from a $\sim 40 \mathrm{kyr}$ to a $\sim 100 \mathrm{kyr}$ pacing of glacial to interglacial cycles.

Sedimentation in each section analysed for cyclostratigraphic and spectral analysis needed to be fairly continuous, with core breaks or heavily disturbed parts of the core creating the potential for inaccurate identification of trends and cycles. For example, spurious values every nine meters associated with the core length need to removed, otherwise this high amplitude, low frequency cycle would dominant the rest of the spectra.

Based on the above considerations, the intervals of core chosen for analysis were: Interval 1) 8.9-0 mbsf; Interval 2) 36.5-18.5 mbsf; Interval 3) 55.3-38.6 mbsf; Interval 4) 72-56.5 mbsf and Interval 5) 101-77 mbsf (Figure 3.3). These intervals correlate to the time periods $\sim 0.5-0 \mathrm{Ma}, \sim 2-1 \mathrm{Ma}, \sim 3-2.5 \mathrm{Ma}, \sim 3.2-2.8 \mathrm{Ma}$ and $\sim 4.2^{-}$ $3.6 \mathrm{Ma}$, respectively. 
The Brunhes-Matuyama boundary $(0.781 \mathrm{Ma})$ is not well constrained due to drilling disturbance in core $2 \mathrm{H}$. Therefore, it is assumed that the upper $\sim 9 \mathrm{~m}$ (core $1 \mathrm{H}$ ) has a linear sedimentation rate of $1.8 \mathrm{~cm} \cdot \mathrm{kyr}^{-1}$, calculated to the top of the Jaramillo chron at $17.8 \mathrm{mbsf} \pm 0.14 \mathrm{~m}$ which includes the mostly disturbed core $2 \mathrm{H}$. This assumption is supported by the underlying interval (2-1 $\mathrm{Ma}$ ) also having an average

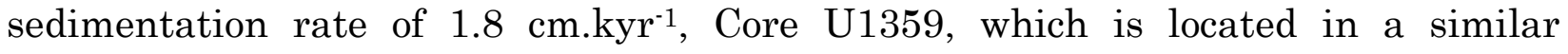
depositional environment on Wilkes Land continental rise also displays a constant sedimentation rate through this interval suggesting that there are no significant regional hiatuses or changes in sedimentation rate (Tauxe et al., 2012). Consistent with this sedimentation rate, is the last appearance of diatom Actinocyclus ingens at $9.03 \mathrm{mbsf}$, constraining the base of core $1 \mathrm{H}$ in U1361A (9 mbsf) to $>0.39 \mathrm{Ma}$ (Cody et al., 2008). The core disturbance in U1361A core $2 \mathrm{H}$ ( 18 to 9 mbsf) spans most of the mid-Pleistocene transition, but has produced unreliable physical property logs for this interval due to a lack of stratigraphic integrity and was therefore excluded for spectral analysis.

Interval 2 is placed between 36.5 and $18.5 \mathrm{mbsf}$, and spans from the base of the Jaramillo chron (0.988 Ma), to the base of the Olduvai subchron (1.945 Ma; Figure 3.1). The location of the Cobb Mountain subchron (1.185-1.173 Ma) between 20.8 and 20.32 mbsf is supportive of a constant sedimentation rate in this interval of 1.8 cm.kyr ${ }^{-1}$ (Figure 3.3).

A lack of drill core recovery between 38.6 and 36.5 mbsf impacts the ability to treat the Interval 2 and Interval 3 as a whole, and they were therefore separated. Interval 3 then includes core between 55.3 and 38.6 mbsf. Assuming a linear sedimentation rate between the base of the Olduvai subchron (1.945 Ma; located in the second interval) and to the top of the Gauss chron (2.581 Ma), Interval 3 was deposited between $\sim 2.8$ and $2.05 \mathrm{Ma}$ (Figure 3.3).

Interval 4 is located between 72 and $56.5 \mathrm{mbsf}$ and is bound by top of core $7 \mathrm{H}$ and the top of the Mammoth reversal (3.207 Ma) located in the base of core $8 \mathrm{H}$ (Figure 
3.3). The physical property logs were not recorded for the last core section of $6 \mathrm{H}$ $(\sim 2.8 \mathrm{Ma})$ for an unknown reason and therefore the third and fourth intervals were treated separately.

The top of the Mammoth chron (3.207 Ma) is constrained at $71.7 \mathrm{mbsf} \pm 0.02 \mathrm{~m}$, but the base is undetermined $(75.21 \mathrm{mbsf} \pm 0.69 \mathrm{~m})$. This depth range also includes a 0.5 $\mathrm{m}$ section with no core recovery, from $75 \mathrm{mbsf}$ extending down to $75.5 \mathrm{mbsf}$ (the start of core 9H). The next paleomagnetic boundary is the Gauss-Gilbert (3.596 Ma), located at $77.48 \mathrm{mbsf} \pm 0.02 \mathrm{~m}$. It is clear from the magnetostratigraphy that sedimentation rates are much lower in this interval $\left(0.08 \mathrm{~cm} . \mathrm{kyr}^{-1}\right)$ than in overlying intervals, indicating the presence of a condensed section or hiatus between 3.58 and 3.33 Ma, and therefore preventing the use spectral analysis in this interval.

Interval 5 occurs between 101 and $77 \mathrm{mbsf}$, and is interpolated to an age of between $\sim 4.2$ and $\sim 3.6 \mathrm{Ma}$ as constrained by the locations of Gauss-Gilbert boundary (3.596 $\mathrm{Ma}$ at $77.48 \pm 0.02 \mathrm{~m})$ and the top of Cochiti subchron $(4.187 \mathrm{Ma}$ at $99.99 \mathrm{mbsf}$; Figure 3.3). 


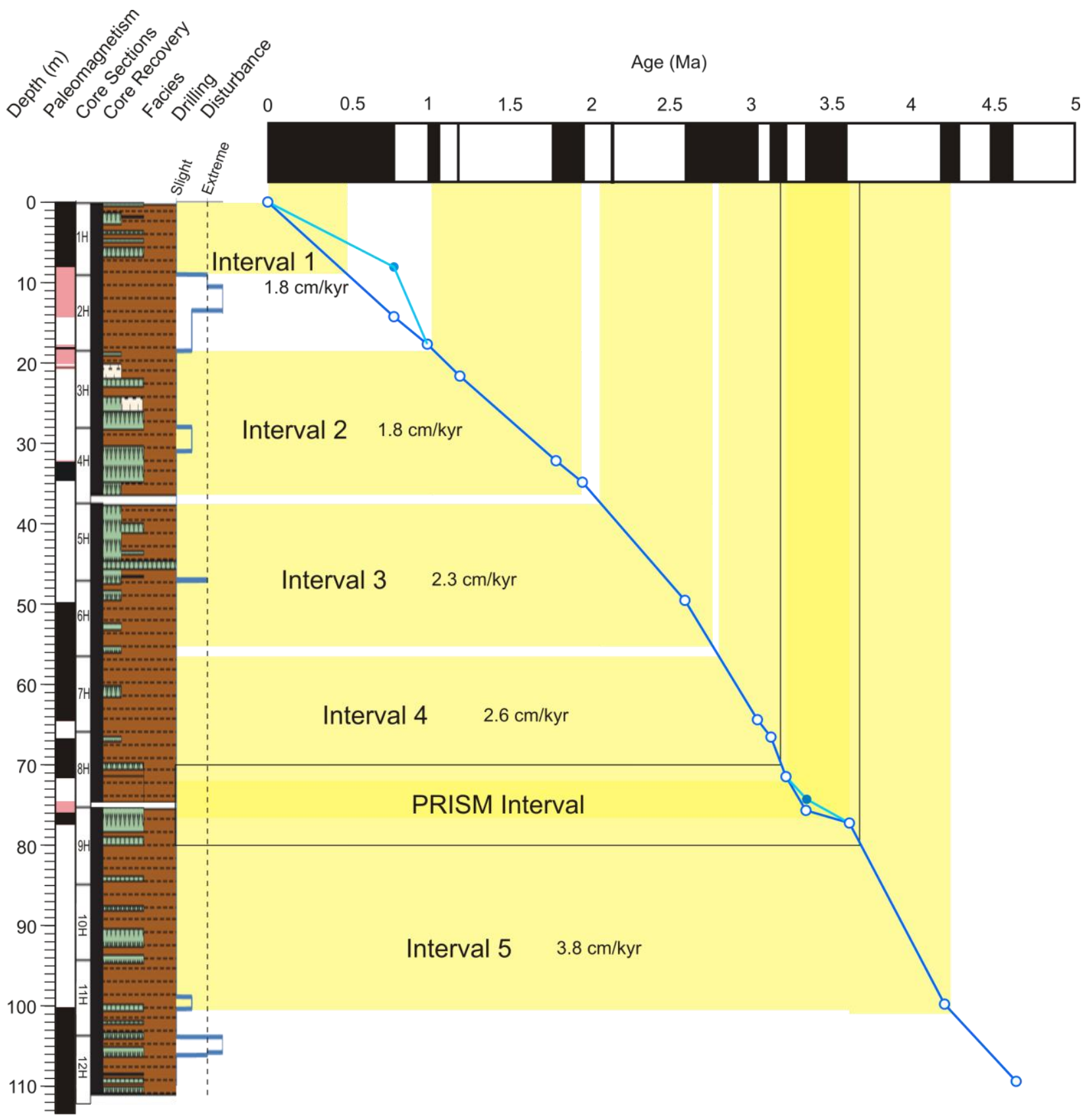

Figure 3.2. Shipboard age model for site U1361A (Tauxe et al., 2012). The core paleomagnetism highlights intervals of uncertainty (in pink) where the associated age-depth points have a large source of error. The dark blue line is the best fit age model, while the light blue line represents the limit of uncertainty. The drilling disturbance is classified as ranging between slightly disturbed to extremely disturbed. Any core with extreme disturbance (above the dashed line) was excluded from data analysis in this thesis. The five intervals chosen for analysis are highlighted pale yellow, the condensed section at the start of the Late Pliocene located between Intervals 4 and 5, are shown by the black lines. 


\subsection{Data Processing}

Prior to conducting spectral estimation, the physical property datasets were processed to increase the signal-to-noise ratio. The noise treated is primarily a product of drilling disturbance and each dataset underwent the same process to attain consistent results (Chart 3.1). GRA density was the only dataset to be detrended due to a linear increase of density with depth caused by compaction during the loading of overlying sediments.

To maintain consistency, each raw physical property dataset (GRA, MS, NGR and colour reflectance) was processed in its entirety. The nature of drilling incurs several different factors that need to be corrected and accounted for. Core expansion (e.g. $105 \%$ core recovery) can cause overlapping in the depth scale. This was manually adjusted for, by ordering the datasets by bottom depth and deleting the least reasonable values, usually in the zone of fall-in at the top of each core, or in the core catcher that was commonly soupy or extremely disturbed. Core expansion affected $69 \%$ of the cores for the upper $160 \mathrm{~m}$ of core, with core recovery ranging from $101 \%$ to $106 \%$. Consolidating the datasets (removing common depth values) was a compromise against the alternative of altering the depth scale to correct for core expansion. However, altering the depth scale makes comparison with other datasets difficult, is time-consuming and has its own associated errors (e.g. correcting depth for soupy core is subjective), while the error associated with consolidation and reduction the datasets can easily be quantified and is minimal, that is on the order of $2 \%$.

The physical property datasets were converted to the age scale using a linear interpolation. Interpolating can introduce artefacts such as reducing the high frequency component, producing spurious peaks and false data points when the new scale is at a higher resolution or interpolated to even increments (Weedon, 2003). The high resolution of the physical properties datasets allowed for confidence in this method and the amount of data points were never increased through this process, to reduce the effect of 'added' data points. Visual comparison of the original dataset 
with the interpolated dataset was also conducted to ensure spurious peaks did not occur during the interpolation processing. In order to analyse the time series for orbital frequencies using the SSA-MTM toolkit (Ghil et al., 2002; Dettinger et al., 1995), the datasets would then be interpolated to even time increments. Each step taken was manually checked to ensure the unreliable data had been removed, and that none of the interpolation steps introduced observable spurious values. Bivariate analysis, undertaken in SPECTRUM, could process time series in uneven increments and therefore data did not need to be interpolated.

Data from intervals where drilling disturbance exceeded 'slightly' and 'moderately disturbed' levels were removed (Figure 3.4). Core breaks, fractures, minor lithologies (e.g. ice rafted debris) and instrumental error can all produce outlying values in the physical properties datasets. Outliers still present after removing drilling disturbance, were treated by deleting any values exceeding three standard deviations from the mean. Excessive magnetic susceptibility values were attributed to a presence of gravel clasts, associated with fall-in or ice rafted debris. Ice rafted debris, however, produced values on the same order of magnitude as values associated with the recurring $9 \mathrm{~m}$ core lengths, thus requiring removal. 
Chart 3.1. Flow chart of data processing steps.

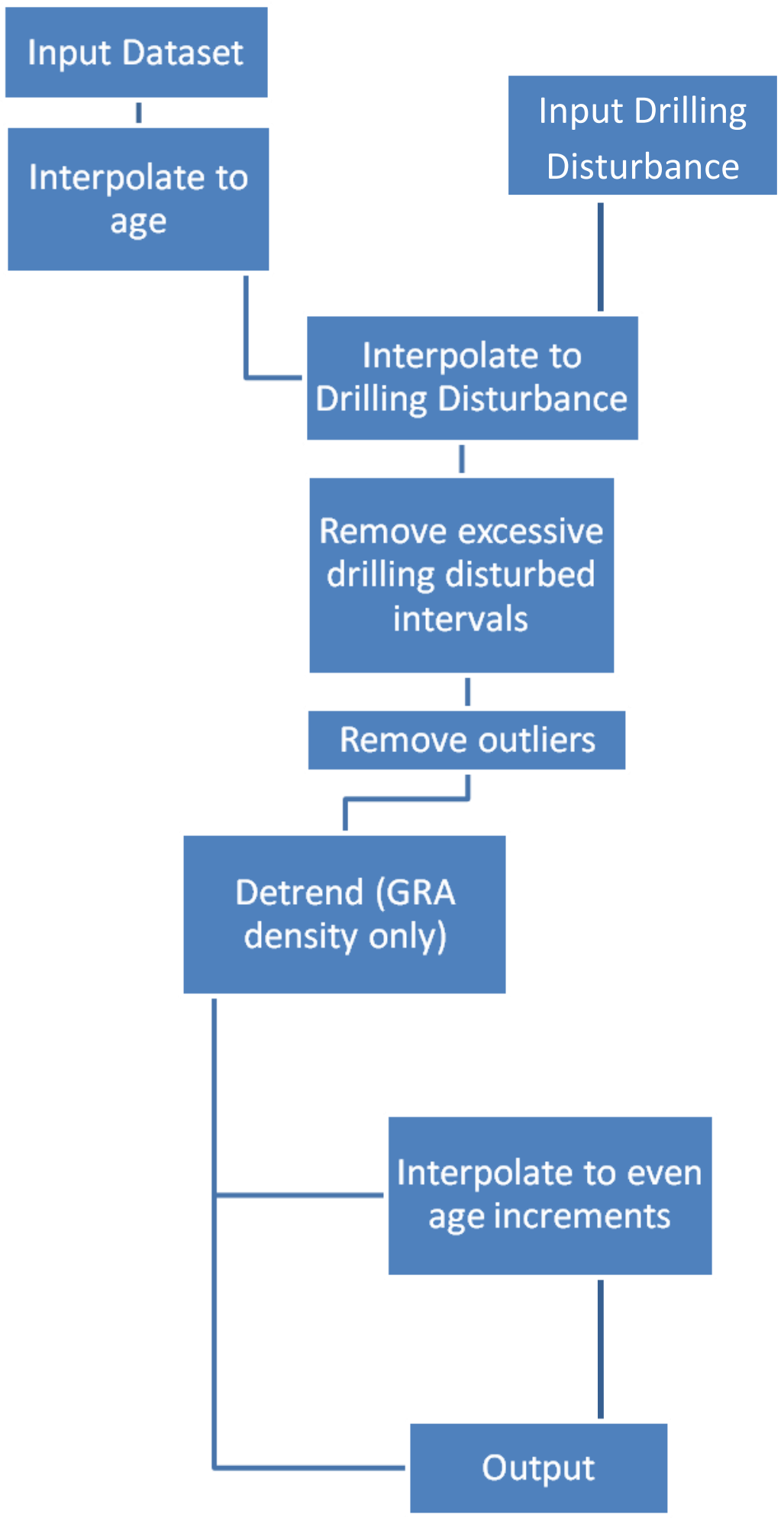



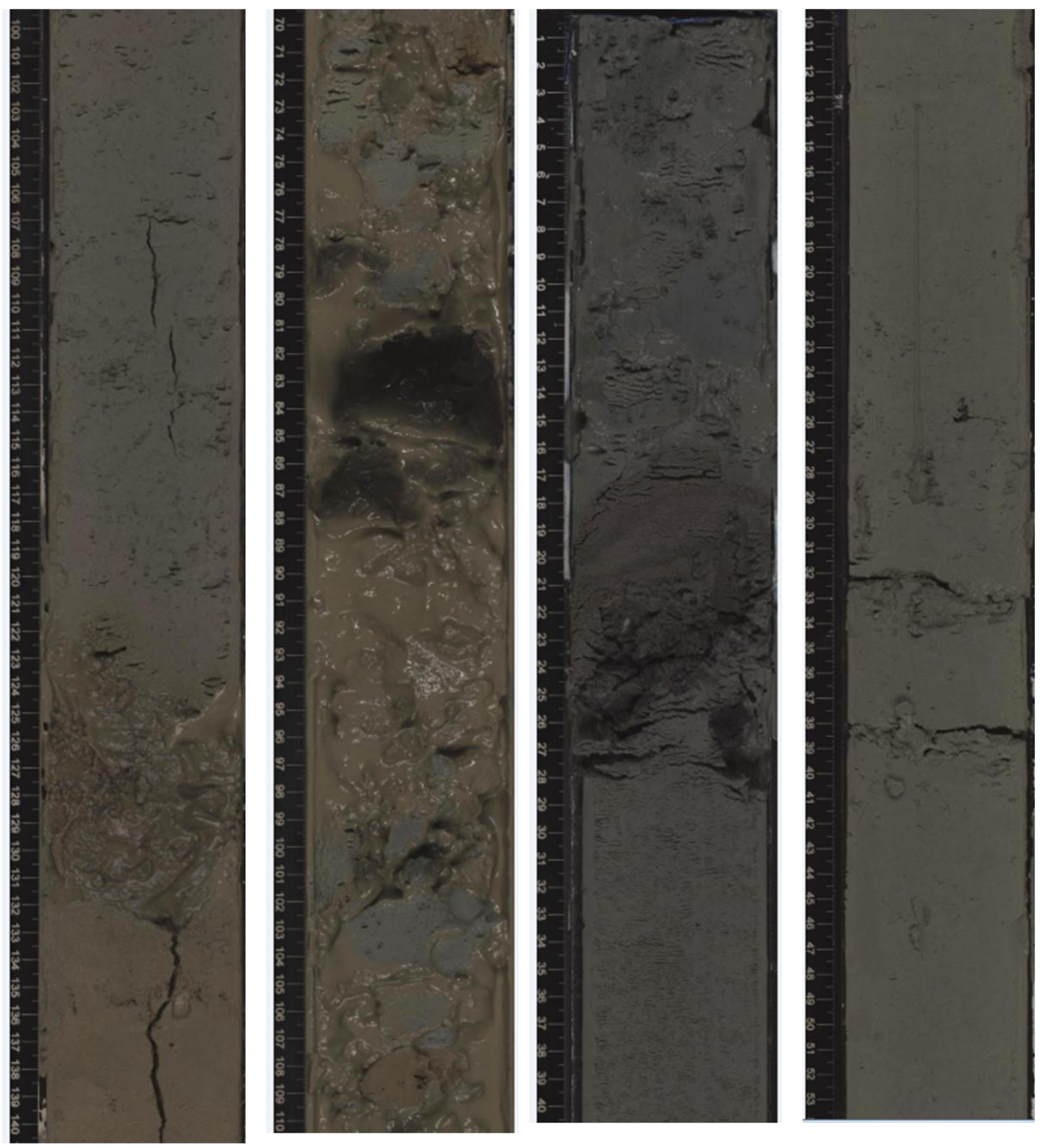

Figure 3.4. Examples of drilling disturbance in core photos from IODP 318- U1361A; a) slightly disturbed to moderately disturbed core section 14.7-14.3 mbsf; b) 'soupy' core section 10.1-9.7 mbsf; c) 'flow in' core section 152.1-151.7 mbsf; d) 'fractures' core section $36-35.6$ mbsf. 


\subsection{Data Analysis}

Geological time series may contain a trend, cyclic and random components, and several methods exist to identify these components in terms of frequency and relative power. The frequency of the cyclic component(s) present in the time series depends on the sampling resolution. The Nyquist frequency is the lower limit of frequencies that can be detected and is defined as half the sampling frequency (Grenander, 1959). Even sampling in the depth domain does not necessarily correlate to even sampling in the time domain, resulting in a varying Nyquist frequency through a time series. As such, frequencies approaching the Nyquist frequency should be interpreted with caution. An aliased record occurs when features in the stratigraphy have higher frequencies then the Nyquist frequency and the small-scale cycles are not sampled at least twice (Weedon, 2003). The high resolution sampling rate $(\sim 2 \mathrm{~cm} / \sim 1 \mathrm{kyr})$ of GRA, MS and colour reflectance are sufficient for orbital frequencies $\left(<0.06 \mathrm{kyr}^{-1 /}>16.7 \mathrm{kyr}\right)$; NGR has a lower sampling rate $(\sim 10 \mathrm{~cm} / \sim 4 \mathrm{kyr})$, which still allows for spectral estimation of the orbital frequencies but spectral peaks nearing the lower limit of the precession frequency band (19 kyr) would only have been sampled a maximum of four times for sedimentation rates of $2.5 \mathrm{~cm} . \mathrm{kyr}^{-1}$. Therefore NGR may not estimate spectral power (for the higher frequency range) correctly for Intervals 4 and 5 where sedimentation rates are $2.6 \mathrm{~cm} . \mathrm{kyr}^{-1}$ and $3.8 \mathrm{~cm} . \mathrm{kyr}^{-1}$, respectively.

Error associated with estimating spectral peaks is recorded as a bandwidth (in kyr 1), dependent on the number of data points for a given time period (i.e. the sampling rate). This error is primarily due to undetected changes in sedimentation rate as a single regular cycle will then be recorded as variable wavelengths.

Half bandwidth is the factor of resolution divided by the sampling interval which is multiplied by the number of data points in the variable (where the full bandwidth is twice this amount). In order for orbital frequencies to be identified, the bandwidth must be smaller than the difference between the orbital frequencies analysed $\left(<0.009 \mathrm{kyr}^{-1}\right)$. The bandwidth signifies the uncertainty in frequency of a spectral 
peak ( \pm half bandwidth), and therefore also represents the range of wavelengths that may add power to a particular spectral peak (Weedon, 2003). Accurate spectral estimates should not vary at scales less than the full bandwidth (Huybers, 2003). That is, the spectral peak should be at a similar scale (width) as the bandwidth.

As each of the Milankovitch cycles have multiple frequencies at which they occur (see Climate Cyclicity, chapter 2.2), it is likely that the physical properties will not record the same singular frequency. Precession in particular, having two significant periods (19 kyr and $23 \mathrm{kyr}$ ), may be recorded as a $21 \mathrm{kyr}$ period (Laskar et al., 2004) and at the resolution of most marine sediment core records, the precession cycles may not be possible to differentiate. Obliquity also has a minor $53 \mathrm{kyr}$ and $28 \mathrm{kyr}$ period, alongside the more significant $41 \mathrm{kyr}$. Influence of either of these cycles may skew the 'obliquity' peak to a higher or lower frequency (Weedon, 2003). Similarly within the eccentricity band, the $95 \mathrm{kyr}$ and $125 \mathrm{kyr}$ cycles are frequently recorded as a 100 kyr period.

Non-linear sampling in the time domain, which increases error in estimation of changing sedimentation rates can produce harmonics in spectra through inconsistency in sampling of a cycle, e.g. in a $10 \mathrm{~m}$ interval with $2.5 \mathrm{~cm}$ linear spacing of measurements, but a changing sedimentation rate over the interval, a $100 \mathrm{kyr}$ cycle may be firstly over sampled, then under sampled, resulting in power for the $100 \mathrm{kyr}$ cycle being spread over multiple frequencies. Harmonics are multiples of the fundamental cycle (e.g. 2f, 3f, 4f, where $\mathrm{f}$ is frequency) and therefore divisions of the period (e.g. T/2, T/3, T/4, where $\mathrm{T}$ is the period; Weedon, 2003). As such, $\sim 40 \mathrm{kyr}$ peaks could be the second harmonic of the $125 \mathrm{kyr}$ eccentricity cycle and $\sim 20 \mathrm{kyr}$ peaks may be the second harmonic of $41 \mathrm{kyr}$ obliquity. Harmonics have progressively less power than the fundamental peak, and the maximum relative power of the harmonics is equal to that of the fundamental (Weedon, 2003). This assists in identifying harmonics and differentiating peaks of possible harmonic frequencies to fundamental orbital peaks. 


\subsubsection{Power spectra analysis methodology}

Fourier's theorem explains that any time series can be recreated by combination of sine and cosine waves forming a set of orthogonal functions (Trauth, 2007). Power spectral analysis assesses the relative power (amplitude) and frequencies (1/Period) of each constituent orthogonal function within a time series, obtained by a Fast Fourier Transform. Power spectra represents average power or squared average amplitude for the time series analysed and therefore cannot determine changing amplitude or power through the interval.

A Fast Fourier Transform predicts that cycles within a time-series will be repeated indefinitely. Therefore, data containing a trend will be treated as though it contains a cycle with a period equal to the length of the time-series. This produces a spectrum dominated by a red noise signal (high power in low frequencies) that may mask higher frequency cycles present in the geological time series, red noise is also produced through changing sedimentation rates which changes the wavelength of regular cycles. Detrending, tapering the dataset (Multi-Taper Method; Thomson, 1990) and dividing the time series into segments or windows (Lomb-Scargle method; Shulz and Stattegger, 1997) can be used to decrease this effect.

A number of methods have been produced to undertake spectral analysis. The MultiTaper Method is used here for single spectral estimation and the Lomb-Scargle method allowing the analysis of un-even time series, was used in SPECTRUM v2.2 (Shulz and Stattegger, 1997) for coherency analysis.

\section{Univariate spectral analysis}

Spectral estimation of a single time-series is based on the Fast Fourier Transform of the autocorrelation function (that is, a lag whereby the time series is multiplied by itself). This simple power spectrum frequently overestimates or underestimates the amplitude for a given frequency as it is averaged over the whole time series. The 
Multi-Taper Method attempts to reduce the variance and increase the confidence of spectral estimates by applying a small set of tapers rather than a singular taper or window as in the Blackman-Tukey method (Thomson, 1982).

Increasing the resolution factor ( $p$, an integer) increases the bandwidth ( $\left.b_{w}=2 . p . f n\right)$, where $f n$ is the Rayleigh frequency (one over the number of data points in the time series multiplied by the sampling rate; Thomson, 1982). The number of tapers $(k)$ used should be less than twice the resolution factor minus one (Thomson, 1982). The default values, $p=2$ and $k=3$, are a compromise between spectral resolution (accuracy) and precision (number of data points analysed for each taper; e.g. Mann and Park, 1993). The robust noise estimation in the SSA-MTM Toolkit 4.1 (supplied by the SSA-MTM Group, University of California, Los Angeles) selects the background noise level through the application of a smoothing window to the raw spectrum with a window width that is the largest of either the Nyquist frequency divided by six, or the bandwidth (2.p.fn). The expected large dynamic range for the spectrum (low power in high frequencies relative to high power in low frequencies), is taken into account when estimating the noise background, by including a log fit criterion. The median smoothing insures the peaks (associated with regular cycles) are insensitive to the noise background (Mann and Lees, 1996). Preliminary spectra for $L^{*}$ colour reflectance indicate low power in low (red) frequencies, and therefore, this red noise model may overestimate noise in the low frequencies for colour reflectance spectra. The confidence levels chosen were $90 \%$ and $95 \%$. All parameters in the SSA-MTM Toolkit 4.1 were set to default, except a predefined smoothing window width of $0.01 \mathrm{kyr}^{-1}$.

Potential drawbacks include the requirement to interpolate to an even sample spacing which leads to lower resolution in the spectral domain - i.e. sharp features are commonly considerably smoothed (Paillard et al, 1996). Interpolation can result in an underestimation of high-frequency components, independent of the interpolation technique, and needs to be considered when running spectral estimates. 


\section{Bivariate spectral analysis}

The SPECTRUM program, designed by Schulz and Stattegger in 1997, utilises the Lomb-Scargle method for spectral analysis which allows for unevenly spaced data in the time domain. SPECTRUM offers harmonic analysis, univariate and crossspectral (or bivariate) analysis, which allows for the analysis of coherency and phase between two time series for the same time interval.

The Lomb-Scargle method (Scargle, 1982) does not require an evenly spaced dataset, and evaluates the data of the time series only at times that are actually measured (Trauth, 2007). The resulting periodiogram is identical to a least-squares fit of sine and cosine functions of the time-series (Lomb, 1976; Scargle, 1982). An exponential probability distribution with unit mean allows for the calculation of the probability that a given peak is not significant (Trauth, 2007), providing a false-alarm level.

Parameters used for cross-spectral analysis in SPECTRUM version 2.2 (Schulz, and Stattegger, 1997) were an oversampling factor (OFAC) of five, and three overlapping segments or windows. Welch was the chosen method for windowing, while linear trends were removed from the dataset. A confidence level of $80 \%$ was chosen and vertical error bars are plotted only for peaks of significance which plot above the false alarm level (Schulz and Stattegger, 1997).

The Welch method of windowing is the division of time-series into overlapping subsections of equal lengths, for which the spectra of each subsection is averaged. The Barlett Method however, uses subsections that are consecutive, rather than overlapping (Weedon, 2003). The Welch method is considered to produce better 'quality' spectra compared to the Bartlett method because it reduces spectral leakage, that is the spread of frequencies due to the 'whole' cycle not consistently sampled (Weedon, 2003). 


\section{Chapter 4 Results}

\subsection{Facies Analysis and Physical Properties}

Facies assigned by the ship-board scientific party of IODP Expedition 318, are defined by colour, lithology, biological content, sedimentary structures and degree of bioturbation. In this section, changes in the physical properties are correlated to changes in the lithology and biological content in order to later identify potential sedimentary processes operating at the Wilkes Land margin, and how the signal of these processes may be manifested in the physical properties.

\subsubsection{Facies Analysis}

Five facies were identified in U1361A, and two lithostratigraphic units were defined by the facies distribution (Table 4.1; Figure 4.1). Facies A is diatom-rich, yellowish brown clay with mottling interpreted as bioturbation. Facies B is diatom-bearing, greenish grey silty clay, with infrequent sets of horizontal laminae and rare foraminifera-rich beds. Facies $\mathrm{D}$ is a diatom-bearing to diatom-rich, light greenish grey silty clay with common bioturbation and dispersed gravels. Facies $\mathrm{E}$ is olive grey laminated clay, with rare bioturbation and gravel-sized clasts (Figure 4.2).

Unit I displays alternations between bioturbated diatom-rich clay (Facies A; with occasional occurrences of the foraminifera-bearing clay) and silty clay (Facies B), in the upper 34.9 meters below sea floor (mbsf; Figure 4.1). Bioturbated silty clays with variable diatom content (Facies D) and laminated clay (Facies E) defines Unit IIa (313.2-34.9 mbsf). Unit IIb (388-313.2mbsf), not analysed in this study due to pervasive drilling disturbance, is dominated by the presence of nannofossil-rich clays and nannofossil oozes (Facies C; Figure 4.1).

Initial interpretations of Unit I by the Shipboard Scientific Party of IODP EXP 318, is that of pelagic/hemipelagic settling (bioturbated diatom-rich clays; Facies A) with 
episodic over bank flow of low density turbidity currents or saline density currents (silty clays; Facies B), however reworking by contour currents is also plausible (Escutia et al., 2007). Unit IIa contains interbedded silty clay and clay indicating regular alternations between hemipelagic settling and current deposition. Differences in bioturbation between the laminated clay (Facies E) and silty clay (Facies D), suggest changes in background terrigenous sediment supply or changes in bottom water oxygenation (Escutia et al., 2007). The higher concentration of gravel-sized clasts in the diatom-bearing Facies D may indicate either a decrease in background sediment supply or increase in iceberg calving/rafting coincident with increased productivity in the waters overlying the site.

Table 4.1. Generalised descriptions for facies observed in U1361A.

\section{Description}

\begin{tabular}{ll}
\hline Facies A & Diatom-rich clay \\
\hline Facies B & Diatom-bearing silty clay \\
\hline Facies C & Nannofossil ooze \\
Facies D & Diatom-bearing to diatom-rich silty clay \\
Facies E & Laminated clay \\
\hline
\end{tabular}




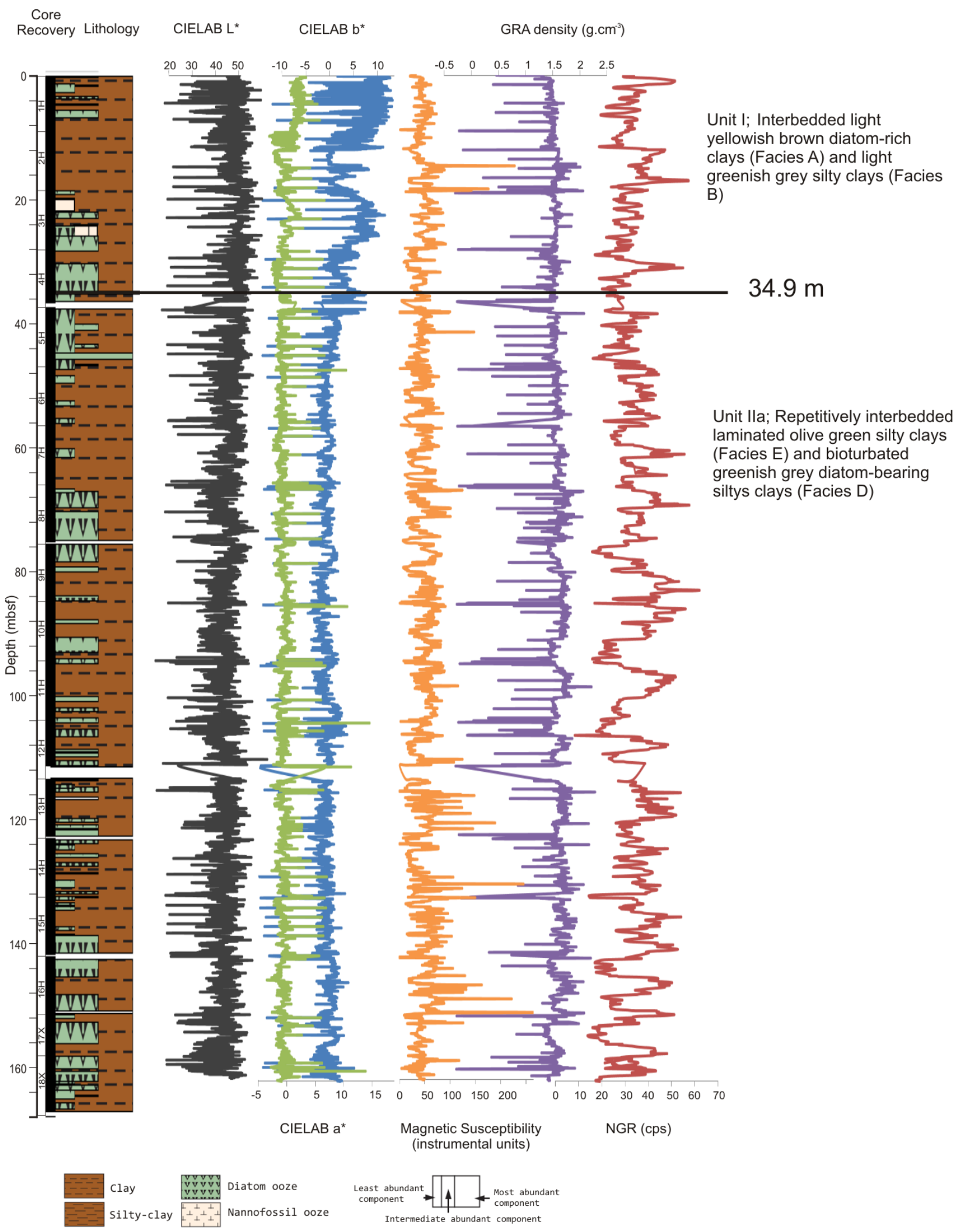

Figure 4.1. U1361A core summary including core recovery, facies log and raw physical properties showing the unit boundary (modified from Expedition 318 Scientists, 2010). 

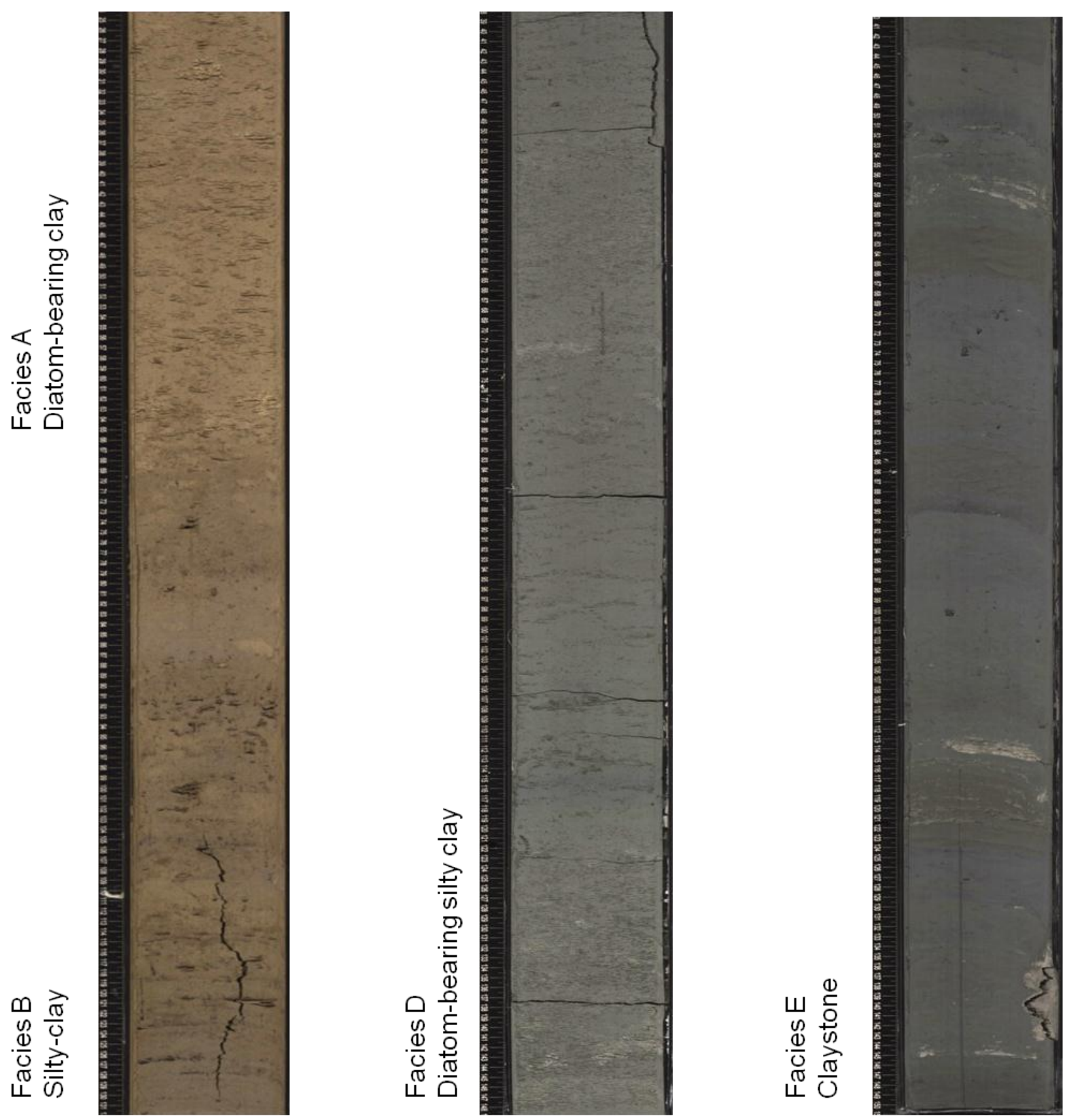

Figure 4.2. Core images illustrating facies A and B (0.25-1.3 mbsf), D (91.4-92.5) and E (96.4-97.5) in core U1361A (Expedition 318 Scientist, 2010).

\subsubsection{Physical Properties}

Gamma-ray attenuated bulk density (GRA), magnetic susceptibility (MS), natural gamma ray $(\mathrm{NGR})$ and $\mathrm{L}^{*}$ colour reflectance $\left(\mathrm{L}^{*}\right)$ provide a high-resolution record of lithological changes within the core. Colour reflectance parameters $\mathrm{a}^{*}$ (red to green 
axis) and b* (yellow to blue axis) are not used in this study after initial observations and preliminary spectral analysis have shown that large wavelength cyclicity in these records swamp lower orbital frequencies (obliquity and precession).

Observable relationships between the physical property logs and individual facies can be used to indicate sediment changes that are not always identified in the visual core description logs (Expedition 318 Scientists, 2010; Figure 4.3; Table 4.2). GRA, a combined record of lithology (grain density, dominant mineralogy) and porosity, shows relatively lower values in the presence of diatomaceous facies and relatively higher values associated with well compacted clays and higher grain density silty clays (Figure 4.3). Facies with higher magnetic susceptibility values contain a high content of terrigenous sourced clays, while in the presence of diatomaceous sediments MS values are low to negative. NGR emissions are higher in minerals containing uranium, thorium and potassium, commonly found in clay minerals; relative clay mineral content therefore influences NGR values (Figure 4.3). L* colour reflectance values $\left(L^{*}=0\right.$ indicates black and $L^{*}=100$ indicates diffuse white) do not show a consistent relationship to facies variations throughout the entire core, especially where lithologic changes are more subtle. However, $L^{*}$ fluctuates extensively within lithologies, recording changes that aren't always apparent in the other physical property logs (Figure 4.3).

To summarize, GRA, NGR and MS commonly show relatively low values in diatombearing to -rich facies (Facies A, C and D) and higher values in association with terrigenous sourced clays and silty clays (Facies B and E; Figure 4.3; Table 4.2). L* colour reflectance parameter is more variable, as diatom-bearing to rich-facies are not consistently light (or dark) relative to the surrounding facies throughout the core. However, it can be seen to correlate with closely with colour changes associated within laminae-rich intervals (Facies E).

An example of physical property logs providing a higher resolution dataset of lithological change is apparent in the core $1 \mathrm{H}$ of U1361A (Figure 4.5 Chapter 4.2), where high amplitude troughs in NGR and GRA correlate directly to diatom-rich 
clays (Facies A). Lower amplitude troughs in NGR and GRA values occur at 7.75$7.25 \mathrm{mbsf}$ and $8.50-8.25 \mathrm{mbsf}$, yet these troughs coincide with a lithology where the diatom content (as identified in smear slides) is below the threshold to be classified as diatom-bearing silty clay in the visual core descriptions. However, based on the previously observed relationships this trough is interpreted as representing a relative increase in diatom content compared to the lithologies directly above and below. Due to the low-resolution nature of smear slide sampling (spacing was $>1 \mathrm{~m}$ ) and the threshold nature of defining a diatom-bearing/rich facies it is expected that higher frequency, but lower amplitude, variations in diatom content would occur in the core that were not recognised in the visual core description.

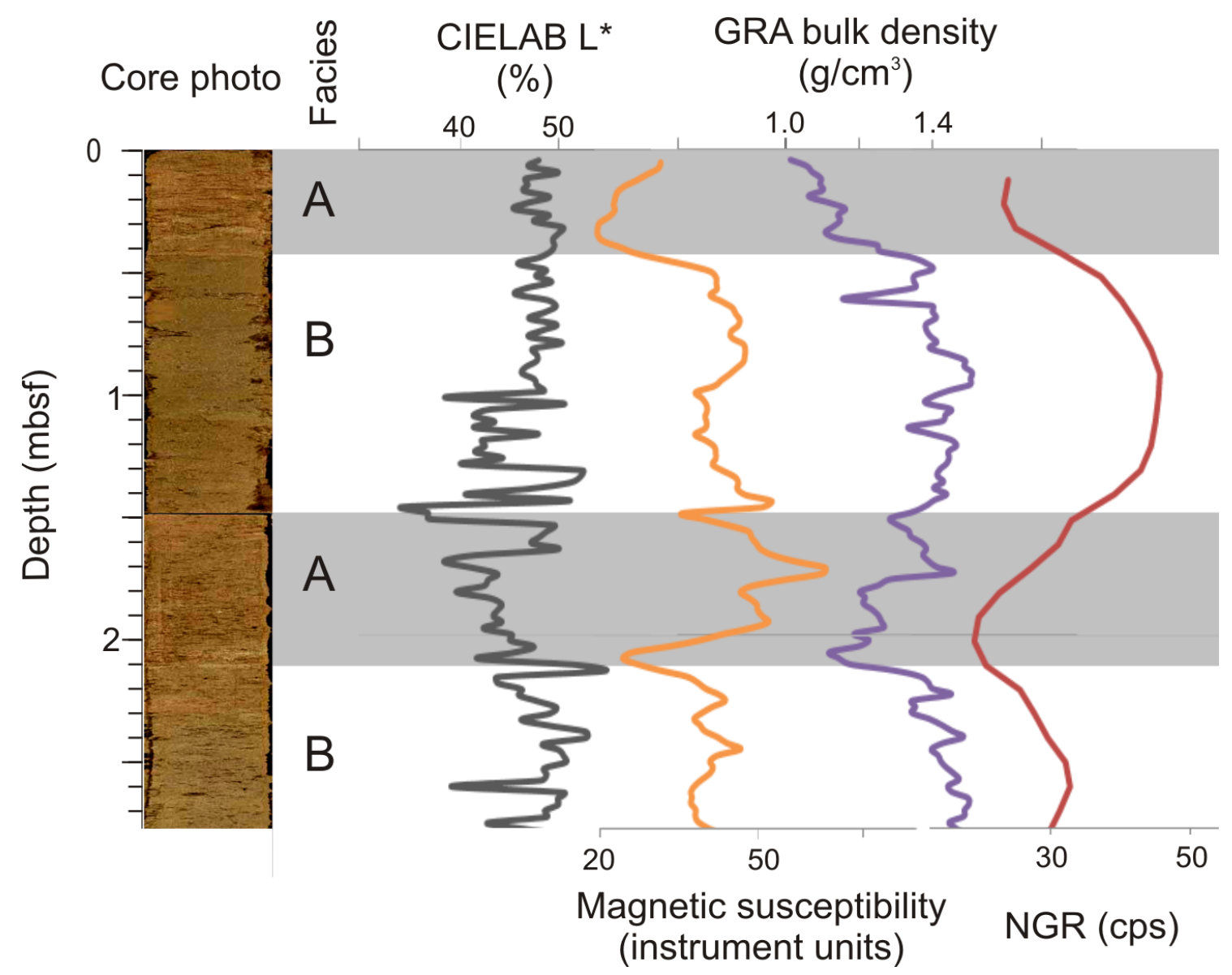

Figure 4.3. An example of facies and physical property response for the upper $2.5 \mathrm{~m}$ of U1361A. Note the simultaneous decrease in NGR, GRA and MS in response to the increase in biogenic component at the boundary of Facies B to Facies A. 
Table 4.2. Relative values for physical property logs associated with facies scheme for U1361.

\begin{tabular}{lllll}
\hline & L* & MS & GRA & NGR \\
\hline Facies A (diatom rich clay) & $\sim$ Low & Low & Low & Low \\
Facies B (silty clay) & $\sim$ High & High & High & High \\
Facies D (diatomaceous silty clay) & $\sim$ High & Low & Low & Low \\
Facies E (laminated clay) & $\sim$ Low & High & High & High \\
\hline
\end{tabular}

Cross spectral analysis of the physical property logs (GRA density, MS, NGR and L* colour reflectance) was conducted on the 3-0 Ma interval of the U1361A core. The length of interval was chosen due to the maximum dataset able to be processed by the SPECTRUM V2.2 program (Shulz and Stategger, 1997). It is, however, presumed that the relationship between the physical property logs and lithology would be maintained throughout the core, taking into consideration increased compaction downcore. Diagenesis effects are likely to be comparable between facies. The results indicate coherency ( $>80 \%$ confidence level) between different physical property logs within the orbital frequency range (Figure 4.4).

Coherency spectrum for GRA density and NGR had the highest coherency at all frequencies. This was expected as the relationship is clearly defined in visual observations (Figure 4.3). The poor coherency of GRA density and NGR with L* colour reflectance indicates that the primary controls GRA density and NGR are different to the $\mathrm{L}^{*}$ colour reflectance proxy for colour change (Figure 4.4). GRA, NGR and $L^{*}$ all have coherency with MS at precession and obliquity frequencies (Table 4.3). The coherency spectra indicate that GRA density and NGR are both responding to the same changes in lithology, while MS responds to only some of the same changes. High frequency changes in $L^{*}$ colour reflectance are also recorded by GRA density and NGR, but primarily, $L^{*}$ colour reflectance does not respond to the lower frequency changes recorded by the other physical properties. 

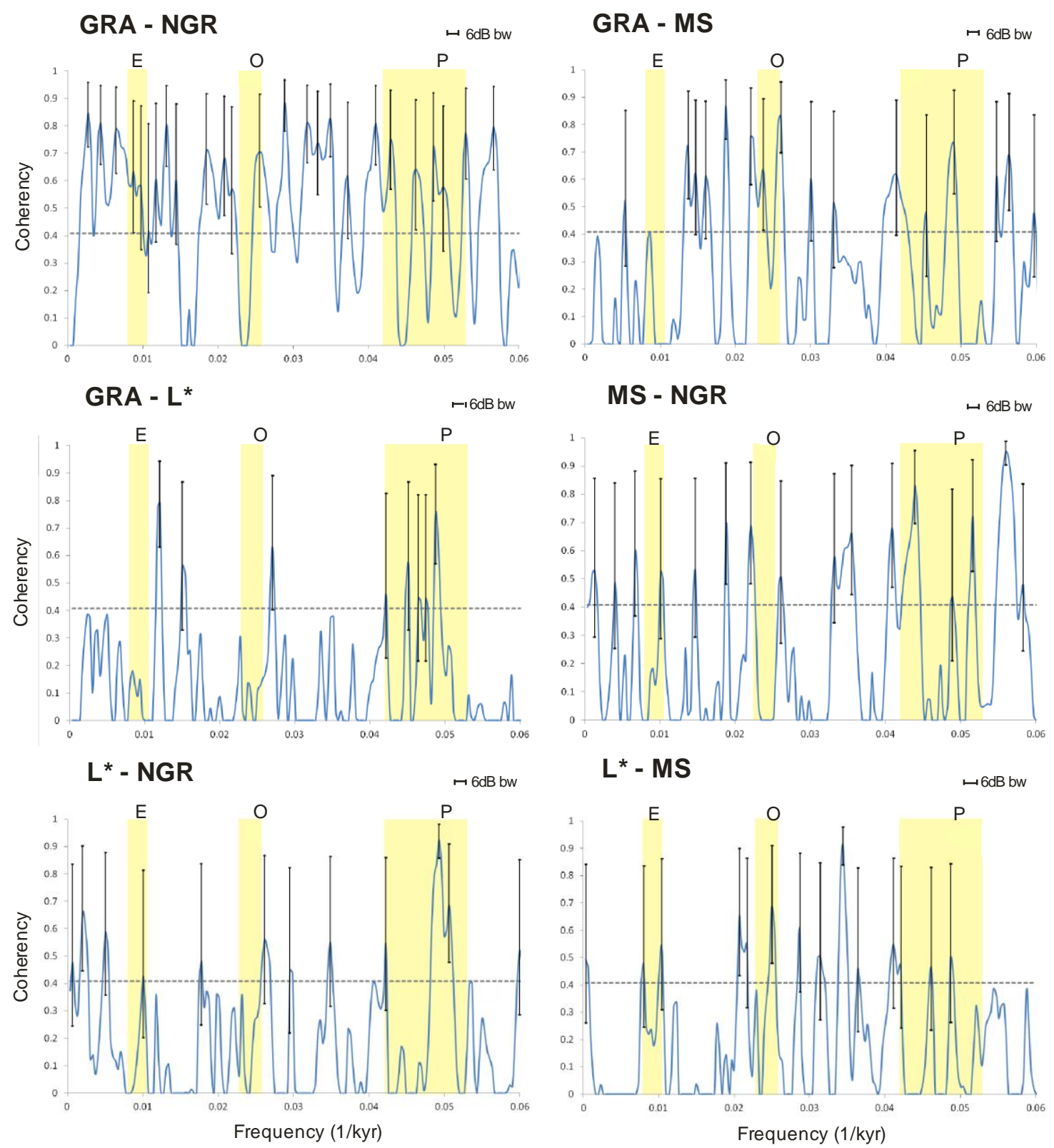

Figure 4.4. Coherency spectra for 3- $0 \mathrm{Ma}$ of the physical property logs. Peaks are considered significant when they (and the associated vertical error) extend above the false alarm level (dashed grey line). The pale yellow bands represent orbital frequencies eccentricity (E: 125-90 kyr; 0.008-0.0105 kyr ${ }^{-1}$ ), obliquity (O: 38.5-43.5 kyr; 0.024-0.025 kyr ${ }^{-1}$ ) and precession ( $\mathrm{P}: 24-19 \mathrm{kyr} ; 0.042-0.053 \mathrm{kyr}^{-1}$ ). The $6 \mathrm{~dB}$ bandwidth (horizontal error) is shown in the upper left corner in each plot.

Table 4.3. Orbital frequencies at which physical properties are significantly coherent.

\begin{tabular}{llll}
\hline & NGR & $\begin{array}{l}\text { Magnetic } \\
\text { Susceptibility }\end{array}$ & L $^{*}$ \\
\hline GRA density & $\begin{array}{l}\text { Eccentricity, obliquity } \\
\text { and precession }\end{array}$ & Obliquity and precession & Precession \\
NGR & -- & Obliquity and precession & Precession \\
Magnetic & -- & -- & Obliquity \\
Susceptibility & & & \\
\hline
\end{tabular}




\subsection{Spectral Analysis}

Using the integrated facies and physical properties classification scheme outlined in the previous section, it is proposed that cyclicity at Milankovitch frequencies can be directly correlated to glacial-interglacial cycles. The observed cycles in the physical properties, were matched one-to-one to corresponding Marine Isotope Stages (MIS) in the benthic $\delta^{18} \mathrm{O}$ stack using the established magnetostratigraphy as an age constraint (Tauxe et al., 2102). Independent of this, physical property logs, processed for noise but unturned, were subjected to spectral analysis to evaluate the presence of Milankovitch scale orbital cycles. The range of frequencies that classify Milankovitch orbital cycles will be reported as 400kyr (long eccentricity), $100 \mathrm{kyr}$ (short eccentricity of combined 90 and $120 \mathrm{kyr}$ frequencies), $40 \mathrm{kyr}$ (obliquity) and $\sim 20 \mathrm{kyr}$ (combined 19 and $23 \mathrm{kyr}$ precession frequencies). Reported bandwidths, and therefore spectral resolution, differ for each interval depending on the length of the interval analysed. Accurate spectral peaks should not vary at scales less than the full bandwidth (Huybers, 2003).

\section{Interval 1}

The upper $\sim 9 \mathrm{~m}$ of core from U1361A contains regular alternations between silty clays (Facies B) grading up into diatom-rich clays (Facies A; Figure 4.5). The core images reflect alternations between the lighter yellow coloured diatom-rich clays (Facies A) and green-grey silty clays (Facies B). Diatom-rich clays (Facies A) have mottling interpreted as bioturbation, however the sediments were too soft in this interval to determine the intensity of the bioturbation during shipboard description so it was not logged (Figure 4.5). A cluster of clasts (iceberg rafted debris) present at the base of diatom rich clay at 5.2-5.0 meters below sea floor (mbsf), is noted in the core image. Laminations are more common towards the base of the core ( $>7 \mathrm{mbsf})$.

As discussed in the previous section, the diatom-rich facies are associated with low natural gamma ray (NGR), gamma ray attenuation density (GRA) and magnetic susceptibility (MS) values. The base of the diatom-rich clays (Facies A) commonly 
correlates with the beginning of an NGR low, and maintains low values throughout this facies. GRA displays relatively low values through the duration of Facies A with some variability. The minimum of NGR and GRA values are located in the lower half of the diatom-rich Facies A. MS commonly shows an extreme low value at the beginning of the diatom-rich facies before returning to a higher average value of $\sim 50$ instrumental units; above $4.5 \mathrm{mbsf}$, MS has a lower overall average value. While $\mathrm{L}^{*}$ colour reflectance displays high variability, colour changes in the core images cannot always be directly correlated to peaks or troughs in the $\mathrm{L}^{*}$ colour reflectance curve. As discussed in the previous section NGR troughs at $\sim 7.75-7.25 \mathrm{mbsf}$ and $\sim 8.50-8.25$ mbsf are associated with GRA and MS troughs, and although these do not correspond to obvious diatom rich clay in the visual core descriptions, given the relationship above, it is likely that it does reflect an increase in diatom abundance.

Correlation to the benthic $\delta^{18} \mathrm{O}$ stack for this interval is limited by a large uncertainty in locating the Brunhes-Matuyama paleomagnetic boundary. However the diatom-rich clay (Facies A) at the core top is correlated to the Holocene interglacial MIS 1 and subsequent diatom-rich clays have been matched to each successively older interglacial. MIS 11, 9 and 5 appear to be represented by thicker diatom-rich clays, with a higher diatom content as indicated by lower NGR values, compared to the other diatom-bearing/rich clays within this interval.

The physical properties from this interval (9-0 mbsf) have been interpolated (following the procedure outlined in the methods section) to an age range of 0.49-0 $\mathrm{Ma}$, which slightly underestimates the age in reference to the visual correlations made above. Statistically significant peaks ( $>90 \%$ confidence), identified in univariate spectral analysis for the physical properties are as follows: 1) L* colour reflectance displays significant power in $\sim 20 \mathrm{kyr}$ and $\sim 26 \mathrm{kyr}$ periods; 2) MS also contains $\sim 20 \mathrm{kyr}$ and $\sim 26 \mathrm{kyr}$ periodicity, while variance at $\sim 50 \mathrm{kyr}\left(0.02 \mathrm{kyr}^{-1}\right)$ fluctuates at a lower scale frequency than the bandwidth and thus, is considered insignificant. 


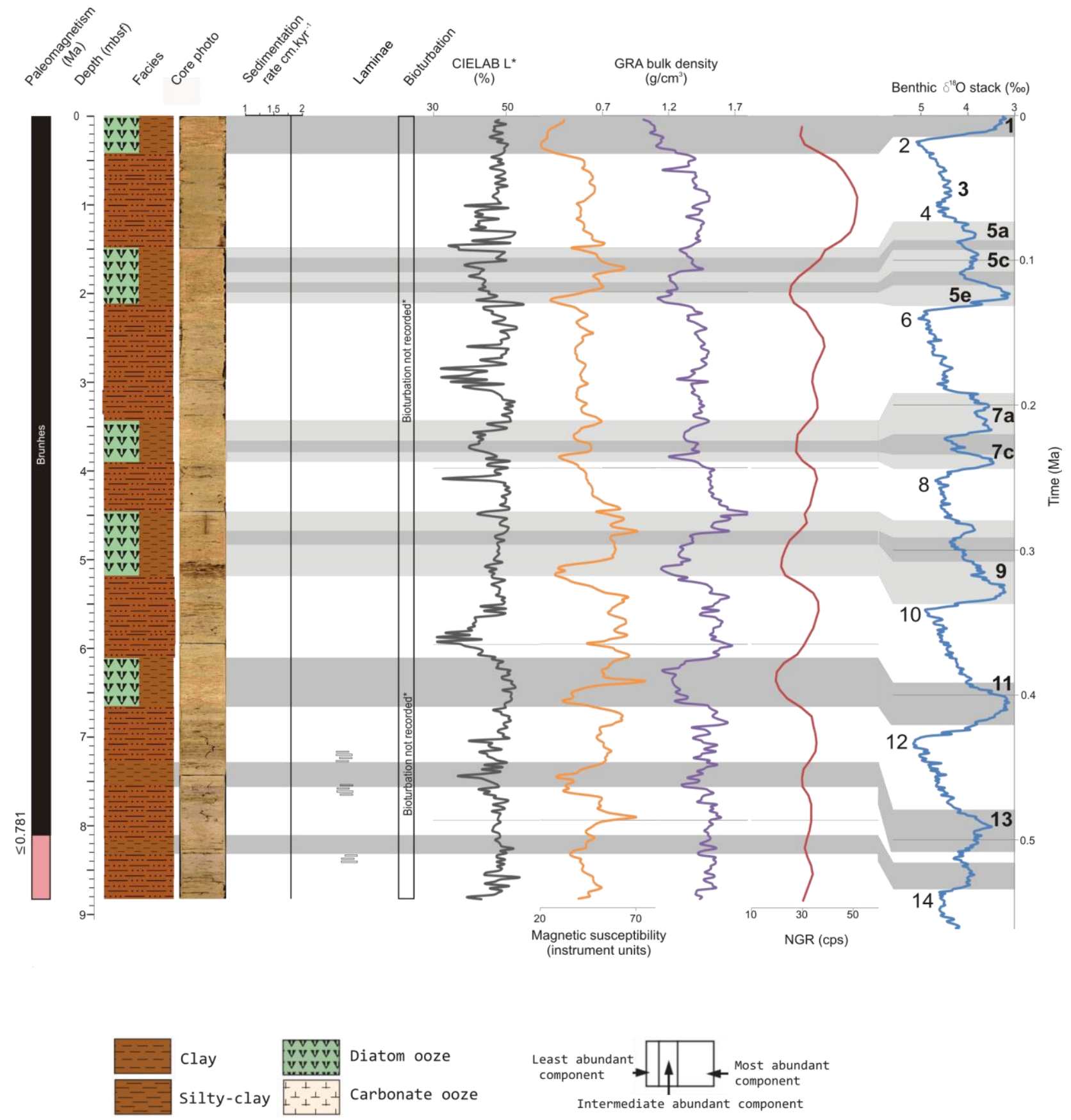

Figure 4.5. U1361A core correlation for Interval 1, of facies and physical properties logs ( $L^{*}, \mathrm{MS}$, GRA and NGR) to the benthic $\delta^{18} \mathrm{O}$ stack (Lisiecki and Raymo, 2004). Marine isotope stages are labelled with interglacials in bold. Grey bands highlight NGR, GRA, MS troughs commonly associated with diatomaceous facies and interpreted as interglacials in the benthic $\delta^{18} \mathrm{O}$ stack. Pink lines extending across the figure are paleomagnetic boundaries. If the boundary is associated with a large uncertainty in depth, they have been positioned to best fit with the physical properties data. The key located at the base of the figure identifies facies included in the five intervals, represented by a combination of clay, silty clay, diatom ooze and foraminifera-bearing silty clays. This caption applies to Figures 4.7, 4.9, 4.11, 4.14 and 4.16. 
3) A 100 kyr periodicity occurs in GRA and NGR spectra and is significant at the 99\% confidence interval; 4) GRA is the only physical property log to hold power in $\sim 40$ kyr (Figure 4.6; Table 4.4). The sharp MS fluctuations in response to the diatom-rich facies may be why a $\sim 100 \mathrm{kyr}$ periodicity is not recorded in the MS spectra, even though it occurs in spectra of GRA and NGR. Spectral analysis of the benthic isotope curve for the same time period, shows significant $\sim 100 \mathrm{kyr}$, obliquity and precession (Figure 4.6). Overestimation of red noise in $L^{*}$ spectra would indicate $100 \mathrm{kyr}$ and $\sim 55 \mathrm{kyr}\left(0.018 \mathrm{kyr}^{-1}\right)$ periods are significant.
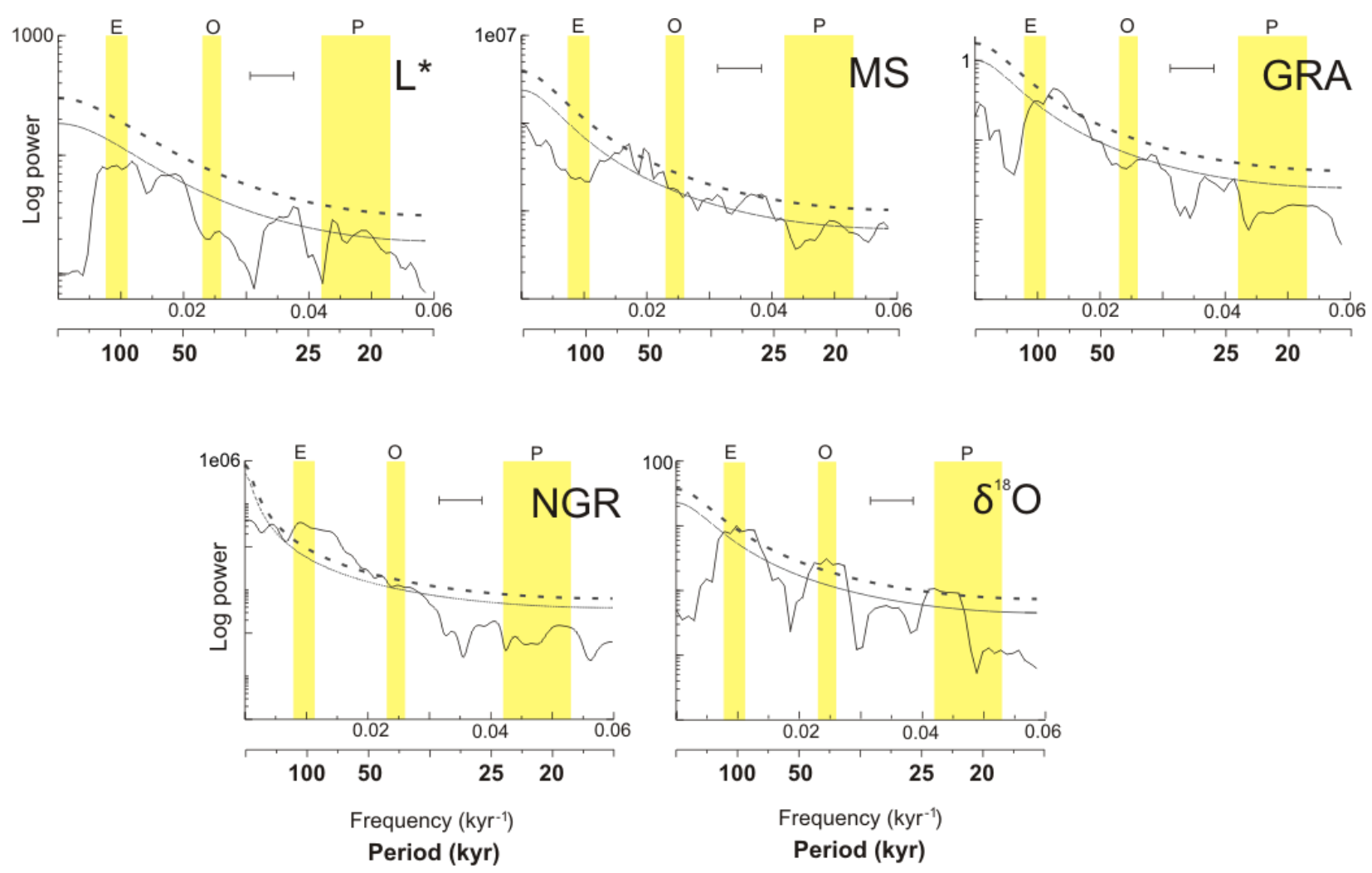

Figure 4.6. Spectral estimates for Interval 1 (0-9 mbsf) of physical property time-series ( $\left.L^{*}, \mathrm{MS}, \mathrm{GRA}, \mathrm{NGR}\right)$ and the Lisiecki and Raymo (2004) benthic $\delta^{18} \mathrm{O}$ record $\left({ }^{18} \mathrm{O}\right)$ using the Multi-taper Method outlined in the methods section. The pale yellow bands represent orbital frequencies eccentricity (E: 125-90 kyr; 0.008-0.011 kyr-1), obliquity (O: $38.5-43.5 \mathrm{kyr} ; 0.023-0.026 \mathrm{kyr}^{-1}$ ) and precession (P: 24-19 kyr; $0.042-0.053 \mathrm{kyr}^{-1}$ ). The confidence levels plotted are $99 \%$ (short dashed grey line) and $90 \%$ (grey line). The $6 \mathrm{~dB}$ bandwidth (horizontal uncertainty) is shown to the left of the graph title. This caption applies to figures $4.8 ; 4.10 ; 4.12 ; 4.13$ and 4.14.

Table 4.4; Significant orbital frequencies identified in spectral analysis for Interval 1, peaks exceeding the 99\% confidence level are underlined.

\begin{tabular}{llllll}
\hline $0.49-0 \mathrm{Ma}$ & $\mathrm{L}^{*}$ & MS & GRA & NGR & $\delta^{18} \mathrm{O}$ \\
\hline $\begin{array}{l}\text { Significant } \\
\text { Frequencies }\end{array}$ & Precession & Precession & $\begin{array}{l}\text { Obliquity } \\
\text { and } \\
\text { eccentricity }\end{array}$ & Eccentricity & $\begin{array}{l}\text { Precession, } \\
\text { obliquity and } \\
\text { eccentricity }\end{array}$ \\
\hline
\end{tabular}




\section{Interval 2}

Interval 2 covers the depth range 36.5 to $18.5 \mathrm{mbsf}$ and consists of alternations between diatom-rich clay (Facies A), silty clay (Facies B) and foraminifera-bearing silty clays. These bioturbated foraminifera-bearing facies were originally assigned to be a subdivision within Facies B (massive silty clay) in the initial shipboard interpretation (Expedition 318 Scientists, 2010), but a subsequent high-resolution description of this core interval in July 2011 indicates that the foraminifera-bearing beds occur within intensely bioturbated intervals and are associated with increased diatom abundance, suggesting they are more closely associated with Facies A (bioturbated diatom-rich clay; Rob McKay, personal communication).

Cyclicity in this interval is less clearly defined by lithologic variation and laminations are sporadic, typically occurring in facies with a higher biogenic content (Figure 4.7). Intense bioturbation is present in the bottom half of the interval, and is sometimes associated with a darkening of colour, apparent in the core images from 26.5 mbsf. Although visual core descriptions for this interval indicate limited cyclicity in the lithofacies, this is probably due to an increase in background diatom content in the core, raising most of the interval above the $10 \%$ threshold used to define diatom-bearing clay. Core images display cyclicity, which are further defined by variations in the physical properties. The relationships between NGR, GRA and MS are used to identify changes in biogenic content, and then matched one-to-one to interglacials in the benthic $\delta^{18} \mathrm{O}$ stack.

GRA varies at low amplitude through depths 25.7 to $22.7 \mathrm{mbsf}$ in association with the foraminifera-bearing silty clays, while MS maintains high amplitude cyclicity. NGR, GRA and MS troughs all show high correlation to colour changes within in the core images. This is associated with peaks in $\mathrm{L}^{*}$ colour reflectance, indicating lighter coloured material, relative to the surrounding material. 


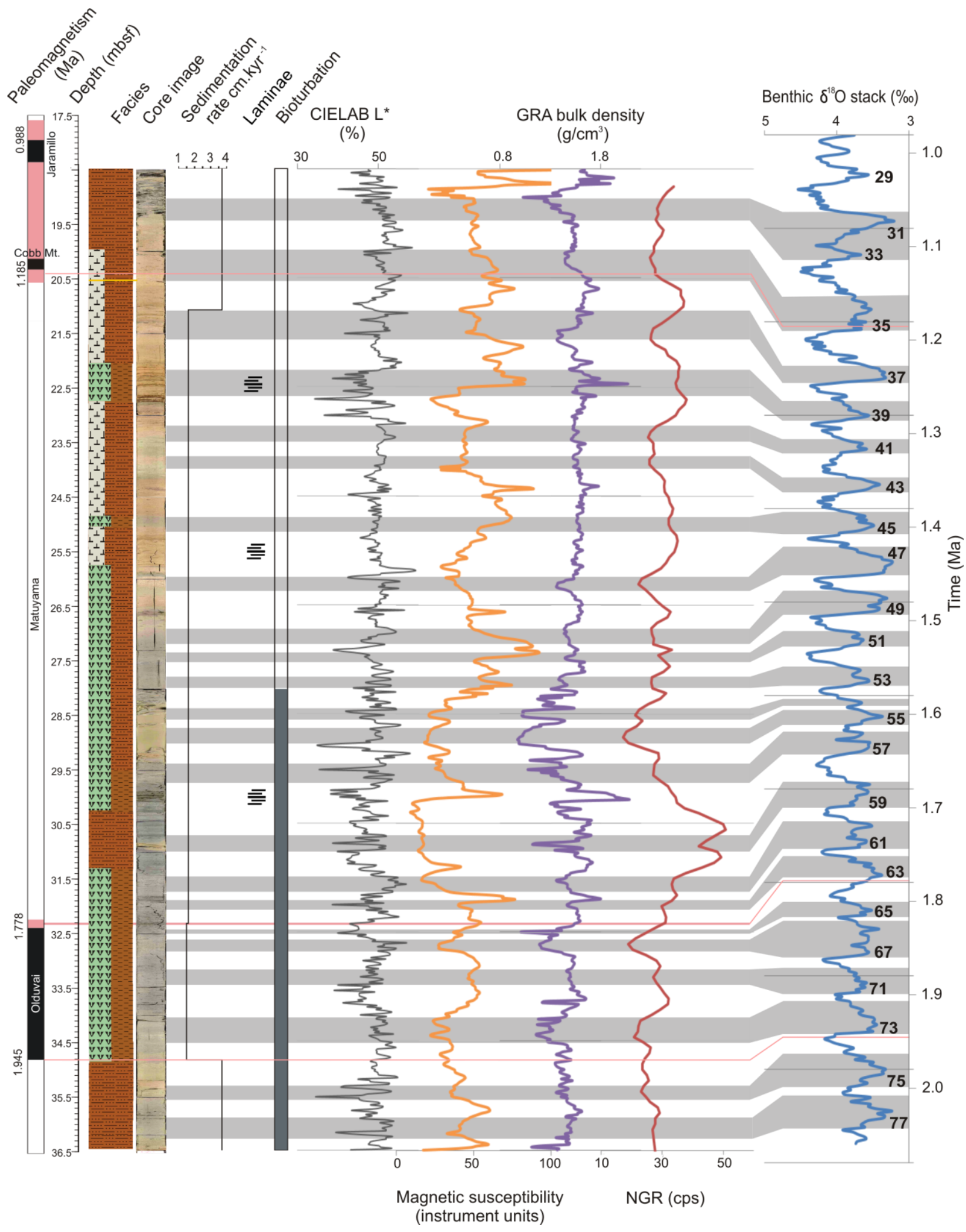

Figure 4.7. Core summary and correlations for Interval 2 (refer to Figure 4.5 caption). Note that although the foraminifera-bearing interval results in a relatively muted signal in the NGR and GRA physical properties, in comparison to the following of the Pliocene interval in U1361A, subtle variations can still be matched without requiring dramatic variations in sedimentation rate. 
Spectral analysis of the physical properties for the period 2-1 Ma all show power at the $\sim 40$ kyr period exceeding the 99\% confidence level (Table 4.5; Figure 4.8), which is consistent with the benthic $\delta^{18} \mathrm{O}$ stack for the same period. Spectra for $\mathrm{L}^{*}$ colour reflectance and GRA density hold statistically significant power at $\sim 23 \mathrm{kyr}$ precession (Figure 4.8). NGR also contains spectral peaks at $\sim 100 \mathrm{kyr}, \sim 55 \mathrm{kyr}$ $\left(0.018 \mathrm{kyr}^{-1}\right)$ and $\sim 30 \mathrm{kyr}\left(0.033 \mathrm{kyr}^{-1}\right.$; Figure 4.8$)$. Variance in the $\sim 100 \mathrm{kyr}$ and $\sim 20$ kyr band is lower in spectral estimates for the benthic $\delta^{18} \mathrm{O}$ stack during this time period, with these frequency bands only just exceeding the $90 \%$ confidence interval (Figure 4.8).
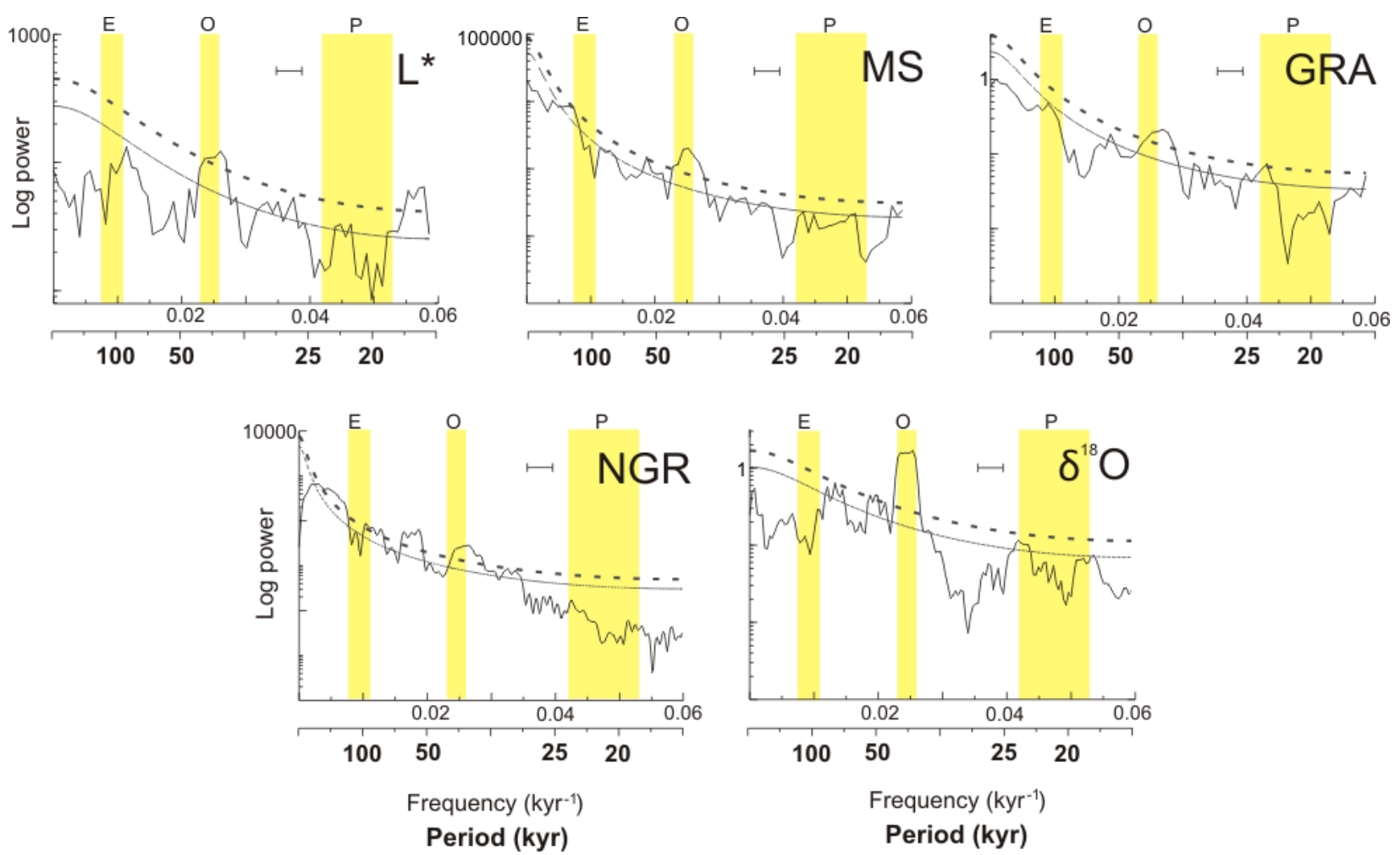

Figure 4.8. Univariate spectral analysis for Interval 2 (refer to Figure 4.6 caption). All physical properties show power at $\sim 40 \mathrm{kyr}$ frequencies at the $99 \%$ confidence interval.

Table 4.5. Significant orbital frequencies identified in spectral analysis for Interval 2, peaks exceeding the $99 \%$ confidence level are underlined.

\begin{tabular}{llllll}
\hline 2-1 Ma & L $^{*}$ & MS & GRA & NGR & $\delta^{18} \mathbf{O}$ \\
\hline $\begin{array}{l}\text { Significant } \\
\text { Frequencies }\end{array}$ & $\begin{array}{l}\text { Precession } \\
\text { and obliquity }\end{array}$ & Obliquity & $\begin{array}{l}\text { Precession } \\
\text { and obliquity }\end{array}$ & $\begin{array}{l}\text { Obliquity and } \\
\text { eccentricity }\end{array}$ & $\begin{array}{l}\text { Precession } \\
\text { and obliquity }\end{array}$ \\
\hline
\end{tabular}




\section{Interval 3}

Interval 3 (55.3-38.6 mbsf) contains a change from predominately bioturbated silty clay (Facies D) above 47 mbsf to laminated clay (Facies E) seen clearly in the core images by a shift from darker-greys to lighter-greys. This is associated with a decrease in the frequency of variations within $\mathrm{L}^{*}$ above $47 \mathrm{mbsf}$, a higher average value for GRA and NGR and a slightly lower variability in amplitude for MS (Figure 4.9). Moderate bioturbation is present throughout the whole interval and laminations are more common in the clay facies (>47 mbsf).

The physical properties for this interval show relatively clear cyclicity. The diatomrich silty clay and clay intervals, documented in the visual core descriptions coincide with high amplitude and stratigraphically extensive troughs in GRA, NGR and MS physical properties (Figure 4.9), while the lower amplitude variations likely represent more moderate variations in diatom abundance. Using the same relationships between facies and physical properties as the previous intervals, glacial-interglacial cycles in the benthic $\delta^{18} \mathrm{O}$ stack appear to match cycles within the physical property logs one-to-one based on the Gauss/Matuyama paleomagnetic boundary and correlation of the diatom-rich facies/high-amplitude NGR variations to MIS G5/109, 101-103, 95 and 81. These represent time periods $\sim 2.79-2.74,2.6$ $2.55, \sim 2.44-2.38$ and $\sim 2.09-2.15$, respectively, each separated by approximately 200 kyr.

Spectral estimates of the physical property logs do not have a high coherency with the benthic $\delta^{18} \mathrm{O}$ stack for this period (2.7-2.1 Ma) in comparison to the last two intervals, as obliquity is not as strongly represented in the physical property log spectra (Figure 4.10). An L* colour reflectance peak in the obliquity band only just exceeds statistical significance. 


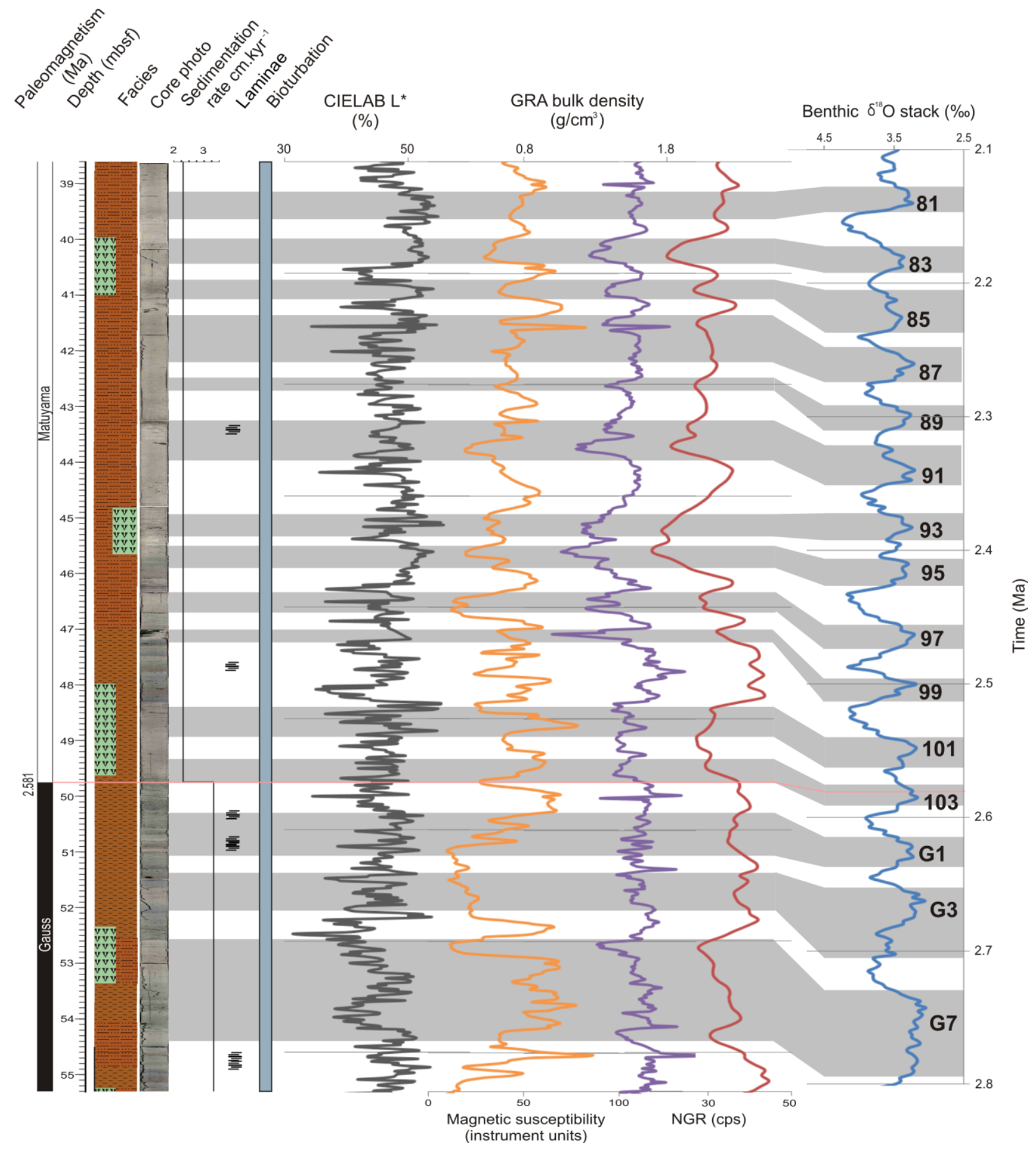

Figure 4.9. Core summary and correlation for Interval 3 (refer to Figure 4.5 caption). 
$\mathrm{L}^{*}, \mathrm{MS}$ and NGR contain significant peaks at the $\sim 25 \mathrm{kyr}$ frequency, which can be interpreted as precession within bandwidth. MS and NGR just reach the confidence level in the $\sim 100 \mathrm{kyr}$ band, coinciding with an increasing $100 \mathrm{kyr}$ power in the benthic $\delta^{18} \mathrm{O}$ stack relative to the 2-1 Ma period (Figure 4.10; Table 4.6). NGR, MS and to a higher degree $\mathrm{L}^{*}$, display above the $90 \%$ confidence level in the $\sim 30 \mathrm{kyr}$ band.
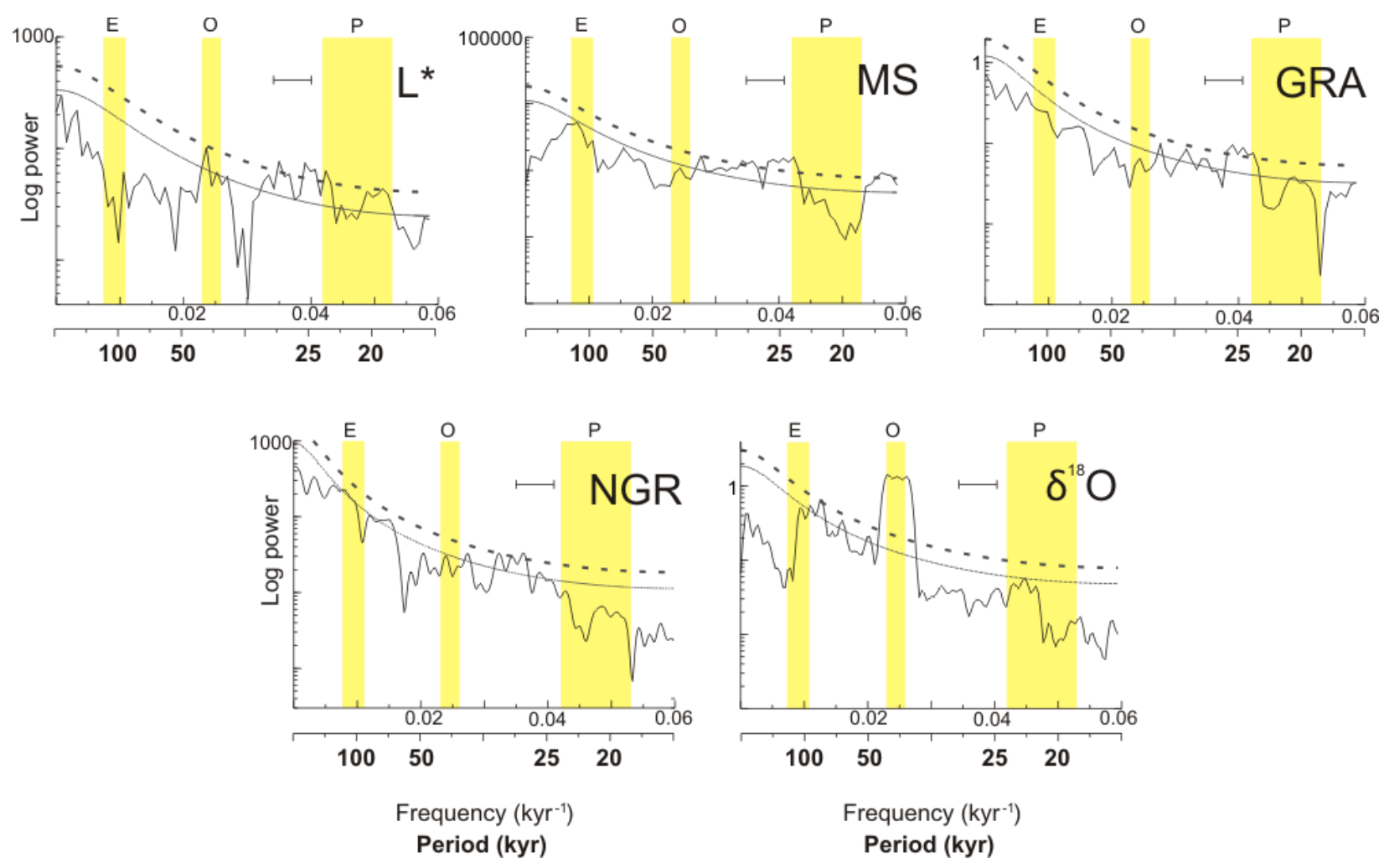

Figure 4.10. Univariate spectral analysis for Interval 3 (refer to Figure 4.6 caption).

Table 4.6. Significant orbital frequencies identified in spectral analysis for Interval 3. Peaks exceeding the 99\% confidence level are underlined.

\begin{tabular}{llllll}
\hline 2.7-2.1 Ma & L $^{*}$ & MS & GRA & NGR & $\delta^{18} \mathrm{O}$ \\
\hline $\begin{array}{l}\text { Significant } \\
\text { Frequencies }\end{array}$ & $\begin{array}{l}\text { Precession } \\
\text { and } \\
\text { obliquity }\end{array}$ & $\begin{array}{l}\text { Precession } \\
\text { and } \\
\text { eccentricity }\end{array}$ & $\underline{\text { Precession }}$ & Eccentricity & $\begin{array}{l}\text { Obliquity } \\
\text { and } \\
\text { eccentricity }\end{array}$ \\
\hline
\end{tabular}




\section{Interval 4}

Interval 4 is a $15.5 \mathrm{~m}$ long section $(72-56.5 \mathrm{mbsf})$, dominated by clay facies (Facies E) with occasional diatom-bearing silty clays (Facies D; Figure 4.11). The Kaena reversal (3.116-3.032 Ma; 66.7-64.6 mbsf) in this core is condensed, with a low sedimentation rate of $2.6 \mathrm{~cm} . \mathrm{kyr}^{-1}$ (relative to sections within this interval). The majority of the interval is moderately bioturbated. The core image shows high colour variability with light grey to dark greenish-grey $\mathrm{dm}^{-}$to $\mathrm{m}^{-}$scale scale interbedding present in both clay and silty clay facies. This colour variability was noted in the visual core description to represent subtle variations in diatom abundance within these beds, although not enough variation to exceed the $10 \%$ threshold on a regular basis (Expedition 318 Scientists, 2010). L*, MS and NGR show a high degree of coherency in this interval, with long wavelength cyclicity generally associated with changes of clay to silty clay, while GRA has low amplitude variability.

The benthic $\delta^{18} \mathrm{O}$ stack for the associated time period for this interval has much lower amplitude glacial-interglacial cycles in comparison to the previous time periods. The longer wavelength cycles in NGR and MS, and low amplitude GRA hinders correlation to the benthic $\delta^{18} \mathrm{O}$ stack. The complete Kaena reversal and top of the Mammoth reversal provide chronological constraints and tentative correlations to benthic $\delta^{18} \mathrm{O}$ stack were made with constraints provided by correlations of the previous core.

Spectral analysis of the physical properties for this interval holds very little power above the red noise level as the time period is short ( $500 \mathrm{kyrs}$ ), similar to the first interval, although the decreased amplitudes of the physical properties variations in this interval may also contribute to an increased noise-to-signal ratio, subduing spectral peaks. When Intervals 3 and 4 are combined, the spectral resolution increases and associated bandwidth decreases. Spectral power increases in

previously identified orbital frequencies precession and $\sim 100 \mathrm{kyr}$ in $\mathrm{L}^{*}$, MS and NGR (Table 4.7). Obliquity periodicity appears in $L^{*}$ and NGR, and a $\sim 100 \mathrm{kyr}$ frequency in the benthic $\delta^{18} \mathrm{O}$ stack (Figure 4.12; Table 4.7). The $80 \mathrm{kyr}$ peak 
identified in MS for Interval 4 appears as a $100 \mathrm{kyr}$ and $57 \mathrm{kyr}\left(0.0175 \mathrm{kyr}^{-1}\right)$ peak in the combined spectra (Figure 4.12).

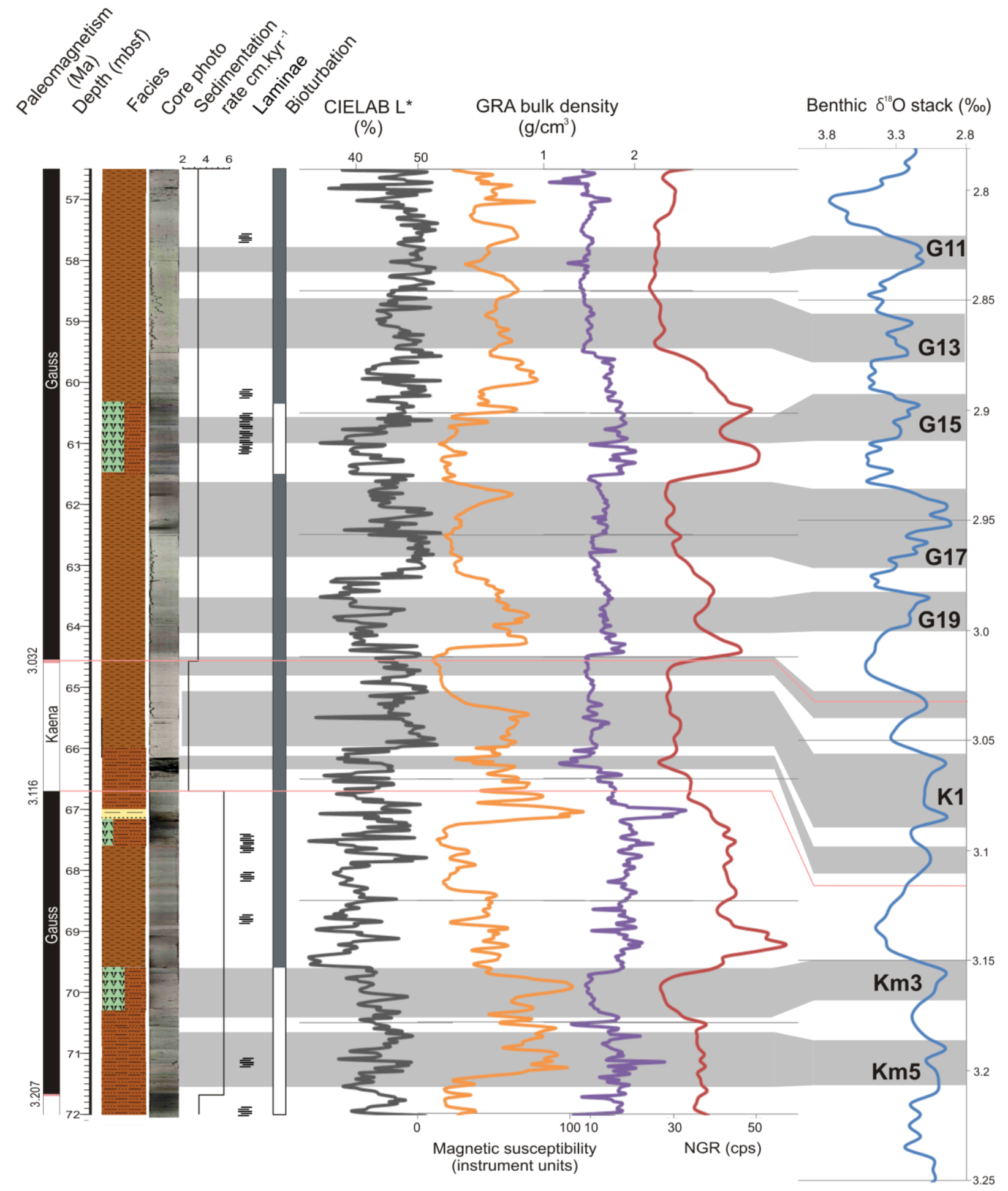

Figure 4.11. Core summary and correlations for Interval 4 (refer to Figure 4.5 caption). 

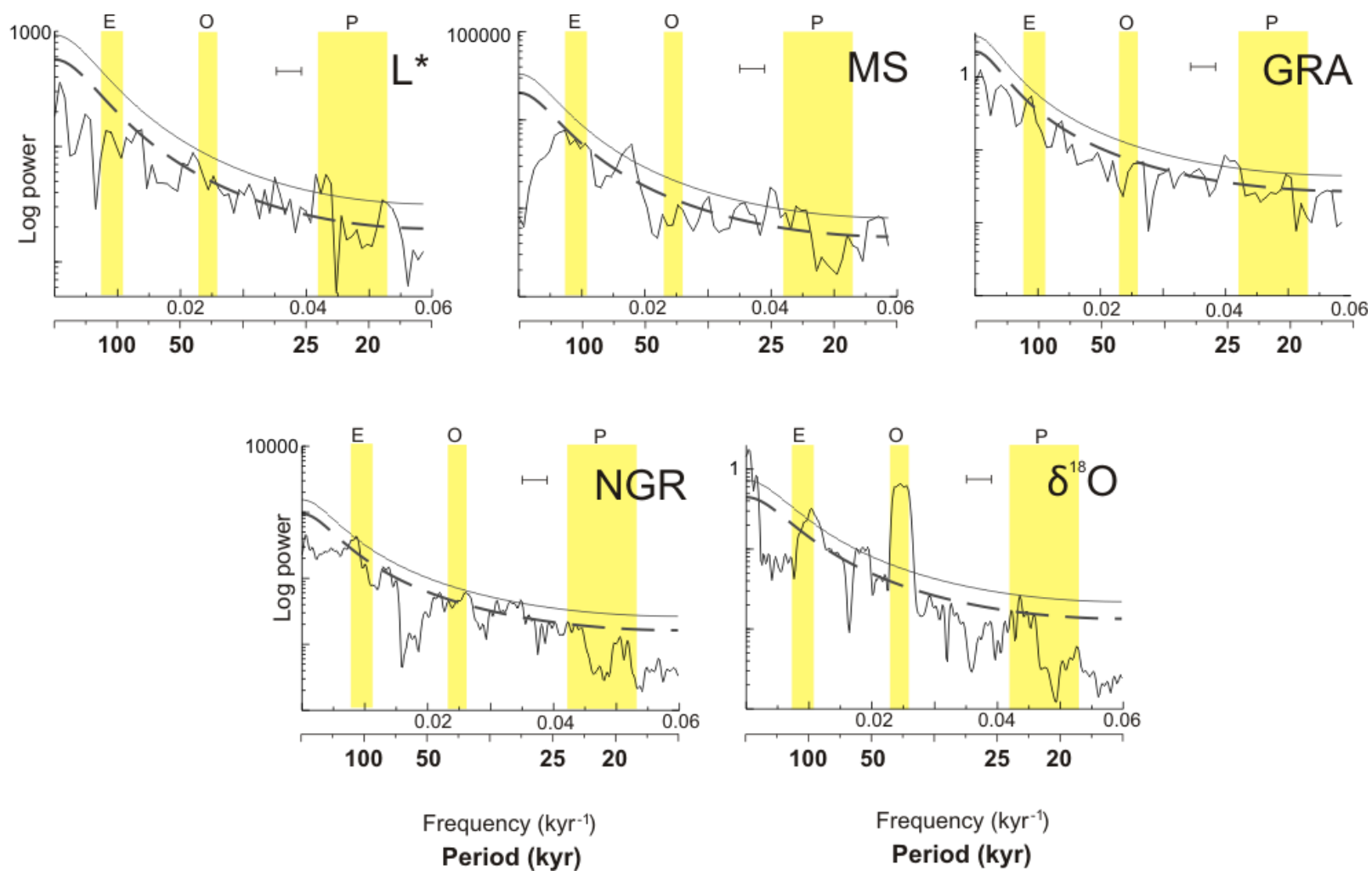

Figure 4.12. Univariate spectral analysis for Interval 3 and 4 (refer to Figure 4.6 caption).

Table 4.7. Significant orbital frequencies identified in spectral analysis for Interval 4 and for combined Intervals 3 and 4 . Peaks exceeding the $99 \%$ confidence level are underlined.

\begin{tabular}{|c|c|c|c|c|c|}
\hline $3.2-2.7 \mathrm{Ma}$ & $\mathrm{L}^{*}$ & MS & GRA & NGR & $\delta^{18} \mathrm{O}$ \\
\hline $\begin{array}{l}\text { Significant } \\
\text { Frequencies }\end{array}$ & $\begin{array}{l}\text { Precession, } \\
\text { obliquity and } \\
\text { eccentricity }\end{array}$ & $\begin{array}{l}\text { Precession } \\
\text { and } \\
80 \mathrm{kyr}\end{array}$ & & Eccentricity & Obliquity \\
\hline \multicolumn{6}{|l|}{$3.2-2.1 \mathrm{Ma}$} \\
\hline $\begin{array}{l}\text { Significant } \\
\text { Frequencies }\end{array}$ & $\begin{array}{l}\text { Precession, } \\
\text { obliquity and } \\
100 \mathrm{kyr}\end{array}$ & Precession & $\begin{array}{l}\text { Precession } \\
\text { and } \\
\text { eccentricity }\end{array}$ & $\begin{array}{l}\text { Precession, } \\
\text { obliquity and } \\
\text { eccentricity }\end{array}$ & $\begin{array}{l}\text { Obliquity } \\
\text { and } \\
\text { eccentricity }\end{array}$ \\
\hline
\end{tabular}




\section{Interval 5}

Interval 5 is a $24 \mathrm{~m}$ long record $(77-101 \mathrm{mbsf})$ spanning the time period $\sim 4.2-3.6 \mathrm{Ma}$ (Figure 4.13). This interval consists of interbedded laminated clay (Facies E) and diatom-rich silty clay (Facies D), with diatom-rich facies shown by a lighter grey colour in the core images. Light grey to dark grey $\mathrm{mm}^{-}$to $\mathrm{cm}^{-}$scale alternations are visible within the Facies E, likely representing silt laminations. Bioturbation is variable throughout the interval, but more commonly associated with diatom-rich facies.

NGR, GRA and MS all have significant troughs associated with the diatom-rich silty clays every $\sim 100 \mathrm{kyr}$ (Figure 4.13). GRA has low amplitude but still displays frequency variance in the laminated clay facies. MS displays high amplitude variations throughout the interval. Depleted values in NGR, GRA and MS in between $\sim 91-95$ mbsf are directly related to the diatom-rich silty clay facies. Above $\sim 91 \mathrm{mbsf}$, cyclicity in NGR and MS is more easily correlated to the $\sim 40 \mathrm{kyr}$ glacial cycles in the benthic $\delta^{18} \mathrm{O}$ stack. Below $95 \mathrm{mbsf}$, NGR and GRA values display a prolonged peak that is not recorded with any significance in MS values.

This interval is bound by the Gilbert-Cochiti (4.187 Ma) and Gauss-Gilbert (3.596 Ma) paleomagnetic boundaries and implies a linear sedimentation rate of 3.8 cm.kyr ${ }^{-1}$ (Figure 4.13). The amplitude of the benthic $\delta^{18} \mathrm{O}$ stack for this interval is relatively low in comparison to the upper $\sim 3 \mathrm{Ma}$. The relative amplitude and shape of glacial-interglacial cycles in the benthic $\delta^{18} \mathrm{O}$ stack compare well with fluctuations in the physical property curves and correlate throughout Interval 5. 


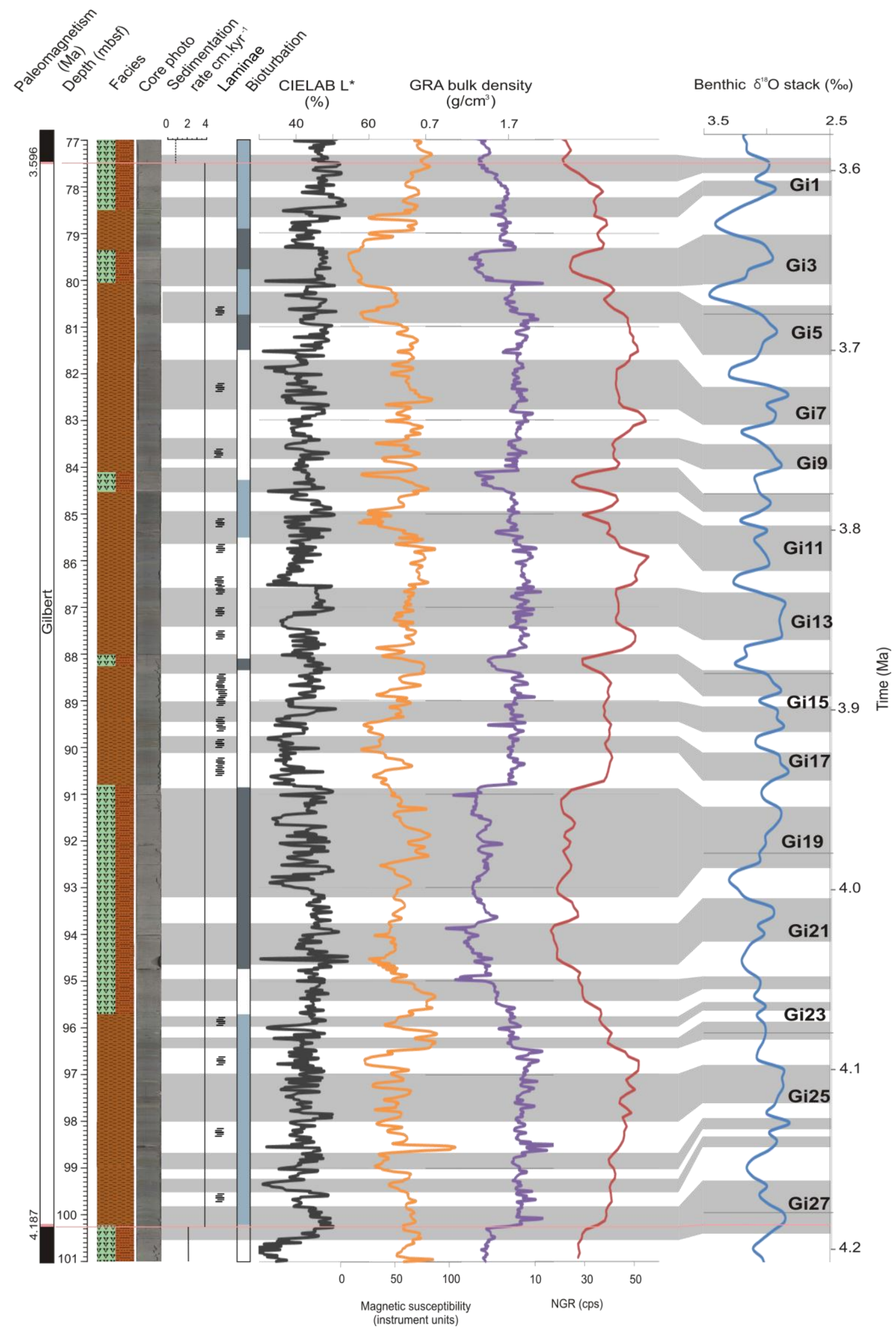

Figure 4.13. Core summary and correlations for Interval 5 (refer to Figure 4.5 caption). 
Spectral estimation of the physical properties time series for Interval 5, show an increase in power of the $\sim 40 \mathrm{kyr}$ band relative to the previous interval, most specifically in $L^{*}$ colour reflectance (within error) and NGR which are significant at the $90 \%$ confidence interval (Table 4.8; Figure 4.14). GRA and NGR are highly coherent, with the most significant peak at $25 \mathrm{kyr}$. MS shows a comparable peak at $\sim 27$ kyr. Spectra for all physical properties time series hold power in the precession band, within bandwidth error. However, spectra for the benthic $\delta^{18} \mathrm{O}$ stack does not show any statistically significant power at precession frequencies. Eccentricity is only significant in MS spectra. Power spectra for the benthic $\delta^{18} \mathrm{O}$ stack only holds significant power in the obliquity band, similar to the previous interval (3.2-2.7 Ma).
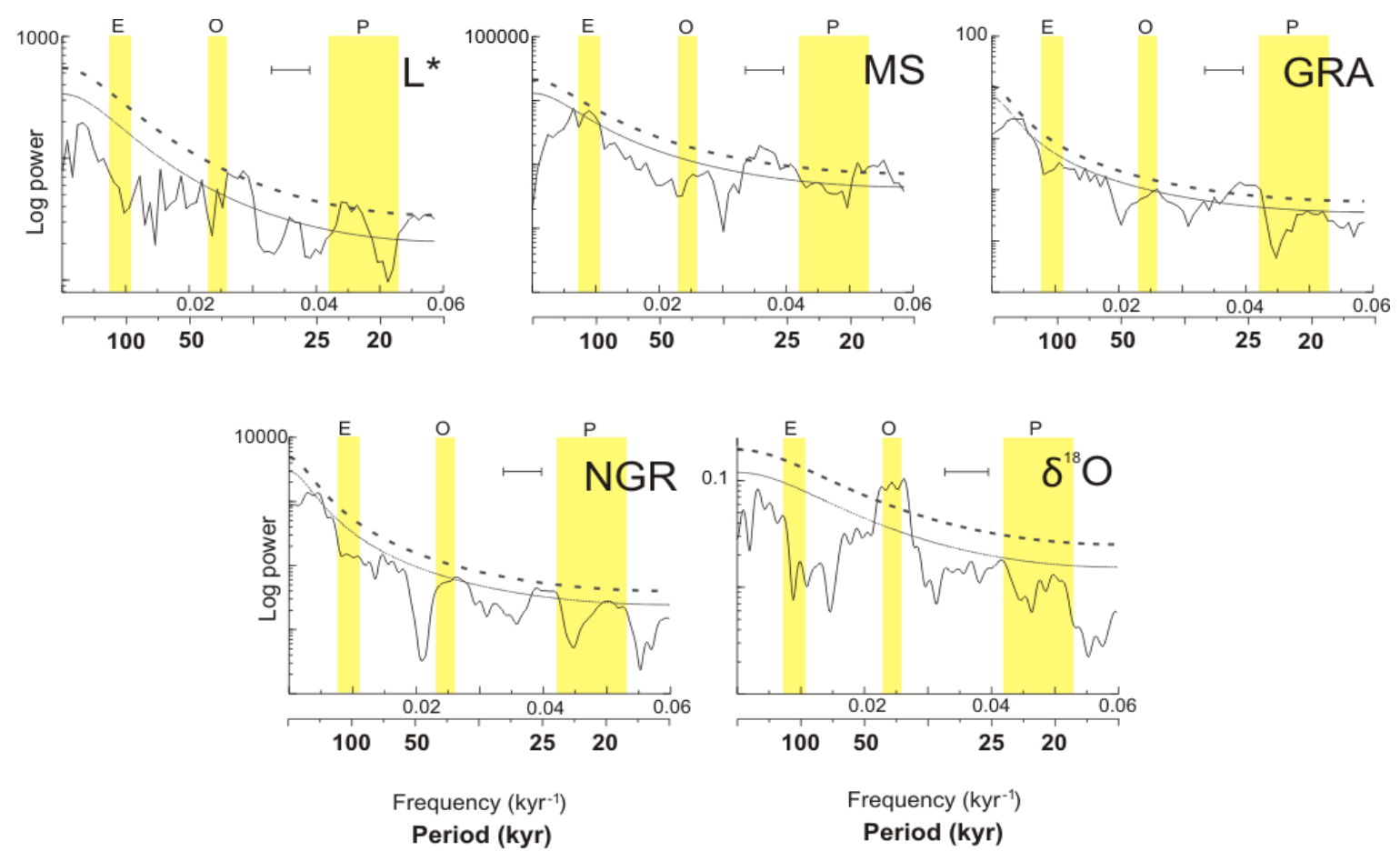

Figure 4.14. Univariate spectral analysis for Interval 5 (refer to Figure 4.6 caption).

Table 4.8. Significant orbital frequencies identified in spectral analysis for Interval 5. Peaks exceeding the 99\% confidence level are underlined.

\begin{tabular}{llllll}
\hline 4.2-3.6 Ma & L $^{*}$ & MS & GRA & NGR & $\delta^{18} \mathbf{O}$ \\
\hline $\begin{array}{l}\text { Significant } \\
\text { Frequencies }\end{array}$ & $\begin{array}{l}\text { Precession } \\
\text { and obliquity }\end{array}$ & $\begin{array}{l}\text { Precession } \\
\text { and }\end{array}$ & $\begin{array}{l}\text { Precession } \\
\text { eccentricity }\end{array}$ & $\begin{array}{l}\text { Precession } \\
\text { and obliquity }\end{array}$ & $\underline{\text { Obliquity }}$ \\
& & & & \\
\hline
\end{tabular}




\section{The Early Pliocene}

Core depth 70-80 mbsf, is the break between Intervals 4 and 5, which was initially excluded because it contains a half meter core break beginning at $\sim 75$ mbsf (Figure 4.15). For this reason, and the large depth error associated with the base of the Mammoth Subchron paleomagnetic boundary, time series analysis was not undertaken. However, as the interval spans the much studied Early Pliocene warm Period between 3.3-3 $\mathrm{Ma}$ and the preceding M2 glaciation (the first high-amplitude glacial excursion in the Pliocene), the relationship between facies and physical property logs in $\mathrm{U} 1361$ and the benthic $\delta^{18} \mathrm{O}$ stack is examined. The facies in this interval alternate between predominantly diatom-rich silty clay (Facies D) to laminated clay (Facies E). This is the first significant appearance of Facies E downcore, which becomes more dominant in Interval 5. Laminations occur in intervals of low diatom-abundance within both silty clay and clay facies.

The third normal polarity interval within the Gauss Chron (3.596 - 3.33 Ma), located between $77.5( \pm 0.02 \mathrm{~m})$ to $75.2( \pm 0.7 \mathrm{~m}) \mathrm{mbsf}$, is highly condensed, with a maximum linear sedimentation rate of $1.1 \mathrm{~cm} \cdot \mathrm{kyr}^{-1}$ and minimum of $0.86 \mathrm{~cm} \cdot \mathrm{kyr}^{-1}$. The base of the Mammoth Subchron (3.33 Ma) is interpolated to a depth of 73.84 mbsf based on

a linear interpolation of sediment rates from the top of the Mammoth Subchron to the top of the Gilbert Chron which are both well constrained.

Tentative correlations from the physical properties to the benthic $\delta^{18} \mathrm{O}$ stack have been made, taking into account the presence of the condensed section. Prior to the M2 glaciation at $\sim 3.3 \mathrm{Ma}$ (interpreted as a major advance of the Antarctic ice sheets; McKay et al., 2012), amplitude variations of the benthic $\delta^{18} \mathrm{O}$ stack are reduced. This is represented in the core as $\sim 3 \mathrm{~m}$ thick diatom-rich silty clay (Facies $\mathrm{D}$ ), as evinced by high amplitude decrease in NGR values (Figure 5.15). This interval of diatomrich silty clays within the Mammoth Subchron and third normal polarity interval of the Gauss Chron is difficult to correlate one-to-one to the benthic $\delta^{18} \mathrm{O}$ stack because of the low amplitude glacial-interglacial cycles. The M2, Gi2 and Gi4 glaciations are 
correlated to significant NGR peaks within clay facies (Facies E). The placement of the M2 glaciation within the clay facies at $\sim 74.8 \mathrm{mbsf}$, is within the uncertainty of the base of the Mammoth Subchron, however in making these correlations, a significant portion of time $(\sim 200 \mathrm{kyr})$ is related to $\sim 75-76 \mathrm{mbsf}$ of the core indicating a sedimentation rate of $0.5 \mathrm{~cm} . \mathrm{kyr}^{-1}$; there is a strong possibility that a hiatus, of no longer duration than $200 \mathrm{kyrs}$, is present within this interval.

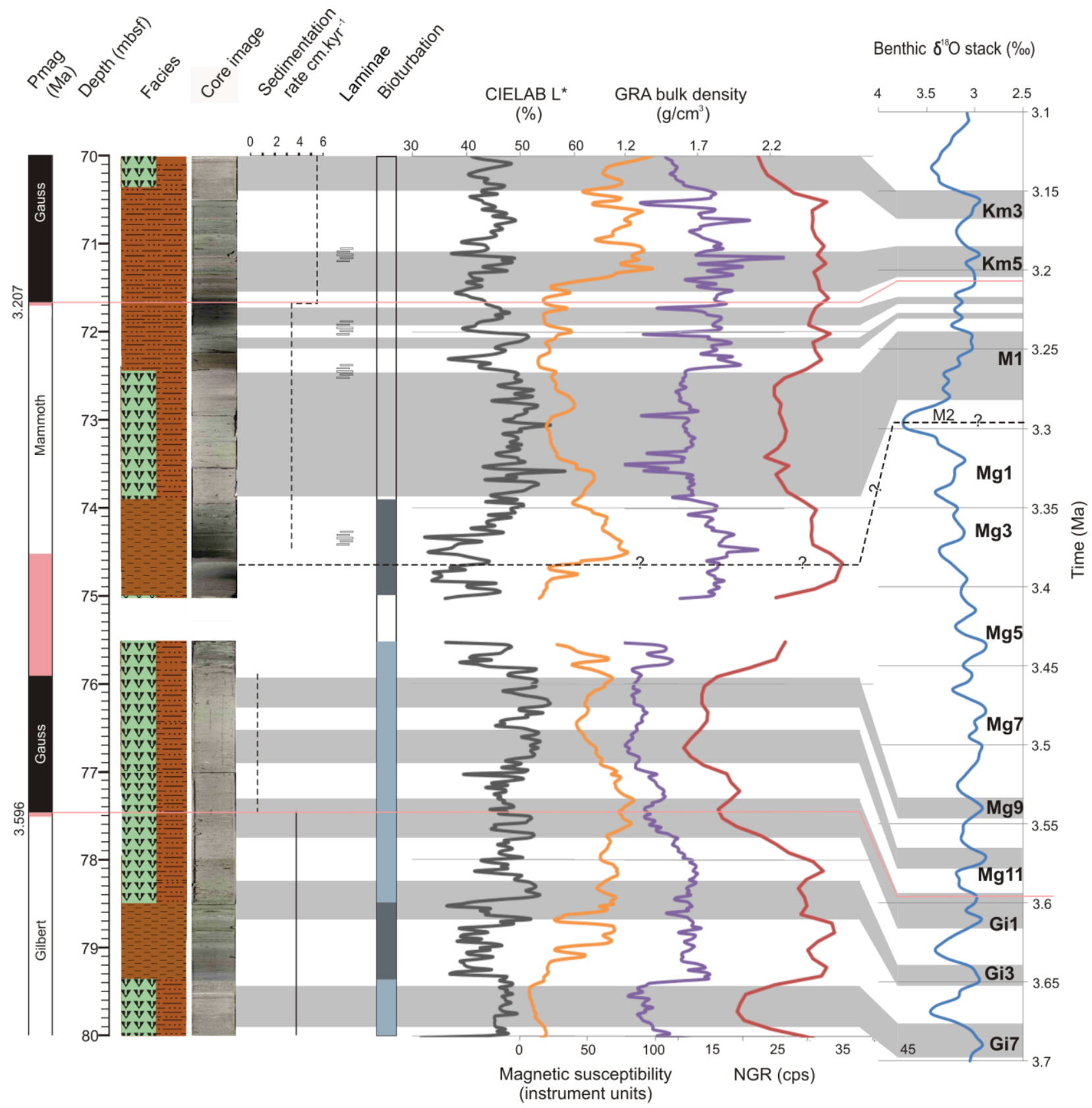

Figure 4.15. Core summary and correlations for the mid warm Pliocene Period (refer to Figure 4.5 caption). 
In summary, correlations have been made between cyclicity in the physical property logs and lithofacies to the benthic $\delta^{18} \mathrm{O}$ stack for intervals within the 4.2-0 Ma record in core U1361A. These correlations were based on the fundamental observation that low NGR, MS and GRA values correspond to an increase in biogenic content and decrease in terrigenous sediment supply that is interpreted to occur during interglacials (see discussion for logic). Spectral analysis of the intervals (0.49-0 Ma; 2-1 Ma, 2.7-2.1 Ma, 3.2- 2.7 Ma, 4.2-3.6 Ma) indicate that cyclicity of the physical properties reflect orbital frequencies. These spectral estimates imply that the 0.49-0 Ma period is dominated by $100 \mathrm{kyr}$ cyclicity, and that the 2-1 Ma period is dominated by obliquity. Prior to $2 \mathrm{Ma}$, precession power appears more significant in the spectral estimates. However, this is contradicted by visual correlations of the physical properties to the benthic $\delta^{18} \mathrm{O}$ stack (which contains a strong $40 \mathrm{kyr}$ cyclicity) where one-to-one correlation implies that the record prior to $1 \mathrm{Ma}$ is paced by 40 kyr obliquity. The improbability of linear sediment rates between documented paleomagnetic reversals and changing sediment rates between glacial-interglacial cycles, may account for some uncertainty in recording significant orbital frequencies throughout the core. The different sample spacing for each physical property and non-linear sampling in the time domain may lead to the slight scatter in peaks within, for example, the precession band (explained further in the previous methods section). 


\section{Chapter 5 Discussion}

\subsection{Depositional history of U1361A during the Late Neogene}

This section interprets the depositional environments at site U1361A associated with glacial-interglacial cycles using the relationships between core physical properties and facies. The well described, long-term global cooling trend since the Late Pliocene (Raymo et al., 1994) has had a significant influence on the evolution of the East Antarctic Ice Sheet (EAIS), which is reflected in sediment deposition on the adjacent continental rise during past glacial-interglacial cycles. Changes in the EAIS as recorded by the sediments, is illustrated here through two sedimentation models that have been developed based on cycles observed in the facies and physical property logs. The upper $9 \mathrm{~m}$ (last $\sim 500$ kyrs; Figure 4.5 ) and lowermost $20 \mathrm{~m}$ of analysed U1361A core (4.2-3.6 Ma; Figure 4.15), are characterised by model A and model B, respectively. These two sedimentation models represent 'end members' of a range of depositional processes occurring at the U1361A core site. The intervening core interval record a transitional period between these two models. This transition between depositional models reflects climatic cooling at the Wilkes Land margin from the warm Early Pliocene (4.2-3.6 Ma; Interval 4) to the $100 \mathrm{kyr}$ glacial/interglacial cycles that characterise the Middle Late Pleistocene (last 500 kyr; Interval 1; Figure 5.1). The marked cyclicity in both lithofacies and physical property logs for the upper $9 \mathrm{~m}$ of U1361A is less apparent in the older intervals of the core. While the physical property logs show identifiable glacial-interglacial cyclicity throughout the core, the older Pliocene facies reflect a more complex mix of depositional processes. 


\subsubsection{Key climate transitions from the Pliocene to present}

Global climate change through the Pliocene to present likely had a large influence on sediment deposition at the U1361A core site. Major climate phases include the warm Early Pliocene ( 5-3.6 Ma), a major advance of the Antarctic ice sheet at $~ 3.3$ $\mathrm{Ma}$, followed by the onset of Northern Hemisphere glaciation $(\sim 3.3-2.6 \mathrm{Ma})$ and the mid-Pleistocene transition ( $~ 800 \mathrm{ka})$ when the $\sim 40 \mathrm{kyr}$ pacing of glacial-interglacial cycles switched to high-amplitude asymmetric $\sim 100 \mathrm{kyr}$ glacial-interglacial cycles in the benthic $\delta^{18} \mathrm{O}$ stack (Figure 5.1). While sedimentation on the continental rise is assumed to record a more distal and less direct signal of Antarctic ice sheet behaviour (relative to sediment deposition on the continental shelf), marked glacialinterglacial cyclicity is clearly recorded by fluctuations in the physical property logs throughout the studied interval. Longer-term climate trends (outlined above) are also manifested as broader stratigraphic changes in the nature of the facies making up the cycles. Associated with these lithostratigraphic changes is a gradual, but persistent, decrease in sedimentation rate within U1361A, from $3.8 \mathrm{~cm} . \mathrm{kyr}^{-1}$ in the Early Pliocene to $1.8 \mathrm{~cm} \cdot \mathrm{kyr}^{-1}$ by the Middle Late Pleistocene (Figure 3.3). The higher sedimentation rates in the Early Pliocene may be a consequence of a warmer glacial regime, and therefore, increased discharge of sediment-laden subglacial meltwater onto the continental shelf, that is then transported to the continental rise via turbidity currents. Sedimentation rates in glaciomarine environments are shown to be highly dependent on glacial thermal regime, and a subpolar regime has been hypothesised for the West Antarctic Ice Sheet (WAIS) at this time (McKay et al., 2009). Increased sedimentation via EAIS outlet glaciers has been recorded for this period (Levy et al., 2012; Golledge et al., 2012).

Seismic reflection profiles linked to drillcores imply that a major advance of the Antarctic ice sheet occurred around its entire margin at $\sim 3 \mathrm{Ma}$ (Rebesco et al., 2006), although the timing of this transition is questioned, on the basis of poor age control (Larter, 2007). If the age control is correct, such a transition would broadly coincide with, or follow the M2 glaciation, characterised by $\sim 1 \%$ increase in $\delta^{18} \mathrm{O}$ in 
the benthic oxygen isotope stack. The M2 glaciation has been associated with a significant cooling of Antarctic coastal waters, and the increased duration and extent of summer sea-ice between 3.3 and $2.6 \mathrm{Ma}$ (McKay et al., 2012a). The M2 glaciation coincides with the base of the Mammoth Subchron which is located between $75.9-74.5 \mathrm{mbsf}$ in the U1361A core, and is characterised by a condensed section (sedimentation rate of less than $1 \mathrm{~cm} . \mathrm{kyr}^{-1}$ ) and a possible hiatus (Figures 3.1 and 4.15).

Prior to $\sim 2.5 \mathrm{Ma}$ the dominant facies are clays with regular $\mathrm{cm}^{-}$to $\mathrm{mm}^{-}$scale laminae composed of silt (Facies E) and bioturbated diatom-rich silty clays (Facies D). Within the Pleistocene, the dominant facies consist of massive silty clays, with occasional silt laminae (Facies B), interbedded with mottled (bioturbated) diatomrich clays (Facies A). A sudden shift in grain size occurs at $47.5 \mathrm{mbsf}(\sim 2.5 \mathrm{Ma})$ with an upcore transition in modal grain size from predominantly clay into silty clay. The timing of this transition coincides with a noted high-latitude cooling and increased duration and extent of sea-ice around the Antarctic continental margin (Hillenbrand and Cortese, 2006; McKay et al., 2012a) and with an increased ice volume in West Antarctica (Naish et al., 2009a; Pollard and DeConto, 2009; McKay et al., 2012a). This high-latitude cooling, following the onset of Northern Hemisphere glaciation (Figure 5.1) was not coincident with a tropical cooling (Ravelo et al., 2004) and may have induced an increase in the latitudinal temperature gradient, which could spin up the wind driven Antarctic Slope Current. The noted increase in sea-ice duration and extent at this time, in association with a cooler Antarctic climate, would likely stimulate dense bottom water production in the three major gyres (Adelie Land, Ross Sea and Weddell Sea) and become entrained in the Antarctic Slope Current (Orsi et al., 1999; Rintoul, 2007). An intensified bottom water current, could explain the grain size coarsening following $\sim 2.5 \mathrm{Ma}$, through winnowing out of the fine clay particles.

A change to more markedly cyclic sedimentation at the core site for the upper $9 \mathrm{~m}$ (last $\sim 500$ kyrs) most likely reflects the increased amplitude of the $\sim 100$ kyr paced 
glacial-interglacial cycles. This is in comparison to the lower amplitude and warmer $\sim 40$ kyr climate cycles for the Pliocene and Early Pleistocene, presented in the lower core intervals by a wider variety of facies and depositional processes during interglacials.

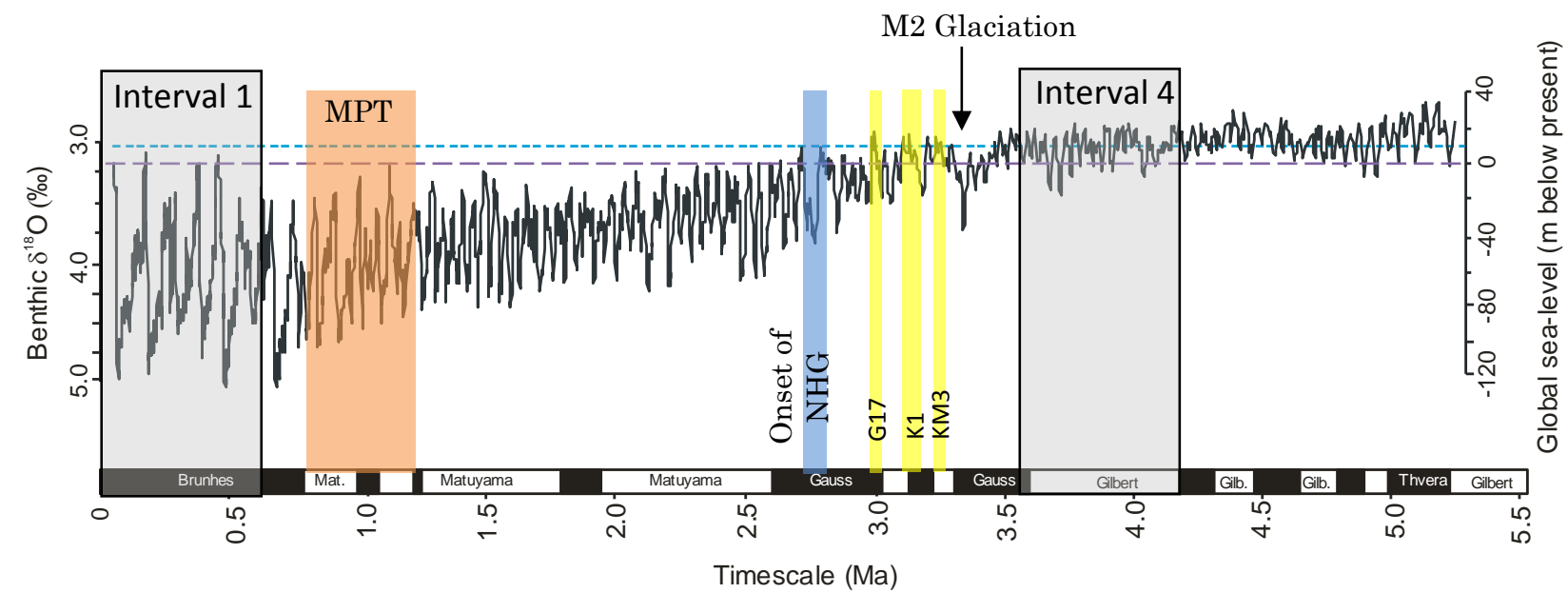

Figure 5.1. Benthic $\delta^{18} \mathrm{O}$ stack (Lisiecki and Raymo, 2005) highlighting the M2 glaciation, the onset of Northern Hemisphere Glaciation at $\sim 2.7 \mathrm{Ma}$ (NHG; Ravelo, et al., 2004), the Pliocene warm period interglacials G17, K1 and KM3 and the mid-Pliestocene transition (MPT; 1.2-0.8 Ma). Highlighted in grey are the associated periods for Intervals 1 and 4 which are represented by sediment model A and B respectively. Sea-level equivalent is displayed on the right axis, with the dashed blue line representing a deglaciated West Antarctica and Greenland and the purple dashed line representing present day sea-level (Naish and Wilson, 2009).

\subsubsection{Sedimentation model A: for the late Pleistocene}

Cyclicity for the upper $9 \mathrm{~m}$ of U1361A is marked by regular and repetitive vertical facies successions, and while higher frequency fluctuations in the physical properties are observed, their characteristic signature can be generalised into a sequence of relatively high gamma-ray attenuation bulk density (GRA), magnetic susceptibility (MS) and natural gamma-ray (NGR) values within the silty clay facies and low values for the diatom-rich clay facies, with $\mathrm{L}^{*}$ showing the opposite relationship (Figure 5.2). The longer (100 kyr) glacial-interglacial cycles for this interval, and the presence of diatom-rich facies corresponding to Marine Isotope Stages (MIS) 1,5,7,9 and 11, provides the opportunity to examine the details of transitions between the facies (Figure 4.5). Firstly, MS reaches a minimum at the 
base of the diatom-rich clay facies, while the GRA and NGR values decrease over a broader interval reaching minimum values in the middle of the diatom-rich clay facies. Secondly, MS displays higher amplitude variation compared to GRA and NGR. Thirdly, MS and GRA show an upward decreasing trend from the top of the diatom-rich clay facies throughout silty clay facies, while NGR shows an upward increasing trend throughout the silty clay facies. $L^{*}$ is much more variable, and while a general increase in lightness is observed in the diatom-rich clay facies, the relative sharp change in values occurs at the facies boundaries and there is no discernable trend within the diatom-rich facies themselves.

While sediment deposition by turbidity currents may be expected during glacial maxima in association with grounding of the EAIS at the continental shelf edge delivering sediment to the shelf break (Rebesco et al., 1997), it is likely the original sedimentary structures associated with turbidity current deposits (laminae) have subsequently been removed by bioturbation or contour/downslope currents. Although the exact intensity of bioturbation was not assessed in the soft sediments of the upper $\sim 28 \mathrm{~m}$ of U1361A, it was noted in the descriptions that the diatom-rich clays were more mottled, compared to silty clays lacking significant diatom remains (which were moderately mottled).

The anomalous presence of silt laminae within silty clay facies (Facies B) between $\sim 8.5^{-7}$ mbsf may be attributed to preservation of original turbidite structures in the absence of subsequent reworking by bioturbation or bottom currents. These laminated intervals are correlated with low amplitude glacials on either side of MIS 13 (but prior to MIS 12 ), which has a relatively lower glacial $\delta^{18} \mathrm{O}$ value in comparison to the glacials MIS 12 and 14 . While these relatively warmer glacial periods would intuitively suggest an increase in bioturbation relative to those above, a subdued dense bottom water production (i.e. less intense sea-ice conditions) could result in less reworking by dense bottom currents.

Four well-defined phases in the relationship between physical properties and facies have been identified for the Middle Late Pleistocene and are interpreted to 
represent depositional processes occurring during the (1) glacial maximum, (2) deglaciation, (3) interglacial and (4) re-advance of the ice sheet at the Wilkes Land margin (Figure 5.2; Table 5.1).

(1) Previous studies suggest that during Middle Late Pleistocene glacial maxima, the EAIS grounded to the outer continental shelf at the Wilkes Land margin, bottom water production reached a maximum and sea-ice persisted throughout the year (Ettreim et al., 1995). This interpretation is supported by high values of MS, GRA and more specifically NGR, which indicate an increased terrigenous derived sediment supply at core site U1361A. Delivery of terrigenous sediment to the site via overbank turbidity current deposits is likely. However, we propose that subsequent reworking and winnowing of these deposits via bioturbation, contour currents or downslope density currents have obscured sedimentary structures characteristic of a pure turbidite origin (i.e. silt laminae; e.g. Bouma, 1962; Figure 4.5). This interpretation is supported by previous studies of cores from the Wilkes Land continental rise (Escutia et al., 2003) and other Antarctic continental rise sites, which indicate an increase in contourite deposition during Late Pleistocene glacial periods (Weber et al., 1994; Busetti et al., 2003, Lucchi and Rebesco, 2007).

(2) Grounding line retreat of the EAIS, iceberg calving, a reduction in sea-ice and an increase in the upwelling of relatively warm Circumpolar Deep Water onto the continental shelf are the proposed processes influencing sedimentation during deglaciation (e.g. Naish et al., 2009a). A general decrease in GRA and NGR values indicate an increase in hemipelagic settling of biogenic silica and clays, and relative decrease in terrigenous silt due to decreased turbidite frequency. Minimum MS values occur at the base of the diatom-rich clay (Facies A), with the decrease initiating at top of the silty clay (Facies B). This minimum is not synchronous with GRA and NGR. MS signifies the relative content of magnetic minerals (e.g. haematite and magnetite) associated with terrigenous sediment. As there is no corresponding change in GRA and NGR values, a decrease in terrigenous material, or change in provenance is unlikely. Hepp et al., (2009) record a similar response 
during the deglaciation phase at ODP core site 1095, taken from a sediment drift on the Pacific continental rise of the Antarctic Peninsula. They suggest this MS minima is the consequence of a high flux of biogenic material, due to the onset of open ocean conditions during deglaciation, that creates a drape on the sea floor and forms suboxic conditions for the seafloor sediments causing reductive dissolution of magnetite.

(3) Interglacial conditions are inferred by the presence of bioturbated diatom-rich clays (Facies A) that reflect enhanced diatom productivity due to increased light availability in the absence of summer sea-ice. This increase in biogenic opal is manifested in the physical properties by a minimum in NGR coincident with, or shortly followed by, a minimum in GRA. Increased bioturbation can be explained by increased oxygenation of bottom water, due to increased ventilation and upwelling of nutrient waters in the absence of sea-ice (Sigman and Boyle, 2000) during interglacials, as well as slower sedimentation rates associated with hemipelagic rather than turbidite deposition.

While GRA and NGR continue to display relatively low values throughout this interval, MS returns to higher values prior to the transition to silty clay (Facies B), and is shortly followed by a peak in GRA. It is proposed that this may be due to a component of the terrigenous sediment being derived from igneous and/or metamorphic basement rock containing magnetic minerals on the Wilkes margin (Goodge and Fanning 2010) via iceberg rafting or hemiplegic settling. A change in provenance would account for the high values of MS and GRA and the relatively lower values of NGR - although an investigation of the provenance of the fine grained component of these sediments is beyond the scope of this thesis.

(4) Re-advance of the EAIS at the Wilkes Land margin is likely to have occurred as ocean temperatures cooled and would have coincided with increased duration of seaice into the summer months, and an associated increase in Adelie Land Bottom Water production. These environmental changes are reflected by the physical property logs as an overall increase in MS, GRA and NGR values. While MS and 
GRA show a decreasing trend throughout the silty clay facies. A relative increase in clay content (high in uranium, thorium and potassium that produce gamma radiation), due to decreased diatom productivity above the drill site during the onset of glacial conditions accounts for these trends in the physical property logs.
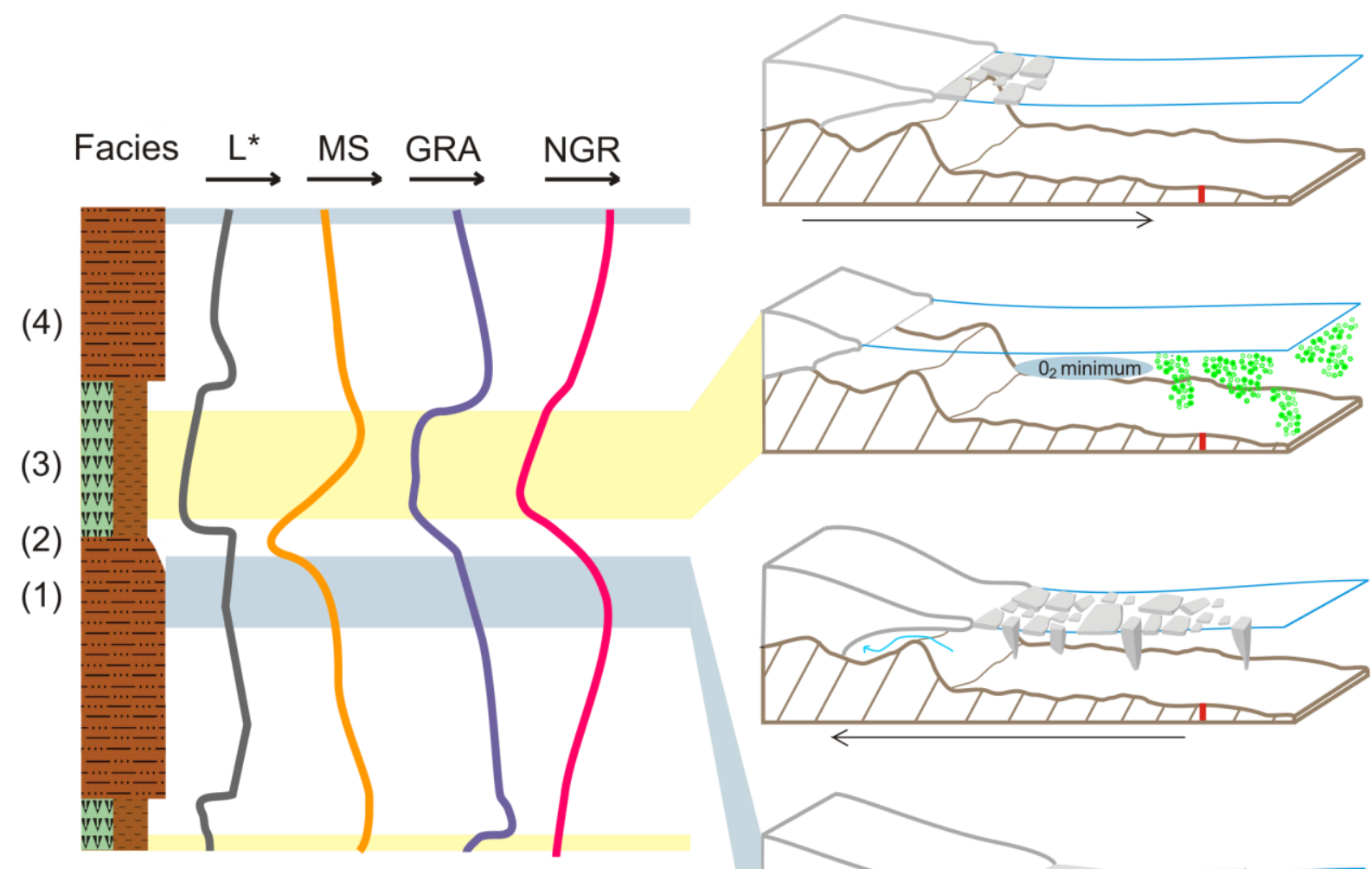

(3)

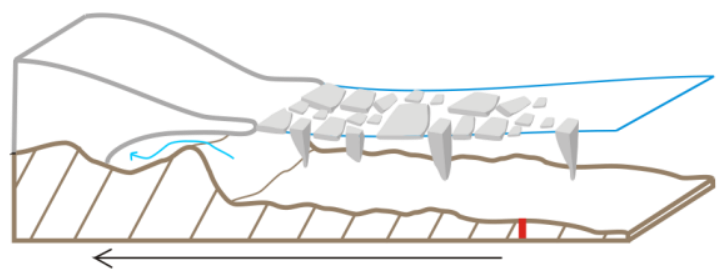

(2)

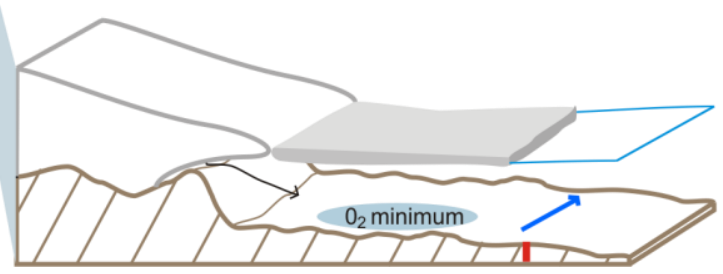

Figure 5.2. A schematic model depicting the general relationship between the facies and physical property logs observed in the upper $9 \mathrm{~m}$ of core U1361A (core site highlighted in red). The physical properties are denoted as L* (colour reflectance), MS (magnetic susceptibility), GRA (bulk density) and NGR (natural gamma-ray), with the arrows below each physical property showing the direction of higher values on a relative scale. There are four phases attributed to four states of the glacial cycle. (1) The glacial maximum highlighted in blue showing an extended ice sheet to the outer continental shelf, perennial sea- ice and ice bergs with the black arrow indicating turbidity currents and the blue arrow indicating contour currents. (2) The deglaciation showing calving ice bergs. (3) The interglacial highlighted in yellow with a reduced ice sheet, annual sea-ice, ice berg rafting and diatom deposition. (4) The re-advance of the ice sheet across the continental shelf. The $\mathrm{O}_{2}$ minimum refers to dissolved oxygen content influence on the intensity of bioturbation. 
Table 5.1. A summary of ice sheet and oceanic processes that influence sedimentation during for each phase . (1) Glacial maximum. (2) Deglaciation. (3) Interglaciation. (4) Re-advance, as identified in the above Figure 5.2.

\begin{tabular}{|c|c|c|c|}
\hline & $\begin{array}{l}\text { Cryogenic state and } \\
\text { processes }\end{array}$ & $\begin{array}{l}\text { Oceanic state and } \\
\text { processes }\end{array}$ & $\begin{array}{l}\text { Sedimentary } \\
\text { deposition }\end{array}$ \\
\hline $\begin{array}{l}\text { (1) Glacial } \\
\text { maximum }\end{array}$ & $\begin{array}{l}\text { Cold polar ice sheet } \\
\text { grounded at } \\
\text { continental shelf } \\
\text { edge } \\
\text { Maximum sea-ice } \\
\text { field }\end{array}$ & $\begin{array}{l}\text { Maximum bottom water } \\
\text { production due to } \\
\text { increased sea-ice extent } \\
\text { and duration }\end{array}$ & $\begin{array}{l}\text { Turbidites and } \\
\text { hemipelagic settling, } \\
\text { with subsequent } \\
\text { reworking by bottom } \\
\text { currents/bioturbation }\end{array}$ \\
\hline $\begin{array}{l}\text { (2) } \\
\text { Deglaciation }\end{array}$ & $\begin{array}{l}\text { Ice sheet retreating } \\
\text { Increased meltwater }\end{array}$ & $\begin{array}{l}\text { CDW incursion on the } \\
\text { shelf } \\
\text { Ocean warming }\end{array}$ & $\begin{array}{l}\text { Hemipelagic and } \\
\text { pelagic deposition, } \\
\text { possible ice-rafted } \\
\text { debris }\end{array}$ \\
\hline (3) Interglacial & $\begin{array}{l}\text { Ice sheet grounded } \\
\text { on the inner } \\
\text { continental shelf } \\
\text { Reduced summer } \\
\text { sea-ice field }\end{array}$ & $\begin{array}{l}\text { Increased oxygenation of } \\
\text { sea floor. } \\
\text { CDW incursion on the } \\
\text { shelf. } \\
\text { Highly productive, } \\
\text { seasonally sea-ice free } \\
\text { surface waters }\end{array}$ & $\begin{array}{l}\text { Increased diatom } \\
\text { deposition } \\
\text { Increased bioturbation }\end{array}$ \\
\hline (4) Re-advance & $\begin{array}{l}\text { Ice sheet expansion } \\
\text { across shelf } \\
\text { Sea-ice field } \\
\text { increasing }\end{array}$ & $\begin{array}{l}\text { Increase in bottom water } \\
\text { production due to } \\
\text { increased sea-ice }\end{array}$ & $\begin{array}{l}\text { Turbidites and } \\
\text { hemipelagic settling. } \\
\text { Increased ice rafted } \\
\text { debris }\end{array}$ \\
\hline
\end{tabular}




\subsubsection{Sedimentation Model B; for the Early Pliocene}

Cyclicity reflected by changes in lithofacies for the lower interval (101-77 mbsf) is less well-defined than the previous interval (lower amplitude fluctuations), but typically alternates between diatom-rich silty clay (Facies D) and laminated clay (Facies E; Figure 4.13). Notwithstanding this, the physical properties maintain a similar relationship as displayed in the upper $9 \mathrm{~m}$ of U1361A. That is, MS and NGR decrease concurrently, while GRA displays low amplitude during the laminated clays (Facies E), it decreases simultaneously during the diatom-rich facies, indicating the physical property logs are still responding to the same processes as recorded in Sedimentation Model A. L* shows high values for the same period, opposite to that in Sedimentation Model A when $L^{*}$ also showed low values in concert with the other physical property log values. This provides a reasonably clear definition of glacial-interglacial cycles that are not always apparent in the lithofacies logs. Some of these subtle changes may be due to variations in sediment grain size and composition and may be identified on closer examination, but is beyond the scope of this thesis. Transitions between interglacial and glacial phases were harder to define due to the absence of diatom-rich facies associated with every interglacial and identifying facies relationships with the physical property logs for the climate transitions (deglaciation and ice sheet re-advance) was not attempted.

A previous study of drift deposits flanking a turbidity channel system on the continental rise in the Antarctic Peninsula (i.e. a similar depositional environment to that of U1361A) examined characteristic sedimentary structures associated with turbidity and contour currents in ice influenced environments (Lucchi and Rebesco, 2007). In that study, core sites located near to a turbidity current channel were characterised by muds with continuous $\mathrm{cm}^{-}$to $\mathrm{mm}^{-}$scale silt laminae, but lacking IRD (Figure 2.18). However, cores recovered from a more distal levee environment with contour current influence (as inferred from seismic cross section), consist of muds with more subtle laminae and a higher abundance of IRD (Figure 2.18; Lucchi and Rebesco, 2007). The laminated clays (Facies E) in the Pliocene interval of 
U1361A are similar to the turbidite facies described by Lucchi and Rebesco (2007), in that they are characterised by discrete to $\mathrm{cm}^{-}$to $\mathrm{mm}^{-}$scale silt laminae with sharp bases, and there is a general lack of IRD (Figure 4.2). This facies is comparable to the muddy turbidite model of Bouma (1962; Figure 2.15) with the exception that a basal erosion surface and rip-up clasts are absent due to the overbank location of the drillsite - i.e. erosion is restricted to the channel. As such, it is interpreted that the clays with silt laminae in the Pliocene interval of U1361A are overbank turbidite deposits with minimal reworking by contour currents or bioturbation.

The Early Pliocene is suggested to have $\mathrm{CO}_{2}$ levels between 350-400 ppmv (Pagani et al., 2010; Seki et al., 2010) and temperatures of $2-3^{\circ} \mathrm{C}$ above modern (Dowsett, 2007), with far-field sea-level estimates ranging between $\sim 10$ to $40 \mathrm{~m}$ above present and a value of $25 \mathrm{~m}$ above present commonly adopted (Raymo et al., 2011). This is illustrated by applying an ice volume calibration of $0.011 \mathrm{ppt} \mathrm{m}^{-1}$ to the benthic $\delta^{18} \mathrm{O}$ stack for the Plio-Pleistocene after assuming a consistent 20\% temperature contribution to the $\delta^{18} \mathrm{O}$ signal (Naish and Wilson, 2009). This calibration infers deglaciated West Antarctic and Greenland ice sheets and a reduced EAIS during interglacial periods with glacial values similar to present (Naish and Wilson, 2009). A reduced EAIS is likely to retreat at sensitive marine-base margins such as Wilkes Land (Pollard and DeConto, 2009). In keeping with this evidence, it is suggested that the EAIS, at the Wilkes Land margin, advanced during glacial maxima to a mid-shelf position and retreated to the coast during interglacials.

Three climatic phases were distinguished for sedimentary cycles in this interval: (1) glacial maxima, (2) cooler interglacials, and (3) extended warm interglacials (Figure 5.3). Glacial maxima and 'cooler' interglacials are both represented by the laminated clay facies (Facies E) which suggests that similar processes transported sediment to the core site during the low amplitude glacial-interglacial cycles of the warm Early Pliocene (Figure 5.1).

(1) and (2) Early Pliocene glacial maxima were characterised by extensive summer seasonal sea-ice, maximum bottom water production and limited advance of the 
EAIS. Throughout the laminated clay facies, GRA displays very low-amplitude fluctuations, while NGR and MS still hold a coherent relationship (Figures 5.3 and 4.13). NGR and MS maxima associated with this glacial phase, indicates either a relative decrease in biogenic deposition or increase in terrigenous clays (or both). A cooler interglacial climate (phase 2) is interpreted for intervals characterised by a decrease in NGR and MS, which suggests enhanced diatom productivity during these periods.

As discussed above, the laminae are interpreted as primary sedimentary structures related to overbank turbidite deposition on the distal channel bank levee. The process by which turbidity currents are triggered and turbidites are deposited during the glacial and interglacial phases is unclear. Ice sheet advance to the continental shelf edge could trigger turbidity currents (Rebesco et al., 1997), but significant ice sheet advance is unlikely as benthic $\delta^{18} \mathrm{O}$ and sequence stratigraphy records imply reduced global ice volume and sea-levels up to $22 \mathrm{~m}$ higher than present (Lisiecki and Raymo, 2005; Miller et al. 2012). A reduced EAIS (relative to present) is implied during most interglacial periods in the Early Pliocene and is most likely to have been pronounced at the Wilkes Land margin due to the occurrence of deep sub-glacial basins in this region (Hill et al., 2007; Pollard and DeConto, 2009). Alternatively, the occurrence of turbidites during interglacial phases in the mid Pliocene interval of U1361A may have formed in response to increased delivery of terrigenous sediment to the continental shelf and slope from a warm-based ice sheet at the Wilkes margin (as seen in Late Pleistocene records from the Labrador Sea; Hesse et al., 1997). This scenario is supported by an observed increase in sedimentation rate during the Early Pliocene relative to the Middle Late Pleistocene.

There is minimal evidence for reworking, homogenisation and winnowing by bottom currents or bioturbation in the Early Pliocene interval of U1361A indicating a reduction in bottom current flow or increased sedimentation rate during Pliocene. Bioturbation is sparse to absent in the laminated clay facies, while background 
levels of IRD are also reduced, suggesting that sedimentation rates were relatively high compared to the Pleistocene. These observations are consistent with calculated sedimentation rates (Figure 4.1).

(3) Warm interglacial states are represented by diatom-rich silty clay facies and pronounced minima in MS, GRA and NGR (Facies D; Figure 5.3). The increased diatom abundance open marine conditions and inferred decrease in terrigenous sediment supply. The lack of laminae in this facies suggests either significant retreat of the EAIS margin (reduced transport of terrigenous sediment to the continental margin) or that bioturbation was enhanced during these intervals reworking bedding structures.

The diatom-rich facies occur roughly every third interglacial (as identified by the variations in NGR and MS) between the depths of 91-79 mbsf. These interglacials are not associated with particularly depleted or prolonged $\delta^{18} \mathrm{O}$ values, which suggest that a major reduction in volume is unlikely (Liseicki and Raymo, 2005). Therefore, it is more likely that turbidite structures have been removed through bioturbation. Furthermore, an unidentified external control on diatom deposition, such as ocean stratification and upwelling of nutrients (rather than a simple response to reduced ice sheet volume and sea-ice, and higher insolation values), is likely. 


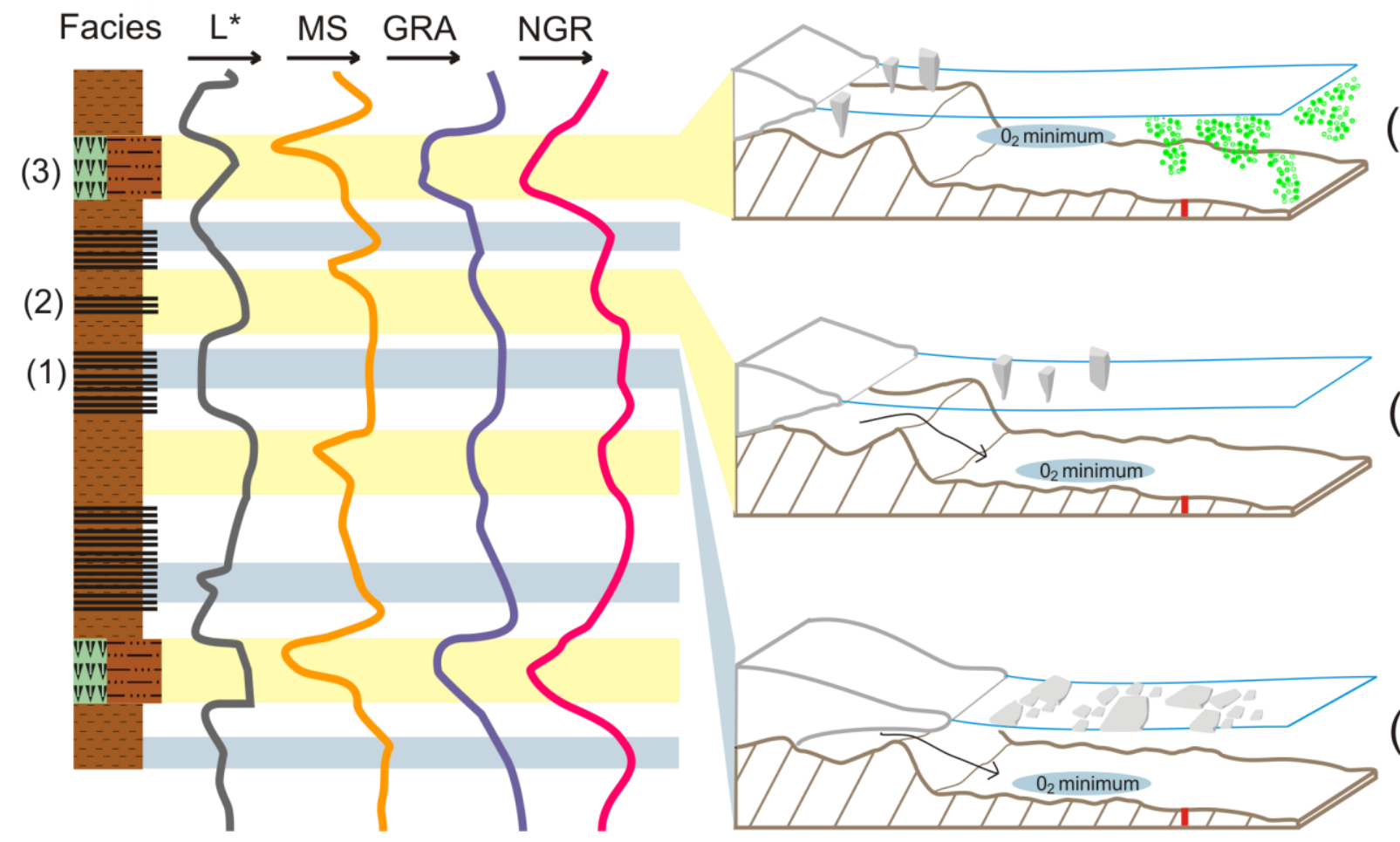

Figure 5.3. Sedimentation model $B$ for the interval 101-77 mbsf $(\sim 4.2-3.6 \mathrm{Ma})$ from U1361A core (site highlighted in red), depicting a generalised physical property log response to the facies. The three phases are represented by a schematic diagram of primary processes affecting sedimentation for each phase. (1) Glacial maximum highlighted in blue showing an extended ice sheet and sea-ice, with the black arrow denoting terrigenous input. (2) Interglacial highlighted in yellow showing a decreased ice sheet extent with ice berg rafting contained within the continental shelf and bottom water currents still active. (3) Pronounced interglacial also highlighted in yellow, showing pelagic diatom settling and ice berg rafting sourced from Ross Sea region. The $\mathrm{O}_{2}$ minimum refers to dissolved oxygen content indicating the probability of bioturbation occurring.

Table 5.2. A summary of ice sheet and oceanic processes influencing sedimentation for each phase. (1) Glacial maximum. (2) Interglacial. (3) Pronounced interglacial. Identified in the above Figure 5.3.

\begin{tabular}{|c|c|c|c|}
\hline & $\begin{array}{l}\text { Cryogenic state and } \\
\text { processes }\end{array}$ & $\begin{array}{l}\text { Oceanographic state } \\
\text { and processes }\end{array}$ & $\begin{array}{l}\text { Sedimentation } \\
\text { response }\end{array}$ \\
\hline (1) Glacial Maximum & $\begin{array}{l}\text { Ice sheet grounded } \\
\text { mid-shelf, } \\
\text { maximum summer sea- } \\
\text { ice field }\end{array}$ & $\begin{array}{l}\text { Maximum bottom water } \\
\text { production, but reduced } \\
\text { relative to the Late } \\
\text { Pleistocene }\end{array}$ & $\begin{array}{l}\text { Turbidite deposition, } \\
\text { with ice-rafted debris } \\
\text { retained on the } \\
\text { continental shelf }\end{array}$ \\
\hline (2)"Cool" Interglacial & $\begin{array}{l}\text { Ice sheet grounded } \\
\text { back from shelf edge }\end{array}$ & $\begin{array}{l}\text { Possible turbid } \\
\text { meltwater plumes } \\
\text { related to glacial } \\
\text { outwash }\end{array}$ & $\begin{array}{l}\text { Turbidite and } \\
\text { hemipelagic deposition } \\
\text { with minor diatom } \\
\text { component and possible } \\
\text { ice-rafted debris }\end{array}$ \\
\hline $\begin{array}{l}\text { (3) Extended } \\
\text { Interglacial }\end{array}$ & $\begin{array}{l}\text { Ice sheet grounded } \\
\text { back from shelf edge, } \\
\text { reduced sea-ice field }\end{array}$ & $\begin{array}{l}\text { 'Warm' sea surface } \\
\text { temperatures, reduced } \\
\text { input from turbid } \\
\text { meltwater plumes and } \\
\text { turbidites }\end{array}$ & $\begin{array}{l}\text { Hemipelagic deposition } \\
\text { with increased diatom } \\
\text { component }\end{array}$ \\
\hline
\end{tabular}




\subsubsection{Sedimentation for the late Pliocene-Early Pleistocene}

Regular synchronous troughs of MS, GRA and NGR are used to define periods of decreased terrigenous sediment deposition at the core site (interpreted as interglacials) in accordance with Sedimentation Models A and B.

An anomalous interval of carbonate silty clay between 25.8 -20 mbsf complicates the established relationship between lithofacies and the physical properties. This carbonate interval is associated with decreased amplitude of GRA, but not MS or NGR, which suggests gamma-ray emitting clays were still present and cyclical. Stratigraphically below the carbonate ooze, NGR and GRA values are low and highly variable, indicating that there are distinct intervals of high diatom productivity between $\sim 2-1.4 \mathrm{Ma}$, that occur at obliquity frequency (Figure 4.8 ). A shift from clay dominated lithofacies (prior to $\sim 2.5 \mathrm{Ma}$ ) to silty clays (following $\sim 2.5$ $\mathrm{Ma}$ ) may be associated with winnowing related to invigoration of the Antarctic Slope Current.

Three prolonged NGR troughs, synchronous with depleted GRA and MS values, indicate increased diatom content and correlate with MIS G17, K1 and KM3. These Marine Isotope Stages are all depleted in the benthic $\delta^{18} \mathrm{O}$ stack relative to other Pleistocene interglacials, and have been inferred to represent a deglaciated West Antarctic and Greenland ice sheet (Naish and Wilson, 2009; Figure 4.15). These significant interglacial intervals follow an initial cooling and major glacial advance associated with the M2 glaciation which is correlated to $74.6 \mathrm{mbsf}$ in U1361A. Oneto-one correlation of the core logs to the benthic $\delta^{18} \mathrm{O}$ undertaken for these intervening intervals places confidence in similar controls and processes occurring throughout the core. 


\subsection{Orbitally-paced-sedimentary cyclicity on the lower continental rise, Wilkes Land margin}

Spectral estimates from physical properties data show statistically significant power in varying Milankovitch frequencies for selected intervals in U1361A during the last 4.2 Myrs (Figures 4.6, 4.8, 4.10, 4.12 and 4.14). The selection of these intervals was based on continuity and chronology of the record, and are also used to test changing orbital influence in response to longer duration climate trends (e.g. prior to, and following, the mid-Pleistocene transition). Sediment deposition at the U1361 core site is shown through spectral analysis to: 1) be paced by 100 kyr cycles in the Middle Late Pleistocene $(<550 \mathrm{ka})$, with both obliquity and precession frequencies present; 2) be dominated by orbital obliquity for the 2-1 Ma period; and 3) contain predominantly precession frequencies prior to $2 \mathrm{Ma}$, with obliquity and eccentricity recorded as less significant overall. Obliquity becomes more significant in $\mathrm{L}^{*}$ and NGR when spectral analysis is undertaken for the entire $\sim 3.2-2.1 \mathrm{Ma}$ period and holds equal power with precession in $L^{*}$ and NGR spectra for the 4.2-3.6 period (Figures 4.12 and 4.14). Spectral estimates of the benthic $\delta^{18} \mathrm{O}$ stack undertaken for the same intervals, show a dominance of obliquity with varying eccentricity influence and low precession for the 4.2-1 Ma period and relatively equal power in eccentricity, obliquity and precession frequencies for the last $550 \mathrm{kyr}$.

While the hypothesis that orbital variations pace past glacial-interglacial cycles is generally accepted, different views remain regarding the dominant mechanisms in

which Milankovitch cycles control the waxing and waning of polar ice sheets (e.g. Huybers, 2006; Raymo et al., 2006; Raymo and Huybers, 2008). This stems from an inability to identify the physical mechanisms by which past insolation variations influences ice sheet mass balance. 


\subsubsection{Precession paced variability with the U1361A physical properties record}

Predominant precession periodicities (frequently above 99\% statistical significance), recorded in all physical property log spectra, particularly prior to $\sim 2 \mathrm{Ma}$, are inconsistent with obliquity pacing of global glacial-interglacial climate cycles as recorded by the benthic $\delta^{18} \mathrm{O}$ stack (Liseicki and Raymo, 2005). This period (4.2- 2 $\mathrm{Ma}$ ) is associated with an inferred reduced EAIS (Miller et al., 2012; Kennett and Hoddell, 1993) at the Wilkes Land margin (Pollard and DeConto, 2009), when ocean circulation and oceanographic transitions are likely to have significant influence on sedimentation at the continental rise core site of U1361.

Diatom-rich silty clays (defined by the lowest NGR values) present in Interval 4 (101-77 mbsf; $\sim 4.2-3.6 \mathrm{Ma}$ ) appear to correlate to every third interglacial period in the benthic $\delta^{18} \mathrm{O}$ curve (Figure 5.4). While spectra for this interval display precession frequencies in all physical property logs, with obliquity only present in $L^{*}$ and NGR spectra, one-to-one correlation of the physical property logs to the benthic $\delta^{18} \mathrm{O}$ stack (Figures 4.7, 4.9, 4.11 and 4.13) supports a primary obliquity influence. The significant precession power in spectra represents a higher frequency cyclicity superimposed on the fundamental $\sim 40 \mathrm{kyr}$ cycle. Curiously, the correlation of diatom-rich silty clays to orbital time series suggests these intervals of highest productivity correspond to nodes in $100 \mathrm{kyr}$ eccentricity and therefore low seasonality (Figure 5.4). In general, they are also generally correlated with times of high axial tilt (obliquity). This indicates that eccentricity-modulated precession minima, and high obliquity may correspond to times of increased productivity at the core site.

While spectra in this study show power in both the precessional and obliquity bands prior to the onset of Northern Hemisphere glaciation, it is suggested that the precession signal recorded is likely a response to changing plankton productivity, as a response to sea-ice extent and sea surface temperature associated with changes in seasonal insolation (Huybers and Denton, 2008). And the increased influence of

obliquity during these eccentricity-muted interglacials has been linked with a 
reduced latitudinal temperature gradient (Young and Bradley, 1984), causing southward migration of the westerly winds and the upwelling of warm nutrient-rich waters around the Antarctic margin, ice margin retreat and increased productivity (e.g. Toggweiler et al., 2008; Naish et al., 2009a). Previous studies invoking precessional pacing of the global climate and specifically the Antarctic ice sheets require a much smaller EAIS with terrestrial margins responding to austral summer insolation driven surface ablation, which is controlled by orbital precession (Raymo et al., 2006). The absence of Northern Hemisphere ice sheets prior to $2.7 \mathrm{Ma}$ (Haug et al., 1999) makes it difficult for of out-of-phase precession forcing to account for the dominance of the $\sim 40 \mathrm{kyr}$ obliquity cycle in the benthic $\delta^{18} \mathrm{O}$ stack.

In-phase hemispheric glaciation for the last $\sim 800 \mathrm{kyrs}$, dominated by $100 \mathrm{kyr}$ pacing, is in accordance with Raymo et al., (2006) hypothesis. However, an obliquity pacing of these "100" kyr cycles has been proposed by Huybers and Wunsch (2005) and Huybers (2007). As with most Middle Late Pleistocene paleoclimate records, time series analysis from this study does not shed new light on the origins of the 100 kyr cycle, as $100 \mathrm{kyr}, \sim 40 \mathrm{kyr}$ and $\sim 20 \mathrm{kyr}$ all hold equal power in physical property spectra. However, this study does demonstrate, at least for the five most recent Late Pleistocene climate cycles that the variability in extent of the EAIS was stronglycontrolled by the $\sim 100 \mathrm{kyr}$ climate cycle. The U1361A record arguably provides one of the most complete direct records of orbital influence of the EAIS during the last 500 kyrs, and shows regular oscillations between grounding line advance to edge of the continental shelf during glacials, with intervening periods of open, productive ocean conditions during interglacials. Thus, although the $\sim 100 \mathrm{kyr}$ ice age cycle is primarily driven by changes in the Laurentide Ice Sheet, volume changes in the EAIS appear to have occurred in-phase. For the most recent retreat of the EAIS since the Last Glacial Maximum, it has been argued that a combination of marine influences including ocean warming and Northern Hemisphere-driven, glacioeustatic sea-level rise have controlled the dynamic response of the EAIS (Mackintosh et al., 2011). This study implies that this may have been the case for EAIS glacial-interglacial variability since the mid-Pleistocene transition. 


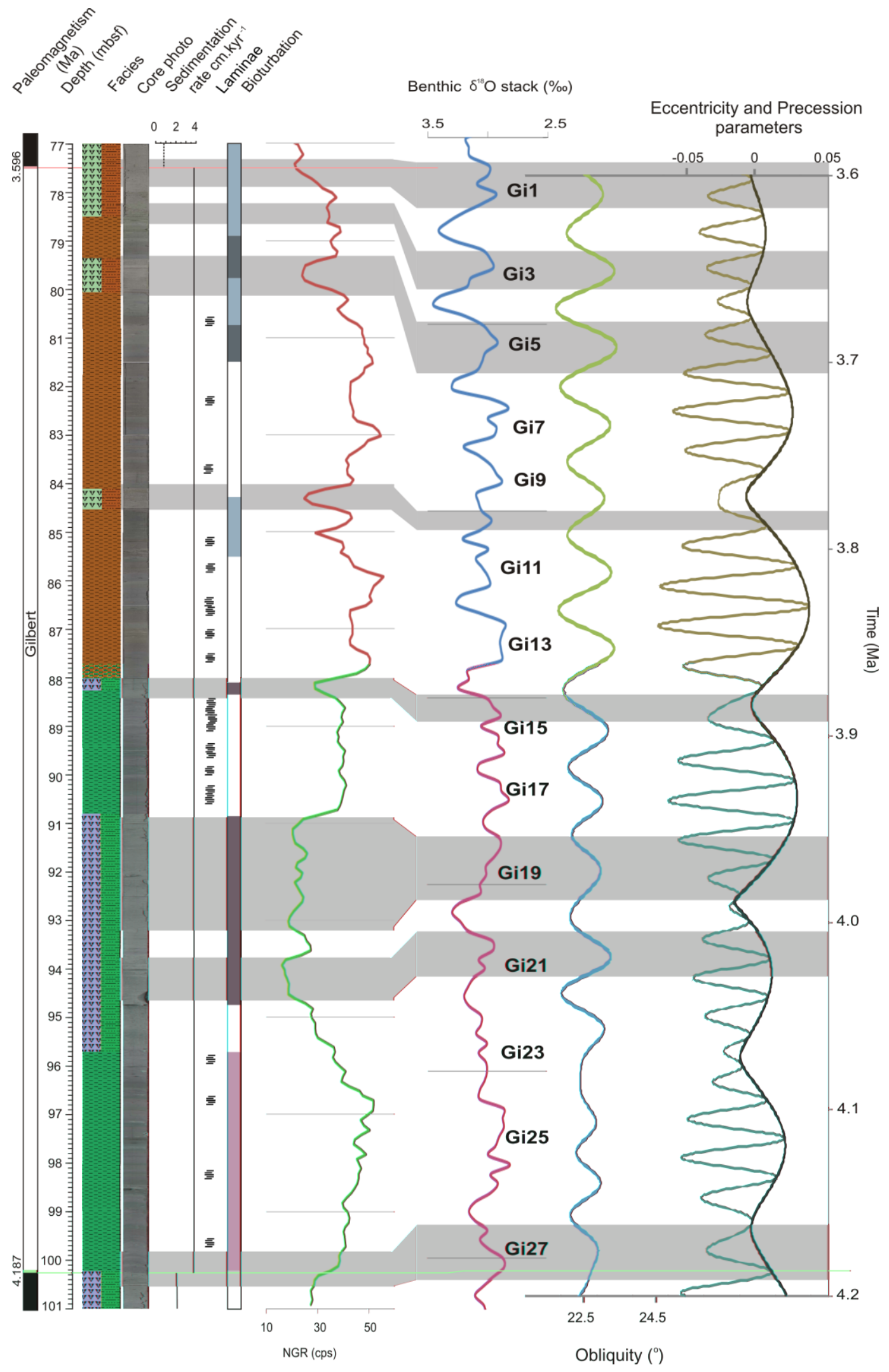

Figure 5.4. Diatom-rich silty clay facies between 101 and $77 \mathrm{mbsf}$, previously associated with minima in NGR and benthic $\delta^{18} \mathrm{O}$ (Figure 4.14), are correlated here to orbital solutions for eccentricity (dark brown), precession (light brown, on the same scale as eccentricity) and obliquity (green). 


\subsubsection{Obliquity pacing of glacial-interglacial fluctuations of the Wilkes Land margin of the EAIS.}

The underlying presence of obliquity in power spectral analysis of the physical properties from core U1361A from 4.2-1 Ma, together with the near one-to-one correlation between the glacial-interglacial cycles interpreted for the drill core and the benthic oxygen isotope stack, suggests obliquity plays a fundamental role on the variability of the EAIS at the Wilkes Land margin. The $\sim 40 \mathrm{kyr}$ obliquity periodicity is recorded more prominently in $L^{*}$ colour reflectance and NGR, reflecting the sensitivity of $L^{*}$ to colour changes associated with changes in biogenic deposition as recorded by NGR. These fluctuations occur within all facies, specifically the laminated clays, and are interpreted here as primarily reflecting changes in ice sheet proximity as discussed with regard to the sedimentation models. The absence of significant obliquity in GRA and MS is expected as GRA has low amplitude variance throughout the laminated clay facies, and does not resolve subtle variations in diatom content as well as NGR ( 4.2-3.6 Ma), while MS fluctuates at a higher frequency than the glacial-interglacial scale due to potential diagenetic and provenance (for both IRD and the fine fraction) complications.

As discussed earlier, variance in the $\sim 20 \mathrm{kyr}$ precessional frequency bands is recorded in all the physical property time series and is interpreted as a potential driver of productivity related to variations in light irradiance availability for diatoms. As variations in sea surface temperature and sea-ice are driven by seasonal insolation variations (Huybers and Denton, 2008). The presence of sea-ice can affect ocean stratification, depth of light penetration and nutrient levels, which are important environmental controls on the production of phytoplankton (Stoemer and Smol, 1999 and references therein). An increased dominance of obliquity in power spectra between 2-1 Ma, can be linked to increased influence (proximity) of an expanded EAIS relative to oceanographic influences on sediment deposition at this time (Liseicki and Raymo, 2005; Figure 5.1). One-to-one correlation of synchronous minima in MS, GRA and NGR to interglacials in the benthic $\delta^{18} \mathrm{O}$ stack is 
particularly marked during this interval of strong $\sim 40$ kyr obliquity pacing (Figure 4.7).

Obliquity pacing of Antarctic ice volume has been investigated by several authors through models involving the forcing of atmospheric and oceanic circulation. Raymo and Nisancioglu (2003) report on the latitudinal temperature gradient (controlled by orbital tilt) forcing the strength of atmospheric and oceanic circulation with the transfer of heat and moisture from tropics to polar regions. Naish et al., (2009a), consider the southward export and upwelling of Circumpolar Deep Water onto the continental shelf due to changes in westerly wind field under a reduced meridional temperature gradients during interglacials to be paced by obliquity to influence melt rates at the marine margins of the Antarctic ice sheet, as facies in the AND-1B core record $\sim 40$ kyr cyclicity for the Pliocene.

Alternatively, Huybers (2006) appealed to Keplers $2^{\text {nd }}$ Law of planetary motion whereby precession control of seasonal duration and intensity becomes unimportant as seasonal intensity is counterbalanced by duration and obliquity becomes the dominant control on the distribution of insolation.

Results of this study, indicate precession influence on insolation at high latitudes for the Early Pliocene to present is important with regards to regulating sea-ice and invigorating primary productivity at the Antarctic margin, particularly prior to the onset of major northern hemisphere glaciation. However, obliquity is suggested as the dominant mechanism by which the EAIS volume fluctuates at the Wilkes Land margin. 


\subsection{Comparison between IODP Site U1361 to $A N D-1 B$ records.}

The AND-1B marine sediment core, drilled off the McMurdo Ice Shelf sector of the Ross Sea, Antarctica, provides a record with high core recovery for the same time period analysed in this study (4.2-0 Ma) and has a detailed analysis of the facies and glacial-interglacials cycles of ice advance and retreat (Naish et al., 2009a; McKay et al., 2009). Sedimentation at the AND-1B core site is influenced by fluctuations of a marine-based ice sheet in Ross Embayment. Fluctuations in the extent of this ice sheet, interpreted from the AND-1B record, have been linked to the overall behaviour of the WAIS. When open marine conditions occur at the AND-1B site, the WAIS is inferred to have undergone partial to complete collapse, together with a thinning of the margins of the EAIS (Naish et al., 2009a; Pollard and DeConto, 2009). Comparison of U1361A with AND-1B core, provides an opportunity to assess whether glacial/interglacial events recorded in the U1361A core are regional or local, and whether some of the inferred fluctuations in the WAIS were also associated with EAIS variability.

Paleomagnetic reversal stratigraphies in each sediment cores provide the basis for correlation (Figure 5.5). Frequent disconformities occur in the AND-1B core, most of which are due to erosion as grounded ice advanced across the core site. These disconformities have been correlated to the approximate time period represented by sediments in the more continuous U1361A record.

U1361A preserves a $4.2 \mathrm{Myr}$ record in $\sim 100 \mathrm{~m}$ of sediment, while AND-1B records the same time period in $\sim 450 \mathrm{~m}$ of core, highlighting the different styles of sediment deposition at each site. These differences primarily reflect higher sedimentation rates in the AND-1B core due to its location on the continental shelf. Consequently, cycles of ice sheet advance and retreat are more clearly recorded in the AND-1B core compared to U1361A, which provides a less direct and less sensitive record due to its more distal setting. Therefore, it is not surprising that glacial-interglacial cycles are more subtle in U1361A. Lithofacies in the AND-1B core alternate between diatomite 
(ice distal depositional environment), mudstone/siltstone (ice proximal) and diamictite (grounded ice), with occurrences of volcanic sediment (Naish et al., 2009a). In comparison to the alternating diatom-rich facies (open marine conditions) and silty clay/clay facies (increased terrigenous supplied by turbidites/decreased pelagic diatom deposition) present in the U1361A core, it is possible to compare 'open marine condition' facies.

An interval containing multiple diatom-rich facies from 80-66 mbsf in U1361A, for the time period $\sim 3.7$ to $\sim 3 \mathrm{Ma}$ broadly correlates with later part of a $\sim 1 \mathrm{Myr}$ period ( 4.4-3.4 Ma) of warmer-than-present open ocean conditions, with no summer seaice, represented in the AND-1B core by $\sim 80 \mathrm{~m}$ of diatomite. This interval has been associated with a reduced WAIS (McKay et al., 2012a). However, in U1361A there are still numerous $\sim 5 \mathrm{~m}$ thick intervals of laminated clays, indicating turbidite deposition occurred at the drill site, although it is acknowledged that the process by which turbidity currents are induced is inconclusive. A reduced presence of diatomrich facies above $66 \mathrm{mbsf}$ in U1361A is followed by a significant change from primarily clay facies to silty clay facies correlated to $\sim 2.5 \mathrm{Ma}$.

The AND-1B core records a shift to ice proximal sediment at 3.3-3 Ma with increasing summer sea-ice extent reaching a maximum at $\sim 2.6 \mathrm{Ma}$, preceding the major change at the Wilkes Land margin ( 2.5 Ma). This 3.3-3 Ma interval also corresponds to a pronounced decrease in opal mass accumulation rates at the Antarctic Peninsula ODP core 1096 (Hillenbrand and Cortese, 2006), and an increase in opal mass accumulation rates in ODP Site 1090 north of the polar frontal zone (McKay et al., 2012a). Furthermore, decreased terrigenous sediment flux in the AND-1B record suggests a general trend and change to a more polar-style glaciation. In U1361A, the decreased sedimentation rate (from $\sim 3.8$ to $1.8 \mathrm{~cm} . \mathrm{kyr}^{-1}$ ) at $\sim 2.5 \mathrm{Ma}$ (47 mbsf) likely represents a decrease in hemipelagic settling due to a cooling glacial regime (i.e. less sediment laden glacial meltwater) or a shorter sea-ice free season reducing diatom productivity and pelagic sedimentation. Additionally, the associated change from clay to silty clay facies in U1361A at this time could be 
attributed to an increased Antarctic Slope Currents winnowing out the clays, due to an enhanced zonal circulation resulting from Antarctic cooling as discussed earlier. All of these scenarios are consistent with the climate record implied by AND-1B record.

A high degree of correlation between changing facies and interpreted glacial cycles at the two core sites is observable (Figure 5.5), suggesting that for the PlioPleistocene that the EAIS and Southern Ocean at the Wilkes Land responded to changing climates at the same frequency as the WAIS. 


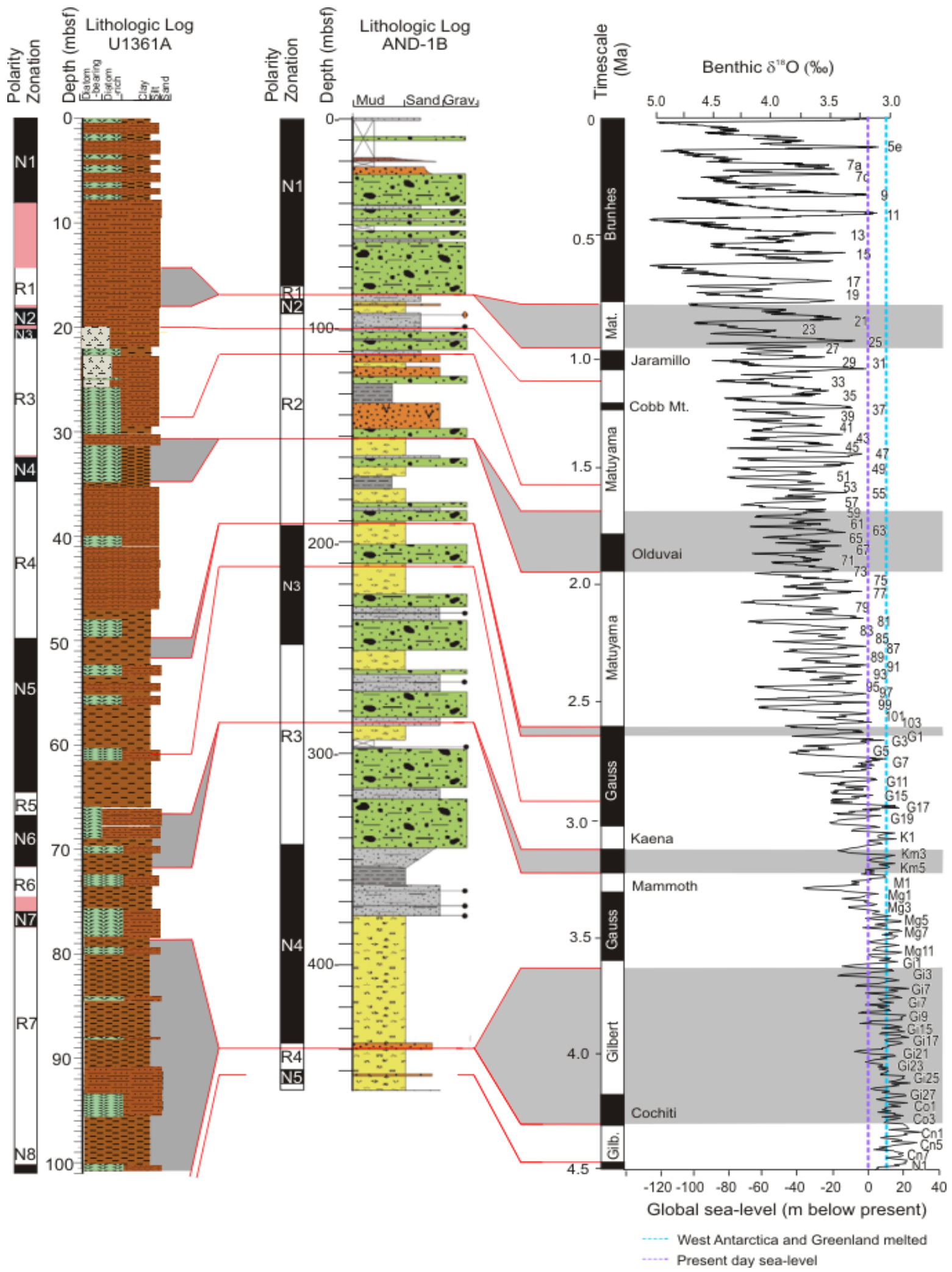

Figure 5.5. A comparison between U1361A and AND-1B core records and the benthic $\delta^{18} \mathrm{O}$ stack (Liseicki and Raymo, 2005) for 4.2-0 Ma. Correlations between the cores are based on the chronology of AND-1B (Naish et al., 2009a), applied to the age model from U1361A (Tauxe et al., 2012). The benthic $\delta 180$ stack was modified from Naish and Wilson (2009). 


\section{Conclusions}

A record of East Antarctic Ice Sheet (EAIS) evolution and fluctuation at the Wilkes Land margin was explored through analysis of marine sediment core U1361A, recovered during IODP Expedition 318. Core U1361A was collected from the eastern levee of the Jussieau Canyon, located on the continental rise adjacent to the Wilkes Land margin of East Antarctica, at a depth of 3454 meters below sea-level. Sediment deposition at this site is controlled by downslope and along slope currents, ice-rafted debris and biogenic pelagic settling, all of which respond to ice sheet proximity. The upper $\sim 100 \mathrm{~m}$ of core, spanning the last $4.2 \mathrm{Ma}$, was analysed in this study. Intervals for analysis were selected on the basis of the quality of drillcore, physical property logs and chronology.

- Analysis of the shipboard facies scheme was undertaken, in association with the physical property logs of gamma-ray attenuation bulk density (GRA), magnetic susceptibility (MS), natural gamma-ray (NGR) and $\mathrm{L}^{*}$ colour reflectance.

- From this analysis, relationships between the facies and physical property logs were observed, primarily based on NGR as a proxy for the biogenic versus terrigenous component, which was not always identified in the shipboard facies scheme.

- These relationships define an interglacial phase whereby NGR, GRA and MS decrease in value in response to an increase in biogenic sediment, and a glacial phase where NGR, GRA and MS displayed an increase in value in response to a relative decrease in the biogenic component and increase in terrigenous sediment.

- Preliminary depositional models were produced for the Middle Late Pleistocene (0.5-0 Ma) and the Early Pliocene (4.2-3.6 Ma) and represent end 
members of the range of depositional processes occurring within the intervening time intervals. These models will evolve as other datasets (e.g. diatom composition, sediment provenance and chemistry) that are still being developed by other members of the shipboard science party are integrated.

- The Middle Late Pleistocene, is characterised by alternating diatom-rich clays (Facies A) and silty-clays (Facies B), which reflect an open marine environment dominated by biogenic sedimentation, and an advancing ice sheet to the continental shelf edge respectively.

- The Early Pliocene is dominated by laminated clays (Facies E), with frequent occurrences of diatom-rich silty clays (Facies D), which reflect intervals characterised by turbidite events, low bottom current activity and bioturbation and other intervals dominated by open marine conditions conducive for diatom deposition, respectively.

- Facies in the intervening time interval exhibited more subtle variation but physical property logs broadly display a cyclical character. This is consistent with the relationships described above for the Early Pliocene and Middle Late Pleistocene, which allowed correlation of the sedimentary record with the benthic $\delta^{18} \mathrm{O}$ stack.

- Using biostratigraphic and paleomagnetic constraints, an age model was developed for the U1361A core (Tauxe et al., 2012). These age constraints enabled spectral analysis of the physical properties time series for the four identified intervals, 4.2-3.6 Ma, 3.2-2.7 Ma, 2.7-2.1 Ma, 2-1 Ma and the last $\sim 500$ kyrs. Results were used to evaluate orbital frequencies within the time series throughout the Late Neogene. 
- Spectral estimates of the Middle Late Pleistocene interval confirmed the observed presence of $\sim 100 \mathrm{kyr}$ cyclicity in the physical property logs, displaying equal power with $\sim 40 \mathrm{kyr}$ obliquity and $\sim 20 \mathrm{kyr}$ precession. The alternating diatom-rich clays and silty clays of this interval imply a strong depositional response to the characteristic large amplitude $\sim 100 \mathrm{kyr}$ glacialinterglacial cycles of the Late Pleistocene. The Wilkes Land margin of the EAIS appears to respond in-phase to $\sim 100 \mathrm{kyr}$ paced fluctuations in the continental Northern Hemisphere ice sheets, perhaps synchronised by marine influences such as global sea-level and ocean temperature.

- While obliquity periodicity is variable in physical property log spectra, the one-to-one correlations of the core logs to the obliquity paced glacialinterglacial cycles recorded in the benthic $\delta^{18} \mathrm{O}$ stack prior to $\sim 1 \mathrm{Ma}$ confirms the importance of obliquity on sediment deposition at the core site. This relationship between the facies, NGR log in particular and the $\delta^{18} \mathrm{O}$ record implies obliquity-paced oscillations of the margin of the EAIS, which is consistent with orbital oscillations of the West Antarctic Ice Sheet (WAIS) during the Pliocene-Early Pleistocene observed in the ANDRILL AND-1B core.

- The presence of precession as well as obliquity in all physical property logs throughout the $\sim 4.2 \mathrm{Myr}$ record may record variations in productivity that is influenced by seasonal insolation forcing on sea-ice extent. This is displayed by the NGR record, where a higher frequency (precession) periodicity is superimposed on obliquity cyclicity.

- Finally, a comparison of the U1361A core to the AND-1B core, recovered from the western Ross Sea, displayed a level of correlation that suggests that periods of high oceanic productivity were occurring during periods of reduced marinebased WAIS extent. In addition, a cooling at $\sim 2.6 \mathrm{Ma}$, inducing the initiation of 
perennial sea-ice and cooling ocean temperatures, recorded in the AND-1B record, is similarly recorded by an upcore transition of predominantly clay to silty clay at $\sim 2.5 \mathrm{Ma}$ in the U1361A core, interpreted as a response to bottom water current invigoration winnowing out the clay. 


\section{References}

BARRETT, P. J. 1989. Antarctic Cenozoic history from the CIROS-1 drillhole, McMurdo Sound. New Zealand Department of Scientific and Industrial Research Bulletin, 245, 254-271.

BARRETT, P. J. 1997. Antarctic paleoenvironment through Cenozoic times: A review. Terra Antarctica, 3, 103-119.

BERGER, W. H. 1974. Deep-sea sedimentation. In: C. A. Burk \& C. L. Drake, Eds. The geology of continental margins, Springer-Verlag, New York, 213-241.

BINDOFF, N. L., ROSENBERG, M. A., \& WARNER, M. J. 2000. On the circulation and water masses over the Antarctic continental slope and rise between 80 and $150^{\circ}$ E. Deep Sea Research, 47, 2299-2326.

BLUM, P. 1997. Physical Properties Handbook. http://www-ODP.tamu.edu/publications/tnotes/tn26.

BOGGS, S. 2001. Principles of Sedimentology and Stratigraphy, $3^{\text {rd }}$ Edition. Prentice Hall, New Jersey, $409 \mathrm{p}$.

BONING, C. W., DISPERT, A., VISBECK, M., RINTOUL, S. R. \& SCHWARZKOPF, F. U. 2008. The response of the Antarctic Circumpolar Current to recent climate change. Nature Geoscience, 1, 864869.

BOUMA, A. 1962. Sedimentology of some flysch deposits. Elsevier, Amsterdam, 168 p.

BOYLE, E. A. \& KEIGWIN, L. D. 1986, Comparison of Atlantic and Pacific paleochemical records for the last 215, 000 years: Changes in deep ocean circulation and chemical inventories. Earth and Planetary Science Letters, 76, 135-150.

BROECKER, W. S. 2000. Was a change in thermohaline circulation responsible for the Little Ice Age? Proceedings of the National Academy of Sciences of the United States of America, 97, 13391342.

BROECKER, W. S. 2003. Does the trigger for abrupt climate change reside in the ocean or in the atmosphere? Science, 300, 1519-1522.

BROECKER, W. S. \& DENTON, G. H. 1990. The Role of Ocean-Atmosphere Reorganizations in Glacial Cycles. Quaternary Science Reviews, 9, 305-341.

BUSETTI, M., CABURLOTTO A., ARMAND L., DAMIANI D., GIORGETTI G., LUCCHI R.G., QUILTY P.G. \& VILLA G. 2003. Plio-Quaternary sedimentation on the Wilkes land continental rise: preliminary results. Deep Sea Research Part II, 50, 8, 1529-1562.

CAI, W., SHI, G., COWAN, T., BI, D. \& RIBBE, J. 2005. The response of the Southern Annular Mode, the East Australian Current, and the southern mid-latitude ocean circulation to global warming. Geophysical Research Letters, 32.

CARTER, L., MCCAVE, I. N., WILLIAMS, M. J. M. 2009. Circulation and Water Masses of the Southern Ocean: A Review. In: F. Florindo and M. Sierget eds. Antarctic Climate Evolution, Developments in Earth and Environmental Science, Elsevier 8, 4, 85-114. 
CHAPPELL, J., OMURA, A., EZAT, T., MCCULLOCH, M., PANDOLFI, J., OTA,Y. \& PILLANS, B. 1996. Reconciliation of late Quaternary sea levels derived from coral terraces at Huon Peninsula with deep-sea oxygen isotope records. Earth and Planetary Science Letters 141, 227-236.

CHAPPELL, J. \& SHACKLETON, N. J. 1986. Oxygen isotopes and sea-level. Nature, 324, 137-140.

CHARLES, C. D. \& FAIRBANKS, R. G. 1992. Evidence from Southern-Ocean Sediments for the Effect of North-Atlantic Deep-Water Flux on Climate. Nature, 355, 416-419.

CLARK, P. U. \& PISIAS, N. G. 2000. Interpreting iceberg deposits in the deep sea. Science, 290, 5157.

CLARK, P.U. \& POLLARD, D. 1998. Origin of the middle Pleistocene transition by ice sheet erosion of regolith. Paleoceanography, 13, 1-9.

CODY, R.D., LEVY, R.H., HARWOOD, D.M. \& SADLER, P.M. 2008. Thinking outside the zone: highresolution quantitative diatom biochronology for the Antarctic Neogene. Palaeogeography,

Palaeoclimatology, Palaeoecology, 260, 1-2, 92-121.

COXALL, H. K., WILSON, P. A., PALIKE, H., LEAR, C. H. \& BACKMAN, J. 2005. Rapid stepwise onset of Antarctic glaciation and deeper calcite compensation in the Pacific Ocean. Nature, 433, 5357.

CROWLEY, T. \& KIM, K. 1995. Comparison of longterm greenhouse projections with the geologic record. Geophysical Research Letters 22, 8, 933-936.

CRUNDWELL, M., SCOTT, G., NAISH, T. \& CARTER, L. 2008. Glacial-interglacial ocean climate variability from planktonic foraminifera during the Mid-Pleistocene transition in the temperate Southwest Pacific, ODP Site 1123. Palaeogeography Palaeoclimatology Palaeoecology, 260, 202-229.

CUNNINGHAM, S. A., ALDERSON, S. G., KING, B. A. \& BRANDON, M. A. 2003. Transport and variability of the Antarctic Circumpolar Current in Drakes Passeage. Journal of Geophysical Research, 108, C5, 80-84.

DAVIS, B. A. S. \& BREWER, S. 2009. Orbital forcing and role of the latitudinal insolation/temperature gradient. Climate Dynamics, 32, 143-165.

DECONTO, R. M. \& POLLARD, D. 2003. A coupled climate-ice sheet modeling approach to the Early Cenozoic history of the Antarctic ice sheet. Palaeogeography Palaeoclimatology Palaeoecology, 198, 39-52.

DE SANTIS, L., BRANCOLINI, G. \& DONDA, F. 2003. Seismic-stratigraphy analysis of the Wilkes Land continental margin (East Antarctica). Influence of glacially-driven processes on the Cenozoic deposition. Deep Sea Research II, 50, 8-9, 1563-1594.

DETTINGER, M. D., GHIL, M. \& KEPPENNE, C. L. 1995. Interannual and Interdecadal Variability in United-States Surface-Air Temperatures, 1910-87. Climatic Change, 31, 35-66.

DICKSON, B., YASHAYAEV, I., MEINCKE, J., TURRELL, B., DYE, S. \& HOLFORT, J. 2002.

Rapid freshening of the deep North Atlantic Ocean over the past four decades. Nature, 416, 832- 837.

DOLAN, A. M., HAYWOOD, A. M., HILL, D. J., DOWSETT, H. J., HUNTER, S. J., LUNT, D. J. \& PICKERING, S. J. 2011. Sensitivity of Pliocene ice sheets to orbital forcing. Palaeogeography Palaeoclimatology Palaeoecology, 309, 98-110. 
DONDA, F., BRANCOLINI, G., DE SANTIS, L., \& TRINCARDI, F. 2003. Seismic facies and sedimentary processes on the continental rise off Wilkes Land (East Antarctica): Evidence of bottom current activity. Deep Sea Research II, 50, 8-9, 1509-1528.

DONDA, F., BRANCOLINI, G., O'BRIEN, P. E., DE SANTIS, L. \& ESCUTIA, C. 2007. Sedimentary processes in the Wilkes Land margin: a record of the Cenozoic East Antarctic Ice Sheet evolution. Journal of the Geological Society, 164, 243-256.

DOWSETT, H. J., 2007. Deep time perspectives on Climate Change: Marrying the signal from computer models and biological proxies. The Micropalaeontological Society Special Publications by The Geological Society of London, 459-480.

DUCE, R., GOLDSTEIN, A., BANERJEE, S., CURRY, W., FRIBERG, M., HUBER, J., JACKSON, M., MUKASA, S., NAISH, T., OLSEN, P., SUMMA, L. \& TREHU, A. 2012. Scientific Ocean Drilling: Accomplishments and challenges. National Academies Press, Washington D.C.

DUNBAR, G. B., NAISH, T. R., BARRETT, P. J., FIELDING, C. R. \& POWELL, R. D. 2008. Constraining the amplitude of late Oligocene bathymetric changes in Western Ross Sea during orbitally-induced oscillations in the East Antarctic Ice Sheet: (1) Implications for glacimarine sequence stratigraphic models. Palaeogeography Palaeoclimatology Palaeoecology, 260, 50-65.

EITTREIM, S. L., COOPER, A. K. \& WANNESSON, J. 1995. Seismic stratigraphic evidence of icesheet advances on the Wilkes Land margin of Antarctica. Sedimentary Geology, 96, 131-156.

EMILIANI, C. 1966. Isotopic Paleotemperatures. Science, 154, 851-860.

EPICA COMMUNITY MEMBERS. 2006. One-to-one coupling of glacial climate variability in Greenland and Antarctica. Nature, 444, 195-198.

ESCUTIA, C., DE SANTIS, L., DONDA, F., DUNBAR, R. B., COOPER, A. K., BRANCOLINI, G. \& EITTREIM, S. L. 2005. Cenozoic ice sheet history from East Antarctic Wilkes Land continental margin sediments. Global and Planetary Change, 45, 51-81.

ESCUTIA, C., DONDA, F., LOBO, F. J. \& TANAHASHI, M. 2007. Extensive debris flow deposits on the eastern Wilkes Land margin: a key to changing glacial regimes. In: A. K. Cooper, C. R. Raymond, et al., Eds. Antarctica: A Keystone in a Changing World - Online Proceedings of the 10th

International Symposium on Antarctic Earth Science 26, 4.

ESCUTIA, C., EITTREIM, S. L., COOPER, A. K. \& NELSON, C. H. 2000. Morphology and acoustic character of the antarctic Wilkes Land turbidite systems: Ice-sheet-sourced versus river-sourced fans. Journal of Sedimentary Research, 70, 84-93.

ESCUTIA, C., WARNKE, D., ACTON, G. D., BARCENA, A., BURCKLE, L., CANALS, M. \& FRAZEE, C. S. 2003. Sediment distribution and sedimentary processes across the Antarctic Wilkes Land margin during the Quaternary. Deep-Sea Research Part II-Topical Studies in Oceanography, $50,1481-1508$.

EVANS, H. B., HARMS, J. C. \& CHOQUETT.PW 1965. Grape - a Device for Continuous Porosity Determinations. Geophysics, 30, 1232-1235.

EXPEDITION 318 SCIENTISTS, 2010. Wilkes Land Glacial History: Cenozoic East Antarctic Ice Sheet evolution from Wilkes Land margin sediments. Integrated Ocean Drilling Program

Preliminary Report, 318. doi:10.2204/iodp.pr.318.2010 
FAIRBANKS, R. G. \& MATTHEWS, R. K. 1978. Marine Oxygen Isotope Record in Pleistocene Coral, Barbados, West-Indies. Quaternary Research, 10, 181-196.

FEILDING, C. R., NAISH, T. R., WOOLFE, K. J. \& LAVELLE, M. A. 2000. Facies Analysis and Sequence Stratigraphy of CRP-2/2A, Victoria Land Basin, Antarctica. Terra Antarctica, 7, 3, 323-338.

FRANCIS, J.E. \& HILL, R.S. 1996. Fossil plants from the Pliocene Sirius group, Transantarctic Mountains: evidence for climate from growth rings and fossil leaves. Palaios, 11, 389-396.

GERSONDE, R., ABELMANN, A., BRATHAUER, U., BECQUEY, S., BIANCHI, C., CORTESE, G., GROBE, H., KUHN, G., NIEBLER, H. S., SEGL, M., SIEGER, R., ZIELINSKI, U. \& FUTTERER, D. K. 2003. Last glacial sea surface temperatures and sea-ice extent in the Southern Ocean (AtlanticIndian sector): A multiproxy approach. Paleoceanography, 18.

GERSONDE, R., CROSTA, X., ABELMANN, A. \& ARMAND, L. 2005. Sea-surface temperature and sea lee distribution of the Southern Ocean at the EPILOG Last Glacial Maximum - A circumAntarctic view based on siliceous microfossil records. Quaternary Science Reviews, 24, 869-896.

GHIL M., ALLEN, R. M., DETTINGER, M. D., IDE, K., KONDRASHOV, D., MANN, M. E., ROBERTSON, A., SAUNDERS, A., TIAN, Y., VARADI, F. \& YIOU, P. 2002 . Advanced spectral methods for climatic time series. Reviews of Geophysics, 40, 1, 3.1-3.41.

GOMEZ, N., POLLARD, D., MITROVICA, J. X., HUYBERS, P. \& CLARK, P. U. 2012. Evolution of a coupled marine ice sheet-sea level model. Journal of Geophysical Research-Earth Surface, 117.

GOODGE, J. W. \& FANNING, C. M. 2010. Composition and age of the East Antarctic shield in eastern Wilkes Land determined by proxy from Oligiocene-Pleistocene glaciomarine sediment and Beacon Supergroup sandstones, Antarctica. Geological Society of American Bulletin, 122, 1135-1159.

GOLLEDGE, N. J., FOGWILL, C. J., MACKINTOSH, A. N. \& BUCKLEY, K. M. 2012. Dynamics of the last glacial maximum Antarctic ice-sheet and its response to ocean forcing. Proceedings of the National Academy of Sciences of the United States of America, 109, 40.

GRENANDER, U., POLLAK, H. O. \& SLEPIAN, D. 1959. The Distribution of Quadratic Forms in Normal Variates - a Small Sample Theory with Applications to Spectral Analysis. Journal of the Society for Industrial and Applied Mathematics, 7, 374-401.

GROBE, H., MACKENSEN, A., HUBBERTEN, H. W., SPIESS, V. \& FUTTERER, D. K. 1990. Stable Isotope Record and Late Quaternary Sedimentation-Rates at the Antarctic Continental-Margin. Geological History of the Polar Oceans : Arctic Versus Antarctic, 308, 539-572.

GRUTZNER, J., HILLENBRAND, C. D. \& REBESCO, M. 2005. Terrigenous flux and blogenic silica deposition at the Antarctic continental rise during the late Miocene to early Pliocene: implications for ice sheet stability and sea ice coverage. Global and Planetary Change, 45, 131-149.

HALL, I. R., MCCAVE, I. N., SHACKLETON, N. J., WEEDON, G. P. \& HARRIS, S. E. 2001. Intensified deep Pacfic inflow and ventilation in Pleistocene glacial times. Nature, 412, 809-812.

HAMBREY, M. J., LARSEN, B. \& EHRMANN, W. U. 1991. The glacial record from the Prydz Bay continental shelf, East Antarctica. In: J. Barron, B. Larsen, et al., (Eds). Ocean Drilling Program, 119, Scientific Results. College Station, Texas, 77-132. 
HAMBREY, M. J. \& MCKELVEY, B. 2000. Neogene fjordal sedimentation on the western margin of the Lambert Graben, East Antarctica. Sedimentology, 47, 1236-1236.

HARMS, J.C. \& CHOQUETTE, P.W. 1965. Geologic evaluation of a gamma-ray porosity device. 6th Annual SPWLA Logging Symposium, Dallas, Texas, C1-C37.

HAUG, F., SIGMAN, D., TIEDEMANN, R., PEDERSEN, T. \& SARNTHEIN, S. 1999. Onset of permanent stratification in the subarctic Pacific Ocean. Nature, 401, 779-782.

HAYS, J. D., IMBRIE, J. \& SHACKLETON, N. J. 1976. Variations in Earths Orbit - Pacemaker of Ice Ages. Science, 194, 1121-1132.

HAYWOOD, A. M., VALDES, P. J., SELLWOOD, B. W. \& KAPLAN, J. O. 2002. Antarctic climate during the middle Pliocene: model sensitivity to ice sheet variation. Palaeogeography Palaeoclimatology Palaeoecology, 182, 93-115.

HEPP, D. A., MORZ, T., HENSEN, C., FREDERICHS, T., KASTEN, S., RIEDINGER, N. \& HAY, W. W. 2009. A late Miocene-early Pliocene Antarctic deepwater record of repeated iron reduction events. Marine Geology, 266, 198-211.

HESSE, R. 1975. Turbiditic and non-turbiditic mudstone of Cretaceous flysch sections of the East Alps and other basin. Sedimentology, 22, 387-416.

HESSE, R., KLAUCKE, I., RYAN, W. B. F. \& PIPER, D. J. W. 1997. Ice-sheet sourced juxtaposed turbidite systems in Labrador Sea. Journal of the Geological Society of Canada, 24, 1, 3-12.

HILL, K. L., RINTOUL, S. R., COLEMAN, R. \& RIDGWAY, K. R. 2008. Wind forced low frequency variability of the East Australia Current. Geophysical Research Letters, 35.

HILL, S. L., REID, K., THORPE, S. E., HINKE, J. \& WATTERS, G. M. 2007. A compilation of parameters for ecosystem dynamics models of the Scotia Sea-Antarctic Peninsula region. Camlr Science, 14, 1-25.

HILLENBRAND, C. D. \& CORTESE, G. 2006. Polar stratification: A critical view from the Southern Ocean. Palaeogeography Palaeoclimatology Palaeoecology, 242, 240-252.

HILLENBRAND, C. D. \& EHRMANN, W. 2005. Late Neogene to Quaternary environmental changes in the Antarctic Peninsula region: evidence from drift sediments. Global and Planetary Change, 45, 165-191.

HILLENBRAND, C. D., EHRMANN, W., LARTER, R. D., BENETTI, S., DOWDESWELL, J. A., COFAIGH, C. O., GRAHAM, A. G. C. \& GROBE, H. 2009. Clay mineral provenance of sediments in the southern Bellingshausen Sea reveals drainage changes of the West Antarctic Ice Sheet during the Late Quaternary. Marine Geology, 265, 1-18.

HOWARD, W. R. \& PRELL, W. L. 1992. Late Quaternary Surface Circulation of the Southern Indian Ocean and its Relationship to Orbital Variations. Paleoceanography, 7, 1, 79-117.

HSU, K. J. 1986. Mesozoic and Cenozoic oceans. American Geophysical Union, Washington, DC, 153 p.

HUNT, C. P., MOSKOWITZ, B. M. \& BANERJEE, S. B. 1995. Magnetic properties of rocks and minerals. In: T.J. Ahrens, Ed. A Handbook of Physical Constants. American Geophysical Union, Washington, DC, 3, 189-204. 
HUYBERS. P. 2003. Spectral estimation using the Thomson multi-taper method wit accurate error estimates. www.people.fas.harvard.edu/ phuybers/mfiles/pmtmPH.m

HUYBERS, P. 2004. On the origins of the ice ages: insolation forcing, age models, and nonlinear climate change. Cambridge, Massachusettes: Ph.D. Thesis, Massachusetts Institute of Technology.

HUYBERS, P. 2006. Early Pleistocene glacial cycles and the integrated summer insolation forcing. Science, 313, 508-511.

HUYBERS, P. \& DENTON, G. 2008. Antarctic temperature at orbital timescales controlled by local summer duration. Nature Geoscience, 1, 787-792.

HUYBERS, P. \& TZIPERMAN, E. 2008. Integrated summer insolation forcing and 40,000-year glacial cycles: The perspective from an ice-sheet/energy-balance model. Paleoceanography, 23.

HUYBERS, P.W. \& WUNSCH, C. 2005. Obliquity pacing of the Late Pleistocene glacial terminations. Nature 434, 491-494.

IPCC._2007. Core Writing Team; Pachauri, R.K; and Reisinger, A., (Eds). Climate Change 2007: Synthesis Report, Contribution of Working Groups I, II and III to the Fourth Assessment Report of the Intergovernmental Panel on Climate Change, Geneva, Switzerland, 104 p.

JANSEN, J. H. F., UFKES, E. \& SCHNEIDER, R. R. 1996. Late Quaternary movements of the Angola-Benguela front, SE Atlantic, and implications for advection in the equatorial ocean. South Atlantic, 553-575.

JERVEY, M. T. 1988. Quantitative geological modeling of siliciclastic rock sequences and their seismic expression. In: C. K., Wilgus, B.S. Hastings, C.G.St.C. Kendall, H.W. Posamentier, C.A. Ross \& J.C.Van Wagoner, Eds. Sea-Level Changes: An Integrated Approach. Society of Economic Paleontologists and Mineralogists, Special Publication, 42, 47-69.

JOUZEL, J., MASSON-DELMOTTE, V., CATTANI, O., DREYFUS, G., FALOURD, S., HOFFMANN, G., MINSTER, B., NOUET, J., BARNOLA, J. M., CHAPPELLAZ, J., FISCHER, H., GALLET, J. C., JOHNSEN, S., LEUENBERGER, M., LOULERGUE, L., LUETHI, D., OERTER, H., PARRENIN, F., RAISBECK, G., RAYNAUD, D., SCHILT, A., SCHWANDER, J., SELMO, E., SOUCHEZ, R., SPAHNI, R., STAUFFER, B., STEFFENSEN, J. P., STENNI, B., STOCKER, T. F., TISON, J. L., WERNER, M. \& WOLFF, E. W. 2007. Orbital and millennial Antarctic climate variability over the past 800,000 years. Science, 317, 793-796.

KANFOUSH, S. L., HODELL, D. A. \& GUILDERSON, T. P. 2000. Interpreting iceberg deposits in the deep sea - Response. Science, 290, 51-52.

KAPLAN, M. R., SCHAEFER, J. M., DENTON, G. H., BARRELL, D. J. A., CHINN, T. J. H., PUTNAM, A. E., ANDERSEN, B. G., FINKEL, R. C., SCHWARTZ, R. \& DOUGHTY, A. M. 2010. Glacier retreat in New Zealand during the Younger Dryas stadial. Nature, 467, 194-197.

KENNETT, J. P. 1977. Cenozoic Evolution of Antarctic Glaciation, Circum-Antarctic Ocean, and Their Impact on Global Paleoceanography. Journal of Geophysical Research-Oceans and Atmospheres, 82, 3843-3860.

KENNETT, J.P. \& HODELL, D.A. 1993. Evidence for relative climatic stability of Antarctica during the early Pliocene: A marine perspective. Geografiska Annaler, 75A, 204-220.

KENNETT, J. P. \& SHACKLETON, N. J. 1975. Laurentide Ice Sheet Meltwater Recorded in Gulf of Mexico Deep-Sea Cores. Science, 188, 147-150. 
KOMINZ, M.A., BROWNING, J.V., MILLER, K.G., SUGARMAN, P.J., MIZINTSEVA, S. \& SCOTESE, C.R. 2008. Late Cretaceous to Miocene sea-level estimates from the New Jersey and Delaware coastal plain boreholes: an error analysis. Basin Research 20, 211-226.

KOPP, R.E., SIMONS, F.J., MITROVICA, J.X., MALOOF, A.C. \& OPPENHEIMER, M. 2009. Probabilistic assessment of sea level during the last interglacial stage. Nature, 462, 7275, 863-U51.

KUENEN, P. H. 1937. On the total amount of sedimentation in the deep sea. American Journal of Science, 34, 457-468.

KUENEN, P. H. 1950. Turbidity currents of high density. Report for International Geological Congress, 18, 8, 44-52.

LAMBERT, F., DELMONTE, B., PETIT, J. R., BIGLER, M., KAUFMANN, P. R., HUTTERLI, M. A., STOCKER, T. F., RUTH, U., STEFFENSEN, J. P. \& MAGGI, V. 2008. Dust-climate couplings over the past 800,000 years from the EPICA Dome C ice core. Nature, 452, 616-619.

LARTER, R.D. 2007. Margin architecture reveals the transition to the modern Antarctic ice sheet ca. 3 Ma: Comment. Geology Online Forum.

LASKAR, J., ROBUTEL, P., JOUTEL, F., GASTINEAU, M., CORREIA, A. C. M. \& LEVRARD, B. 2004. A long-term numerical solution for the insolation quantities of the Earth. Astronomy \& Astrophysics, 428, 261-285.

LEAR, C.H., ROSENTHAL, Y., COXALL, H.K. \& WILSON, P.A. 2004 Late Eocene to early Miocene ice sheet dynamics and the global carbon cycle. Paleoceanography, 19, 4, 1-11.

LEWIS, A. R., MARCHANT, D. R., ASHWORTH, A. C., HEDENA, L., HEMMING, S. R., JOHNSON, J. V., LENG, M. J., MACHLUS. M. L., NEWTON, A. E., RAINE, J. I., WILLENBRING, J. K., WILLIAMS, M., \& WOLFE, A. P. 2008. Mid-Miocene cooling and the extinction of tundra in continental Antarctica. Proceedings of the National Academy of Sciences of the United States of America, 105, 31, 10676-10680.

LEWIS, A. R., MARCHANT, D. R., ASHWORTH, A. C., HEMMING, S. R. \& MACHLUS, M. L. 2007. Major middle Miocene global climate change: Evidence from East Antarctica and the Transantarctic Mountains. Geological Society of America Bulletin, 119, 1449-1461.

LEVY, R., CODY, R., CRAMPTON, J., FIELDING, C., GOLLEDGE, N., HARWOOD, D., HENRYS, S., MCKAY, R., NAISH, T., OHNEISER, C., WILSON, G., WILSON, T. \& WINTER, D. 2012. Late Neogene climate and glacial history of the Southern Victoria Land coast from integrated drill core, seismic and outcrop data. Global and Planetary Change, 80/81, 61-84.

LISIECKI, L. E. \& RAYMO, M. E. 2005. A Pliocene-Pleistocene stack of 57 globally distributed benthic delta O-18 records. Paleoceanography, 20.

LISIECKI, L. E., RAYMO, M. E. \& CURRY, W. B. 2008. Atlantic overturning responses to Late Pleistocene climate forcings. Nature, 456, 85-88.

LOMB, N. R. 1976. Least-Squares Frequency-Analysis of Unequally Spaced Data. Astrophysics and Space Science, 39, 447-462.

LOZIER, M. S. 2010. Deconstructing the Conveyor Belt. Science, 328, 1507-1511. 
LUCCHI, R. G. \& REBESCO, M. 2007. Glacial contourites on the Antarctic Peninsula margin: insight for palaeoenvironmental and palaeoclimatic conditions. In: A. R. Viana \& M. Rebesco, Eds. Economic and Palaeoceanographic Significance of Contourite Deposits. Geological Society, London, Special Publications, 276, 111-127.

LYTHE, M. B., VAUGHAN, D. G. \& THE BEDMAP CONSORTIUM. 2001. BEDMAP: A new ice thickness and subglaical topographic model of Antarctica. Journal of Georphysical Research, 106, B6, 11335-11351.

MACKINTOSH, A., GOLLEDGE, N., DOMACK, E., DUNBAR, R., LEVENTER, A., WHITE, D., POLLARD, D., DECONTO, R., FINK, D., ZWARTZ, D., GORE, D. \& LAVOIE, C. 2011. Retreat of the East Antarctic ice sheet during the last glacial termination. Nature Geoscience, 4, 195-202.

MANN, M. E. \& LEES, J. M. 1996. Robust estimation of background noise and signal detection in climatic time series. Climatic Change, 33, 409-445.

MANN M. E. \& PARK J. 1993. Spatial correlations of interdecadal variation in global surface temperatures. Geophysical Research Letters, 20, 1055-1058.

MARCHANT D.R., DENTON, G.H., SUGDEN, D.E. \& SWISHER, C.C. 1993. Miocene glacial stratigraphy and landscape evolution of the western Asgard Range, Antarctica. Geografiska Annaler, 75, 303-330.

MARSLAND, S. J., BINDOFF, N. L., WILLIAMS, G. D. \& BUDD, W. F. 2004. Modeling water mass formation in the Mertz Glacier Polynya and Adelie Depression, East Antarctica. Journal of Geophysical Research-Oceans, 109.

MARSLAND, S. J., CHURCH, J. A., BINDOFF, N. L. \& WILLIAMS, G. D. 2007. Antarctic coastal polynya response to climate change. Journal of Geophysical Research, 112.

MARTINEZ-GARCIA, A., ROSELL-MELÉ, A., JACCARD, S.L., GEIBERT, W., SIGMAN, D.M. \& HAUG, G.H. 2011. Southern Ocean dust-climate coupling over the past four million years. Nature, $76,312-315$.

MASLIN M.A., LI, X. S., LOUTRE M. F., \& BERGER A. 1998. The contribution of orbital forcing to the progressive intensification of Northern Hemisphere Glaciation. Quaternary Science Reviews, 17, 411-426.

MASSOM, R. A., HILL, K. L., LYTLE, V. I., WORBY, A. P., PAGET, M. \& ALLISON, I. 2001. Effects of regional fast-ice and iceberg distributions on the behaviour of the Mertz Glacier polynya, East Antarctica. Annals of Glaciology, Vol 33, 391-398.

MCCARTNEY, M. S. \& DONOHUE, K. A. 2007. A deep cyclonic gyre in the Australian-Antarctic Basin. Progress in Oceanography, 75, 675-750.

MCCAVE, I. N., CARTER, L. \& HALL, I. R. 2008. Glacial-interglacial changes in watermass structure and flow in the SW Pacific Ocean. Quaternary Science Reviews, 27, 19-20, 1886-1908.

MCKAY, R. M., BROWNE, G., CARTER, L., COWAN, E., DUNBAR, G., KRISSEK, L., NAISH, T., POWELL, R., REED, J., TALARICO, F. \& WILCH, T. 2009. The stratigraphic signature of the late Cenozoic Antarctic Ice Sheets in the Ross Embayment. Geological Society of America Bulletin, 121, 1537-1561.

MCKAY, R. M., BARRETT, P., HARPER, M. \& HANNAH, M. 2008. Atmospheric transport and concentration of diatoms in the Allan Hills, Transantarctic Mountains. Palaeogeography,

Palaeoclimatology, Palaeoecology, 260, 168-183. 
MCKAY, R. M., NAISH, T., CARTER, L., RIESSELMAN, C., DUNBAR, R., SJUNNESKOG, C., WINTER, D., SANGIORGI, F., WARREN, C., PAGANI, M., SCHOUTEN, S., WILLMOTT, V., LEVY, R., DECONTO, R. \& POWELL, R. D. 2012a. Antarctic and Southern Ocean influences on Late Pliocene global cooling. Proceedings of the National Academy of Sciences of the United States of America, 109, 6423-6428.

MCKAY, R. M., NAISH, T., POWELL, R., BARRETT, P., SCHERER, R., TALARICO, F., KYLE, P., MONIEN, D., KUHN, G., JACKOLSKI, C. \& WILLIAMS, T. 2012b. Pleistocene variability of Antarctic Ice Sheet extent in the Ross Embayment. Quaternary Science Reviews, 34, 93-112.

MERCER, J. H. 1986. Southern Chile: A modern analogue of the southern shores of the Ross embayment during Pliocene warm intervals. Antarctic Journal of the United States, 21, 5, 103-105.

MILANKOVITCH, M.M. 1941. Kanon der Erdbestrahlung und seine Anwendung auf das Eiszeitenproblem. Royal Serbian Sciences, Special Publications 132, Section of Mathematical and Natural Sciences, Belgrade, (Canon of Insolation and the Ice Age Problem, English translation by Israel Program for Scientific Translation, published for the US Department of Commerce and the National Science Foundation, Washington DC, 1969).

MILLER, K.G., BROWNING, J.V, KULPECZ, A., NAISH, T. R., KOMINZ. M., ROSENTHAL, Y., CRAMER, B.S., PELTIER, R., SOSDIAN, S. \& WRIGHT, J.D. 2012. The high tide of the Pliocene: Implications of a 25$20 \mathrm{~m}$ eustatic peak for Antarctic glaciation. Geology. In press.

MILLER, K. G. \& HART, M. B. 1987. Cenozoic Planktonic Foraminifers and Hiatuses on the NewJersey Slope and Rise - Deep-Sea Drilling Project Leg-95, Northwest Atlantic. Initial Reports of the Deep Sea Drilling Project, 95, 253-265.

MiLleR, K. G., KOMINZ, M. A., BROWNING, J. V., WRIGHT, J. D., MOUNTAIN, G. S., KATZ, M. E., SUGARMAN, P. J., CRAMER, B. S., CHRISTIE-BLICK, N. \& PEKAR, S. F. 2005. The phanerozoic record of global sea-level change. Science, 310, 1293-1298.

MILLER, K. G., WRIGHT, J. D. \& FAIRBANKS, R. G. 1991. Unlocking the Ice House - OligoceneMiocene Oxygen Isotopes, Eustasy, and Margin Erosion. Journal of Geophysical Research-Solid Earth and Planets, 96, 6829-6848.

MITROVICA, J.X. \& WAHR, J. 2011. Ice Age Earth Rotation. Annual Review of Earth and Planetary Sciences, 39, 1, 577-616.

NAISH, T. 1997. Constraints on the amplitude of late Pliocene eustatic sea-level fluctuations: New evidence from the New Zealand shallow-marine sediment record. Geology, 25, 1139-1142.

NAISH, T., CARTER, L., WOLFF, E., POLLARD, D. \& POWELL. R. 2009a. Late PliocenePleistocene Antarctic climate variability at orbital and suborbital scale: Ice sheet, ocean and atmospheric interactions. In: F. Florindo and M. Siegert, Eds. Antarctic Climate Evolution, Developments in Earth and Environmental Science, Elsevier. 8, 11, 465-529.

NAISH, T., POWELL, R., LEVY, R., WILSON, G., SCHERER, R., TALARICO, F., KRISSEK, L., NIESSEN, F., POMPILIO, M., WILSON, T., CARTER, L., DECONTO, R., HUYBERS, P., MCKAY, R., POLLARD, D., ROSS, J., WINTER, D., BARRETT, P., BROWNE, G., CODY, R., COWAN, E., CRAMPTON, J., DUNBAR, G., DUNBAR, N., FLORINDO, F., GEBHARDT, C., GRAHAM, I., HANNAH, M., HANSARAJ, D., HARWOOD, D., HELLING, D., HENRYS, S., HINNOV, L., KUHN, G., KYLE, P., LAUFER, A., MAFFIOLI, P., MAGENS, D., MANDERNACK, K., MCINTOSH, W., MILLAN, C., MORIN, R., OHNEISER, C., PAULSEN, T., PERSICO, D., RAINE, I., REED, J., RIESSELMAN, C., SAGNOTTI, L., SCHMITT, D., SJUNNESKOG, C., STRONG, P., TAVIANI, M., 
VOGEL, S., WILCH, T. \& WILLIAMS, T. 2009b. Obliquity-paced Pliocene West Antarctic ice sheet oscillations. Nature, 458, 322-U84.

NAISH, T. R. \& WILSON, G. S. 2009. Constraints on the amplitude of Mid-Pliocene (3.6-2.4 Ma) eustatic sea-level fluctuations from the New Zealand shallow-marine sediment record. Philosophical Transactions of the Royal Society a-Mathematical Physical and Engineering Sciences, 367, 169-187.

NAISH, T. R., WOOLFE, K. J., BARRETT, P. J., WILSON, G. S., ATKINS, C., BOHATY, S. M., BUCKER, C. J., CLAPS, M., DAVEY, F. J., DUNBAR, G. B., DUNN, A. G., FIELDING, C. R., FLORINDO, F., HANNAH, M. J., HARWOOD, D. M., HENRYS, S. A., KRISSEK, L. A., LAVELLE, M., VAN DER MEER, J., MCINTOSH, W. C., NIESSEN, F., PASSCHIER, S., POWELL, R. D., ROBERTS, A. P., SAGNOTTI, L., SCHERER, R. P., STRONG, C. P., TALARICO, F., VEROSUB, K. L., VILLA, G., WATKINS, D. K., WEBB, P. N. \& WONIK, T. 2001. Orbitally induced oscillations in the East Antarctic ice sheet at the Oligocene/Miocene boundary. Nature, 413, 719-723.

NISANCIOGLU, K. 2004. Modeling the impact of atmospheric moisture transport on global ice volume. Cambridge, Massachusetts: Ph.D thesis, Massachusetts Institute of Technology.

O'BRIEN, P. E., COOPER, A. K., RICHTER, C., et al. 2001. Proceedings of the Ocean Drilling Program, Initial Reports. Vol. 188 [Online], http://www.odp.tamu.edu/publications/188_IR/188ir.htm

ORSI, A. H., JOHNSON, G. C. \& BULLISTER, J. L. 1999. Circulation, mixing, and production of Antarctic Bottom Water. Progress in Oceanography, 43, 55-109.

ORSI, A. H., NOWLIN, W. D. \& WHITWORTH, T. 1993. On the Circulation and Stratification of the Weddell Gyre. Deep-Sea Research Part I-Oceanographic Research Papers, 40, 169-203.

ORSI, A.H., \& WHITWORTH III, T. 2005. Hydrographic Atlas of the World Ocean Circulation Experiment (WOCE). In: M. Sparrow, P. Chapman and J. Gould Eds. Volume 1: Southern Ocean International WOCE Project Office, Southampton, U.K.

ORSI, A.H., WHITWORTH III, T. \& NOWLIN JR. W.D. 1995. On the meridional extent and fronts of the Antarctic Circumpolar Current. Deep-Sea Research, 42, 641-673.

PAGANI, M., LIU, Z. H., LARIVIERE, J. \& RAVELO, A. C. 2010. High Earth-system climate sensitivity determined from Pliocene carbon dioxide concentrations. Nature Geoscience, 3, 27-30.

PAGANI, M., ZACHOS, J. C., FREEMAN, K. H., TIPPLE, B. \& BOHATY, S. 2005. Marked decline in atmospheric carbon dioxide concentrations during the paleogene. Science, 309, 5734, 600-603.

PAHNKE, K. \& ZAHN, R. 2005. Southern hemisphere water mass conversion linked with North Atlantic climate variability. Science, 307, 1741-1746.

PAILLARD, D., LABEYRIE, L. \& YIOU, P. 1996. Macintosh Program performs time-series analysis. Eos, Transactions American Geophysical Union, 77, 39, 379-379.

PALIKE, H., NORRIS, R. D., HERRLE, J. O., WILSON, P. A., COXALL, H. K., LEAR, C. H., SHACKLETON, N. J., TRIPATI, A. K. \& WADE, B. S. 2006. The heartbeat of the oligocene climate system. Science, 314, 1894-1898.

PEARSON, P. N. \& PALMER, M. R. 2000. Atmospheric carbon dioxide concentrations over the past 60 million years. Nature, 406, 695-699.

PETIT, J. R., JOUZEL, J., RAYNAUD, D., BARKOV, N. I., BARNOLA, J. M., BASILE, I., BENDER, M., CHAPPELLAZ, J., DAVIS, M., DELAYGUE, G., DELMOTTE, M., KOTLYAKOV, V. M., 
LEGRAND, M., LIPENKOV, V. Y., LORIUS, C., PEPIN, L., RITZ, C., SALTZMAN, E. \& STIEVENARD, M. 1999. Climate and atmospheric history of the past 420,000 years from the Vostok ice core, Antarctica. Nature, 399, 429-436.

PILLANS, B. J., CHAPPELL, J. \& NAISH, T. 1998, The Milankovitch climatic beat: template for Plio/Pleistocene sea level changes and sequence stratigraphy. Sedimentary Geology, 122, 5-22.

PIPER, D. J. W. \& NORMARK, W. R. 1983. Turbidite Depositional Patterns and Flow Characteristics, Navy Submarine Fan, California Borderland. Sedimentology, 30, 681-694.

POLLARD, D. \& DECONTO, R. M. 2009. Modelling West Antarctic ice sheet growth and collapse through the past five million years. Nature, 458, 329-U89.

POWELL, R. D. \& COOPER, J. M. 2002. A glacial sequence stratigraphic model for temperate, glaciated continental shelves. Glacier-Influenced Sedimentation on High-Latitude Continental Margins, 203, 215-244.

PRENTICE, M. L. \& MATHEWS, R. K. 1988. Cenozoic ice-volume history: Development of a composite oxygen isotope record. Geology, 4, 413-416.

PUTNAM, A. E., DENTON, G. H., SCHAEFER, J. M., BARRELL, D. J. A., ANDERSEN, B. G., FINKEL, R. C., SCHWARTZ, R., DOUGHTY, A. M., KAPLAN, M. R. \& SCHLUCHTER, C. 2010. Glacier advance in southern middle-latitudes during the Antarctic Cold Reversal. Nature Geoscience, 3, 700-704.

RAVELO, A. C., ANDREASEN, D. H., LYLE, M., LYLE, A. \& WARA, M. W. 2004. Regional climate shifts caused by gradual global cooling in the Pliocene epoch. Nature, 429, 263-267.

RAYMO, M. E. 1994. The Initiation of Northern Hemisphere Glaciation. Annual Review of Earth and Planetary Sciences, 22, 353 -383.

RAYMO, M. E. 1997. The timing of major climate terminations. Paleoceanography, 12, 577-585.

RAYMO, M. E., LISIECKI, L. E. \& NISANCIOGLU, K. H. 2006. Plio-pleistocene ice volume, Antarctic climate, and the global delta O-18 record. Science, 313, 492-495.

RAYMO, M. E., MITROVICA, J. X., O'LEARY, M. J., DECONTO, R. M. \& HEARTY, P. L. 2011. Departures from eustasy in Pliocene sea-level records. Nature Geoscience, 4, 328-332.

RAYMO, M. E. \& NISANCIOGLU, K. 2003. The 41 kyr world: Milankovitch's other unsolved mystery. Paleoceanography, 18.

RAYMO, M. E., RUDDIMAN, W. F., CLEMENT, B. M., KIDD, R. B., BALDAUF, J. G., DOLAN, J. F., EGGERS, M. R., HILL, P. R., KEIGWIN, L. D., JR., MITCHELL, M., PHILIPPS, I., ROBINSON, F., SALEHIPOUR, S. A., TAKAYAMA, T., THOMAS, E., UNSOLD, G., WEAVER, P. P. E. \& ORLOFSKY, S. E. 1987. Pliocene-Pleistocene paleoceanography of the North Atlantic at Deep Sea Drilling Project Site 609 Initial reports of the Deep Sea Drilling Project covering Leg 94 of the cruises of the drilling vessel Glomar Challenger, Norfolk, Virginia, to St. John's, Newfoundland, June-August 1983. Initial Reports of the Deep Sea Drilling Project, 94, 895-901.

REBESCO, M., CAMERLENGHI, A., GELETTI, R. \& CANALS, M. 2006. Margin architecture reveals the transition to the modern Antarctic ice sheet ca. 3 Ma. Geology, 34, 4, 301-304. 
REBESCO, M., LARTER, R. D., BARKER, P. F., CAMERLENGHI, A. \& VANNESTE, L. E. 1997. The history of sedimentation on the continental rise west of the Antarctic Peninsula. In: P. F. Barker, \& A. K. Cooper (Eds). Geology and Seismic Stratigraphy of the Antarctic Margin, 2. American Geophysical Union, Washington, DC, Antarctic Research Series, 71, 29-49.

RIDGWAY, K. R. \& DUNN, J. R. 2007. Observational evidence for a Southern Hemisphere oceanic supergyre. Geophysical Research Letters, 34.

RINTOUL, S. R. 2007. Rapid freshening of Antarctic Bottom Water formed in the Indian and Pacific oceans. Geophysical Research Letters, 34.

RINTOUL, S. R. \& TRULL, T. W. 2001. Seasonal evolution of the mixed layer in the Subantarctic Zone south of Australia. Journal of Geophysical Research-Oceans, 106, 31447-31462.

ROEMMICH, D. 2007. Physical oceanography - Super spin in the southern seas. Nature, 449, 34-35.

SALLE, J. B., SPEER, K. G. \& RINTOUL, S. R. 2010. Zonally asymmetric response of the Southern Ocean mixed-layer depth to the Southern Annular Mode. Nature Geoscience, 3, 4, 273-279.

SCARGLE, J. D. 1982. Studies in Astronomical Time-Series Analysis .2. Statistical Aspects of Spectral-Analysis of Unevenly Spaced Data. Astrophysical Journal, 263, 835-853.

SCHAEFER, J. M., DENTON, G. H., BARRELL, D. J. A., IVY-OCHS, S., KUBIK, P. W., ANDERSEN, B. G., PHILLIPS, F. M., LOWELL, T. V. \& SCHLUCHTER, C. 2006. Near-synchronous interhemispheric termination of the last glacial maximum in mid-latitudes. Science, 312, 1510-1513.

SCHAEFER, J. M., DENTON, G. H., KAPLAN, M. R., PUTNAM, A., FINKEL, R. C., BARRELL, D. J. A., ANDERSEN, B. G., SCHWARTZ, R., MACKINTOSH, A., CHINN, T. \& SCHLUCHTER, C. 2009. High-Frequency Holocene Glacier Fluctuations in New Zealand Differ from the Northern Signature. Science, 324, 622-625.

SCHERER, R. P., BOHATY, S. M., DUNBAR, R. B., ESPER, O., FLORES, J. A., GERSONDE, R., HARWOOD, D. M., ROBERTS, A. P. \& TAVIANI, M. 2008. Antarctic records of precession-paced insolation-driven warming during early Pleistocene Marine Isotope Stage 31. Geophysical Research Letters, 35.

SCHMITZ, W. J. 1995. On the Interbasin-Scale Thermohaline Circulation. Reviews of Geophysics, $33,151-173$.

SCHULZ, M. \& STATTEGGER, K. 1997. SPECTRUM: Spectral analysis of unevenly spaced paleoclimatic time series. Computers \& Geosciences, 23, 929-945.

SEKI, O., FOSTER, G. L., SCHMIDT, D. N., MACKENSEN, A., KAWAMURA, K. \& PANCOST, R. D. 2010. Alkenone and boron-based Pliocene $\mathrm{pCO}_{2}$ records. Earth and Planetary Science Letters, 292, 201-211.

SHACKLETON, N. J. 1987. Oxygen Isotopes, Ice Volume and Sea-Level. Quaternary Science Reviews, 6, 183-190.

SHACKLETON, N. J. 2000. The 100,000-year ice-age cycle identified and found to lag temperature, carbon dioxide, and orbital eccentricity. Science, 289, 1897-1902.

SHACKLETON, N. J., HALL, M. A. \& PATE, D. 1995. Pliocene stable isotope stratigraphy of ODP site 846. In: Pisias, N., Mayer, L. and Janacek, T., et al., (Eds.), Proceedings of Ocean Drilling Program, Scientific results, Volume 138: College Station, Texas, Ocean Drilling Program, 337-353. 
SHACKLETON, N. J. \& OPDYKE, N. D. 1973. Oxygen isotope and paleomagnetic stratigraphy of equatorial Pacific Core V28-238: oxygen isotope temperatures and ice volume on a 105 year and 106 year scale. Quaternary Research, 3, 39-55.

SHEVENELL, A. E., KENNETT, J. P. \& LEA, D. W. 2004. Middle Miocene Southern Ocean cooling and Antarctic cryosphere expansion. Science, 305, 1766-1770.

SIGMAN, D. M. \& BOYLE, E. A. 2000. Glacial/interglacial variations in atmospheric carbon dioxide. Nature, 407, 859-869.

STEFFENSEN, P., ANDERSEN, K., BILGER, M., CLAUSEN, H., DAHL-JENSEN, D., FISCHER, H., et al., 2008. High-Resolution Greenland Ice Core Data Shows Abrupt Climate Change Happens in Few Years. Science, 321, 5889, 680-684.

STEIG, E. J. 2006. Climate change - The south-north connection. Nature, 444, 152-153.

STOERMER, E.F. \& SMOL, J.P. 1999. The Diatoms: Applications for the Environmental and Earth Sciences. Cambridge University Press, Cambridge. 469 pp.

STOW, D. A. V. \& PIPER, D. J.W. 1984. Deep-water fine-grained sediments: facies models. In D. A. V. Stow \& D. J. W. Piper Eds. Fine-grained Sediments: Deep-Water Processes and Facies. Special Publication for the Geological Society of London, 15, 611-645.

STOW, D. A. V., READING, H., AND COLLINSON, J. D. 1996. Deep seas. In: H. Reading, Ed. Sedimentary environments: Processes, facies and stratigraphy. Blackwell Science Ltd., Oxford, 395453.

TAUXE, L., STICKLEY, C., SUGISAKI, S., BIJL, P.K., BOHATY, S., BRINKHUIS, H., ESCUTIA, C,, FLORES, J.A., IWAI, M., MCKAY, R., PASSCHIER, S., PROSS, J., ROHL, U., WELSH, K., WILLIAMS, T., and the EXPEDITION 318 SCIENTISTS. 2012. Chronostratigraphic framework for the IODP Expedition 318 cores from the Wilkes Land Margin: Constraints for paleoceanographic reconstruction. Paleoceanography, in press.

THOMSON D. J. 1982. Spectrum estimation and harmonic analysis. Proceedings of the Institute of Electrical and Electronics Engineers, 70, 9, 1055-1096.

THUNELL, R., ANDERSON, D., GELLAR, D. \& MIAO, Q. M. 1994. Sea-Surface Temperature Estimates for the Tropical Western Pacific during the Last Glaciation and Their Implications for the Pacific Warm Pool. Quaternary Research, 41, 255-264.

TOGGWEILER, J. R. \& RUSSELL, J. 2008. Ocean circulation in a warming climate. Nature, 451, 286-288.

TOGGWEILER, J. R., RUSSELL, J. L. \& CARSON, S. R. 2006. Midlatitude westerlies, atmospheric CO2, and climate change during the ice ages. Paleoceanography, 21. doi:10.1029/2005PA001154(2007).

TOGGWEILER, J. R. \& SAMUELS, B. 1995. Effect of Sea-Ice on the Salinity of Antarctic Bottom Waters. Journal of Physical Oceanography, 25, 1980-1997.

TRAUTH, M. H. 2007. MATLAB ${ }^{\circledR}$ Recipes for Earth Science, $2^{\text {nd }}$ Ed. Springer Berlin Heidelberg, New York, 288 p. 
TURNER, J., COMISO, J. C., MARSHALL, G. J., LACHLAN-COPE, T. A., BRACEGIRDLE, T., MAKSYM, T., MEREDITH, M. P., WANG, Z. \& ORR, A. 2009. Non-annular atmospheric circulation change induced by stratospheric ozone depletion and its role in the recent increase of Antarctic sea ice extent. Geophysical Research Letters, 36, L08502.

WALKER, R. G. \& JAMES, N. P. 1992. Facies Models: Response to sea level change. Geological Association Canada, Canada, 409 p.

WALTHER, J. 1984. Einleitung in die Geologie als Historische Wissenschaft, Bd. 3. Lithogenesis der Gegenwart, 535-1055. Fischeri Verlag, Jena. (As summarised in Boggs, S. 2001. Principles of sedimentology and stratigraphy $3^{\text {rd }}$ Edition. Prentice Hall, New Jersey).

WEBB, P. N., HARWOOD, D. M., MCKELVEY, B. C., MERCER, J. H. \& STOTT, L. D. 1984. Cenozoic marine sedimentaion and ice-volume variation on the East Antarctic craton. Geology, 12, 287-291.

WEBER, M. E., BONANI, G. \& FUTTERER, K. D. 1994. Sedimentation processes within channelridge systems, southeastern Weddell Sea, Antarctica. Paleoceanography, 9, 6, 1027-1048.

WEBER, M. E., KUHN, G., SPRENK, D., ROLF, C., OHLWEIN, C. \& RICKEN, W. 2012. Dust transport from Patagonia to Antarctica - A new stratigraphic approach from the Scotia Sea and its implications for the last glacial cycle. Quaternary Science Reviews, 36, 177-188.

WEEDON, G. P. 2003. Time-series analysis and cyclostratigraphy. Cambridge University Press, United Kingdom, $261 \mathrm{p}$.

WHITEHEAD, J. M., WOTHERSPOON, S. \& BOHATY, S. M. 2005. Minimal Antarctic sea ice during the Pliocene. Geology, 33, 137-140.

WHITWORTH, T., ORSI, A. H., KIM, S. J. \& NOWLIN JR. W. D. 1998. Water masses and mixing near the Antarctic Slope Front. In S.S. Jacobs \& R.F. Weiss, Eds. Ocean, Ice, and Atmosphere Interactions at the Antarctic Continental Margin, Antarctic Research Series, American Geophysical Union, Washington, 1-27.

WILGUS, C. K., HASTINGS, B. S., POSAMENTIER, H. W., ROSS, C. A \& KENDALL, C. G. ST.C. (Eds). 1998. Sea level changes: an integrated approach. Society of Economic Paleontologist and Mineralogists, Special Publication 42, 407 p.

WILLIAMS, G. D., BINDOFF, N. L., MARSLAND, S. J. \& RINTOUL, S. R. 2008. Formation and export of dense shelf water from the Adelie Depression, East Antarctica. Journal of Geophysical Research-Oceans, 113.

WINKLER, S. \& MATHEWS, J.A. 2010. Holocene Glacier chronologies: Are 'high resolution' global and inter-hemispheric comparisons possible. The Holocene 20, 7, 1137-1147.

WISE, S. W., BREZA, J. R., HARWOOD, D. M. \& WEI, W. 1991. Paleogene glacial history of Antarctica. In: Controversies in modern geology, Academic Press, New York, 133-171.

YOUNG, M. A., AND R. S. BRADLEY, 1984: Insolation gradients and the paleoclimatic record. Milankovitch and Climate, Part 2, A. Berger et al., (Eds.), 707-713.

ZACHOS, J. C., BREZA, J. R. \& WISE, S. W. 1992. Early Oligocene Ice-Sheet Expansion on Antarctica - Stable Isotope and Sedimentological Evidence from Kerguelen Plateau, Southern IndianOcean. Geology, 20, 569-573. 
ZACHOS, J., PAGANI, M., SLOAN, L., THOMAS, E. \& BILLUPS, K. 2001a. Trends, rhythms, and aberrations in global climate $65 \mathrm{Ma}$ to present. Science, 292, 686-693.

ZACHOS, J. C., SHACKLETON, N. J., REVENAUGH, J. S., PALIKE, H. \& FLOWER, B. P. 2001b. Climate response to orbital forcing across the Oligocene-Miocene boundary. Science, 292, 274-278. 